\author{
Черняховская Л.Р., Васильев В.И., Гвоздев В.Е., \\ Никулина Н.О., Малахова А.И., \\ Вульфин А.М., Бежаева О.Я.
}

\title{
МЕТОДЫ И МОДЕЛИ ПОДДЕРЖКИ ПРИНЯТИЯ РЕШЕНИЙ ПРИ УПРАВЛЕНИИ ИННОВАЦИОННЫМИ ПРОЕКТАМИ В ПРОИЗВОДСТВЕННО-ЭКОНОМИЧЕСКИХ СИСТЕМАХ
}

Сетевое научное издание

(C) Л.Р. Черняховская, В.И. Васильев, В.Е. Гвоздев, Н.О. Никулина, А.И. Малахова, А.М. Вульфин, О.Я. Бежаева, 2021

(C) ИД «Академия Естествознания»

(C) АНО «Академия Естествознания» ISBN 978-5-91327-668-1

Москва

2021 
УДК 005.2

ББК 65.290-2

Ч49

\section{Рецензенты:}

Даринцев О.В. - доктор технических наук, доцент, главный научный сотрудник, и.о. зав. лабораторией «Робототехника и управление в технических системах» Института механики им. Р.Р. Мавлютова УФИЦ РАН;

Мартынов В.В. - доктор технических наук, профессор, заведующий кафедрой экономической информатики Уфимского государственного авиационного технического университета.

Черняховская Л.Р., Васильев В.И., Гвоздев В.Е., Никулина Н.О., Малахова А.И., Вульфин А.М., Бежаева О.Я.

Ч49 Методы и модели поддержки принятия решений при управлении инновационными проектами в производственно-экономических системах / под общ. ред. д.т.н., проф. Черняховской Л.Р. - М.: Издательский дом Академии Естествознания, 2021. - 230 с. ил.

\section{ISBN 978-5-91327-668-1 \\ DOI 10.17513/np.437}

В монографии рассматриваются задачи построения интеллектуальной системы поддержки принятия решений для повышения эффективности управления инновационными проектами в производственно-экономических системах с применением методов искусственного интеллекта, онтологического инжиниринга и математического моделирования в условиях неопределенности и рисков.

Для широкого круга специалистов в области инженерии знаний и управления сложными системами, научных работников и аспирантов.

ISBN 978-5-91327-668-1

(C) Л.Р. Черняховская, В.И. Васильев, В.Е. Гвоздев, Н.О. Никулина, А.И. Малахова, А.М. Вульфин, О.Я. Бежаева, 2021

(C) ИД «Академия Естествознания»

(C) $\mathrm{AHO}$ «Академия Естествознания» 


\section{ОГЛАВЛЕНИЕ}

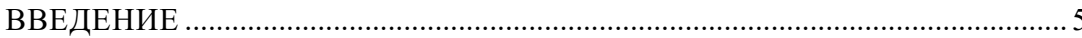

ГЛАВА 1. АНАЛИЗ ПРОБЛЕМЫ ОРГАНИЗАЦИИ ПОДДЕРЖКИ ПРИНЯТИЯ РЕШЕНИЙ В ПРОЦЕССАХ ИННОВАЦИОННОГО ПРОЕКТИРОВАНИЯ В ПРОИЗВОДСТВЕННОЭКОНОМИЧЕСКИХ СИСТЕМАХ

1.1. Состояние инновационного развития Российской Федерации и Республики Башкортостан. 8

1.2. Анализ проблем управления инновационными проектами на современном этапе развития производственноэкономических систем региона.

1.3. Классификация проблемных ситуаций инновационного проекта как основа информационной поддержки принятия решений

1.4. Анализ рисков и проблемных ситуаций на примере инновационного проекта, реализуемого на крупном производственном предприятии

ГЛАВА 2. МЕТОДОЛОГИЯ ИНТЕЛЛЕКТУАЛЬНОЙ ПОДДЕРЖКИ ПРИНЯТИЯ РЕШЕНИЙ ПРИ УПРАВЛЕНИИ ИННОВАЦИОННЫМИ ПРОЕКТАМИ

2.1. Постановка задачи на разработку методологии интеллектуальной поддержки принятия решений при управлении инновационными проектами.

2.2. Интегрированная онтология поддержки принятия решений при управлении инновационными проектами.

2.3. Разработка структуры и принципов построения базы знаний для интеллектуальной системы поддержки принятия решений в процессе управления инновационным проектом.

2.4. Организация поддержки принятия коллективных решений для проектных команд..

2.5. Методическое и алгоритмическое обеспечение интеллектуальной системы поддержки принятия решений. 86

ГЛАВА З. АНАЛИЗ И УПРАВЛЕНИЕ РИСКАМИ ИННОВАЦИОННЫХ ПРОЕКТОВ И ПРОМЫШЛЕННЫХ ОБЪЕКТОВ С ПОМОЩЬЮ ТЕХНОЛОГИЙ КОГНИТИВНОГО МОДЕЛИРОВАНИЯ 118

3.1 Моделирование процессов управления инновационной деятельностью в регионе с применением нечетких когнитивных карт

3.2 Анализ рисков инновационных проектов с использованием технологии многослойных нечетких когнитивных карт 
3.3 Оценка рисков кибербезопасности АСУ ТП промышленных объектов на основе вложенных нечетких когнитивных карт

3.4 Анализ рисков кибербезопасности промышленных объектов с помощью ансамбля нечетких когнитивных карт

ГЛАВА 4. ИННОВАЦИОННОЕ РАЗВИТИЕ ПРОИЗВОДСТВЕННО-ЭКОНОМИЧЕСКИХ СИСТЕМ

НА ПРИМЕРЕ СОЗДАНИЯ «УМНЫХ» ПРЕДПРИЯТИЙ 170

4.1. Влияние доктрины «Индустрия 4.0» на развитие интеллектуальных информационных технологий управления производственно-экономическими системами

4.2. Методологическая основа построения «умного» предприятия

4.3. Системная модель «умного» предприятия 182

4.4. Информационные системы как компоненты цифровой экосреды «умного» предприятия

4.5. Организационная структура «умного» предприятия ........................... 199

4.6. Корпоративная культура «умного» предприятия...................................207

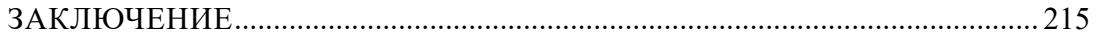

ПЕРЕЧЕНЬ СОКРАЩЕНИЙ И УСЛОВНЫХ ОБОЗНАЧЕНИЙ .................. 217

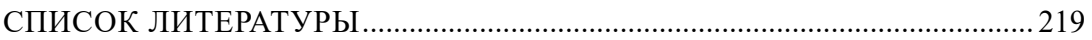




\section{ВВЕДЕНИЕ}

Одной из важнейших задач государственной политики Российской Федерации является обеспечение конкурентоспособности отечественной продукции и технологий, в том числе, на международных рынках. Этого можно добиться за счет активного роста инновационной деятельности производственных предприятий, которая осуществляется для достижения комплекса социальных, экономических, научно-исследовательских, организационных целей с высокой динамикой изменений как внешней, так и внутренней среды. По данным [1] в 2017 году Республика Башкортостан вошла в первую группу рейтинга инновационного развития субъектов Российской Федерации по индексу научнотехнического потенциала. Вместе с тем ретроспективный анализ инновационной деятельности в Республике Башкортостан показывает, что организации сокращают инновационную активность - удельный вес организаций, осуществляющих технологические инновации, снизился с 12,6\% в 2012 году до 5,9\% в 2017 году [2]. Такие неблагоприятные внешние факторы, как изменившиеся экономические условия осуществления производственной деятельности вследствие экономического кризиса, безработица, снижение объемов инвестиций в научно-исследовательские разработки, а также внутренние факторы, в том числе, изношенность основных средств, недостаточные компетенции персонала, усложнение коммуникаций работников в удаленном режиме в условиях пандемии являются причинами снижения уровня инновационной активности. Следовательно, обеспечение динамического подъема инноваций является актуальной задачей государственного значения. В связи с этим особое внимание уделяется вопросам реорганизации производственно-хозяйственной деятельности промышленных предприятий, совершенствования функций проектного менеджмента, повышения качественных характеристик управленческой информации, необходимой для принятия решений при управлении инновационными проектами.

Сложность управления инновационными проектами за последнее десятилетие многократно увеличилась в связи с высокой степенью неопределенности параметров проекта, высокой динамикой изменений внутренней и внешней среды проекта, большим объемом данных 
для управленческой деятельности, необходимостью привлечения специалистов высокой квалификации для создания и применения интеллектуальной собственности, применением современных технологий и материальных ресурсов. Поэтому эффективное управление инновационными проектами в современных условиях нуждается во внедрении и использовании новых подходов, методов и технологий обработки управленческой информации, ориентированных на качество и своевременность принимаемых решений на основе инженерии знаний.

Вопросам повышения эффективности проектного менеджмента посвящены многочисленные научные исследования, в результате которых разработаны и активно применяются различные методологии управления проектами, в том числе и инновационными, с использованием современных информационных технологий. Практики использования систем управления проектами, построенных на основе таких программных продуктов как, например, Microsoft Project, Primavera, уже давно вошли в жизнь проектного менеджмента крупных предприятий.

Большое внимание в настоящее время уделяется управлению знаниями в ходе планирования и реализации проектов, разработаны соответствующие стандарты [3, 4]. Рассмотрению проблем в области управления знаниями посвящены труды многих ученых, работающих над созданием моделей и методов искусственного интеллекта в различных областях инженерных наук, в том числе моделей представления знаний и методов поиска решений на их основе [5-7].

Однако, на наш взгляд, дальнейшее развитие инструментов системного представления процессов управления инновационными проектами возможно только в том случае, если удастся найти методы и подходы, позволяющие в формализованном виде накапливать и обрабатывать знания и опыт управления в проблемных ситуациях (ПС), возникающих в процессе проектирования, а также информацию о параметрах внешней среды, в которой реализуются инновационные проекты. Поэтому целью исследований является разработка методического и алгоритмического обеспечения для поддержки принятия решений при управлении инновационными проектами на основе онтологического и интеллектуального анализа данных. Для обработки данных и знаний предложена интеллектуальная система поддержки принятия решений (ИСППР), позволяющая осуществлять проектирование базы знаний (БЗ) и алгоритмов формирования рекомендаций по управлению инновационной деятельностью [8-10]. 
В монографии изложены результаты исследований, поддержанных грантом РФФИ №18-00-00238 «Методы и модели поддержки принятия решений при управлении инновационными проектами на основе инженерии знаний», входящего в состав комплексного проекта № 18-00-00345(К) «Инструментарий поддержки принятия решений при разработке стратегий инновационного развития регионов России на основе адаптивных моделей управления, технологий интеллектуальной обработки знаний и имитационного моделирования».

При подготовке монографии распределение материалов по главам осуществлялось следующим образом: Л.Р. Черняховская - главы 1, 2, 3; Н.О. Никулина, А.И. Малахова - главы 1, 2; В.И. Васильев, А.М. Вульфин - глава 3; В.Е. Гвоздев, О.Я. Бежаева - глава 4.

Авторы выражают благодарность коллегам, принявшим активное участие в обсуждении затронутых проблем и отмечают, что раздел 1.4 написан совместно с канд. техн. наук И.Ф. Ивановой - начальником отдела проекта вертолетных двигателей ПАО «ОДК-УМПО».

Авторы выражают благодарность рецензентам - д-ру техн. наук О.В. Даринцеву и д-ру техн. наук, проф. В.В. Мартынову за ценный труд по рецензированию рукописи и высказанные полезные замечания.

В рамках одной монографии невозможно провести подробный анализ проблем поддержки принятия решений при управлении инновационными проектами в производственно-экономических системах, однако авторы надеются, что монография заинтересует широкий круг специалистов в области инженерии знаний и управлении сложными системами и будет полезна при решении практических задач. 


\section{ГЛАВА 1 \\ АНАЛИЗ ПРОБЛЕМЫ ОРГАНИЗАЦИИ ПОДДЕРЖКИ ПРИНЯТИЯ РЕШЕНИЙ В ПРОЦЕССАХ ИННОВАЦИОННОГО ПРОЕКТИРОВАНИЯ В ПРОИЗВОДСТВЕННО-ЭКОНОМИЧЕСКИХ СИСТЕМАХ}

\section{1. Состояние инновационного развития Российской Федерации и Республики Башкортостан}

\subsection{1. Основные особенности инновационных проектов}

Понятие «инновации» подразумевает внедрение в производственный процесс достижений научно-технического прогресса, вовлечение научных коллективов и высококвалифицированных кадров в формирование высокотехнологичной продукции отечественных предприятий. При этом понятие «инновации» в литературе трактуется очень широко - от объекта - результата какой-либо уникальной, зачастую творческой деятельности, до процесса, преобразующего идеи в реализуемый на рынке продукт. Так, в [11] приведены следующие виды инновационной деятельности: продуктовые, процессные, организационные, маркетинговые инновации. Различные виды инновационной деятельности могут быть сопоставлены с типами экономических объектов (предприятий, организаций), в которых они реализуются. Инновационная деятельность в разных странах регулируется в соответствии с национальным законодательством, кроме того, существует целый ряд международных неправительственных организаций, например, Организация экономического сотрудничества и развития (ОЭСР), разрабатывающих методические рекомендации по внедрению инноваций.

В Российской Федерации сфера науки, технологии и инновации сегодня регламентируется Федеральным законом № 127 «О науке и государственной научно-технической политике», принятым в 1996 году [12]. Жизнь не стоит на месте, тем более в сфере высоких наукоемких технологий, меняется политическая и экономическая ситуация в стране и в мире, поэтому за истекшие более чем два десятка лет в этот закон были приняты более сорока изменений и дополнений, делались по- 
пытки принятия новых федеральных законов об инновационной деятельности. На данный момент действует целый ряд законов и постановлений правительства, направленных на стимулирование инновационной деятельности, под которой понимается совокупность научной, технологической, организационной, финансовой и коммерческой видов деятельности, направленных на реализацию инновационных проектов, а также на создание инновационной инфраструктуры и обеспечение ее деятельности. Вот только небольшая часть истории законотворческой деятельности в области регулирования сферы инноваций:

- проект Федерального закона «Об инновационной деятельности и о государственной инновационной политике» разработан в 1999 г. отклонен Президентом РФ в 2000 г.;

- проект Федерального закона «Об инновационной деятельности в Российской Федерации» разработан в 2010 году, внесен на рассмотрение в Государственную Думу РФ 05.10.2010 г. - отклонен;

- проект Федерального закона «О государственной поддержке инновационной деятельности в Российской Федерации» разработан в 2011 году, внесен на рассмотрение в Государственную Думу РФ 22.11.2017 г. - отклонен;

- проект Федерального закона «О научной, научно-технической и инновационной деятельности в Российской Федерации» - разработан в марте 2018 года, пока не внесен на рассмотрение в ГД РФ.

Несмотря на довольно обширный свод законодательных актов, попытки использования их в практической деятельности свидетельствуют о том, что они недостаточно взаимосвязаны между собой. В нашей стране часто пытаются бездумно копировать зарубежный опыт, использовать инструменты инновационной политики, применяемой на Западе. Однако там эти механизмы действуют в естественной институциональной, организационной, управленческой, инфраструктурной и ментальной среде, сложившейся исторически много лет назад. Перенимая опыт развитых стран, нужно соотносить его с реалиями хозяйственно-экономической деятельности в различных субъектах Российской Федерации, которые развиваются далеко не равномерно.

На текущий момент Российская Федерация ставит перед собой цели долгосрочного развития, заключающиеся в обеспечении высокого уровня благосостояния населения и закреплении геополитической роли страны как одного из лидеров, определяющих мировую политическую повестку дня. Единственным возможным способом достиже- 
ния этих целей является переход экономики на инновационную социально ориентированную модель развития. Несмотря на сложную экономическую обстановку в стране и в мире, в 2020 году началась подготовка к актуализации Стратегии инновационного развития Российской Федерации [13], а также разработка факторной модели по достижению национальной цели «Ускорение технологического развития Российской Федерации, увеличение количества организаций, осуществляющих технологические инновации, до 50 процентов от их общего числа» [14].

Последовательная и устойчивая активизация инновационных процессов в производственно-экономических системах необходима для повышения конкурентоспособности предприятий, усиления конкурентной борьбы за высококвалифицированные кадры и для привлечения инвестиций, несущих в проекты новые знания и технологии. Активная инновационная деятельность необходима и для успешного выполнения программ импортозамещения, обеспечения независимости отечественных компаний от иностранных поставщиков материалов, комплектующих и оборудования в случае обострения политических и экономических разногласий.

В этих условиях государство целенаправленно принимает меры, способствующие развитию приоритетных направлений науки и техники. К таким направлениям относятся, в том числе, информационнотелекоммуникационные системы, энергоэффективность и энергосбережение, перспективные виды вооружения, военной и специальной техники [15]. Возникает необходимость опережающего развития специфичных научных исследований и разработок, включая экологически чистую энергетику, геномную медицину, новые технологии в сельском хозяйстве. Дальнейшее развитие приоритетных направлений науки и техники должны поддерживать критические технологии, имеющие широкий потенциальный круг конкурентоспособных инновационных приложений в разных отраслях экономики. В свою очередь, развитие критических технологий может осуществляться только в рамках реализации инновационных проектов, поскольку именно инновационные проекты выполняются в тесном взаимодействии науки, экономики и производства.

Согласно указанной Стратегии повышение инновационного потенциала страны играет одну из ключевых ролей для обеспечения безопасности государства и повышения его конкурентоспособности в ми- 
ровом масштабе. При этом инновационное развитие по стране в целом и по отдельным регионам происходит неравномерно, что связано со специфическими особенностями регионов, в частности, со структурой промышленного производства, демографией, наличием наукоемких отраслей, уровнем социально-экономического развития.

\subsection{2. Состояние инновационного развития Российской Федерации и Республики Башкортостан}

В Российский Федерации регулярно публикуются статистические исследования, отражающие состояние инновационной деятельности [16], и, к сожалению, в последние годы не всё складывается благополучно. Одной из причин, осложнивших реализацию инновационных проектов в стране, явился мировой экономический кризис 20082009 гг, который в целом замедлил развитие экономической системы страны, в том числе и его инновационной составляющей. Несмотря на все предпринимаемые усилия, по результатам оценки совокупного уровня инновационной активности Россия с 8,4\% занимает крайне слабую позицию среди других развитых стран - лидеров в данной сфере (например, Швейцария имеет совокупный показатель инновационной активности 75,3\%). Вместе с ней в первую десятку рейтинга «Глобальный инновационный индекс» (ГИИ, Global Innovation Index) [17] вошли Швеция, США, Великобритания, Нидерланды, Дания, Финляндия, Сингапур, Германия и Республика Корея (впервые в 2020 году).

В 2013-2016 гг. России удалось значительно улучшить свои позиции в рейтинге, переместившись с 62-го на 43-е место. Данный период фактически совпал со временем реализации активной государственной инновационной политики.

По оценкам составителей рейтинга, результативность инноваций в России ниже ожидаемого уровня при текущих значениях показателей ВВП на душу населения и инвестиций в науку, технологии и инновации. Отставание от стран-лидеров традиционно определяет низкая эффективность институтов, формирующих условия для предпринимательской и творческой деятельности.

По результатам отраслевого анализа динамики основных показателей инновационной деятельности в Российской Федерации можно сделать вывод, что наибольшей инновационной активностью обладают промышленные предприятия $(9,2 \%)$, в том числе предприятия энергетики $(4,1 \%)$ (рис. 1.1) [18]. Причем замечено, что чем больше 
масштаб самой организации, тем больше совокупный уровень ее инновационной активности.

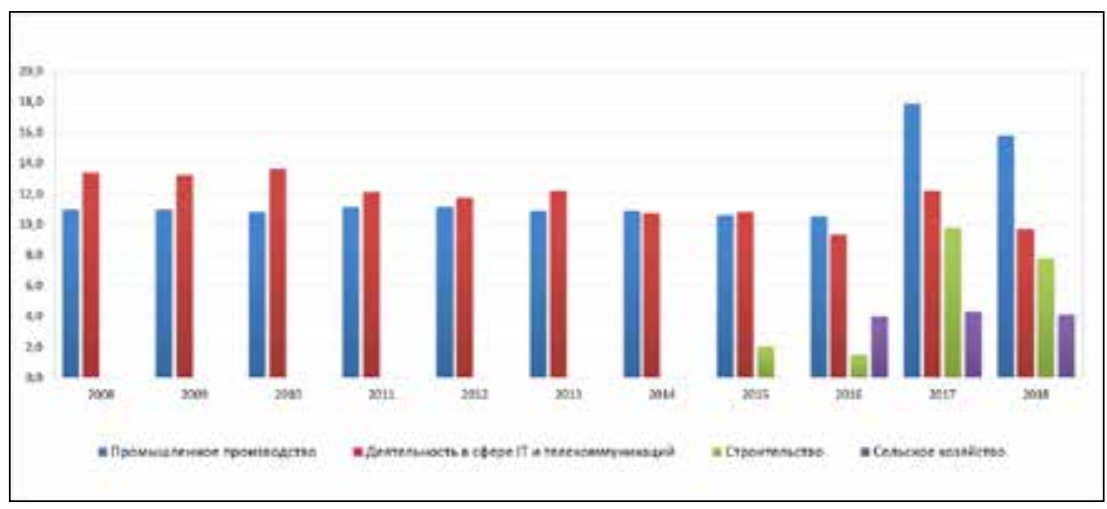

Рис. 1.1. Отраслевой анализ инновационной активности в РФ

В настоящее время инновационные проекты являются неотъемлемой составляющей развития сложных производственно-экономических систем (ПЭС). По данным исследований [16, 18-20], более 70\% успешных инновационных проектов выполняются в рамках существующих ПЭС, что обусловлено наличием производственных мощностей и сформировавшимся коллективом исполнителей.

Результаты отраслевого анализа реализации инноваций в Республике Башкортостан (РБ), как по объемам финансирования проектов, так и по их совокупной численности, подтверждают общую картину по стране - наибольшей инновационной активностью в регионе обладают промышленные предприятия (рис. 1.2). Наибольшее количество инновационных проектов наблюдается в столице - г. Уфе, где сконцентрировано подавляющее большинство вузов и ведущих промышленных предприятий Республики.

Динамика основных показателей инновационной деятельности наглядно демонстрирует неизменность числа организаций, осуществляющих технологические инновации в сфере промышленного производства, при снижении результирующего количества инновационных продуктов в виде произведенных товаров, работ и услуг. Также неуклонно в течение последних лет снижаются и затраты на технологические инновации (рис. 1.3). 


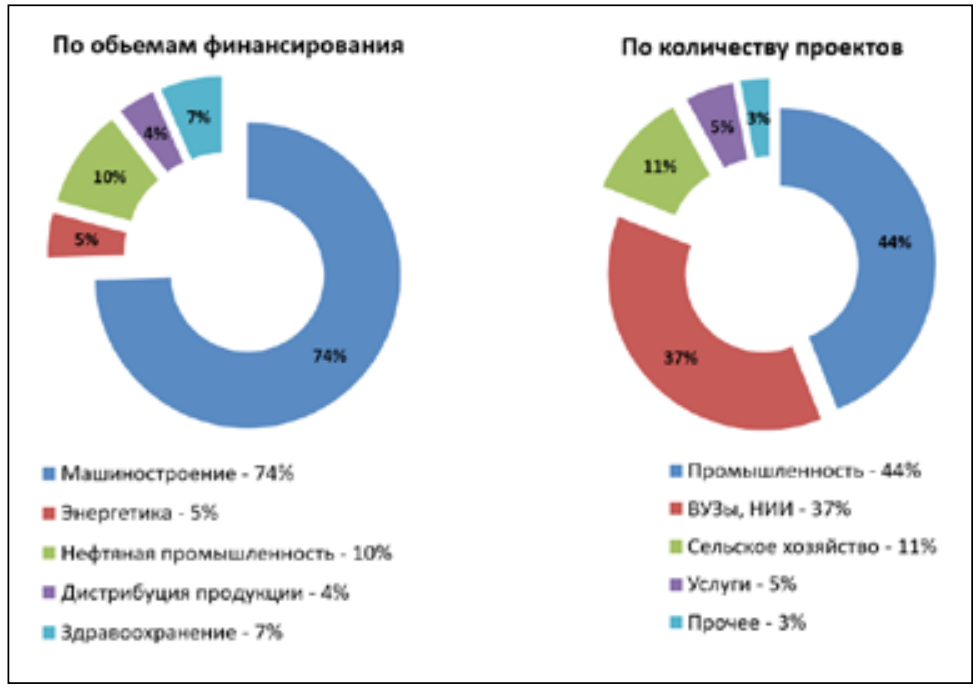

Рис. 1.2. Отраслевой анализ инновационной активности в РБ

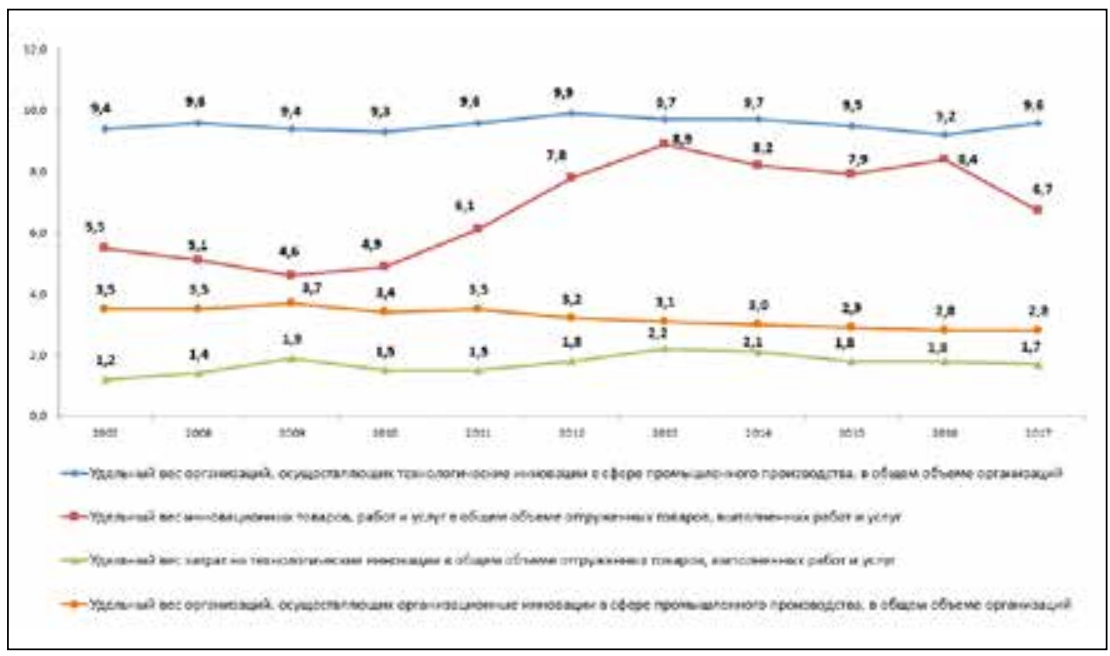

Рис. 1.3. Инновационная деятельность промышленных предприятий РФ 
По данным Росстата за период с 2011 по 2018 год показатели внутренних затрат на исследования и разработки в процентах от валового внутреннего продукта и совокупного уровня инновационной активности организаций промышленного производства остаются практически неизменными, а в некоторые периоды даже снижаются (рис. 1.4) [21].

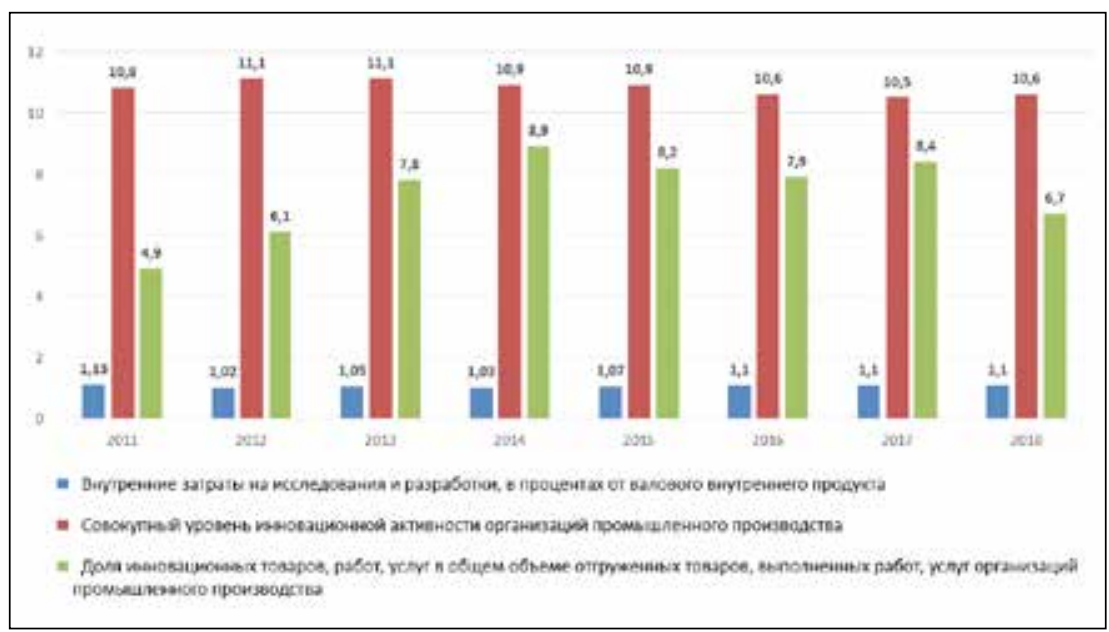

Рис. 1.4. Целевые индикаторы реализации

Стратегии инновационного развития Российской Федерации

При этом затраты на проведение исследований и разработок (а именно эта деятельность служит основой инноваций) составляют меньше четверти из общих затрат на инновации. Основную же долю занимает приобретение машин и оборудования (рис. 1.5).

Основные эффекты инноваций по оценке организаций достигаются за счет улучшения качества товаров, работ и услуг (рис. 1.6).

В чем же причины такого положения дел? Реализация инновационных проектов в РФ в настоящее время осуществляется в довольно непростой финансово-экономической ситуации, которая возникла из-за постоянно обновляемых зарубежных экономических санкций, из-за воздействия негативных тенденций мирового финансового кризиса, а также из-за новой глобальной проблемы - пандемии COVID-19, которая провоцирует возникновение дополнительных рисков во всех сферах деятельности. 


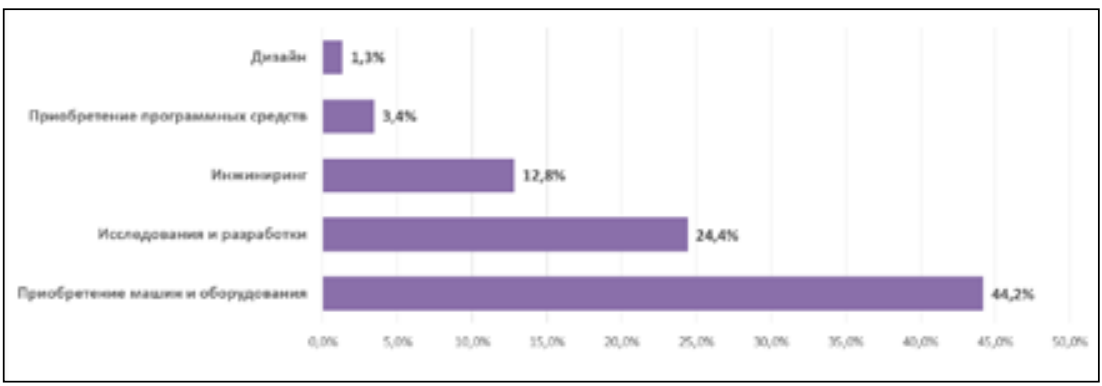

Рис. 1.5. Структура затрат на инновационную деятельность в ПЭС.

Затраты по видам инновационной деятельности в промышленности

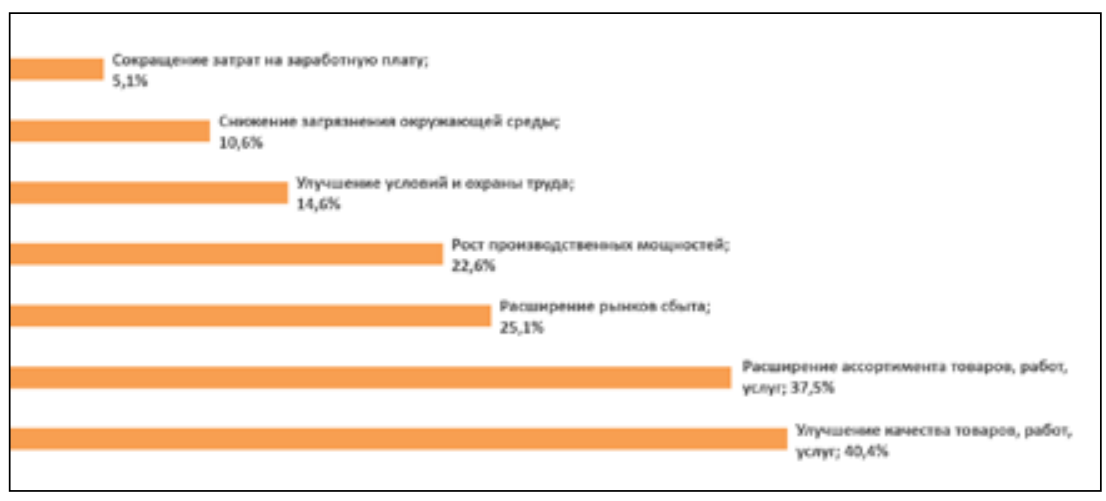

Рис. 1.6. Основные эффекты инноваций по оценке организаций

Хорошо известна статистика выполнения проектов, которую уже больше 20 лет собирают и анализируют консалтинговая компания Standish Group, а также Project Management Institute (PMI). Интересен тот факт, что в различных предметных областях она имеет схожие результаты - около половины всех проектов заканчивается в срок, с заданным качеством и в рамках согласованного бюджета, у остальных проектов либо есть отдельные недостатки, либо они и вовсе не завершаются. По данным за 2018 год согласно опроса более 4000 респондентов, 69\% проектов достигли заявленных целей, 57\% проектов выполнены в рамках бюджета, 52\% проектов выполнены в срок, 52\% проектов столкнулись с «расползанием содержания», 15\% проектов 
провалились полностью [22]. При этом 58\% организаций в полной мере осознают ценность проектного менеджмента, 93\% организаций используют стандартизированные практики в управлении проектами.

Результаты исследований показывают, что с увеличением количества организаций, использующих методологию проектного менеджмента, доля успешных и частично успешных проектов год от года увеличивается (рис. 1.7) [20]. При этом доля провальных проектов за последние годы остается практически неизменной и составляет $12-15 \%$ от общего числа проектов. Так, по данным за 2019 год согласно опроса 3133 специалистов по управлению проектами, 441 директора проектного офиса и 368 топ-менеджеров из различных отраслей, $12 \%$ проектов провалились полностью по всем показателям, а $76 \%$ проектов хоть и признаны состоявшимися, но по отдельным показателям не достигли целевых значений.

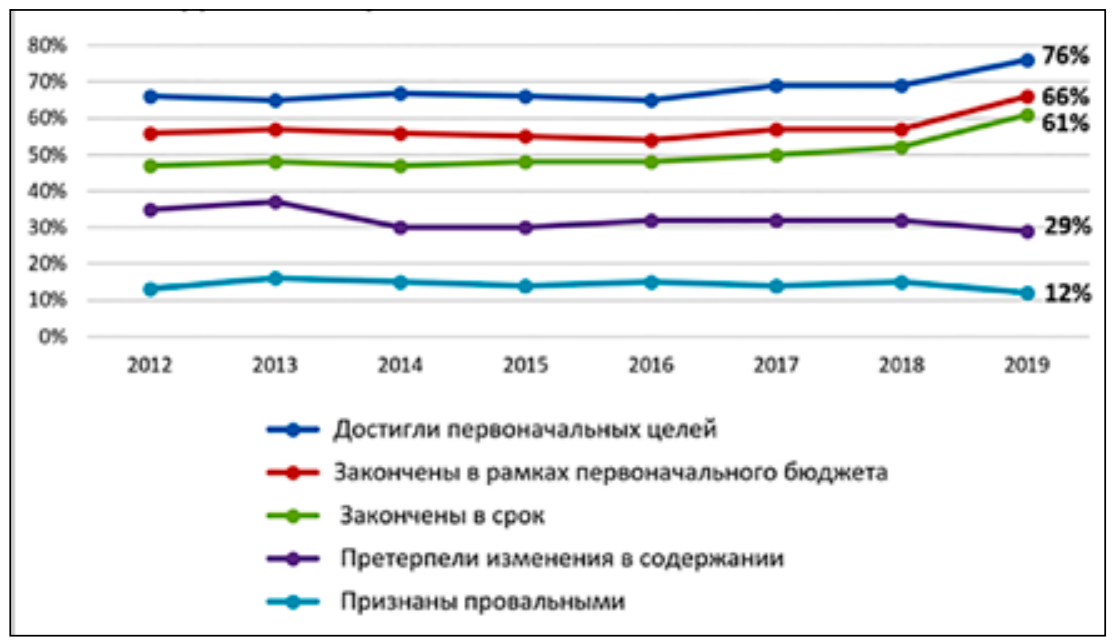

Рис. 1.7. Статистика выполнения проектов по РМI

Чрезвычайно важную роль в инновационной деятельности играет прединвестиционная стадия (рис. 1.8), которая зачастую требует больших вложений при большой протяженности во времени и неопределенности в получении значимого результата. Достаточно большой процент научных идей получает отрицательную оценку с точки зрения 
ее экономической перспективности и далеко не все научные разработки, дошедшие до стадии прототипа, находят своих инвесторов для запуска в серийное производство. Как показывает практика, именно на этой стадии из-за недостатка сведений о различных аспектах реализации предполагаемого проекта в одной или нескольких областях чаще всего и заканчивается его жизненный цикл.

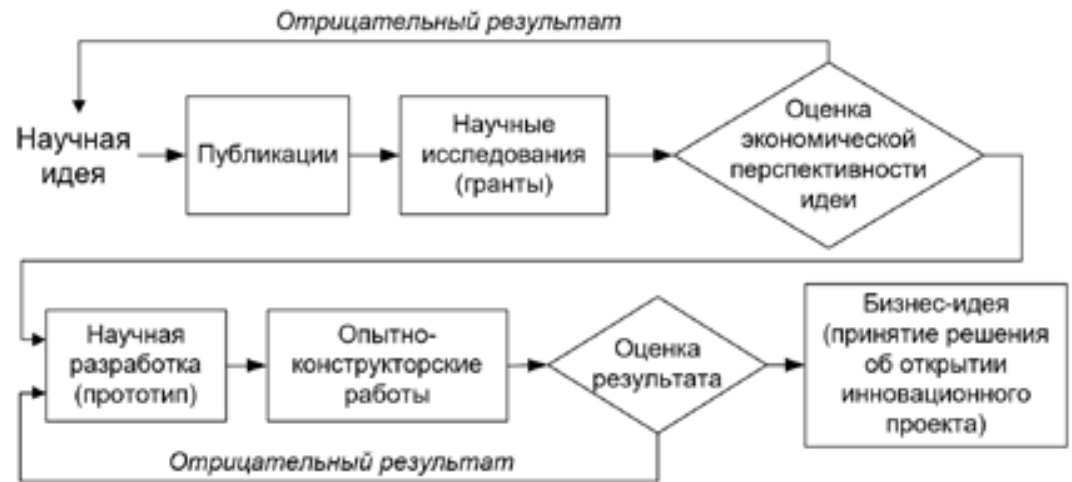

Рис. 1.8. Схема прединвестиционной стадии инновационного проекта

На данный момент одной из главных проблем, обуславливающих отказ от участия в инновационных проектах, является низкий спрос российских производственных предприятий на инновации. Зачастую руководство предприятий стремится закупить готовое оборудование или технологии (в том числе, за рубежом) (см. рис. 1.5), нежели вкладывать средства в развитие собственных разработок. Такой подход объясняется желанием получить быстрый возврат инвестиций за счет внедрения зарекомендовавших себя на рынке решений. Кроме того, процедуры закупки хорошо известны и не вызывают затруднений с точки зрения принятия решений, если финансовых и иных ресурсов достаточно для заключения договоров поставки. Внедрение же инноваций требует гораздо больших усилий и со стороны предприятия, и со стороны возможных инвесторов при высокой степени неопределенности в получении ожидаемого результата.

Неопределенность касается не только качества и стоимости конечного инновационного продукта, но и сроков его получения. Поэтому ни частный, ни государственный сектор не проявляют достаточного 
интереса во внедрении инноваций. При этом для поддержки инновационной деятельности в свое время корректировались статьи Бюджетного и Налогового кодексов, благодаря чему было снижено бремя налоговой нагрузки на инновационные предприятия. Тем не менее, по результатам опросов руководителей промышленных предприятий, основными причинами снижения инновационной активности за последние 5 лет являются проблемы с финансированием, а также снижение спроса на товары, работы и услуги, обусловленное общим падением уровня жизни платежеспособного населения, которое в предстоящие годы только усугубится (рис. 1.9). Таким образом, к факторам, тормозящим развитие инноваций, можно отнести:

- нехватку собственных денежных средств компаний при высокой стоимости нововведений;

- сложность привлечения инвестиций;

- незнание методов инновационного проектирования;

- сложные схемы оценки перспектив внедрения инноваций;

- сложность определения экономического эффекта от использования интеллектуальной собственности.

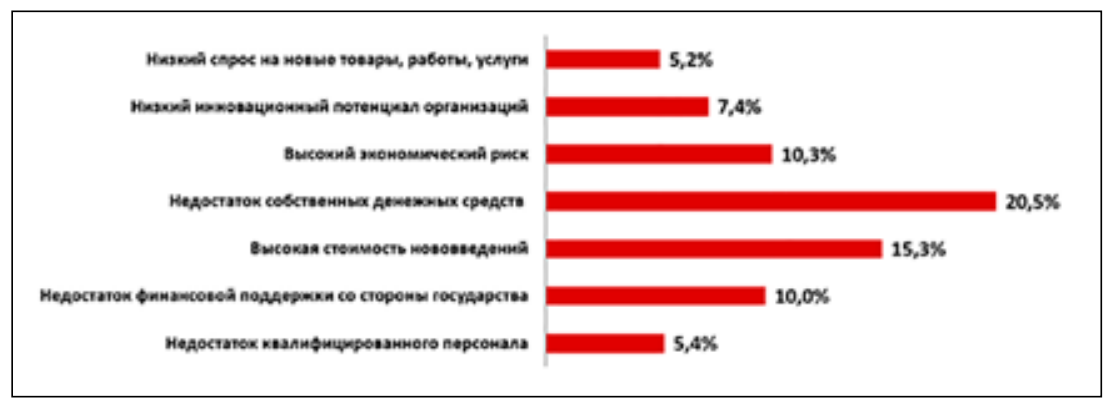

Рис. 1.9. Основные причины снижения активности инновационной деятельности

Тем не менее, несмотря на все сложности, инновационная деятельность открывает для предприятий путь к повышению конкурентоспособности, вопросы обретения которой для большинства производственных предприятий стоят сегодня как никогда остро. При этом основной целью иногда является не столько увеличение доли присутствия на рынке или повышение размера чистой прибыли, а элементарное сохранение рабочих мест и выживание в непростых условиях. 


\subsection{3. Анализ проблем инновационной деятельности в рамках стратегического планирования территориального развития региона}

Стратегическая для субъектов Российской Федерации задача выхода на инновационную модель развития на сегодняшний день вряд ли может быть решена без масштабного использования передовых технологий и новаций, обеспечивающих переход на новый технологический уклад, основанный на производстве товаров и услуг с высоким уровнем добавленной стоимости. Другая приоритетная задача - построение собственно инновационно-ориентированной системы стратегического планирования, способной обеспечить интеграцию инновационных проектов и программ в имеющуюся, весьма инерционную модель воспроизводственного процесса, оценивать воздействие инновационных компонент на развитие экономики в целом, взаимно адаптировать и синхронизировать данные процессы в пределах рассматриваемого цикла стратегического планирования [23].

На текущий момент решение задачи связано с множеством негативных факторов практического свойства, в том числе, несогласованностью целей и задач, недостаточной системностью осуществляемой экономической политики, потребностью в применении полнофункциональной системы анализа и эффективного применения фактографической информации и аккумулированных знаний, а также имеющимися пробелами в методическом обеспечении задач стратегического планирования на уровне субъектов Российской Федерации. В результате имеет место неудовлетворительное качество разрабатываемых прогнозных оценок по ключевым показателям развития регионов, включая программы и стратегии инновационного развития, что определяет необходимость их многократной корректировки непосредственно в рамках практической деятельности региональных органов власти и управления.

В сложившихся условиях последующее совершенствование подходов к стратегическому планированию территориального развития нуждается в качественном переосмыслении, обусловленным необходимостью учета перманентных изменений характеристик и условий в рамках глобальной конкурентной среды, их воздействия на инновационное развитие. В данных условиях, разработка инновационных программ не только на долгосрочный, но и на среднесрочный период 
нуждается в применении алгоритмов учета интересов и адаптации стратегий функционирования экономических субъектов различного уровня, использования процедур согласования, а далее - совместной реализации, мониторинга и корректировки ключевых показателей развития региона.

В рассматриваемом контексте, действенным инструментарием развития методов стратегического планирования могут выступить перспективные технологии поддержки принятия решений (ППР) на базе методов инженерии знаний и имитационного моделирования, обеспечивающие эффективную информационную поддержку в ходе разработки и реализации программ инновационного развития на уровне субъектов Российской Федерации.

Исследование текущего уровня разработок по изучаемому вопросу подразумевает комплексный анализ подходов к стратегическому планированию территориального развития, проблем развития инновационной экономики и созданию систем поддержки принятия решений (СППР). Вместе с тем, отдельно необходимо выделить аспекты формирования экономико-математических моделей, используемых в данных сферах и являющихся, в некоторой мере, связующим звеном.

В отдельности, указанные направления имеют уже наработанную научную основу. В частности, теория инновационной экономики была заложена еще в начале прошлого века Й. Шумпетором, предложившим базовое определение и классификацию типов инноваций. Инновационным процессам отводится важное место в исследованиях длинных волн Кондратьева, диффузий инноваций К. Фримена и др. Сегодня лидирующие в научно-технической сфере государства мира сформировали постиндустриальное общество с доминированием инновационной экономики.

Также следует отметить теорию технологических укладов, рассматриваемую во взаимосвязи с проблемами инновационного развития страны и освещенную в работах С.Ю. Глазьева, Д.С. Львова, К. Переса, Ю.В. Яковца и др. Обращает на себя внимание, что проводимые в этой области исследования носят в существенной мере характер лишь качественного описания инновационных процессов, и зачастую не направлены на количественное обоснование параметров взаимовлияния инноваций и социально-экономического развития региона и, в том числе, построения соответствующих стратегических прогнозов и планов развития. 
На сегодняшний день становится очевидным, что с технологической позиции решение этой задачи невозможно без разработки специальных методов ППР, включая системы класса DSS (ERP, OLAP, DataMining, CRM и т.д.). Но и в данном случае существующие разработки ориентированы на решение проблем микроэкономического уровня, в том числе, в рамках задачи обеспечения функционирования отдельных производственно-экономических систем - начиная от планирования ресурсов организации и управления проектами, до организации ППР в работе со слабоструктурированными данными. В рамках макроэкономической проблематики, в частности, для разработки планов инновационного развития субъектов Российской Федерации, данные системы фактически не использовались. Проводимые единичные исследования в рассматриваемой области (например, информационно-аналитическая система поддержки принятия решений по управлению инновационной деятельностью в регионе [24], СППР по стратегии инновационного развития региона [25] и т.д.) не в полной мере отражают такое весьма существенное свойство региональной системы как адаптивность поведения базовых экономических агентов. Кроме того, имеется ряд работ, носящих сугубо теоретический и/или отраслевой характер [26], и не адаптированных для использования в реальной практике стратегического планирования на макроуровне.

В рамках проблематики моделирования развития региональных систем аналогично рассматриваются различные подходы, в том числе модели общеэкономического равновесия; модели, ориентированные на применение вероятностно-статистических методов; имитационные модели; модели, базирующиеся на применении различного типа интеллектуальных информационных технологий. В основном, модели, применяемые на практике, интегрируют различные подходы. В мировой науке и практике примерами моделей, основанных на балансовом и эконометрическом методах, являются модель «LIFT», «Уортонская годовая модель экономики США», «Модель налогово-бюджетной политики США», «Брукингская модель экономики США» и др.

Среди отечественных моделей можно отметить модельно-программные комплексы «СИРЕНА» и «СИРЕНА-2» (ИЭОПП СО РАН), модельный комплекс «ПОЛИГОН-2» (Новосибирский государственный университет), модель «Russian Interindustry Model» (ИНП РАН), «Эконометрическая модель экономики России», «CGE-модель соци- 
ально-экономической системы России со встроенными нейронными сетями» (ЦЭМИ РАН), «Модель региона Российского Севера» (Сыктывкарский государственный университет), модель «Губернатор», «Агент-ориентированная модель г. Москвы» (ЦЭМИ РАН) и др. Многие комплексные информационно-аналитические системы базируются на применении методов имитационного моделирования, включая широко применяемый в практике государственного и муниципального управления информационно-аналитический комплекс «Прогноз» (ЗАО «Прогноз»).

Одновременно с этим следует отметить, что представленные модели, во многих случаях, не в полной мере воспроизводят особенности инновационного развития субъектов Российской Федерации, так как не включают описания характеристик инновационной деятельности как управляемого адаптивного процесса. Вместе с тем, ряд моделей, построенных, в том числе, на основе регрессионных уравнений, утрачивают свои прогностические возможности в условиях трансформации экономики в связи с недостаточным учетом адаптивных свойств элементов территориальной системы, а, следовательно, не могут выступать в качестве основы для разработки СППР. В связи с этим, несмотря на значительное количество исследований по рассматриваемой тематике, до сих пор не решены в полной мере проблемы, связанные с методическими и практическими вопросами организации ППР, например, в части системного моделирования инновационных процессов на региональном уровне, более эффективного использования интеллектуальных информационных технологий на базе методов инженерии знаний.

\section{2. Анализ проблем управления инновационными проектами на современном этапе развития производственно-экономических систем региона}

Ни одно современное предприятие, вне зависимости от сферы деятельности и масштаба бизнеса, не может быть абсолютно уверенным в незыблемости своих позиций на рынке даже в ближайшей перспективе. Давно прошли те времена, когда организационные и производственные процессы выполнялись в неизменном виде годами на основе утвержденных регламентов и инструкций, одни и те же сотрудники годами занимали свои рабочие места, а руководители 
различных рангов принимали решения, придерживаясь, казалось бы, раз и навсегда установленных правил. Практически не менялось и внешнее окружение предприятия - одни и те же контрагенты с хорошо изученными потребностями, отработанные технологии взаимодействия с партнерами, неизменные вышестоящие управляющие структуры. В этих условиях можно было строить планы стратегического развития на 10-15 лет вперед.

Все изменилось после политического и экономического переустройства жизни российского общества, совпавшего с началом информационного века. Разрыв экономических и политических связей, ломка привычных схем взаимодействия, чехарда в законотворческой деятельности, падение курса национальной валюты сделали невозможным существование предприятий, не готовых быстро адаптироваться к изменениям. Положение усугубило введение международных санкций, ограничивающих сотрудничество с зарубежными предприятиями и использование «импортных» технологий и изделий. Горизонт стратегического планирования сильно приблизился и стал составлять не более 3-5 лет. К тому же не секрет, что смена владельцев бизнеса (особенно, среднего и малого) в России в последние 20 лет - достаточно частое явление, что тоже не способствует активному ведению инновационной деятельности в рамках одного предприятия.

Производственное предприятие для обеспечения своего устойчивого положения и дальнейшего перспективного развития должно трансформироваться в производственно-экономическую систему [27]. Безусловно, такая трансформация возможна только в результате системных изменений на базе научно-обоснованных подходов. Принцип системности является важнейшим при создании, функционировании и развитии ПЭС. Он заключается в рассмотрении предприятия как единого целого, позволяет выявить многообразные типы связей между структурными элементами, установить направления деятельности системы и реализуемые функции.

Системный подход позволяет использовать математическое описание функционирования отдельных элементов и системы в целом, что дает возможность моделировать протекающие в производственноэкономической системы процессы для принятия тактических и стратегических решений по ее дальнейшему развитию. На рис. 1.10 приведена упрощенная схема управления объектом управления (ОУ), в качестве которого выступает ПЭС, на основе моделей ПЭС и внеш- 
ней среды. Здесь $X=\left\{x_{1}, x_{2}, \ldots, x_{n}\right\}$ - вектор входных параметров ОУ; $Y=\left\{y_{1}, y_{2}, \ldots, y_{m}\right\}-$ вектор выходных параметров ОУ, являющихся результатом его функционирования; $U=\left\{u_{1}, u_{2}, \ldots, u_{k}\right\}$ - вектор управляющих воздействий со стороны субъекта управления, в качестве которого выступают лица, принимающие решения (ЛПР) различных уровней иерархической организационной структуры; $g=\left\{g_{l}, g_{2}, \ldots, g_{m}\right\}$ - вектор плановых параметров функционирования ОУ; $f=\left\{f_{l}, f_{2}, \ldots, f_{p}\right\}-$ вектор возмущающих воздействий внешней среды.

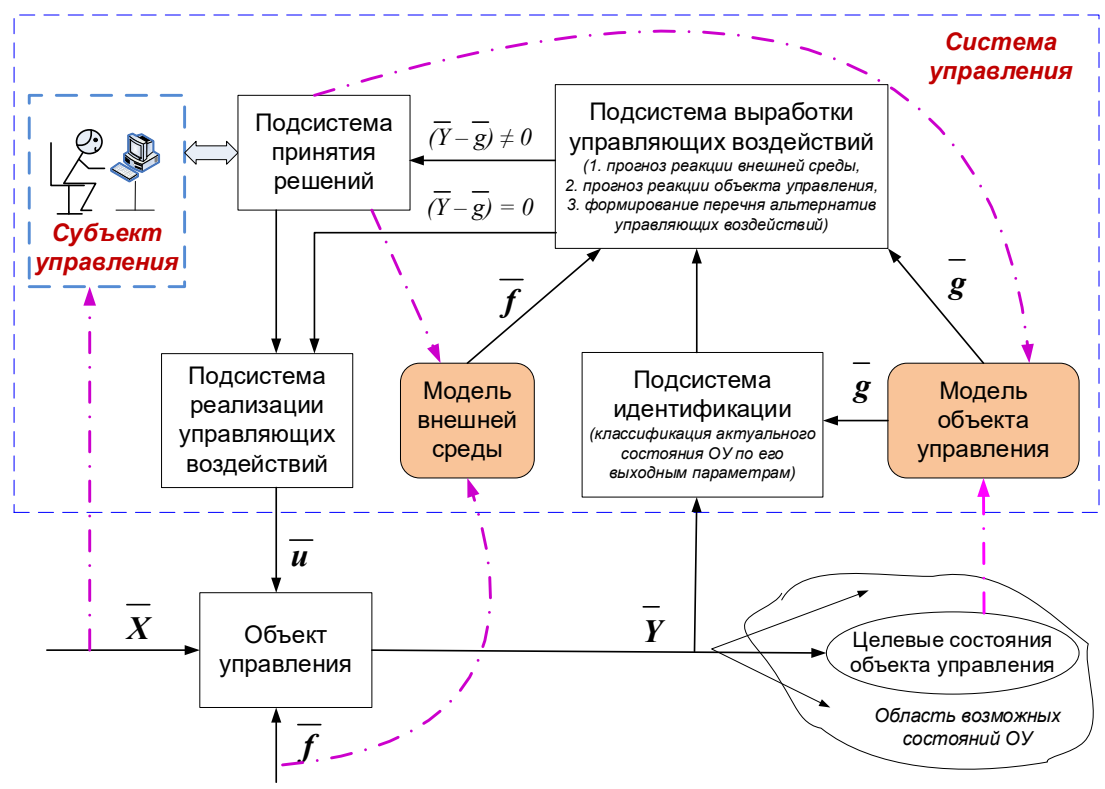

Рис. 1.10. Схема управления ПЭС

Использование такой схемы позволяет прогнозировать состояние ПЭС и отдельных ее элементов после применения тех или иных управленческих решений до реального воздействия на объект управления. В этих условиях особо важное значение приобретает владение актуальной и достоверной информацией как о состоянии всех элементов производственно-экономической системы, так и о событиях, происходящих во внешней по отношению к ней среде и влияющих на достижение запланированных целей. 
Появление новых сфер деятельности, связанных с цифровыми технологиями, сетевой экономикой и другими современными методами организации бизнеса и производства, заставляет по-новому взглянуть на классификацию проектов, предлагаемую в известных научно-методических источниках $[28,29]$, включив в нее класс инновационных проектов, как один из передовых способов реализации в рамках существующих ПЭС прорывных инициатив, наукоемких производств и ноу-хау. В соответствии с Законом об инновационной деятельности РБ, «инновационный проект - комплекс направленных на достижение экономического эффекта мероприятий по осуществлению инноваций, в том числе по коммерциализации научных и (или) научно-технических результатов» [30]. Поэтому вопросы экономической и финансовой отдачи от реализации инновационных проектов являются основополагающими при формирования целевых показателей отдельных проектов и стратегических целей производственных предприятий в целом.

Инновационная активность производственно-экономической системы характеризует степень участия предприятия в осуществлении инновационной деятельности в целом или отдельных ее видов в течение определенного периода времени. Инновации могут затрагивать различные сферы деятельности, поэтому результаты инновационных проектов могут представлять ценность как для внешних потребителей (продукты и услуги), так и для внутренних подразделений предприятия (например, новые методы и технологии выполнения работ, новые организационные подходы к управлению предприятием и т.д.) (рис. 1.11).

Бурное развитие информационных и коммуникационных технологий предоставляет возможность использовать инструменты, позволяющие собирать и обрабатывать информацию о ходе производственнохозяйственной деятельности и различных аспектах функционирования всех компонентов ПЭС. К таким инструментам относятся автоматизированные системы управления бизнес-процессами, системы электронного документооборота, ERP-системы. Но применение этих инструментов бессистемно, в отсутствии продуманной стратегии развития ПЭС, не может дать серьезного экономического эффекта. Поэтому применение инструментов управления производственно-экономической системой возможно при условии функционирования всех компонентов ПЭС в едином информационном пространстве, которое 
обеспечивают корпоративные информационно-управляющие системы (такие как 1C: ERP 2.0, SAP S/4HANA, Infor $L N$ и др.). Связующим звеном может стать инновационная деятельность, благодаря которой четко определяются цели и результаты функционирования ПЭС.

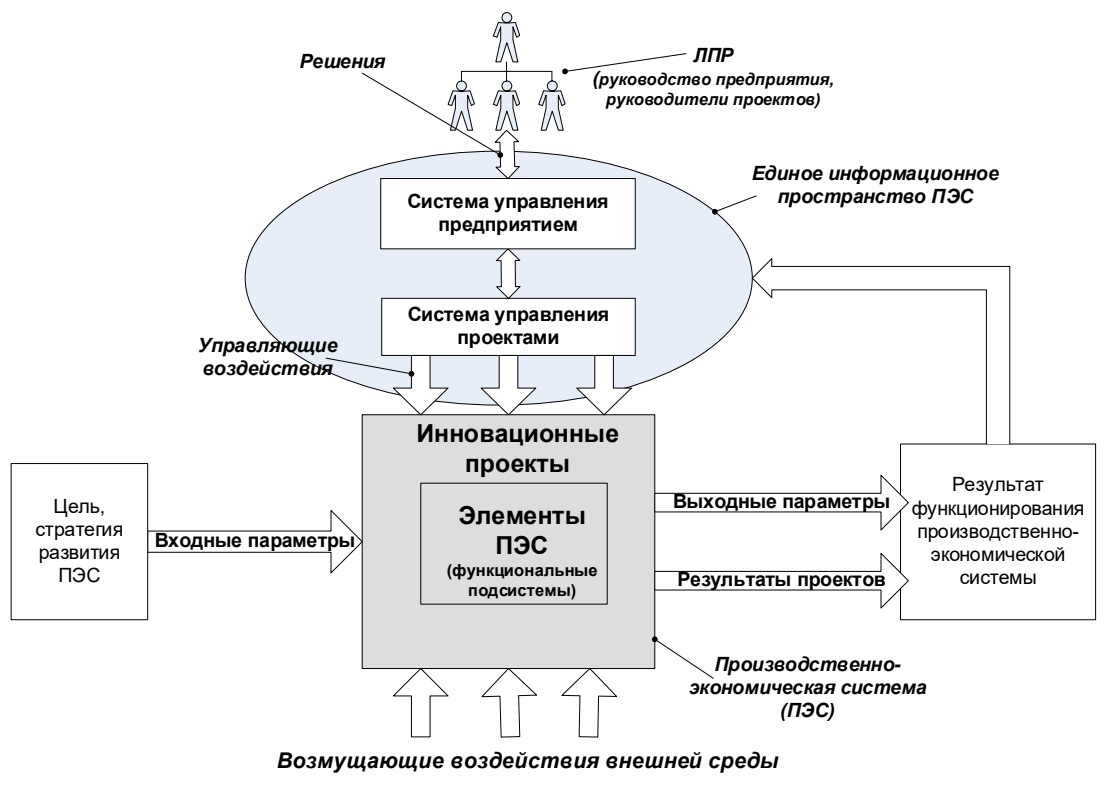

Рис. 1.11. Управление инновационным проектом в рамках производственно-экономической системы

На сегодняшний момент инновационная деятельность предприятий и организаций в основном осуществляется в рамках реализуемых ими проектов, поэтому к управлению инновациями могут быть применены известные методы и подходы проектного менеджмента.

Управление проектами за долгие годы оформилось в отдельную масштабную дисциплину. Сегодня невозможно представить основную деятельность компаний без реализаций проектной, управленческую деятельность - без применения средств проектного управления. За все время развития проектного менеджмента прилагались объединенные усилия по составлению сводов знаний, которые содержали бы в себе рекомендации по управлению проектами на осно- 
ве накопленного опыта специалистов в данной области. Две наиболее известные версии таких документов были разработаны и опубликованы в начале века Институтом управления проектами (Project Management Institute, PMI: the PMBOK Guide, 2000) в Соединенных Штатах и Ассоциацией управления проектами (Association of Project Management, APM, 2000) в Великобритании. Использование РМВОК Guide (A Guide to the Project Management Body of Knowledge - Свод знаний по управлению проектами) в Соединенных Штатах в качестве национального стандарта (ANSI, PMI 99-001-200) было одобрено Американским национальным институтом стандартизации (American National Standards Institute, ANSI). В России с учетом национальных особенностей ведения проектной деятельности ведется активная разработка собственных взаимосвязанных стандартов управления проектами на основе $P M B o K$ [31], создано и активно функционирует российское отделение $P M I$ и его региональные филиалы, в том числе, в Республике Башкортостан.

Управление ПЭС через реализацию инновационных проектов различной направленности может дать весьма ощутимые результаты при условии включения в единое информационное пространство систем управления проектами (Primavera, Microsoft Project, PowerProject и др.). Системы управления проектами могут использоваться обособленно, и тогда становится необходимым вручную сопоставлять данные, полученные из ERP-систем, с данными хода выполнения проекта, а это представляет собой отдельную довольно большую проблему. Лучшим вариантом является интеграция системы управления проектами в информационно-управляющую систему в виде ее отдельного модуля. Это существенно облегчает взаимодействие между собой ЛПР различного уровня и позволяет принимать обоснованные решения по управлению производственно-экономической системой и проектом.

Инновационные проекты отличает сочетание уникальных результатов и уникальных технологий получения результатов при высокой степени неопределенности как требований к конечному продукту, так и к процессам достижения цели. Современные подходы к организации проектной деятельности предполагают формирование комплексной системы управления сложными динамично меняющимися объектами, которыми и являются проекты. При этом под системой управления проектами понимается не только инструментальное средство, позволяющее автоматизировать наиболее распространенные отдельные 
функции руководителя проекта такие, как составление графика работ, фиксация факта выполнения задач и подготовка отчетов. Данные системы должны включать в себя интегрированные компоненты, отвечающие за полный цикл управления знаниями для накопления и применения корпоративных знаний и опыта [32].

Выделим основные проблемы управления инновационными проектами, которые на сегодняшний день характерны для производственно-экономических систем.

Анализ положения дел показал, что доля финансирования инновационных проектов предприятий государством либо из имеющихся внешних источников остается крайне малой. В связи с этим предприятия при осуществлении инновационных проектов несут высокие риски невозврата именно собственных вложенных средств, что напрямую влияет на качество работы предприятия в целом. Отсюда следует, что особое внимание нужно уделять всестороннему анализу возможных проблем, с которыми могут столкнуться лица, принимающие решения, при управлении инновационным проектом. Основные проблемы, возникающие при управлении инновационными проектами, вытекают из самой их сути - необходимости выполнения уникальных работ для достижения уникальных результатов при ограниченных ресурсах [4]. Многолетняя практика управления проектами позволила выделить наиболее существенные проблемы, с которыми сталкиваются ЛПР при реализации проектов в рамках ПЭС:

- высокая степень неопределенности при оценке текущей ситуации и прогнозировании последствий принимаемых решений;

- сжатые сроки решения проблем, устанавливаемые на вышестоящем уровне;

- кадровый голод, обусловленный сложностью привлечения персонала, сочетающего высокий профессионализм, навыки командной работы, умение ставить и решать задачи;

- высокая изменчивость внешней и внутренней среды реализации проекта;

- отсутствие доступа к информации о ходе выполнения смежных проектов.

По опросам специалистов, значительная часть проблем возникает в связи с отсутствием согласованности в действиях участников проекта и недостатком информации о параметрах и ходе выполнения проекта (рис. 1.12). 


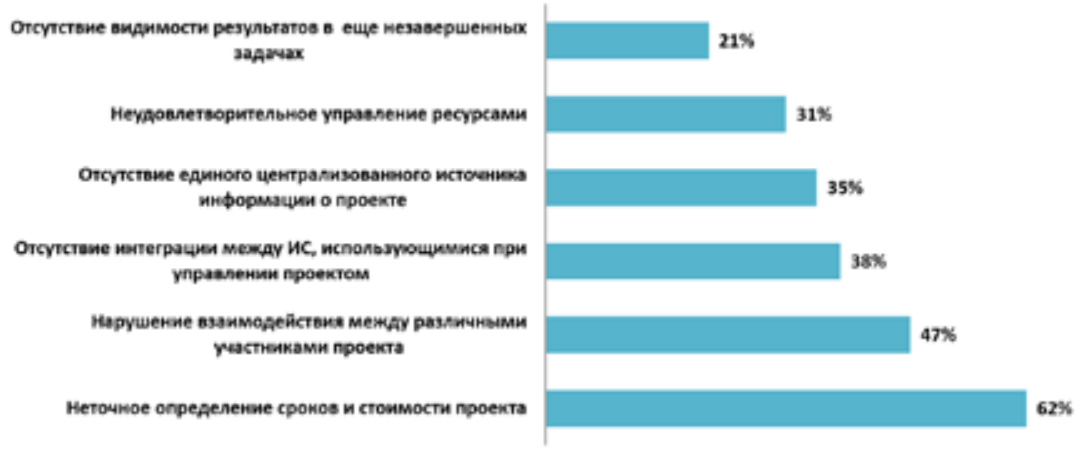

Рис. 1.12. Причины возникновения проблемных ситуаций в проектах

Инновационные проекты, выполняемые на крупных производственных предприятиях, затрагивающие интересы большого числа участников (в том числе, государственных структур) и требующие координации деятельности множества кооперантов, требуют от команды управления проектом своевременного контроля параметров проекта по всем областям знаний. Следует заметить, что команда управления проектом представляет собой сложную иерархическую организационную структуру, включающую представителей активных участников проекта, организация эффективного взаимодействия между которыми может представлять довольно сложную и нетривиальную задачу.

Для инновационных проектов характерна высокая степень неопределенности как в оценке текущей ситуации, так и в прогнозировании последствий принимаемых решений. Усугубляется эта проблема для инновационных проектов, входящих в состав долгосрочной государственной программы. Они часто имеют более высокую степень неопределенности, чем индивидуальные проекты, ведь, чем протяженнее проект во времени, тем более непредсказуемой становится среда его реализации. Это связано с высокой изменчивостью внешней среды проекта, обусловленной возможным изменением государственной политики, внешнеполитической ситуации, приоритетов финансирования, а также появлением новых технологий. При этом сжатые сроки, устанавливаемые на уровне Правительства или профильного министерства, зависимость от множества смежных участников вы- 
нуждают руководителя проекта принимать непродуманные решения, часто основанные лишь на собственном опыте реализации предыдущих проектов (не всегда схожих по своей сути) и приводящие к серьезным нежелательным последствиям. Кроме того, при включении в число участников проекта представителей государственных структур существенно удлиняется цепочка лиц, принимающих решения, а взаимодействие между участниками усложняется. Известно, что с увеличением числа участников проекта количество информационных связей растет нелинейно.

Выполнение инновационных проектов немыслимо без привлечения высококвалифицированных, высокоинтеллектуальных участников, обладающих глубокими познаниями не только в предметной области, где выполняется проект, но и в области организационного, процессного и проектного управления $[33,34]$. Это связано с тем, что инновационные проекты требуют к себе повышенного внимания со стороны руководства предприятия, поскольку они несут в себе большие риски от невозврата инвестиций, нежели другие реализуемые проекты. Но даже наличие таких людей в команде проекта еще не гарантирует их успешного завершения. Для инновационных проектов особенно остро стоит проблема, связанная с подбором и назначением исполнителей, обладающих не только определенными профессиональными знаниями и навыками, но и качествами, необходимыми для работы в команде. При этом наиболее сложной ситуация представляется для ЛПР, который одновременно является исполнителем, ответственным за получение одного из результатов проекта, и руководителем, который должен правильно определить исполнителей вверенного ему комплекса задач проекта. Хорошо известно, что далеко не всегда в одном человеке сочетаются качества хорошего руководителя и профессионала в предметной области. В этом случае обобщенные знания и опыт помогут избежать ошибок или хотя бы снизить негативные последствия от неверных решений.

И наконец, проблема, связанная с затрудненным доступом к информации о ходе выполнения смежных проектов. Чаще всего она вызвана тем, что взаимодействие ЛПР смежных проектов ограничено, во-первых, рамками существующих организационных структур как самих проектов, так и предприятия в целом, а во-вторых, понятиями субординации, когда руководители смежных проектов находятся на разных уровнях иерархии, хотя и не в прямом подчинении друг 
у друга. Кроме того, часто смежные проекты конкурируют за доступ к одним и тем же ресурсам производственно-технической базы и персонала, что также не способствует эффективному взаимодействию в решении общих проблем.

Исходя из вышеперечисленного, следует обратить особое внимание на оказание информационной и интеллектуальной поддержки принятия решений для лиц, находящихся на различных уровнях организационной структуры проекта, и для проблемных ситуаций, относящихся к различным аспектам проектной деятельности из крайне широкого спектра управленческих проектных задач.

\section{3. Классификация проблемных ситуаций инновационного проекта как основа информационной поддержки принятия решений}

После получения инвестиционной поддержки инновационной идеи можно начинать подготовку к планированию и реализации инновационного проекта. На этом пути может встретиться множество проблем, с частью из которых, возможно, участники проекта уже сталкивались, и имеют позитивный или негативный опыт их преодоления. Следовательно, нужно в первую очередь искать причинно-следственные связи, приводящие к неудачам проектов на различных стадиях их жизненного цикла, и устранять вероятные проблемы еще до их возникновения.

На ранних стадиях жизненного цикла, как правило, решения принимаются коллективно, что связано с широким кругом обсуждаемых вопросов, влияющих на судьбу проекта (рис. 1.13).

На стадии исполнения планы воплощаются в результаты, за которые несут ответственность конкретные исполнители, принимающие решения согласно своей компетенции, навыкам и знаниям. Стадия завершения проекта предполагает, помимо административных процедур закрытия договоров и написания отчетов, обязательную фиксацию полученных знаний, что также делает необходимым взаимодействие ЛПР, а также привлечение инженеров знаний. Для повышения эффективности взаимодействия участников при выполнении проектов разработаны и успешно применяются в различном сочетании множество инструментов - от основополагающих методов проектного менеджмента до методов математического моделирования и принятия решений. Повсеместное признание, которое завоевывает методология 
управления проектами, является показателем того, что применение соответствующих знаний, процессов, навыков, инструментов и методов может иметь решающее значение для успеха проекта. Но, судя по результатам выполнения проектов, использования только лишь стандартов и методов проектного управления недостаточно для достижения поставленных целей.

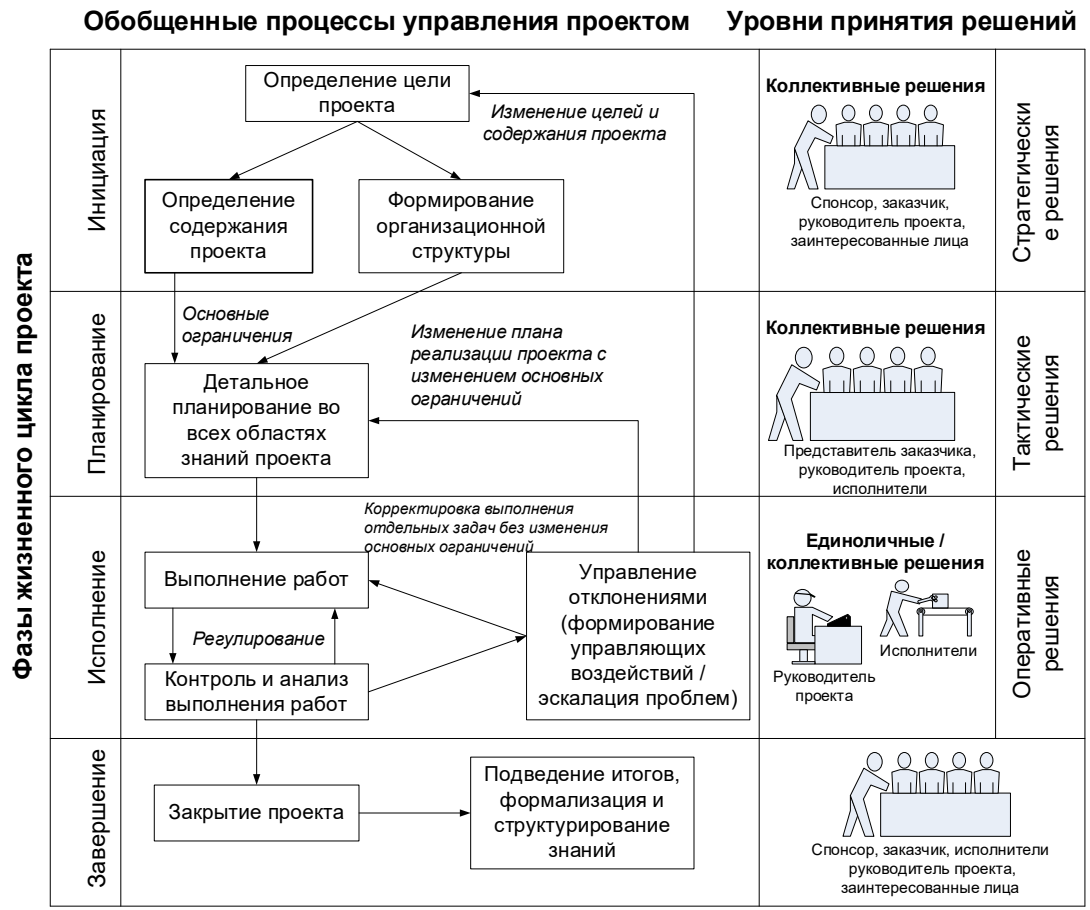

Рис. 1.13. Обобщенная модель жизненного цикла управления инновационным проектом

Таким образом, будущее за целым набором подходов - организации, использующие более одного формализованного подхода к управлению проектами и комбинирующие различные техники, показывают лучшие результаты. Тем не менее, базовый подход к эффективному управлению проектами основан на изучении и применении на практике Свода знаний по управлению проектами $[4,35,36]$, в котором определены раз- 
личные аспекты управления проектами, в частности, разновидности жизненных циклов управления проектами и сопутствующие им процессы. Для каждой стадии жизненного цикла проекта необходимо определять перечень лиц, принимающих решения, для оказания адресной информационной поддержки в проблемных ситуациях.

Один из подходов, помогающих справиться с неопределенностью и повысить эффективность управления проектами, основан на классификации проблем и выработке типовых решений. Каждому классу проблемных ситуаций соответствует класс типовых решений. При этом следует опираться на действующие документы, регулирующие и регламентирующие рассматриваемую деятельность. Кроме того, классифицируются и участники проекта по признаку исполняемых ими ролей в проектной деятельности и занимаемому уровню в иерархической организационной структуре ПЭС. Во многом именно положение участника проекта в организационной структуре влияет на доступность информации и, как следствие, возможность решения проблем. Несмотря на то, что управление различными системами имеет под собой довольно мощную научно-методическую и инструментальную базу, при управлении инновационной деятельностью возникают проблемы с переносом в эту область методов управления, хорошо зарекомендовавших себя в той или иной предметной области.

Причина заключается в том, что инновации, в отличие от многих других явлений и процессов, сочетают в себе элементы многих систем, изучаемых в отдельности (технических, технологических, организационных, экономических, юридических, управления знаниями), и используют разные механизмы управления, свойственные для каждой из этих систем. Это делает чрезвычайно сложной задачу разработки системной модели инновационного проекта в формальной постановке, на которой возможно было бы применение точных методов поиска решений. Не секрет, что даже достаточное количество всех требуемых ресурсов не гарантирует достижения конечных целей проекта.

Эффективное управление инновационным проектом возможно только при соблюдении следующих условий:

1) гибкая организационная структура, способствующая быстрому реагированию ЛПР на возникновение проблемных ситуаций как в проекте, так и во внешней среде;

2) полнота знаний о проекте;

3) высокая квалификация ЛПР. 
В связи с динамично меняющимися условиями ведения бизнеса руководство предприятий все чаще задумывается о переходе от громоздкой неповоротливой иерархической модели управления к более гибким матричным или проектно-целевым. Такой переход обусловлен еще и тем, что конкурентное преимущество получают, как правило, компании, способные предоставить клиентам качественный товар или услугу в соответствии с их требованиями за более короткий срок. Удовлетворение потребностей клиентов приводит к необходимости иметь огромное количество разнообразных сценариев исполнения производственных и организационных процессов, что свидетельствует о постепенном смещении акцентов с управления бизнес-процессами к управлению проектами. Поэтому компании, осуществляющие свою деятельность преимущественно через реализацию проектов различной природы, можно считать проектно-ориентированными.

Эффективное управление проектно-ориентированной организацией возможно лишь в случае акцентированного внимания на вопросах стратегического планирования. Ускорение изменений в окружающей среде, появление новых запросов и изменение позиции потребителя, возрастание конкуренции, развитие современных технологий, а также ряд других причин привели к резкому возрастанию значения стратегического управления. Не только руководство компании, но и каждый сотрудник должен хорошо представлять себе цели своей деятельности, влияние успешного решения своих задач на достижение стратегических целей компании, а для этого каждому сотруднику в пределах его компетенции должна быть предоставлена полная и непротиворечивая информация о различных аспектах проекта, т.е., оказана информационная поддержка.

Руководство РМВоК предоставляет и содействует применению общего словаря терминов в профессии управления проектами для обсуждения, написания и употребления понятий управления проектами. Такой стандартный словарь является существенным элементом любой профессиональной дисциплины и может быть положен в основу научно-методической базы управления инновационным проектом. Авторы предлагают при разработке системной модели инновационного проекта отталкиваться от хорошо известного стандарта, но рассматривать его с позиций того, как принимаемые разными участниками ре- 
шения связаны с группами процессов и областями знаний - этими ключевыми понятиями $P M B о K$.

Интересно, что проблемные ситуации могут относиться как к процессному, так и к проектному управлению, которые не исключают, а взаимно дополняют и усиливают друг друга в случае выполнения инновационных проектов в производственно-экономической системе. Совместное использование разных типов управления предполагает «нацеленность действий на разные по своей природе объекты, например, на систему управления проектами для процессного подхода и на сами проекты для проектного» [37]. При этом ЛПР, находящимися на разных уровнях организационной структуры управления производственно-экономической системы и исполняющими различные роли при управлении проектом, могут быть приняты различные решения при возникновении одной и той же проблемной ситуации. Следовательно, необходимо прогнозировать возможные негативные последствия принятых решений из-за неадекватной оценки проблемной ситуации, связанной с недостаточным опытом ЛПР или его некомпетентностью. Вопросы повторного использования знаний применительно к производственным сетям малых и средних предприятий рассматривались в [38], вопросы принятия решений при управлении взаимодействующими процессами в проектно-ориентированных организациях освещались в [39-41]. В развитие этих подходов авторы предлагают классифицировать проблемные ситуации и принятые решения в соответствии с областями знаний и уровнем ЛПР в организационной структуре управления проектом.

Область знаний трактуется как «выделенная область управления проектом, определяемая ее требованиями к знаниям и описываемая в терминах ее составных процессов, практик, входов, выходов, инструментов и методов» $[4,36]$. Процессы управления проектом представляют собой «систематическую последовательность операций, направленную на достижение конечного результата, когда один или несколько входов используются для последующих действий с целью получения одного или нескольких выходов». Руководитель проекта должен обладать определенным уровнем компетенций в каждой из областей знаний, который выражается во владении навыками и умениями применения соответствующих процессов управления, включенных в каждую область знаний. Все 49 процессов управления проектами 
поделены на 5 групп - процессы инициации, планирования, исполнения, мониторинга и контроля, завершения. Группы процессов управления проектом не являются фазами проекта и могут присутствовать на каждой фазе жизненного цикла проекта.

Следует заметить, что процессы распределены по группам процессов и по областям знаний неравномерно [35], поэтому предлагается три варианта пересечения областей знаний с некоторым набором процессов из групп процессов управления проектом (рис. 1.14) [10].

Область знаний 1 группы охватывает полный набор процессов жизненного цикла проекта. Это такие области знаний, как управление заинтересованными сторонами и управление интеграцией, оказывающие наибольшее влияние на слаженность работы команды над проектом, а также позволяющие учитывать разнообразные аспекты внешнего воздействия на проект.

Область знаний 2 группы охватывает только процессы планирования, а также процессы мониторинга и контроля. Эти области знаний составляют хорошо известный «проектный треугольник» - управление расписанием, управление стоимостью и управление содержанием, баланс между сторонами которого означает высокую вероятность достижения конечной цели проекта в соответствии с заданными ограничениями продукта по срокам, цене и функционалу.

Область знаний 3 группы охватывает процессы, непосредственно связанные с ходом реализации проекта, когда стадия инициации пройдена и есть команда, поставившая перед собой цель выполнения проекта. Это процессы планирования, процессы выполнения, а также процессы мониторинга и контроля. Указанные группы процессов связаны с такими областями знаний, как управление качеством, управление коммуникациями, управление рисками, управление закупками и управление ресурсами. Знания, умения и навыки в этих областях необходимы для решения реальных задач, ежедневно возникающих в ходе выполнения проекта.

В рамках проведенных исследований были выделены основные проблемные ситуации, которые могут быть отнесены к приведенным областям знаний и характерны для этапов реализации проектов различного уровня и масштаба, выполняющихся в производственно-экономических системах (табл. 1.1) [10]. Перечень областей знаний и основные процессы, относящиеся к ним, соответствуют [4]. 


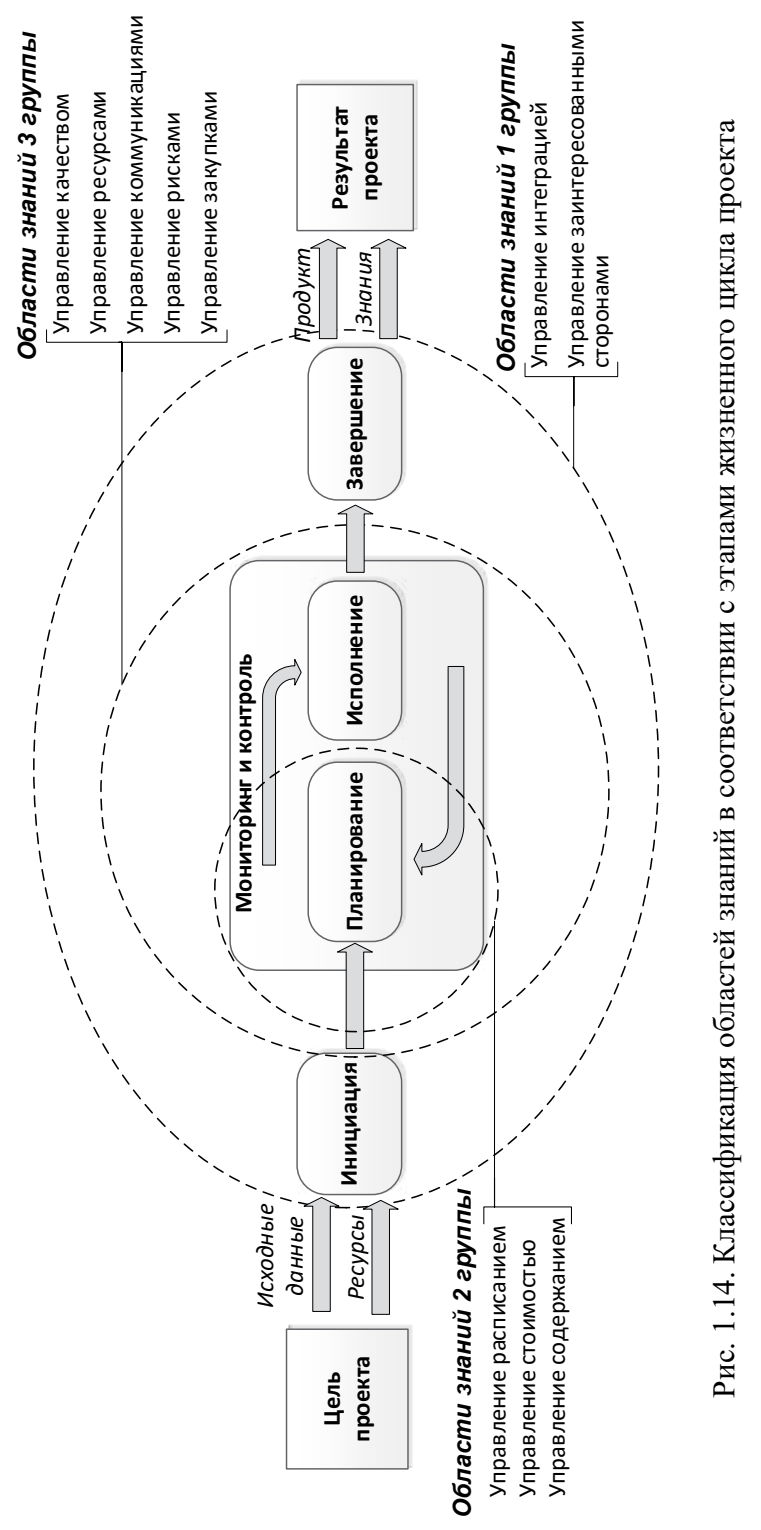


Л.Р. Черняховская, В.И. Васильев, В.Е. Гвоздев, Н.О. Никулина,

А.И. Малахова, А.М. Вульфин, О.Я. Бежаева

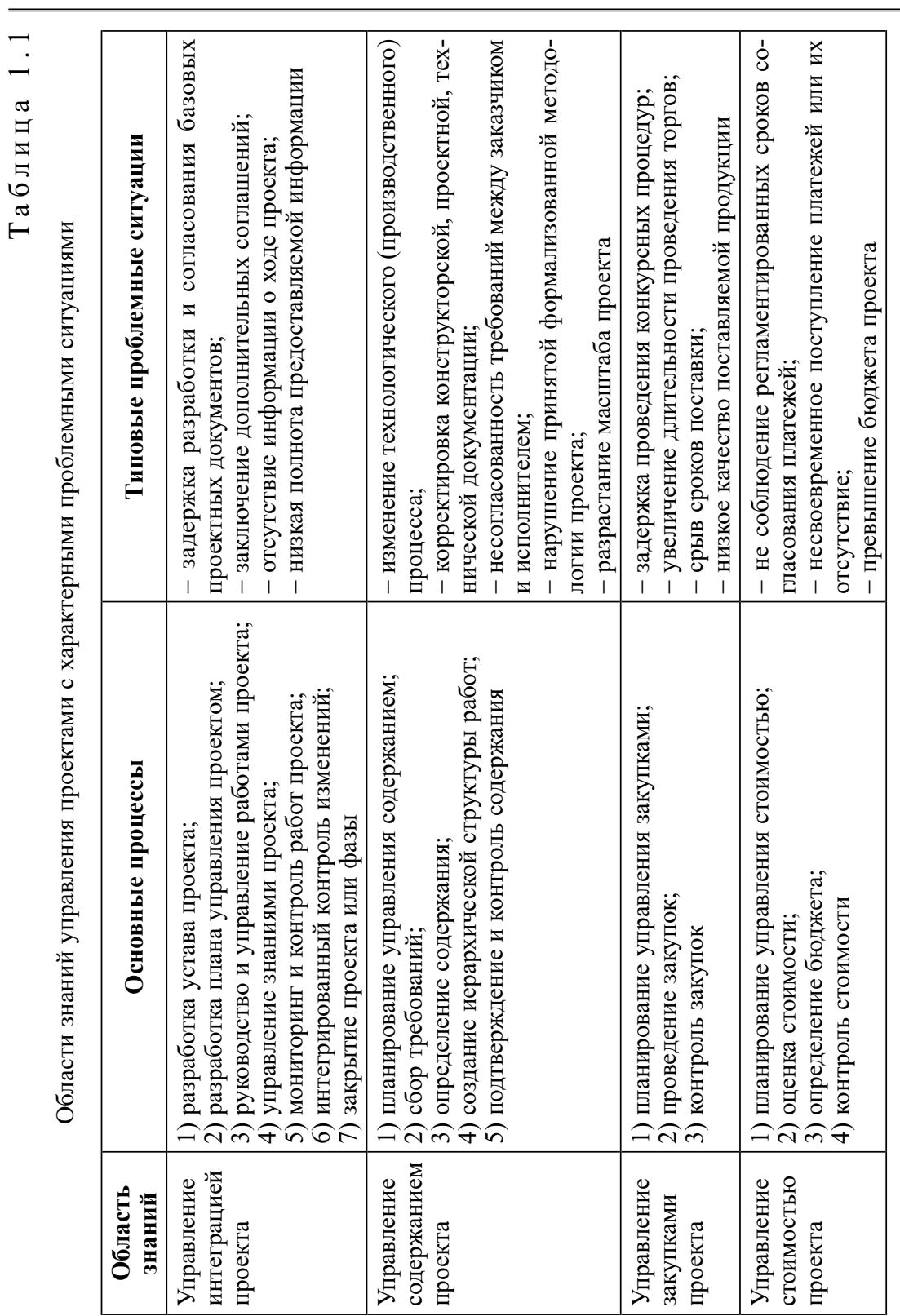


Глава 1

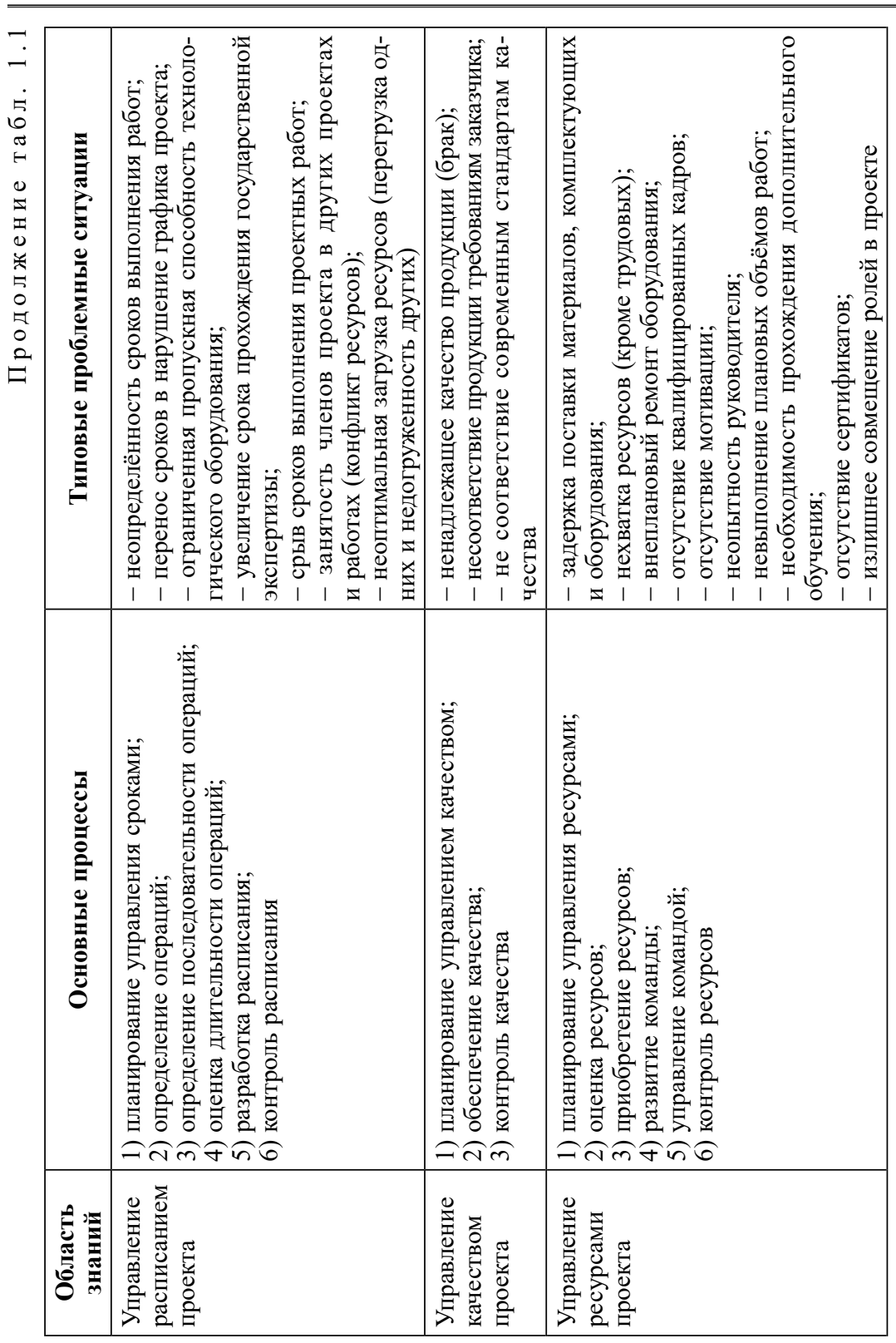


Л.Р. Черняховская, В.И. Васильев, В.Е. Гвоздев, Н.О. Никулина, А.И. Малахова, А.М. Вульфин, О.Я. Бежаева

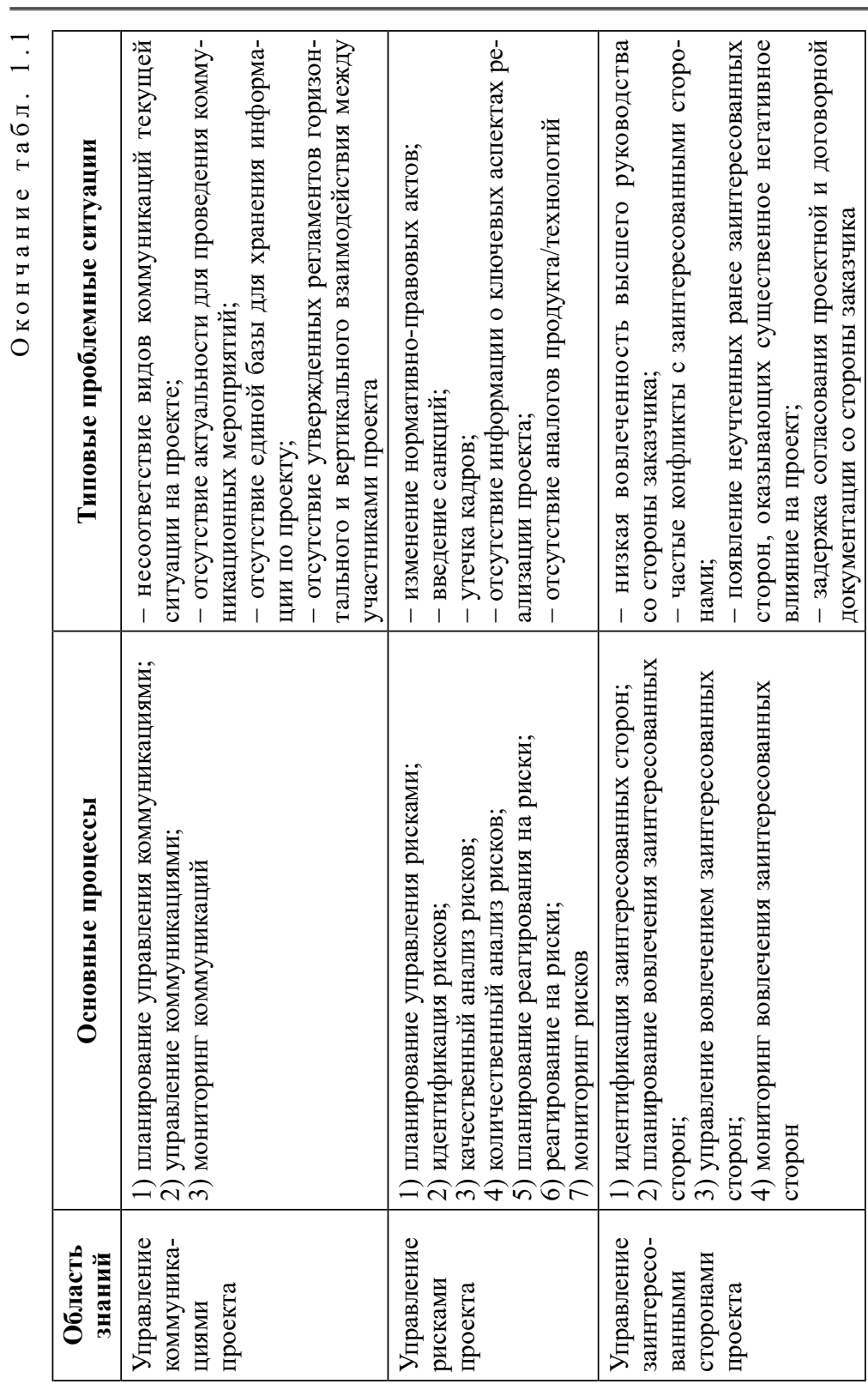


В условиях ограниченности ресурсов, выделяемых для выполнения проектов, важно выделить наиболее приоритетные проблемы, решение которых может повысить отдачу от инновационной деятельности. Из обобщенного перечня проблем можно выделить те, которые связаны с недостатком квалифицированных кадров на всех уровнях принятия решений и отсутствием информации для оценки текущей ситуации. Для решения этих задач как нельзя лучше подходят методы интеллектуального анализа данных и управления знаниями, позволяющие на основе накопленного опыта реализации удачных и неудачных проектов коллективом исполнителей прогнозировать и направлять ход выполнения текущих проектов.

\section{4. Анализ рисков и проблемных ситуаций на примере инновационного проекта, реализуемого на крупном производственном предприятии}

Несмотря на то, что в последние годы методы проектной деятельности завоевывают все большую популярность, все еще недостаточно проработаны вопросы извлечения и формализации знаний, полученных в ходе управления проектами, с целью использования их для обоснования принятых решений при формировании управляющих воздействий, а также в последующих проектах. На наш взгляд, тому есть несколько причин:

1) непостоянство команды проекта и временный характер деятельности руководителя проекта, у которого нет гарантий назначения на эту роль в дальнейшей перспективе и, соответственно, нет желания периодически (а это очень важно!) тратить время на описание текущего положения дел. В результате подведение итогов случается лишь при закрытии проекта или его фазы и в большинстве случаев носит весьма формальный характер;

2) высокая динамика самого проекта, жестко ограниченного временными рамками, что приводит к отсутствию возможности спокойно проанализировать текущий ход проекта. Возникающие время от времени проблемы, нарушающие запланированный график работ, еще более усугубляют ситуацию. Чаще всего проблемы приходится преодолевать всеми возможными способами в очень сжатые сроки, и руководителю проекта, как правило, не до фиксации действий и описания принятых решений в формализованном виде; 
3) незнание положений международных и национальных стандартов проектного управления, отсутствие практики ведения подобной документации. Несмотря на рост количества реализуемых проектов различного масштаба во всех сферах хозяйственной и общественной деятельности, количество сертифицированных руководителей проектов различного профиля в масштабах страны весьма незначительное - по состоянию на 10 января 2020 года в Реестре $P M I$ числится 1735 человек, имеющих сертификат PMP (Project Management Professional, профессионал проектного управления) в России [42];

4) отсутствие инструментов, шаблонов и методик, позволяющих удобно и быстро осуществлять фиксацию текущего состояния проекта и получать прогнозы его дальнейшего развития. Конечно, существует множество автоматизированных систем, сопровождающих выполнение проекта (Microsoft Project, Project Expert, Primavera, Asta PowerProject и др.), но, во-первых, все они дают разрозненную информацию о различных параметрах проекта (или их небольшой совокупности), во-вторых, руководитель проекта (или ЛПР) должен быть уверенным пользователем множества информационных систем, в-третьих, не на всех стадиях жизненного цикла проекта использование указанных систем целесообразно и оправдано (например, на ранних стадиях еще нет календарного плана в Microsoft Project, а проблемные ситуации, случающиеся на стадии инициации, могут привести к краху проекта еще до этапа планирования);

5) нельзя игнорировать и психологические аспекты - если проблемная ситуация на первый взгляд кажется несерьезной, легко устранимой, то велик соблазн не фиксировать ее, а постараться принять меры и сделать так, как будто ничего и не происходило. У руководителя проекта, как правило, есть резервы, которые он может потратить на решение незначительных проблем, не привлекая вышестоящих руководителей. Так же могут поступать и рядовые члены команды проекта, скрывая от руководителя незначительные, на их взгляд, проблемы, особенно, если они сами явились причиной их возникновения. В этом кроется опасность накопления мелких проблем, совокупность которых может послужить причиной провала проекта в целом.

Информационная поддержка ЛПР направлена на снижение неопределенности при принятии решений, что влечет за собой уменьшение вероятности наступления рисковых событий и сокращение коли- 
чества проблемных ситуаций. Прежде всего, для организации информационной поддержки необходимо обеспечить сбор и классификацию данных о проблемных ситуациях, возникновение которых связано с организационными, производственными и финансово-экономическими рисками. Риски, относящиеся к любому из этих трех классов, наиболее сильно влияют на выполнение работ по проекту и, следовательно, имеют наивысший приоритет при выделении ресурсов на мероприятия по их предупреждению и предотвращению.

Например, в ПАО «ОДК-УМПО» на стадии инициации проекта (и в дальнейшем при его актуализации на всех остальных стадиях жизненного цикла) рассматривается около 20 наиболее часто идентифицируемых рисков, характерных для инновационного проекта $[34,43]$.

Описание рисков сведено в табл. 1.2. Для более точной оценки каждый риск получает количественную экспертную оценку по методу анализа причин и последствий отказов (Failure Mode and Effect Analysis - FMEA) в соответствии с формулой:

$$
K_{p}=K_{n} \times K_{H} \times K_{o},
$$

где $K_{p}-$ коэффициент риска; $K_{n}-$ коэффициент тяжести последствий отказов (степень влияния возможного последствия отказа, связанного с риском, на ход проекта); $K_{н}$ - коэффициент, учитывающий вероятность, с которой отказ или его причина не могут быть обнаружены до возникновения его последствий; $K_{o}$ - коэффициент, учитывающий вероятность отказа.

Каждый коэффициент, приведенный в (1.1), оценивается по десятибалльной шкале, поэтому коэффициент риска $K_{p}$ по каждой строке колеблется от 1 до 1000. Затем определяется уровень риска $L_{p}$ как отношение величины суммарного риска по всем строкам к максимально возможной величине суммарного риска по этим строкам, выраженное в процентах.

$$
L_{p}=K_{p} / K_{p \max } \times 100
$$

Для приведенного в табл. 1.2 перечня рисков для рассматриваемого инновационного проекта уровень риска в соответствии с (1.2) составил $12,2 \%$, что укладывается в диапазон допустимых значений, поскольку благоприятный уровень риска для России должен составлять не более $25 \%$. 
Л.Р. Черняховская, В.И. Васильев, В.Е. Гвоздев, Н.О. Никулина, А.И. Малахова, А.М. Вульфин, О.Я. Бежаева

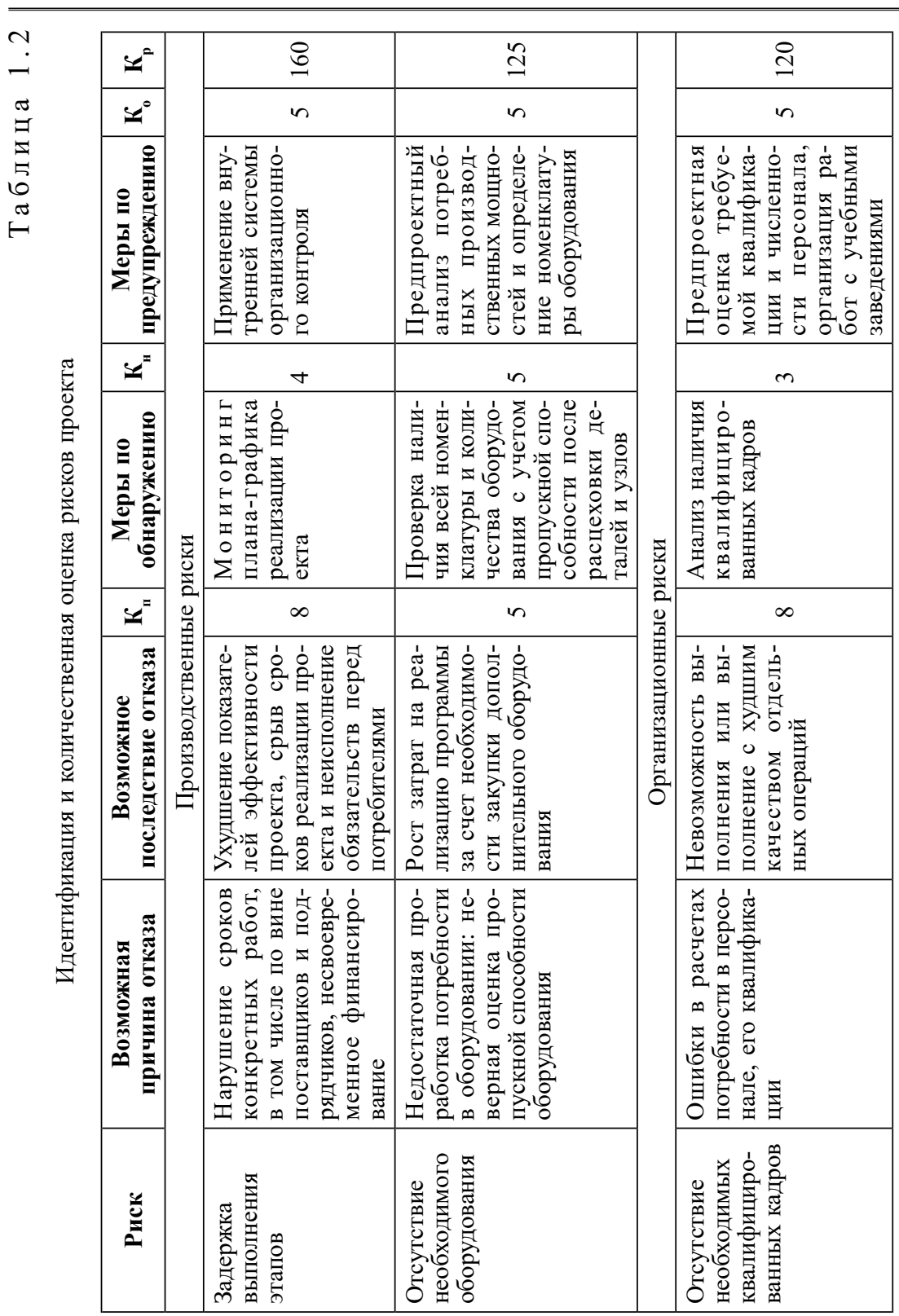


Глава 1

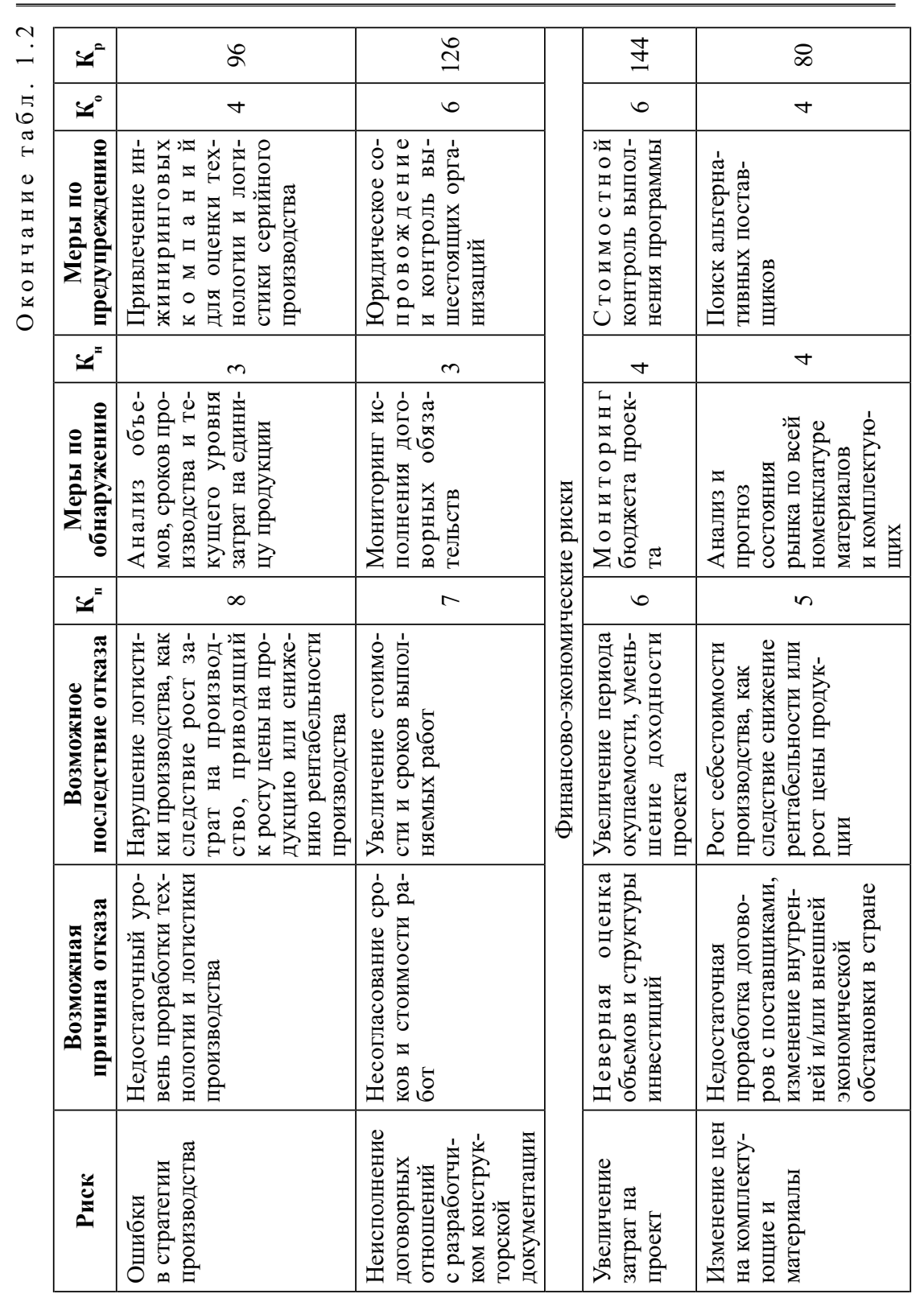


Количественные оценки позволяют ранжировать риски по степени их негативного воздействия на проект. Риски с наивысшим приоритетом регулярно отслеживаются с целью своевременного реагирования при изменении степени угрозы, и проводятся целенаправленные мероприятия по предупреждению дефектов, которые приводят к предотвращению причин отказов, снижению вероятности появления отказа, снижению влияния первопричины на появление отказа и тяжесть его последствий, повышению вероятности обнаружения отказа.

Следует заметить, что риски являются типовыми для группы проектов (продуктовые проекты, проекты по созданию центров специализации, проекты реконструкции и технического перевооружения, проекты в сфере информационных технологий и др.), что дает возможность распространить их и на другие инновационные проекты, выполняемые в производственной среде на различных предприятиях.

В ходе исследований в ПАО «ОДК-УМПО» была проведена большая работа по упорядочению информации не только о возможных рисках, но и о проблемных ситуациях, которые возникают в результате наступления рисковых событий. Так, в табл. 1.3 определены 3 уровня проблем, соответствующих уровням, которые занимают лица, обладающие полномочиями в принятии решений, в организационной структуре проекта.

Таблица 1.3

Уровни проблемных ситуаций инновационного проекта

\begin{tabular}{|c|l|l|l|}
\hline $\begin{array}{c}\text { Уровень } \\
\text { проблемной } \\
\text { ситуации }\end{array}$ & $\begin{array}{c}\text { Место } \\
\text { возникновения }\end{array}$ & $\begin{array}{c}\text { Характеристика уровня } \\
\text { проблемной ситуации }\end{array}$ & Уровень ЛПР \\
\hline 1 & Локальная & $\begin{array}{l}\text { Управляемая (не требует } \\
\text { эскалации) }\end{array}$ & $\begin{array}{l}\text { Руководитель } \\
\text { проекта }\end{array}$ \\
\hline 2 & $\begin{array}{l}\text { Затрагивает } \\
\text { смежные проекты } \\
\text { или подразделения } \\
\text { предприятия }\end{array}$ & Мешает оперативной работе & $\begin{array}{l}\text { Руководство } \\
\text { предприятия }\end{array}$ \\
\hline 3 & Глобальная & $\begin{array}{l}\text { Критическая (возможна } \\
\text { полная остановка проекта) }\end{array}$ & $\begin{array}{l}\text { Руководство } \\
\text { корпорации }\end{array}$ \\
\hline
\end{tabular}

Уровень проблемы, который оценивает руководитель проекта, свидетельствует о необходимой срочности принимаемых мер. Фиксируется и статус решения проблемной ситуации, благодаря чему можно от- 
слеживать ее жизненный цикл. Определено 4 возможных статуса решения проблемной ситуации:

1 - проблемная ситуация находится на стадии обсуждения;

2 - определены задачи по решению проблемной ситуации, назначены исполнители;

3 - выявлена задержка решения проблемной ситуации;

4 - проблемная ситуация решена.

На данном этапе описание возникающих проблемных ситуаций и фиксация решений, принимаемых на проектных комитетах или координационных совещаниях на уровне куратора проекта, управляющего директора или генерального директора корпорации, выполняется в слабоструктурированном неформализованном виде, например, может представлять собой таблицу, ячейки которой заполняются администратором проекта и согласовываются руководителем проекта. Пример заполнения подобного журнала приведен в табл. 1.4.

Таблица 1.4

Описание проблемных ситуаций инновационного проекта

\begin{tabular}{|c|c|c|}
\hline Признак ПС & Проблемная ситуация 1 & Проблемная ситуация 2 \\
\hline Уровень проблемы & 2 & 3 \\
\hline Описание проблемы & $\begin{array}{l}\text { Отсутствие уточненного } \\
\text { плана производства, что } \\
\text { не позволяет запланировать } \\
\text { приобретение материалов } \\
\text { и покупных полуфабрика- } \\
\text { тов для запуска материаль- } \\
\text { ной части в производство }\end{array}$ & $\begin{array}{l}\text { Риск срыва сроков постав- } \\
\text { ки оборудования со сторо- } \\
\text { ны поставщика, что может } \\
\text { повлиять на срок ввода } \\
\text { объекта в эксплуатацию }\end{array}$ \\
\hline Дата регистрации & 20.01 .19 & 20.01 .19 \\
\hline $\begin{array}{l}\text { Предложение по } \\
\text { решению }\end{array}$ & $\begin{array}{l}\text { Уточнить план производ- } \\
\text { ства на год и текущий квар- } \\
\text { тал }\end{array}$ & $\begin{array}{l}\text { Направление специалистов } \\
\text { на завод-изготовитель обо- } \\
\text { рудования для инспектиро- } \\
\text { вания его производства }\end{array}$ \\
\hline $\begin{array}{l}\text { Должностное лицо, } \\
\text { помощь или решение } \\
\text { которого требуется }\end{array}$ & $\begin{array}{l}\text { Директор по производству, } \\
\text { Директор по продажам }\end{array}$ & Технический директор \\
\hline Срок решения & 31.01 .19 & 15.02 .19 \\
\hline Статус решения & 2 & 1 \\
\hline
\end{tabular}


Подобная таблица формируется периодически в рамках подготовки презентации для проектного комитета или совещания, где обсуждается ход выполнения проекта. К ней имеет доступ ограниченное число лиц: команда проекта и участники проектного комитета или координационного совета, на котором рассматривается проблема. Члены проектной команды, непосредственно не принимающие участия в совещании, не имеют доступа к этой информации, что затрудняет взаимодействие участников проекта и мешает давать адекватную оценку сложившейся ситуации. Руководителям других проектов и их командам подобная информация также была бы очень полезной в случае возникновения похожей проблемы. Таким образом, обеспечение слаженного взаимодействия множества участников проекта представляет собой отдельную задачу.

В ходе выполнения инновационного проекта ЛПР необходимо оказывать все виды поддержки принятия решений - информационную, вычислительно-аналитическую, интеллектуальную. И если с первыми двумя видами довольно успешно справляются системы управления проектами, предоставляя в наглядном виде графики и отчеты, свидетельствующие о ходе выполнения проектных работ, то для принятия решений в проблемных ситуациях необходимы более сложные алгоритмы, основанные на знаниях и опыте не только ЛПР, ведущих текущий проект, но и ЛПР других проектов, реализованных в смежных областях. 


\section{ГЛАВА 2}

\section{МЕТОДОЛОГИЯ ИНТЕЛЛЕКТУАЛЬНОЙ ПОДДЕРЖКИ ПРИНЯТИЯ РЕШЕНИЙ ПРИ УПРАВЛЕНИИ ИННОВАЦИОННЫМИ ПРОЕКТАМИ}

\section{1. Постановка задачи на разработку методологии интеллектуальной поддержки принятия решений при управлении инновационными проектами}

Инновации, в отличие от многих других явлений и процессов, сочетают в себе элементы многих систем, изучаемых в отдельности (технических, технологических, организационных, экономических, юридических, управления знаниями), и используют разные механизмы управления, свойственные для каждой из этих систем. Это делает чрезвычайно сложной задачу разработки системной модели инновационного проекта в формальной постановке, на которой возможно было бы применение точных методов поиска решений [44].

Системный подход к управлению инновационным проектированием предполагает постоянный контроль за ходом выполнения проекта, выявление отклонений фактического хода выполнения работ от запланированного и принятие корректирующих действий вплоть до согласованной с заинтересованными сторонами корректировки основных параметров проекта - сроков, стоимости, характеристик конечного продукта и даже целей $[32,43]$. Важность своевременного контроля подчеркивается и в международном стандарте проектного управления $P M B o K 6^{\text {th }}$ Edition - процессы мониторинга и контроля включены во все области знаний [4]. Нельзя забывать и о том, что в сложных системах при воздействии на один из ее компонентов изменения могут произойти и в других, на первый взгляд, не связанных элементах. В этом и заключается сложность проблемы выбора оптимального решения из множества возможных вариантов, когда наряду с улучшением одних количественных и качественных показателей проекта необходимо исключить или хотя бы минимизировать ухудшение других показателей. Например, при сокращении сроков выполнения работ и/или эко- 
номии бюджета проекта важно не допустить ухудшения качества продукта проекта. В инновационных проектах далеко не всегда удается предугадать возможные последствия принятых решений в связи с высокой степенью неопределенности, поэтому использование разного рода моделей может существенно облегчить задачу выбора. Кроме того, нужно принять во внимание, что риски инновационного проекта как в количественном, так и в качественном выражении, всегда выше по сравнению с рисками других проектов.

Повышению эффективности управления инновационными проектами способствует оказание интеллектуальной и информационной поддержки принятия решений в проблемных ситуациях, возникающих в ходе реализации инновационных проектов. В проводимых исследованиях в качестве эффективного инструмента для решения рассматриваемых задач предлагается разработка методологии, представляющей собой комплекс моделей, методов и средств поддержки принятия решений на основе технологий инженерии знаний, обеспечивающих информационно-аналитическую поддержку управляющей системы на основе интегрированного описания ситуаций, требующих принятия решений, системного сочетания знаний и опыта экспертов, результатов математического и имитационного моделирования. Предлагаемая методология обеспечивает возможность уникального «наполнения» содержания моделей и методов в зависимости от специфики проекта, данных и знаний о составе этапов и стадий, перечня оцениваемых показателей и методик их оценки, позволяющей автоматизировать процесс подготовки решений, а также создавать алгоритмическое и программное обеспечение для обеспечения процессов принятия управленческих решений, адаптируемое под конкретную отрасль и проект [23].

В последние годы большое внимание уделяется становлению «экономики знаний», как высшего этапа инновационной экономики [45]. Проблемы поддержки принятия решений на основе применения баз знаний рассматриваются в научных исследованиях российских и зарубежных ученых В.А. Виттиха, С.Н. Васильева, Б.Е. Федунова, Н.И. Юсуповой, Т.А. Гавриловой, В.И. Васильева, Н.К. Загоруйко, A. Aamodt, A. Hart [46-50]. Приобретение и накопление знаний особенно важно для реализации инновационных технологий. Инновационный процесс, наряду с формальными механизмами управления, обеспечивает основу для интеграции неформальных механизмов коорди- 
нации, целью которой является интеграция существующих явных и неявных знаний, а также их накопление и использование для обоснования управленческих решений. Одним из основных свойств систем управления знаниями является эмерджентность, благодаря которой взаимодействие специалистов на основе формализации представления и обработки знаний при разработке интеллектуальных компонентов (онтологии, базы знаний) способствует созданию новых знаний. Ключевыми аспектами процесса накопления знаний являются совместное получение знаний партнерами, сотрудничество и/или борьба за использование знаний. Люди делают знания явными и обобщают опыт выполнения различных инновационных проектов.

Разработка баз знаний предполагает сбор и анализ знаний, полученных из различных источников: стандартов управления проектами, документов, регламентирующих процесс управления проектом, знаний и опыта экспертов, а также формализация этих знаний в соответствии с определенной моделью представления знаний. В области искусственного интеллекта созданы различные модели представления знаний и способы разработки баз знаний (табл. 2.1).

Предлагаемая методология предполагает создание интегрированной онтологии управления знаниями, которая является центральным звеном базы знаний и формируется на основе системной интеграции онтологии управления инновационными проектами, онтологии поддержки принятия решений и онтологии предметной области. По результатам процедур сбора, идентификации, переработки и анализа знания заносятся в интегрированную онтологию в виде правил ППР, либо в виде прецедентов проблемных ситуаций, которые вместе с онтологией составляют основу базы знаний (рис. 2.1).

Правила выражают причинно-следственные отношения между событиями, являющимися причинами возникновения проблемных ситуаций в ходе реализации инновационного проекта, самими проблемными ситуациями и действиями, которые рекомендуется выполнить для их разрешения. Таким образом, правила служат связующим звеном между предметной областью реализации проекта и математическими методами поиска наилучших рациональных решений.

База знаний обеспечивает возможность поддержки принятия решений с применением методов и алгоритмов поиска решений, а также моделей и методов оптимизации и интеллектуального анализа данных, представленных в онтологии. 
Классификация методов извлечения знаний

\begin{tabular}{|c|c|c|c|}
\hline $\begin{array}{c}\text { Интерпретация } \\
\text { знаний из } \\
\text { различных } \\
\text { источников } \\
\end{array}$ & \multicolumn{3}{|c|}{ Методы извлечения знаний } \\
\hline \multirow{3}{*}{$\begin{array}{l}\text { Приобретение } \\
\text { экспертных } \\
\text { знаний }\end{array}$} & \multicolumn{2}{|c|}{$\begin{array}{c}\text { Коммуникативные методы } \\
\text { извлечения знаний }\end{array}$} & \multirow{2}{*}{$\begin{array}{c}\text { Визуальное } \\
\text { моделирование } \\
\text { обработки знаний }\end{array}$} \\
\hline & Пассивные методы & Активные методы & \\
\hline & $\begin{array}{l}\text { • Приобретение } \\
\text { знаний в диалоге } \\
\text { с экспертами } \\
\text { • Наблюдение } \\
\text { • Получение и } \\
\text { обработка эксперт- } \\
\text { ных оценок }\end{array}$ & $\begin{array}{l}\text { - Мозговой штурм } \\
\text { - Метод Дельфи } \\
\text { - Метод сценариев } \\
\text { - Анкетирование } \\
\text { - Экспертные игры }\end{array}$ & $\begin{array}{l}\text { • Объектно-ориен- } \\
\text { тированный анализ } \\
\text { и моделирование } \\
\text { • Когнитивные } \\
\text { карты } \\
\text { • Структурирован- } \\
\text { ный анализ } \\
\text { сценариев }\end{array}$ \\
\hline \multirow[t]{2}{*}{$\begin{array}{l}\text { Интеллектуаль- } \\
\text { ный анализ } \\
\text { данных }\end{array}$} & $\begin{array}{c}\text { Методы } \\
\text { индуктивного } \\
\text { обучения }\end{array}$ & $\begin{array}{c}\text { Методы } \\
\text { поиска } \\
\text { ассоциаций }\end{array}$ & $\begin{array}{c}\text { Классификация } \\
\text { и кластерный } \\
\text { анализ }\end{array}$ \\
\hline & $\begin{array}{l}\text { • Индукция правил } \\
\text { на основе примеров } \\
\text { с применением } \\
\text { алгоритма ID3 } \\
\text { • Построение } \\
\text { деревьев решений } \\
\text { с применением } \\
\text { алгоритмов See5 }\end{array}$ & $\begin{array}{l}\text { • Регрессионный } \\
\text { анализ } \\
\text { • Поиск ассоциа- } \\
\text { тивных правил } \\
\text { • Причинно-след- } \\
\text { ственные модели }\end{array}$ & $\begin{array}{l}\text { • Нейронные сети, } \\
\text { метод } k \text {-ближайших } \\
\text { соседей } \\
\text { • Байесовский } \\
\text { классификатор } \\
\text { CART (Classification } \\
\text { and Regression Tree) }\end{array}$ \\
\hline \multirow{2}{*}{$\begin{array}{l}\text { Формализация } \\
\text { знаний на основе } \\
\text { текстов }\end{array}$} & \multicolumn{3}{|c|}{$\begin{array}{c}\text { Автоматизированный лингвистический анализ } \\
\text { текстовых документов }\end{array}$} \\
\hline & $\begin{array}{l}\text { Морфологический } \\
\text { анализ }\end{array}$ & $\begin{array}{c}\text { Синтаксический } \\
\text { анализ }\end{array}$ & $\begin{array}{l}\text { Семантический } \\
\text { анализ }\end{array}$ \\
\hline $\begin{array}{l}\text { Формирование } \\
\text { знаний на основе } \\
\text { прецедентов } \\
\text { проблемных } \\
\text { ситуаций }\end{array}$ & $\begin{array}{l}\text { • Создание базы } \\
\text { прецедентов } \\
\text { - Классификация } \\
\text { прецедентов }\end{array}$ & $\begin{array}{l}\text { Поиск ближайших } \\
\text { прецедентов }\end{array}$ & $\begin{array}{l}\text { Адаптация } \\
\text { решений и } \\
\text { занесение новых } \\
\text { прецедентов } \\
\text { в базу знаний } \\
\end{array}$ \\
\hline \multicolumn{4}{|c|}{$\begin{array}{l}\text { Онтологический анализ проблемно-ориентированных областей знаний и } \\
\text { создание онтологий, включающих полученные фрагменты знаний }\end{array}$} \\
\hline \multicolumn{4}{|c|}{ Разработка интегрированной онтологии } \\
\hline
\end{tabular}




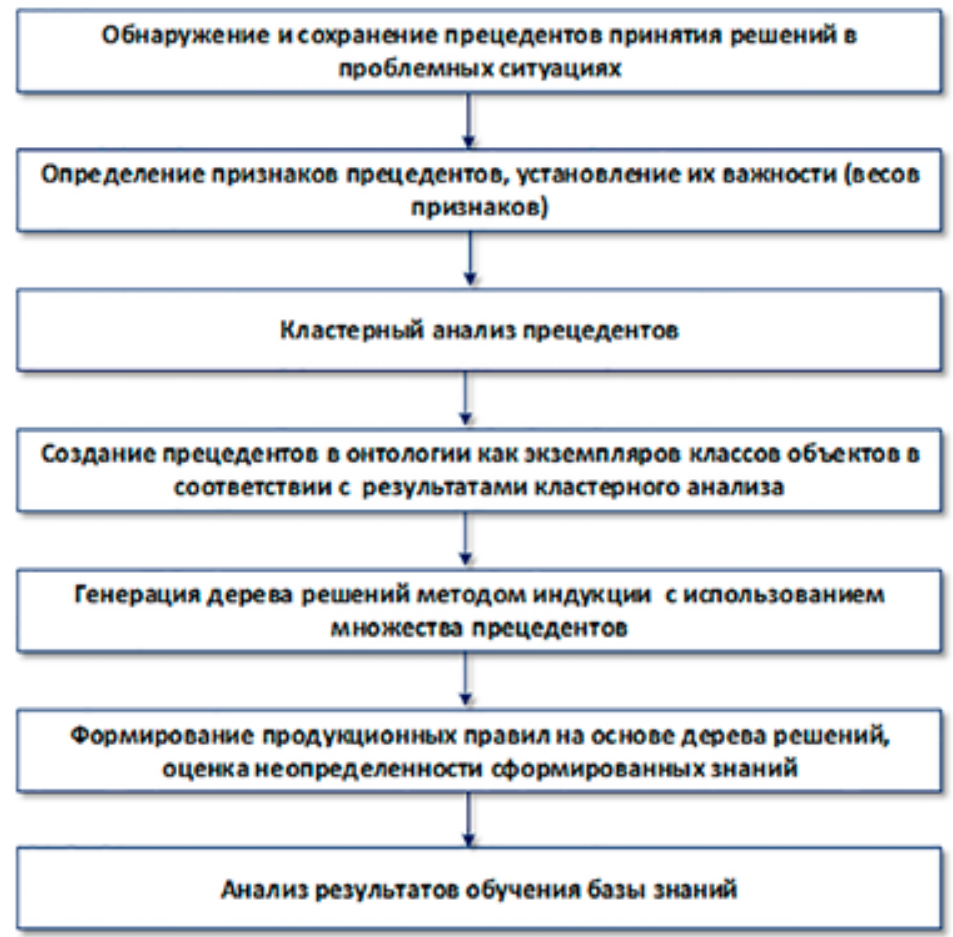

Рис. 2.1. Методика построения базы знаний

Опираясь на предложенный выше подход к выделению проблемных ситуаций, возникающих в ходе выполнения инновационного проекта, становится возможным говорить о контекстно-ориентированных правилах и рекомендациях, учитывающих целый спектр характеристик проблемных ситуаций, например, кому из заинтересованных лиц проекта данная рекомендация предназначается, на каком этапе реализации проекта, в рамках какого процесса и к какой области знаний может быть отнесена. Работы по построению контекстно-ориентированных онтологий уже ведутся исследователями в других областях знаний [51-54]. Применительно к рассматриваемой задаче данный подход позволяет обеспечить необходимую полноту базы знаний, создаваемой для проектов различного уровня и масштаба, выполняющихся в производственно-экономических системах. 
Поддержка принятия решений необходима не только для анализа инновационной активности организаций на региональном уровне, но и для управления реализацией конкретных инновационных проектов. Процесс принятия решений при реализации проекта поддерживается некоторым набором знаний и алгоритмами их обработки, позволяющим ЛПР обосновать выбор той или иной альтернативы действий. Это могут быть как оперативные данные о состоянии проекта в текущий момент времени, так и некоторые устоявшиеся правила поведения ЛПР в контексте полученных характеристик проблемной ситуации. Реализация и применение базы знаний направлены на повышение полноты и улучшение качества удовлетворения информационных потребностей пользователей, ориентированных в конечном итоге на точность, своевременность и обоснованность принимаемых управленческих решений. Процесс поддерживается наличием знаний организации и применением механизма логического вывода, позволяет ЛПР обосновать выбор той или иной альтернативы действий.

Последствия решений, связанных с крупными капиталовложениями, влияют на финансовую устойчивость предприятия и могут привести к риску невыполнения проекта. Принятие оперативных, качественных, обоснованных решений в этой области остро нуждается в строгой регламентации и грамотной информационно-методической поддержке. Следовательно, необходимо осуществлять сбор накапливаемых в проектном менеджменте знаний в форме прецедентов и проверенных на практике правил принятия решений, источниками которых являются эксперты, стандарты и организационные документы, регламентирующие реализацию проектов.

Определим задачу информационной и интеллектуальной поддержки формально. Пусть $R$ - множество знаний пользователя о возникающих и требующих принятия решений ПС, $Q$ - множество сформулированных пользователем требований на удовлетворение его информационных потребностей в связи необходимостью решения возникающих ПС. Тогда $D$ - множество решений, предпринимаемых для устранения возникающих ПС. В этих условиях информационная поддержка может быть определена с помощью двух формальных функций: $\psi: R \Rightarrow Q ; \xi: Q \Rightarrow D$.

На первом этапе реализации информационной поддержки функция $\psi(r)$ отображает знания пользователя о конкретной ПС $r \in R$ в не- 
который формальный запрос $q \in Q$ на предоставление нужной ему информации для разрешения ПС.

На втором этапе реализации информационной поддержки функция $\xi(q)$ преобразует этот запрос $q \in Q$ в некоторое подмножество $d \in D$ альтернатив решений, принимаемых ЛПР для разрешения данной ПС $r \in R$.

Таким образом, в рамках предлагаемой методологии интеллектуальной поддержки принятия решений сформулирована методика поддержки принятия решений, включающая следующие этапы [55]:

1) сбор данных об инновационном проекте, методах и средствах принятия решений по управлению проектом из структурированных и неструктурированных источников;

2) формализация данных путем построения системной модели предметной области в виде интегрированной онтологии управления инновационным проектом;

3) разработка базы знаний, включающей механизм логического вывода, основанного на применении прецедентов и полученных из них правил принятия решений;

4) классификация правил и прецедентов принятия решений в соответствии с разработанным набором иерархий знаний с учётом различных аспектов принятия решений - с позиции соотнесения их с различными этапами, областями знаний, участниками инновационного проекта, применения математических и аналитических моделей принятия решений в проблемной ситуации;

5) формирование запросов к базе знаний при возникновении проблемных ситуаций в ходе выполнения проектов, а также при необходимости классификации проектов для принятия решений о возможности выделения ресурсов для их реализации на различных этапах;

6) сохранение решений, предложенных базой знаний, с целью их дальнейшей оценки ЛПР с помощью имитационного моделирования;

7) адаптация базы знаний по результатам обобщения устойчивых структур прецедентов и построение на их основе новых правил для обучения системы поддержки принятия решений.

Предложенная методология интеллектуальной поддержки принятия решений обобщает и систематизирует накопленный опыт управления знаниями, математического и имитационного моделирования, служит основой для дальнейшей разработки и комплексного использования технологий адаптивного управления и имитационно- 
го моделирования на базе современных информационных технологий применительно к решению поставленной задачи управления инновационными проектами в производственно-экономических системах.

\section{2. Интегрированная онтология поддержки принятия решений при управлении инновационными проектами}

\subsection{1. Онтологический инжинирине процессов интеллектуальной поддержки принятия решений при управлении инновационными проектами}

Знания - это закономерности предметной области (принципы, связи, законы), полученные в результате практической деятельности и профессионального опыта, позволяющие специалистам ставить и решать задачи в этой области [50]. Одной из ключевых задач при формировании баз знаний является структурирование и представление полученных знаний. Знания могут быть извлечены из множества разнородных источников: нормативных и регламентирующих документов различного уровня, проектной документации, баз данных, а также получены вербально от лиц, имеющих достаточный опыт практической деятельности в области инновационного и проектного менеджмента и выступающих в качестве экспертов предметной области. Эффективным средством интеграции знаний, полученных из различных источников, является онтологический инжиниринг, который позволяет создать абстрактную модель предметной области, описывающую систему понятий предметной области и отношений между ними. В настоящее время онтологии и базы знаний применяются в управлении социально-экономическими системами и в проектном менеджменте [56-59].

Онтологический инжиниринг включает выявление основных классов сущностей (базовых понятий) в описании реальных взаимодействующих процессов, отношений между этими классами, а также совокупности свойств, которые определяют их изменение и поведение во взаимодействии. Целями онтологического инжиниринга являются:

- повышение уровня интеграции информации, необходимой для принятия управленческих решений;

- повышение эффективности информационного поиска;

- предоставление возможности совместной обработки знаний на основе единого семантического описания пространства знаний. 
Формально онтология состоит из множества терминов предметной области, организованных в таксономию, их определений и атрибутов, а также связанных с ними аксиом и правил вывода [60]:

$$
\text { Onto }=<C, \operatorname{Pr}, V, I, R, A, D>\text {, }
$$

где $C=\left\{C_{l}, C_{2}, \ldots, C_{N}\right\}$ - множество классов понятий и их интерпретации в определенной области знаний; $\operatorname{Pr}=\left\{\operatorname{Pr}_{l}, \operatorname{Pr}_{2}, \ldots, \operatorname{Pr}_{M}\right\}-$ множество свойств классов понятий. В онтологии существует разделение свойств на два класса: объектные свойства и свойства типов данных; $V=\left\{V_{1}, V_{2}, \ldots, V_{K}\right\}-$ значения свойств; $I=\left\{I_{l}, I_{2}, \ldots, I_{L}\right\}-$ множество экземпляров класса, или индивидов, которые определяются при помощи аксиом индивидов (так называемых фактов); $R=\left\{R_{l}, R_{2}, \ldots, R_{n}\right\}-$ множество отношений; $A=\left\{A_{1}, A_{2}, \ldots, A_{Q}\right\}$ - множество аксиом; $D=\left\{D_{1}, D_{2}, \ldots, D_{H}\right\}-$ множество алгоритмов вывода на онтологии.

Онтологическое моделирование обеспечивает коммуникацию и обмен знаниями между участниками проекта и прикладными вычислительными системами, реализацию логического вывода и рассуждения с применением онтологической базы знаний, а также облегчает приобретение контекста проектирования из разнообразных и разнородных источников. При этом для более точной формализации предметной области можно использовать модели процессов управления инновационными проектами, разработанные в различных нотациях [61]. Разработанная в результате онтология является удобным способом создания унифицированной, детальной и непротиворечивой терминологии с учетом контекста предметной области [62].

Специфика реализации инновационного проекта требует представления различных областей знаний, необходимых для успешного управления проектом [4], что подразумевает возможность существования нескольких онтологий, представляющих концептуализацию содержания конкретного проекта, а также областей знаний проектного менеджмента (управление расписанием проекта, стоимостью, сроками выполнения, качеством, ресурсами и др.). С целью обеспечения объективного представления знаний, а также отображения понятий из одной области знаний в другую при формировании правил принятия решений выполняется объединение онтологии задач, моделей и методов поддержки принятия решений и онтологии проектного менеджмента в интегрированную онтологию. 
Основой построения онтологии управления инновационными проектами являются понятия из области управления проектами, полученные в соответствии с Руководством к своду знаний по управлению проектами A Guide to the Project Management Body of Knowledge $(P M B o K)[4]$. В зависимости от специфики конкретного инновационного проекта и предметной области онтология подлежит последующему наполнению и корректировке (рис. 2.2).

Описание онтологии производится на языке OWL DL (Web Ontology Language based on Description Logic). Разработка онтологий ведется в онтологическом редакторе Protégé 5.2.0 [63].

Объединение онтологий осуществляется с применением встроенной функции объединения онтологий merge ontologies, которая предусматривает реализацию операции объединения эквивалентных классов, сущностей и синонимов (в рассматриваемом контексте предметной области) с участием экспертов. В результате в семантической сети интегрированной онтологии отображаются объектные отношения между классами объектов из онтологии управления разрабатываемым инновационным проектом и онтологии задач, моделей и методов принятия решений. Фрагмент предложенной интегрированной онтологии представлен на рис. 2.3.

Исходя из предложенного подхода, интегрированная онтология управления знаниями Onto описывается как набор объединенных онтологий в соответствии с формулой:

$$
\text { Onto }=<O^{D M}, O^{P M}, \operatorname{Inf}^{F}>,
$$

где $O^{P M}$ - онтология управления инновационным проектом; $O^{D M}-$ онтология поддержки принятия решений; $\operatorname{Inf}^{F}$ - модель машины логического вывода.

Модель машины вывода выполняет функцию активации сущностей и отношений, описывающих конкретную задачу, то есть организации динамической компоненты базы знаний.

Потенциальными пользователями интегрированной онтологии являются заинтересованные стороны разрабатываемого инновационного проекта, такие как заказчики, спонсоры, партнеры проекта, руководство предприятия с одной стороны, а также участники команды проекта, пользователи проекта, проектный офис, эксперты предметной области и области инженерии знаний с другой. 


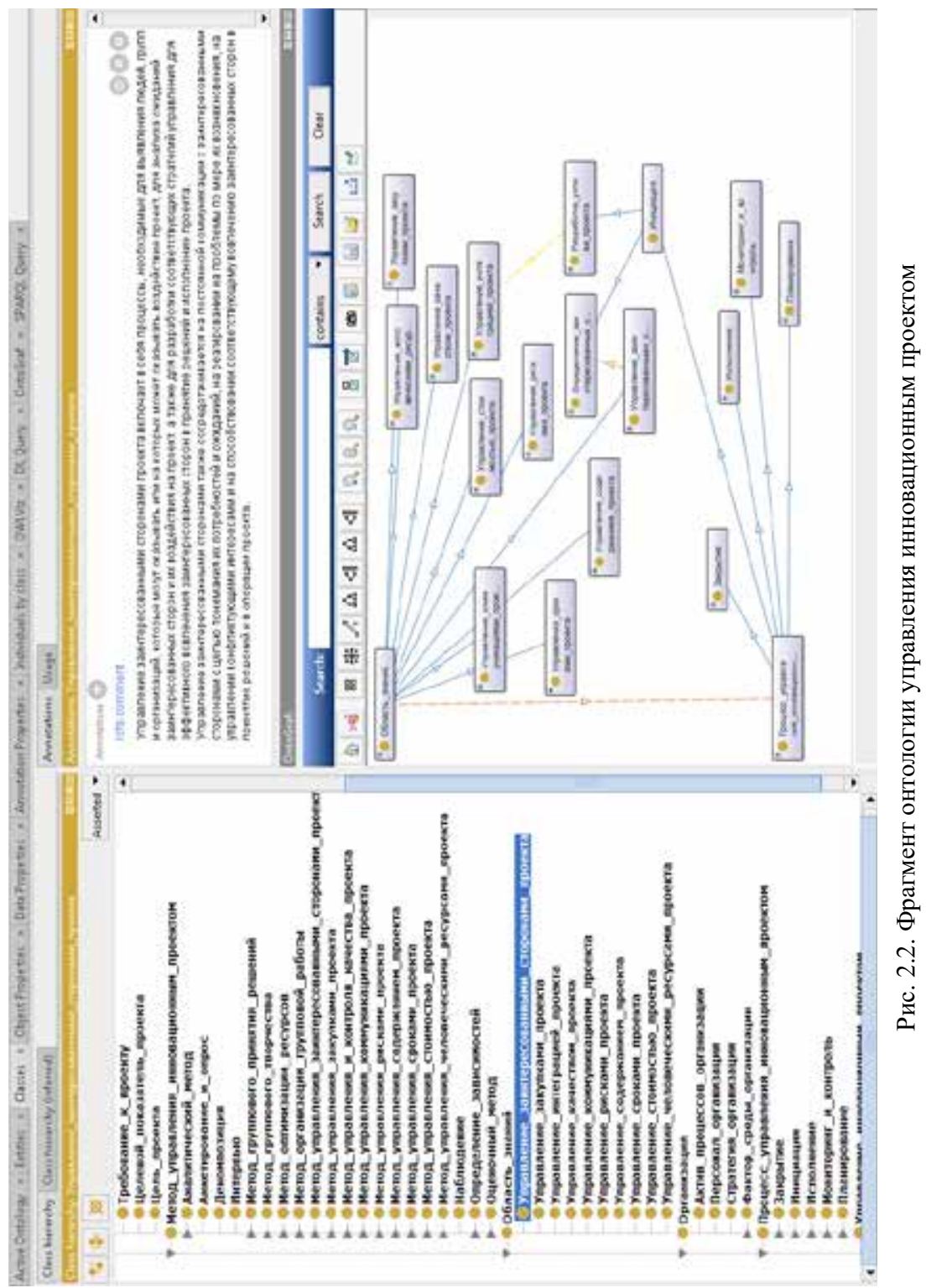




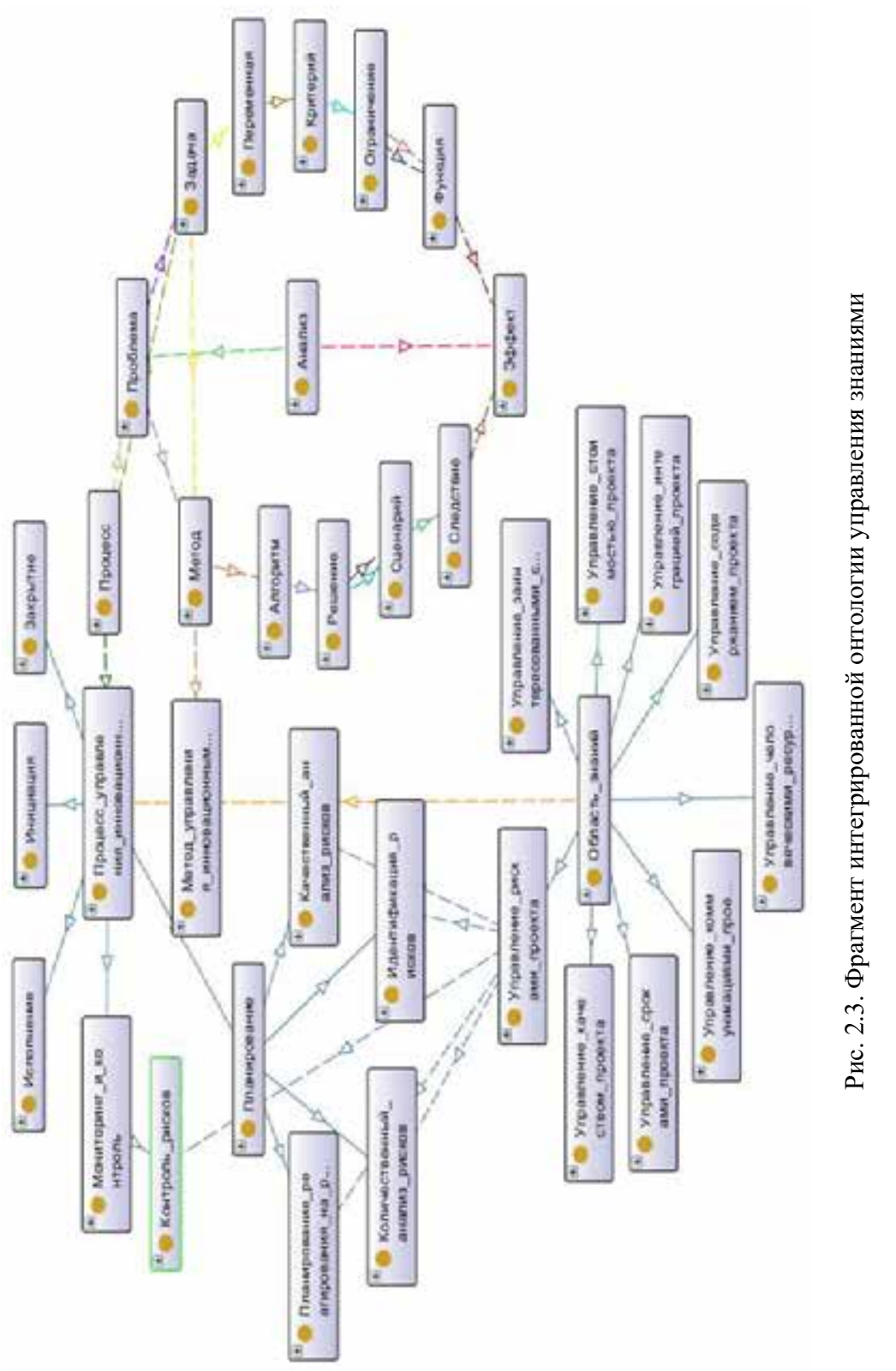


У каждой из перечисленных на рис. 2.4 заинтересованных сторон в ходе выполнения проекта возникают определенные вопросы или проблемы, особенно это касается ЛПР, участвующих одновременно в нескольких проектах [64]. Своевременная и точная оценка сложившейся ситуации позволяет правильно организовать процедуры проектного управления, связанные с принятием решений и их фиксацией в проектной документации.

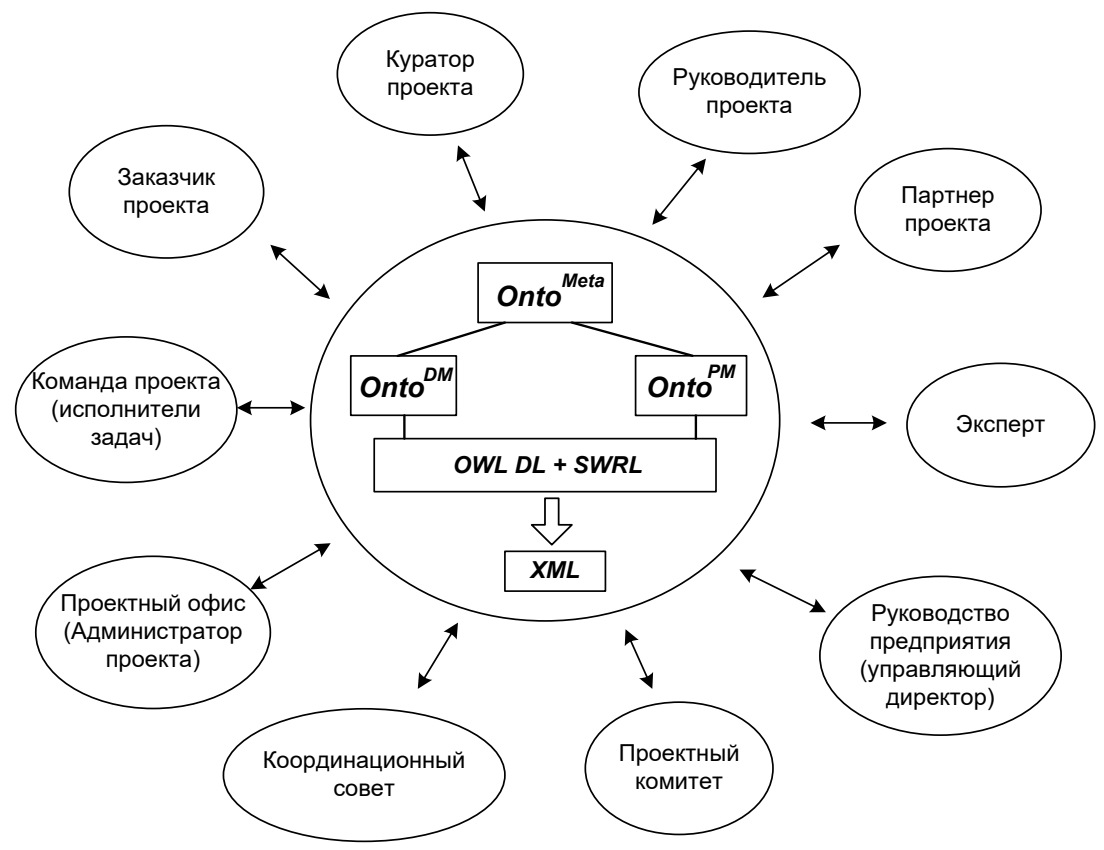

Рис. 2.4. Схема использования онтологии заинтересованными сторонами инновационного проекта

В табл. 2.2 для заинтересованных сторон проекта указана потребность в информации, которая запрашивается чаще всего [65].

Онтология может быть представлена в качестве центрального компонента информационных систем и приложений предприятия для совместного использования персоналом организации и аннотирования информации. При этом онтология выполняет две основные функции: 
определяет общую терминологическую базу для всех ЛПР и позволяет формулировать правила и прецеденты, используя одни и те же понятия предметной области.

Таблица 2.2

Описание проблемных ситуаций инновационного проекта

\begin{tabular}{|c|c|}
\hline $\begin{array}{c}\text { Заинтересованная } \\
\text { сторона }\end{array}$ & Потребности в информации \\
\hline $\begin{array}{l}\text { Заказчик, куратор, } \\
\text { партнер проекта }\end{array}$ & $\begin{array}{l}\text { Как получить общую информацию о ходе выполнения ра- } \\
\text { бот проекта? } \\
\text { Как определить, не нарушены ли основные ограничения } \\
\text { проекта (стоимость, сроки, качество)? } \\
\text { Какие проблемы в настоящее время есть у проекта? (срывы } \\
\text { сроков поставки оборудования и материалов или выполне- } \\
\text { ния работ, задержка согласования платежей управляющей } \\
\text { компанией, внутренние нестыковки в бизнес-процессах, } \\
\text { препятствующие реализации проекта и т.п.) }\end{array}$ \\
\hline $\begin{array}{l}\text { Проектный комитет, } \\
\text { координационный } \\
\text { совет }\end{array}$ & $\begin{array}{l}\text { Как организовать взаимодействие между участниками } \\
\text { проекта, относящимися к различным организациям? } \\
\text { Какие проблемные ситуации эскалировать на вышестоя- } \\
\text { щий уровень принятия решений? } \\
\text { Как распределить ресурсы между проектами? } \\
\text { Как сопоставить цели проекта со стратегией развития } \\
\text { предприятия? } \\
\text { Кого назначить руководителем проекта? } \\
\text { На каких стадиях проекта информировать руководство } \\
\text { предприятия? } \\
\text { Каковы сроки утверждения проектной документации? }\end{array}$ \\
\hline $\begin{array}{l}\text { Руководство } \\
\text { предприятия }\end{array}$ & $\begin{array}{l}\text { Как планировать и контролировать ресурсы портфеля } \\
\text { проектов? } \\
\text { Какие критерии и КPI задать с целью оценки эффектив- } \\
\text { ности реализации проекта и мотивации проектной ко- } \\
\text { манды? } \\
\text { Как распределить накладные расходы между проектами? } \\
\text { Как распределить оборудование между проектами } \\
\text { и учесть его амортизацию при закрытии проекта? } \\
\text { Как организовать конкурсные процедуры по проекту без } \\
\text { задержек и увеличения сроков выполнения проекта? } \\
\text { Как выбрать поставщиков? } \\
\text { Все ли сертификаты есть у предприятия для выполнения } \\
\text { проекта? }\end{array}$ \\
\hline
\end{tabular}


Продолжение табл. 2.2

\begin{tabular}{|c|c|}
\hline $\begin{array}{c}\text { Заинтересованная } \\
\text { сторона }\end{array}$ & Потребности в информации \\
\hline $\begin{array}{l}\text { Руководитель } \\
\text { проекта }\end{array}$ & $\begin{array}{l}\text { Какая последовательность инициации проекта и разработ- } \\
\text { ки базовых документов, распределение ответственности } \\
\text { между подразделениями? } \\
\text { Какие проблемы и ограничения в настоящее время есть } \\
\text { у проекта? } \\
\text { Какие риски срыва сроков проекта существуют и как их } \\
\text { минимизировать? } \\
\text { Какими способами можно ускорить реализацию проекта? } \\
\text { Каков механизм защиты проекта и утверждения/ коррек- } \\
\text { тировки бюджета? } \\
\text { Какие современные средства применимы для мониторинга } \\
\text { команды проекта? } \\
\text { Как устранить противоречия между командой проекта } \\
\text { и его пользователями? } \\
\text { Как организовать обучение персонала? } \\
\text { Как оптимально подобрать кадры проекта? } \\
\text { Как часто проводить координационные совещания? } \\
\text { Как предупредить отставание от сроков выполнения про- } \\
\text { екта? } \\
\text { Какую методологию выбрать для выполнения проекта? } \\
\text { Как разработать смету трудозатрат проекта? } \\
\text { Из чего складывается и в какой форме описывается бюд- } \\
\text { жет проекта? } \\
\text { Как переводить трудозатраты в финансы и наоборот? } \\
\text { Как управлять стоимостью проекта, какие показатели от- } \\
\text { слеживать? } \\
\text { Что делать в случае возникновения конфликта ресурсов? } \\
\text { Как рассчитать прибыль проекта и премии сотрудников? }\end{array}$ \\
\hline $\begin{array}{l}\text { Команда проекта } \\
\text { (исполнители задач) }\end{array}$ & $\begin{array}{l}\text { От кого и в какой форме получать задания? } \\
\text { Что делать, если задания накладываются по срокам? } \\
\text { Как выстроить приоритеты выполнения заданий? } \\
\text { В какой форме и кому отчитываться о выполнении зада- } \\
\text { ний? } \\
\text { Что считать проблемой и кому сообщать об их возникно- } \\
\text { вении? } \\
\text { Перед кем и в какой форме ставить вопрос о необходимо- } \\
\text { сти пересмотра объема и/или сроков выполнения работ? } \\
\text { Как рассчитать свой бонус от участия в проекте? }\end{array}$ \\
\hline
\end{tabular}


Окончание табл. 2.2

\begin{tabular}{|l|l|}
\hline $\begin{array}{c}\text { Заинтересованная } \\
\text { сторона }\end{array}$ & \multicolumn{1}{|c|}{ Потребности в информации } \\
\hline Проектный офис & $\begin{array}{l}\text { Как открыть/закрыть проект? } \\
\text { Какие базовые документы необходимо оформить? Есть } \\
\text { ли шаблоны? } \\
\text { Как составить сводный и оперативный план проекта, } \\
\text { есть ли шаблоны? } \\
\text { Как сформировать плановый фонд рабочего времени? } \\
\text { Как фиксировать в учетной системе проектные затраты } \\
\text { и процент выполнения работ? } \\
\text { Какова процедура начисления премии по проектам? } \\
\text { Как и какие отчеты формировать по проектам? }\end{array}$ \\
\hline
\end{tabular}

Семантический подход к анализу ситуаций позволяет эксперту или группе экспертов описать при помощи единого стандартизованного языка общую модель исследуемой предметной области, а также задать способ обработки исходных данных, поступающих в онтологическую модель, в виде используемого системой набора продукционных правил. Таким образом, на основе полученной интегрированной онтологии управления знаниями строятся модели представления знаний в виде правил и прецедентов принятия решений в проблемных ситуациях, которые вместе с онтологией составляют основу базы знаний. Использование базы знаний позволяет ее пользователям получать ответы на вопросы, аналогичные сформулированным в табл. 2.2.

\subsection{2. Онтологический анализ рисков при управлении инновационными проектами в производственно-экономических системах}

В соответствии с предложенным подходом к построению онтологии управления знаниями (см. табл. 1.1) область знаний по управлению рисками проекта включает в себя $[4,35,36]$ (рис. 2.5):

- процессы, связанные с осуществлением планирования управления рисками, их идентификацией и анализом, планированием реагирования на риски, а также контролем рисков в проекте;

- методы и инструменты, применяемые в ходе выполнения каждого из вышеперечисленных процессов;

- перечень входных и выходных данных, необходимых для успешного выполнения процессов. 


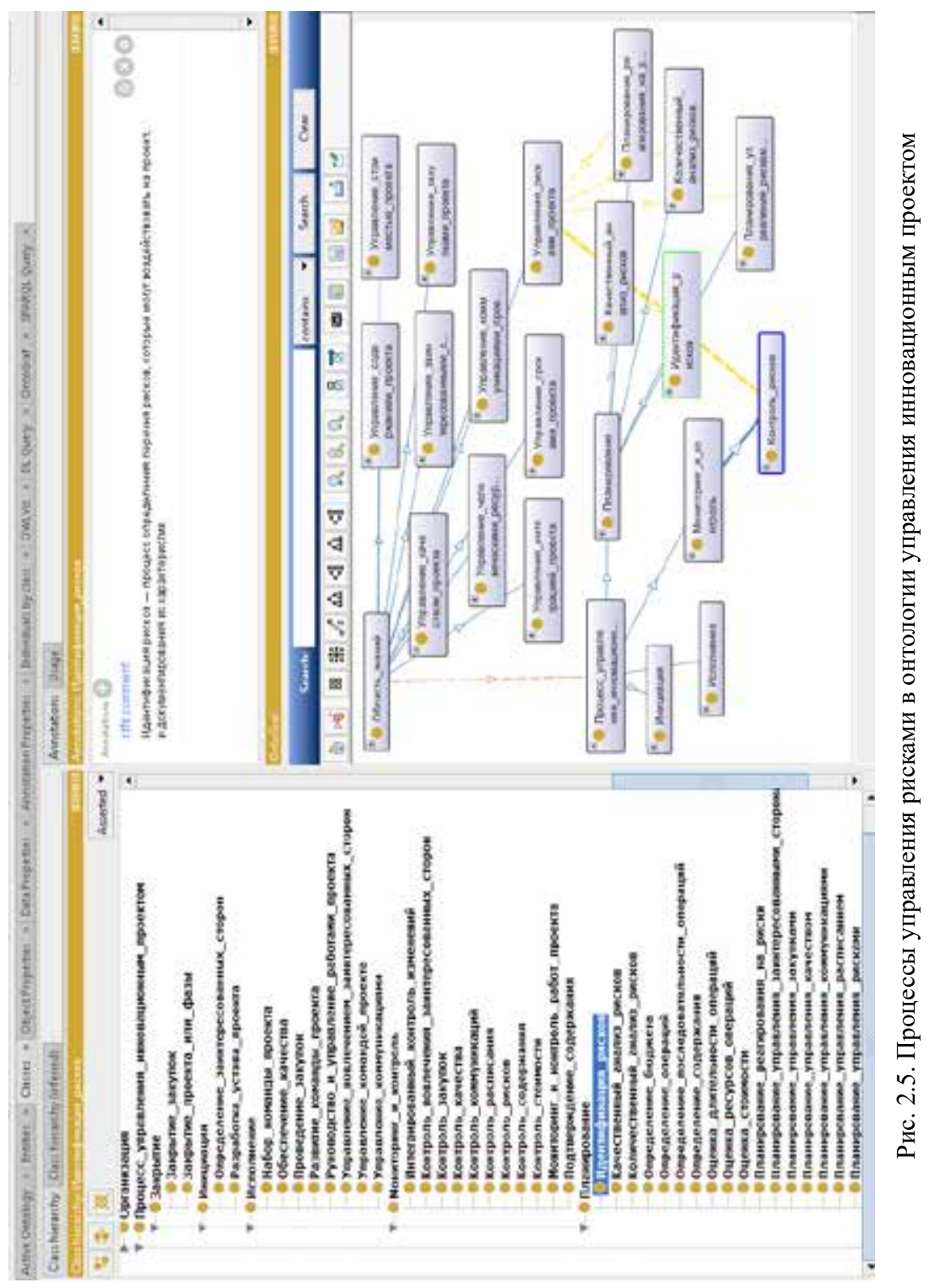


Целями управления рисками проекта являются:

1) повышение вероятности возникновения и усиление воздействия благоприятных событий в ходе реализации проекта;

2) снижение вероятности возникновения и ослабление воздействия неблагоприятных событий в ходе реализации проекта.

В инновационных проектах высок риск изменения не только основных проектных ограничений (сроков и стоимости), но и самого содержания проекта, а также конечных и промежуточных целей. Тем не менее, инновационными проектами, как и другими, необходимо управлять, учитывая возможность кардинальных изменений вплоть до окончания проекта. Снизить риски провала проекта можно, используя имитационные модели процессов управления проектом. Необходимость имитационного моделирования процессов управления проектом возникает как при планировании проекта для определения требуемого объема резервов различных ресурсов, так и на стадии его реализации в случае значительной угрозы проекту, например, из-за повышения вероятности наступления рисковых событий или изменения состава участников проекта. На рис. 2.6 показан фрагмент онтологии, отображающий отношения между классами проблем управления проектом и классами методов имитационного моделирования, применяемых в процессе управления рисками проекта.

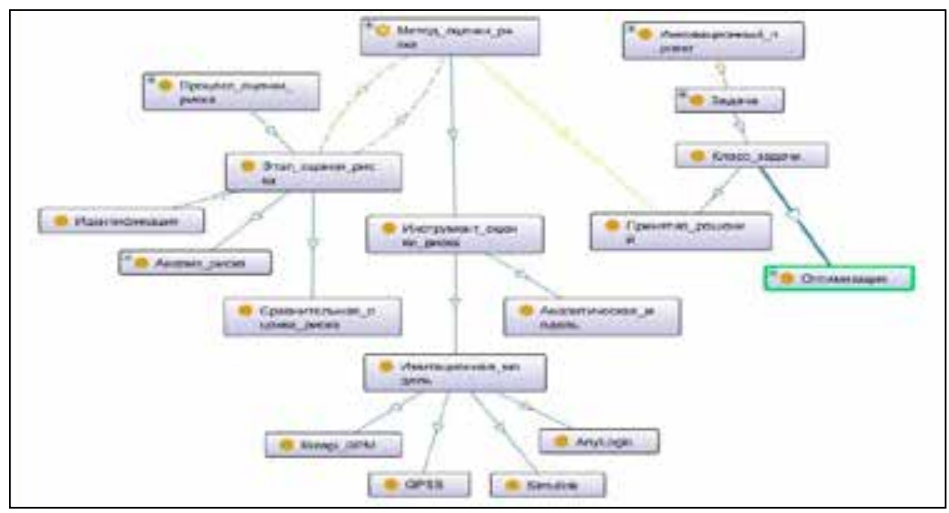

Рис. 2.6. Фрагмент онтологии анализа рисков инновационного проекта

Процессы управления рисками включают в себя идентификацию рисков, их качественный и количественный анализ, разработку и осуществление мер реагирования на риски в ходе реализации проекта. 
Общие рекомендации и схемы процессов управления рисками представлены также в [66], а также во множестве других источников. Международные и национальные стандарты являются основой корпоративных стандартов проектного управления, разрабатываемых для ведения инновационных проектов на предприятиях. Регламентация деятельности по управлению рисками в инновационных проектах делает возможным применение формализованных методов извлечения и использования знаний. Вместе с тем выявляются следующие недостатки существующего процесса анализа рисков инновационного проекта в производственно-экономических системах:

1) существует большое количество регламентных документов (стандарты предприятия, положения, методики), в которых детально расписаны принципы управления рисками, их идентификация и оценка, но при возникновении проблем их не связывают с выявленными рисками, что не дает обратной связи и делает невозможным извлечение уроков из сложившейся проблемной ситуации;

2) наблюдаются расхождения в терминологии, классификации и описании рисков в различных документах, сопровождающих ведение одного или нескольких проектов. Это, в первую очередь, связано с тем, что документы создаются разными людьми для разных проектов, и, зачастую, опыт, полученный в ходе анализа рисков одного проекта, никак не используется в другом;

3) архив проектов, даже если он существует, содержит в себе наиболее общую информацию, которая по большей части бесполезна при возникновении ПС, либо информацию в виде план-графиков и ежемесячных отчетов, которую очень трудно интерпретировать для оценки конкретной ситуации в текущем проекте.

Вопросы моделирования различных сценариев при планировании проектов рассматривались в [67], имитационное моделирование бизнес-процессов, встраиваемых в проектную деятельность различных организаций - в $[68,69]$. Важно заметить, что модели и методы управления рисками должны быть интегрированы в модель управления инновационным проектом.

Риски имеют отношение ко всем областям знаний проекта, а это значит, что руководитель проекта должен быть хорошо осведомлен и компетентен во всех сферах деятельности. В реальной жизни такая ситуация маловероятна, что делает необходимым делегирование пол- 
номочий по управлению отдельными областями знаний проекта членам команды проекта. Но без формализованного подхода такая ситуация грозит, с одной стороны, размыванием ответственности за принимаемые решения, а с другой - разрастанием административного аппарата управления проектом, что усложняет взаимодействие между членами проектной команды. Выходом может стать применение инструментов интеллектуальной поддержки принятия решений. Авторы предлагают методику описания рисков проекта с учетом использования разработанной онтологии управления инновационным проектом [68], включающую следующие шаги:

1) идентификация рисков (определение источников, возможных причин, вероятности их возникновения);

2) назначение ответственного за каждый риск;

3) выявление толерантности заинтересованных сторон к рискам;

4) установление зависимости рисков друг от друга;

5) определение степени их влияния на отдельные характеристики проекта;

6) фиксация идентифицированных рисков в онтологии управления проектом.

В ходе анализа процессов управления проектными рисками было выявлено, что при определении степени влияния рисков на характеристики проекта возможны следующие варианты (рис. 2.7):

1) один риск влияет только на одну характеристику проекта, например, срок (несмотря на известный в проектном менеджменте «железный треугольник», изменение срока не всегда может влиять на изменение других параметров, особенно, если потери времени невелики или работа, которая задерживается, не находится на критическом пути);

2) один риск влияет на несколько характеристик проекта, например, срок и стоимость, либо напрямую, либо через цепочку событий (например, увеличивается срок выполнения работ и в связи с этим растет стоимость проекта, например, из-за увеличения длительности аренды);

3) несколько несвязанных друг с другом рисков оказывают влияние на одну характеристику проекта;

4) влияющие друг на друга риски оказывают совокупное влияние на несколько характеристик проекта. 


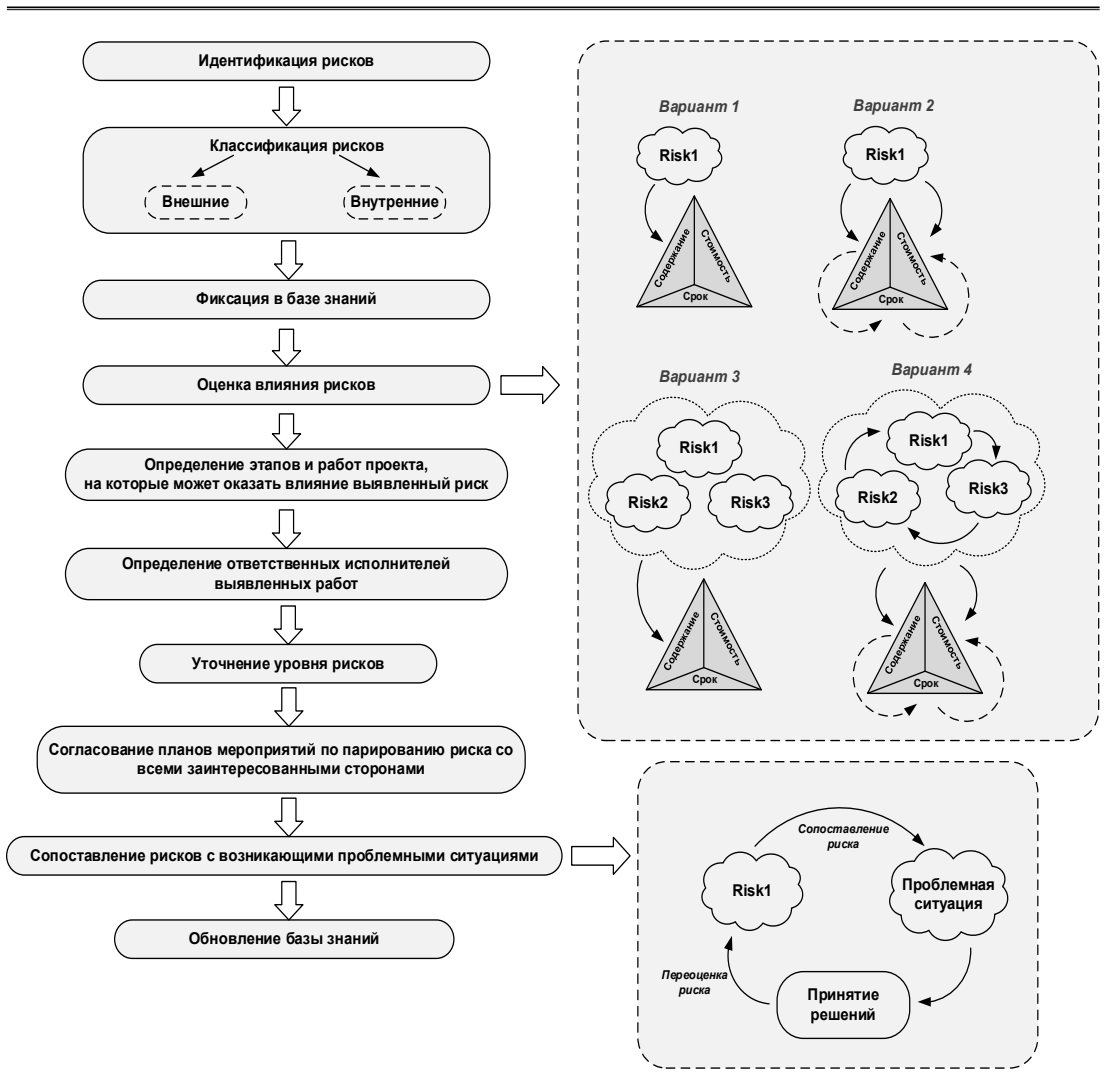

Рис. 2.7. Методика управления проектными рисками

Таким образом, алгоритм действий при управлении проектными рисками может быть описан как:

1) выявление (идентификация рисков);

2) классификация рисков на внешние и внутренние (с внешними рисками чаще всего связаны проблемные ситуации, которые ежеквартально выносятся на проектный комитет (компетенции руководителя проекта для борьбы с такого рода проблемами недостаточно), с внутренними рисками чаще связаны внутренние проблемные ситуации, решаемые руководителем проекта самостоятельно (иногда при помощи куратора проекта - ответственного за проект среди руководства предприятия); 
3) определение этапов и работ проекта, на которые может оказать влияние выявленный риск (помимо определения характеристик самого проекта - стоимости, сроков, качества и содержания). Эту информацию можно получить из паспорта проекта, где влияние риска распределено по периодам - из календарного плана можно легко установить, какие работы с какими ресурсами (в том числе, трудовыми, а также оборудованием) подпадают под возможное влияние риска;

4) определение ответственных исполнителей вышеуказанных работ и включение их в перечень заинтересованных сторон, которых необходимо оповещать о возможных проблемах;

5) уточнение уровня рисков с учетом выявления дополнительного влияния на работы;

6) согласование планов мероприятий по парированию риска или по реагированию на риск со всеми заинтересованными сторонами, а не только с вышестоящими ЛПР (куратором, спонсором проекта, проектным комитетом);

7) в случае возникновения проблемных ситуаций необходимо выяснять, с каким идентифицированным риском они связаны, и на основе этой информации переоценить вероятность и силу влияния этого риска.

В ходе управления проектом необходимо вести журнал проблемных ситуаций, фиксируя принятые решения и связывая проблемные ситуации с выявленными рисками. При этом, если возникшая проблемная ситуация не связана ни с одним из рисков, вошедшим в перечень, необходимо особо отмечать такую ситуацию и отслеживать ее дальнейшее развитие.

\section{3. Разработка структуры и принципов построения базы знаний для интеллектуальной системы поддержки принятия решений в процессе управления инновационным проектом}

Методика создания базы знаний, встроенной в онтологию на основе формальной семантики онтологий, описана в [70]. Подход к формированию онтологии для описания различных областей знаний специалистов управления инновационными проектами приведен в $[10,71]$. Разработанная структура базы знаний, включающая модель правил и модуль прецедентов, основана на использовании результатов си- 
стемного анализа и моделирования предметной области, что обеспечивает формирование базы знаний, ориентированной на предметную область $[8,9,71]$.

Сформулированная методология интеллектуальной поддержки принятия решений в управлении инновационными проектами, основанная на системе принципов интеллектуального управления, включает:

1) принцип построения единой информационной среды для управления инновационными проектами в условиях неопределенности и риска возникновения проблемных ситуаций;

2) принцип разработки базы знаний в единой информационной среде на основе технологии распределенной обработки знаний с применением совместно используемой онтологии для взаимодействия пользователей и экспертов в процессе управления инновационными проектами;

3) принцип разработки информационного и алгоритмического обеспечения поддержки принятия решений при управлении проектами в условиях неопределенности и риска с использованием базы знаний, математических моделей принятия решений, а также методов искусственного интеллекта.

Методология направлена на организацию управления процессами инновационного проектирования и оказание интеллектуальной поддержки принятия решений в проблемных ситуациях. Принятие и реализация решения в проблемных ситуациях - один из сложнейших аспектов управленческой деятельности. Решения в условиях ПС принимаются в различной оперативной обстановке, включая критическую, и в ограниченное время, что не снимает требований по обоснованности решений, полному и эффективному использованию всех возможностей, имеющихся в распоряжении лиц, принимающих решения. В подобных условиях требуется всесторонняя, объективная оценка ситуации и перспектив ее развития, отчетливое понимание направлений и задач деятельности, знание возможностей и ресурсов, необходимых для управления ситуацией, а также формирование варианта, ведущего к решению [72]. Таким образом, целью интеллектуального управления является помощь коллективу участников выполняемого проекта в принятии решений на основе управления знаниями.

База знаний в интеллектуальной системе поддержки принятия решений разрабатывается на основе логической модели интегрированной онтологии с применением двух моделей представления зна- 
ний - в форме правил поддержки принятия решений и в форме прецедентов проблемных ситуаций (рис. 2.8).

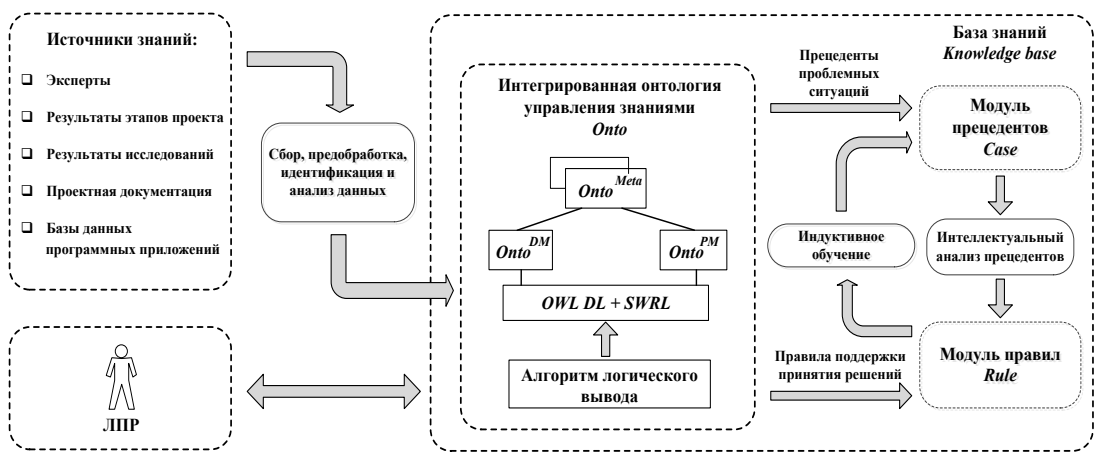

Рис. 2.8. Структура базы знаний как части ИСППР

Источниками для получения знаний служат данные, содержащиеся в проектной документации, причем рассматриваются как документы текущего проекта, так и данные, содержащиеся в комплектах документов по ранее закрытым проектам. Данный подход позволяет накапливать в базе знаний как положительный, так и отрицательный опыт принятия решений в проблемных ситуациях, возникающих в ходе выполнения инновационных проектов в рассматриваемой отрасли.

В качестве экспертов могут выступать как участники проектных команд, руководители и пользователи проектов, сотрудники проектного офиса, представители руководства предприятия, обладающие достаточной квалификацией, знаниями и опытом по принятию решению в проблемных ситуациях, так и эксперты в инженерии знаний и специалисты-эксперты предметной области. Это актуально для инновационных проектов, поскольку состав заинтересованных сторон проекта меняется в зависимости от специфики разработки. Важно закрепить и не потерять имеющийся корпоративный опыт по управлению инновационными проектами и принятию решений в проблемных ситуациях, аналогичных возникающим в текущем проекте.

На современном уровне развития проектного менеджмента имеется возможность комплексной автоматизации процессов управления проектами, что обязывает к анализу и переработке данных об этапах и стадиях выполнения проекта, содержащихся в программных при- 
ложениях. Все вышеперечисленное в совокупности с фактическими результатами выполнения проектов и исследований служат основой для построения базы знаний. По результатам процедур сбора, переработки, идентификации и анализа знания заносятся в интегрированную онтологию, которая является центральным элементом базы знаний и включает в себя онтологию задач, моделей и методов поддержки принятия решений и онтологию проектного менеджмента. Данный подход позволяет учитывать требования теории и технологии распределенной обработки знаний и использовать современные языки представления правил поддержки принятия решений в проблемных ситуациях.

Знания, логическая система которых упорядочена, представлены в модуле правил с применением языка Semantic Web Rule Language $(S W R L)$. Использование $S W R L$-правил является простым и удобным средством внедрения знаний продукционного характера в онтологическую модель. Язык $S W R L$ является расширением языка $O W L-$ при формировании условной части и заключения правила используются объекты разработанной онтологии $O W L D L$. Таким образом, поддерживается интеграция правил в семантическую сеть онтологии, так как при разработке правил применяются предикаты, определенные при разработке онтологии в части формирования аксиом иерархии классов, описания отношений ассоциации и аксиомы, накладываемые на свойства классов.

Полученные правила записываются в онтологии в следующем виде:

$$
\text { Rule: } C_{1}(? x) \wedge C_{2}(? y) \wedge P_{1}(? x, ? y) \wedge C_{3}(? x, ? z) \rightarrow C_{2}(? z, ? y),
$$

где $\left(C_{1}, C_{2}, C_{3}\right) \in C, C$ - класс в $O W L D L ; P_{1} \in P, x, y-$ экземпляры или переменные; $z$ - переменные или значения.

Возможность работы с $S W R L$-правилами уже реализована во многих редакторах онтологий, в том числе, и в Protégé. Правила $S W R L$ не содержат конкретных объектов, а только ссылаются на них, что дает возможность применять одно и то же правило к ряду групп объектов. Таким образом, приведенные ранее типовые риски проекта, принадлежащие к различным группам рисков, последствия и причины отказа, меры по обнаружению и предотвращению данных рисков могут быть представлены в онтологии в виде набора правил (например, для риска «Увеличение затрат на проект») (рис. 2.9). 


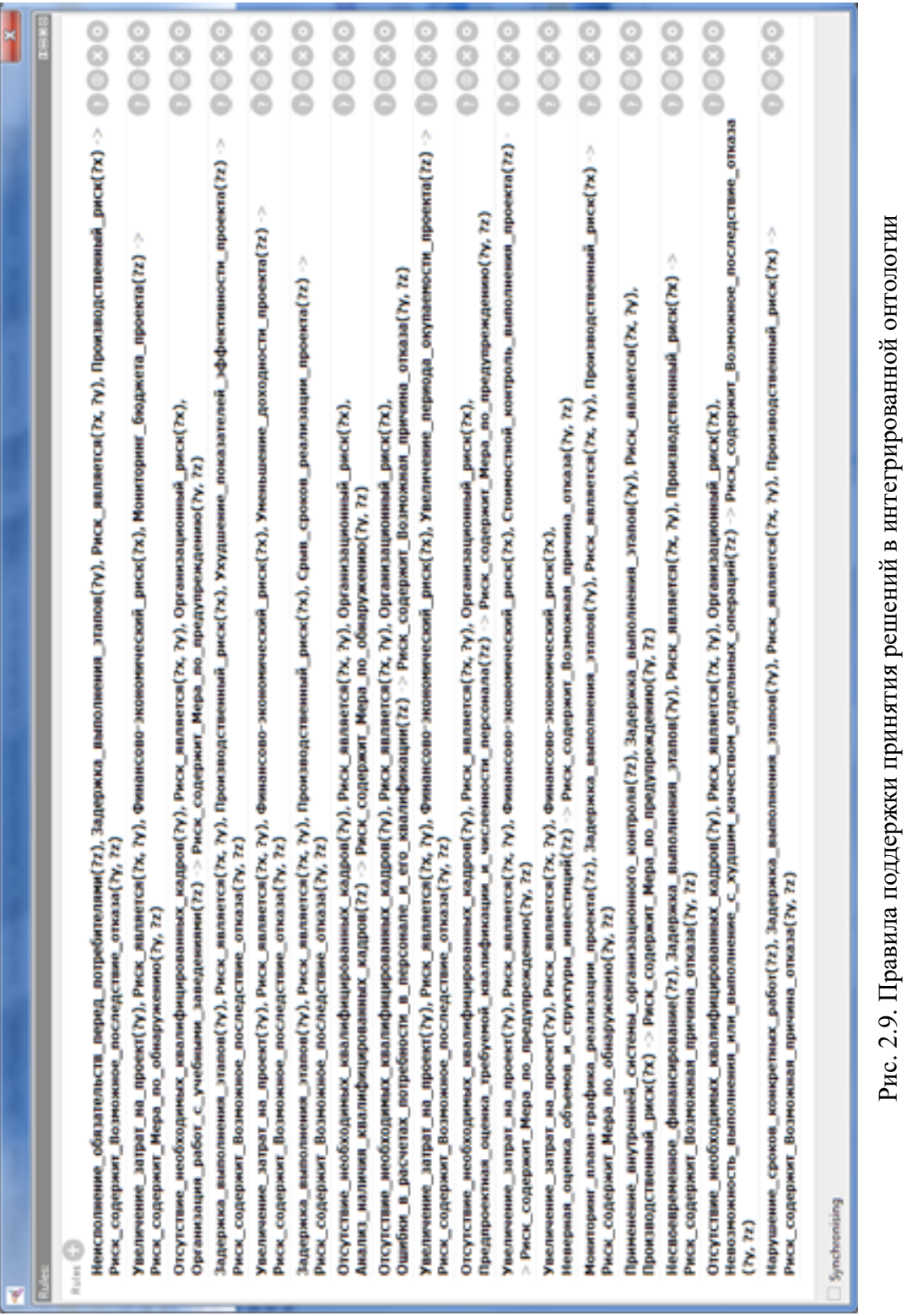


Rule: Финансово-экономический_риск(?x),

Риск_является (?x, ?y), Увеличение_затрат_на_проект(?y),

Мониторинг_бюджета_проекта(?z) ->

Риск_содержит_Мера_по_обнаружению(?y, ?z)

Rule: Финансово-экономический_риск(?x),

Увеличение_затрат_на_проект(?у),

Риск_является(?x, ?у), Уменьшение_доходности_проекта(?z) ->

Риск_cодержит_Возможное_последствие_отказа(?y, ?z)

Rule: Финансово-экономический_риск(?x),

Увеличение_затрат_на_проект(?у),

Риск_является(?x, ?у), Увеличение_периода_окупаемости проекта $(? z)->$

Риск_содержит_Возможное_последствие_отказа(?у, ?z)

Rule: Финансово-экономический риск(?x),

Увеличение_затрат_на_проект(?у),

Риск_является(?x, ?y), Стоимостной_контроль_выполнения_ проекта $(? z)$-> Риск_содержит_Мера_по_предупреждению(?y, ?z)

Rule: Финансово-экономический_риск(?x),

Увеличение_затрат_на_проект(?у),

Риск_является(?x,?y),

Неверная_оценка_объемов_и_структуры_инвестиций(?z) ->

Риск_содержит_Возможная_причина_отказа(?у, ?z)

Сформулированные в онтологии правила выражают причинноследственные отношения между классами событий, возникающими в ходе выполнения инновационного проекта и являющихся причинами возникновения проблемных ситуаций, самими проблемными ситуациями и действиями, которые необходимо предпринимать ЛПР для разрешения подобных проблемных ситуаций.

Таким образом, авторы предлагают алгоритм получения знаний из онтологии на основе правил и механизма логического вывода на правилах, результатом работы которого является генерация сообщений о проблемных ситуациях, принятии решений или управлении событиями посредством выдачи команд на выполнение управляющих воздействий.

Кроме того, предлагается фиксировать в интегрированной онтологии проблемные ситуации и принятые по ним решения, которые имели место в ходе реализации инновационных проектов, в форме 
прецедентов проблемных ситуаций. Правила для данных проблемных ситуаций еще не сформулированы ввиду отсутствия достаточных примеров принятия решений. Онтологический анализ позволяет выявить наиболее существенные признаки проблемных ситуаций, классифицировать прецеденты по различным основаниям, обобщить и уточнить разрозненную, противоречивую и неполную информацию. Данный подход позволит руководителям и членам команд последующих проектов также обращаться к ним в случае возникновения схожих проблем за счет адаптации их к конкретной проблемной ситуации.

Предлагается описывать с помощью онтологической модели как успешные прецеденты принятия решений, которые включают в себя успешные решения и описание контекста их применения, так и те прецеденты принятия решений, которые содержат в себе описание действий, являющихся ошибочными и малоэффективными, и от которых следует воздержаться при выполнении проекта.

Важным моментом при построении базы знаний является наличие в правилах и прецедентах проблемных ситуаций указаний на участников проектных команд, которые выполняли приведенные в них действия, или же должны реализовать предлагаемые рекомендации и нести ответственность за их выполнение.

Например, в рассматриваемом ранее проекте ПАО «ОДК-УМПО» (см. табл. 1.4) был зафиксирован следующий прецедент проблемной ситуации:

\section{Уровень проблемы - средний.}

Описание проблемы - Риск срыва сроков поставки оборудования со стороны поставщика, что может повлиять на срок ввода объекта в эксплуатацию.

Дата регистрации проблемы - 20.01.19.

Предложение по решению - Направление специалистов на заводизготовитель оборудования для инспектирования его производства.

Ответственный (ЛПР) - Технический директор.

Срок решения - 15.02.19.

Статус решения - на контроле.

Данный прецедент представлен в модуле прецедентов онтологической базы знаний как экземпляр класса «Прецеедент категории N» с соответствующим атрибутами типов данных. 
Для эффективного использования и обмена знаниями, имеющимися в БЗ, необходимо обеспечить регулярно-воспроизводимую работу с данной моделью и поддержание в актуальном состоянии модулей правил и прецедентов. Анализ, коррекция и пополнение прецедентов осуществляется на основе онтологии и установления противоречий между правилами и устаревшими прецедентами.

Адаптация и обучение базы правил производится по результатам интеллектуального анализа прецедентов и обобщения выявленных устойчивых структур прецедентов в форме новых правил, что включает в себя:

- поиск прецедентов, схожих с возникшей проблемной ситуацией;

- применение найденных прецедентов для решения возникшей проблемы;

- оценка эффективности полученных результатов принятия решений;

- сохранение нового прецедента для текущей проблемы в базе знаний;

- в случае успешного применения найденных прецедентов для текущей проблемной ситуации рассмотрение вопроса о преобразовании их в правила принятия решений;

- интеллектуальный анализ прецедентов и добавление новых правил в базу знаний.

Таким образом, представленный выше прецедент проблемной ситуации может быть преобразован в правила принятия решений следующего вида:

Rule 1: Производственный_риск(?x), Риск_является(?x, ?y), Срыв_сроков_поставки_оборудования_со_стороны_поставщика, что_может_повлиять_на_срок_ввода_объекта_в_эксплуатаичю (?у), Направление_спечиалистов_на_завод_изготовитель_оборудования_ для_инспектирования_его_производства(?z) ->

Риск_содержит_Действие(?у, ?z)

Rule 2: Производственный_риск(?x), Риск_является(?x, ?y), Срыв_сроков_поставки_оборудования_со_сторонындпотавщика, что_может_повлиять_на_срок_ввода_объекта_в_эксплуатацию (?у), Направление_специалистов_на_завод_изготовитель_оборудования_для_инспектирования_его_производства (?z),

Риск_cодержит_Действие(?y, ?z), Технический_дректор (?a) -> Действие_имеет_Исполнителя(?z, ?a) 
Модули правил и прецедентов в базе знаний структурированы в соответствии с множеством классов, выделенных по результатам онтологического анализа процессов управления инновационными проектами. В рамках рассматриваемого подхода к управлению знаниями предлагается построение некоторого набора классификаций знаний, содержащихся в правилах и прецедентах, с учетом различных аспектов принятия решений, принимаемых в ходе проектного управления. Подобная структура базы знаний на практике обеспечит наиболее эффективный поиск, применение и обмен знаниями.

Изначально определены правила двух видов: правила, определяющие структуру отношений между классами объектов предметной области с использованием объектных свойств классов, и правила, определяющие ограничения для экземпляров классов.

Правила первого вида обычно создаются с применением экспертных знаний и регламентирующих документов предметной области управления проектами, например:

Rule 2.1:

hasInformationInnovation(? $x, ? c)$, hasOrganozationInnovativeActivity $(? x, ? d)$, hasTechnicalInnovation $(? x, ? a)$, hasTechnologyInnovation $(? x, ? b)$-> InnProject(?x)

\section{Rule 2.2:}

Problem_situation(?x), Problem_solving(?solv), connectedWith $(? x, ? P r S p)$, connectedWith(?x, ?com), hasAlternatives(? $x$, ?v), hasCriterion $(? x, ? c)$, hasDecision $(? x, ? d)$, hasTextDescription $(? x, ? b)$, isRecognition $(? x, ? a)$-> hasProblemSolving $(? x$, ?solv)

Правила второго вида формулируются с использованием данных об экземплярах классов, например:

\section{Rule 3.1:}

Alternative(?v), hasAdvantages(?v, «Low»), hasConsistency(?v, «High»), hasDisadvantages(?v, «Middle»), hasPreference(?v, «Low») -> hasRating of_the_alternative(?v, «Middle»)

В построении таких правил могут использоваться различные источники знаний: экспертные знания и знания, полученные на основе прецедентов проблемных ситуаций методом индукции.

Правила второго вида строятся в форме иерархии. Предлагается построить иерархическую базу знаний таким образом, чтобы класс правил мог быть классом верхнего уровня или подклассом, связанным с одним объектом предметной области. Декомпозиция базы правил 
выполняется в соответствии с иерархией объектов, установленной в результате моделирования. Таким образом, каждое правило включает ограниченное число входных переменных. Иерархия объектов базы знаний организована в соответствии с метамоделями представления знаний на основе принципа наследования, что означает построение новых классов на основе существующих с возможностью добавления или переопределения данных и методов (например, в процессе изучения нового знания).

По результатам проведенного ранее анализа было отмечено, что процессы управления проектами распределены по группам процессов и по областям знаний неравномерно - было выделено три варианта пересечения областей знаний с некоторым набором процессов из групп процессов управления проектом (см. рис. 1.14). Таким образом, важно проводить классификацию правил принятия решений и прецедентов проблемных ситуаций, встречающихся при управлении инновационным проектом, с позиций отнесения их к приведенным областям знаний и этапам (группам процессов) реализации проекта.

В соответствии с данным подходом и распределением ролей и полномочий можно выделить правила принятия решений, предназначенные для различных участников команды проекта (руководитель проекта, исполнитель, владелец ресурсов, заказчик, спонсор и т.д.) в различных ситуациях, связанных с различными областями знаний. При этом в проблемных ситуациях, требующих принятия решений, указанным лицам может потребоваться информационная поддержка, связанная с областями знаний при выполнении различных процессов управления проектом (рис. 2.10).

Кроме того, ввиду наличия в базе знаний рекомендаций по применению математических методов, моделей и алгоритмов принятия решений в ходе проектного управления, база знаний содержит множество правила принятия решений в проблемных ситуациях, возникающих в процессе управления инновационным проектом, и правила классификации математических моделей принятия решений.

Проверка базы знаний путем систематического контроля системы в условиях внедрения позволяет обнаруживать и исправлять ошибки, связанные с неполнотой базы знаний, и избавляться от противоречивых и бесполезных правил, что повышает точность и быстродействие работы системы. 


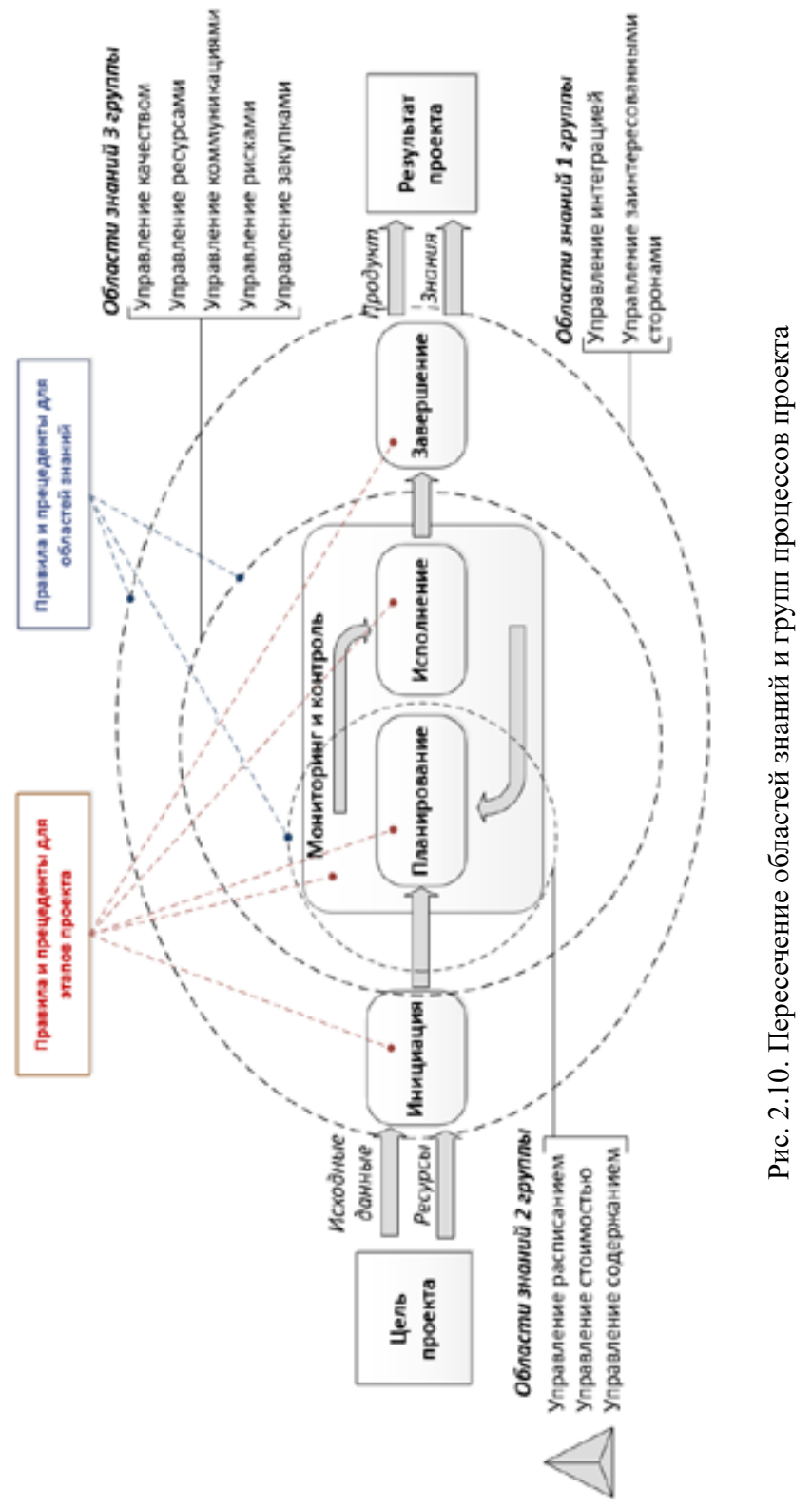




\section{4. Организация поддержки принятия коллективных решений для проектных команд}

Анализ выполнения инновационных проектов в ПЭС $[10,71]$ показал, что успешность их подготовки и реализации во многом зависит:

1) от грамотного применения методов проектного менеджмента, соотнесенных с конкретной ситуацией на реализуемом проекте;

2) от использования современных информационных технологий, во многом являющихся основой для поиска новых технологических решений и повышения экономической эффективности от их применения;

3) от умения руководителя проекта при принятии решений опираться не только на собственный опыт и знания, но использовать совокупный опыт ПЭС и лучшие практики отрасли в целом.

Крупные инновационные проекты имеют, как правило, организационную структуру, сложность которой зависит не только от количества участников, но и от характера решаемых в проекте задач. Так, для получения конечного результата может потребоваться разработка и внедрение системы управления проектом (программный проект), строительство или модернизация производственной площадки (строительный проект), разработка сложных схем привлечения финансирования в проект (инвестиционный проект) и др. Таким образом, описанная ранее модель управления инновационным проектом в рамках ПЭС (см. рис. 1.11) может быть дополнена до комплексной модели, включающей контур управления знаниями (рис 2.11).

Сочетание разнородных проектов, являющихся составными частями инновационного проекта, усложняет систему управления им, поскольку в каждом подпроекте могут быть приняты свои подходы к управлению и распределению ресурсов, существют различные способы представления результатов и форматы исходных данных. Чаще всего такие проекты выполняются различными коллективами, в каждом из которых сложились свои принципы взаимодействия, могут быть приняты свои методы управления и принятия решений (рис. 2.12).

Ключевым фактором успеха инновационного проекта является целенаправленная скоординированная совместная деятельность различных коллективов участников проекта. Для получения запланированных результатов комплексного проекта при соблюдении интересов всех участников необходим единый центр управления. Иногда таким центром является назначенный руководитель проекта, наделенный 
большими полномочиями. В этом случае сфера ответственности ЛПР четко определена, решения принимаются быстрее, но они могут носить субъективный, волюнтаристский характер, когда есть стремление реализовать желаемые цели без учёта объективных обстоятельств и возможных последствий.

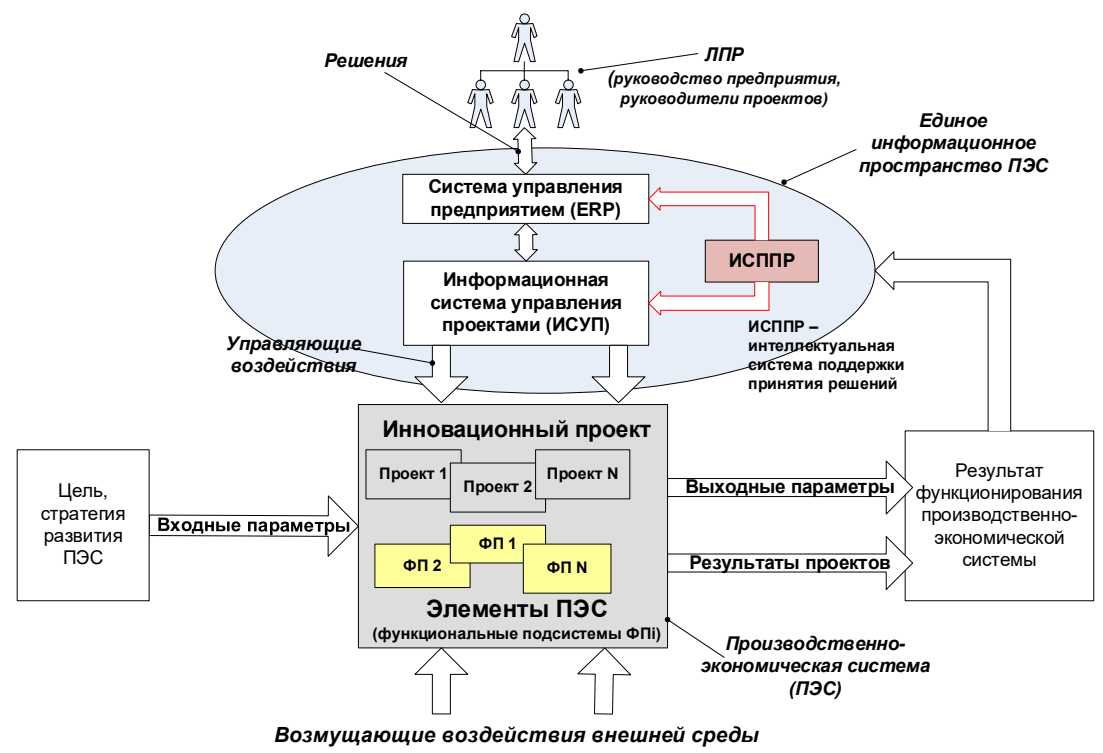

Рис. 2.11. Управление комплексным инновационным проектом в рамках ПЭС с использованием ИСППР

В другом случае центром принятия решений может служить так называемый проектный комитет, что замедляет процесс принятия решений из-за необходимости их всестороннего рассмотрения и согласования, но в то же время гарантирует сбалансированный подход к интересам всех участников комплексного проекта. В случае принятия коллективных решений процедуры взаимодействия существенно усложняются, что вызывает необходимость использования научно-обоснованных подходов для достижения консенсуса в кратчайшие сроки.

Необходимо также помнить о том, что организационная структура проекта будет накладываться на организационную структуру производственно-экономической системы, что зачастую приводит к кон- 
фликтам участников. Поэтому все компоненты (как производственноэкономической системы, так и инновационного проекта) должны функционировать в едином информационном пространстве, которое предоставляет разнородным коллективам лиц, принимающим решения, актуальную и достоверную информацию о ходе производственнохозяйственной деятельности ПЭС и выполнении проектов.

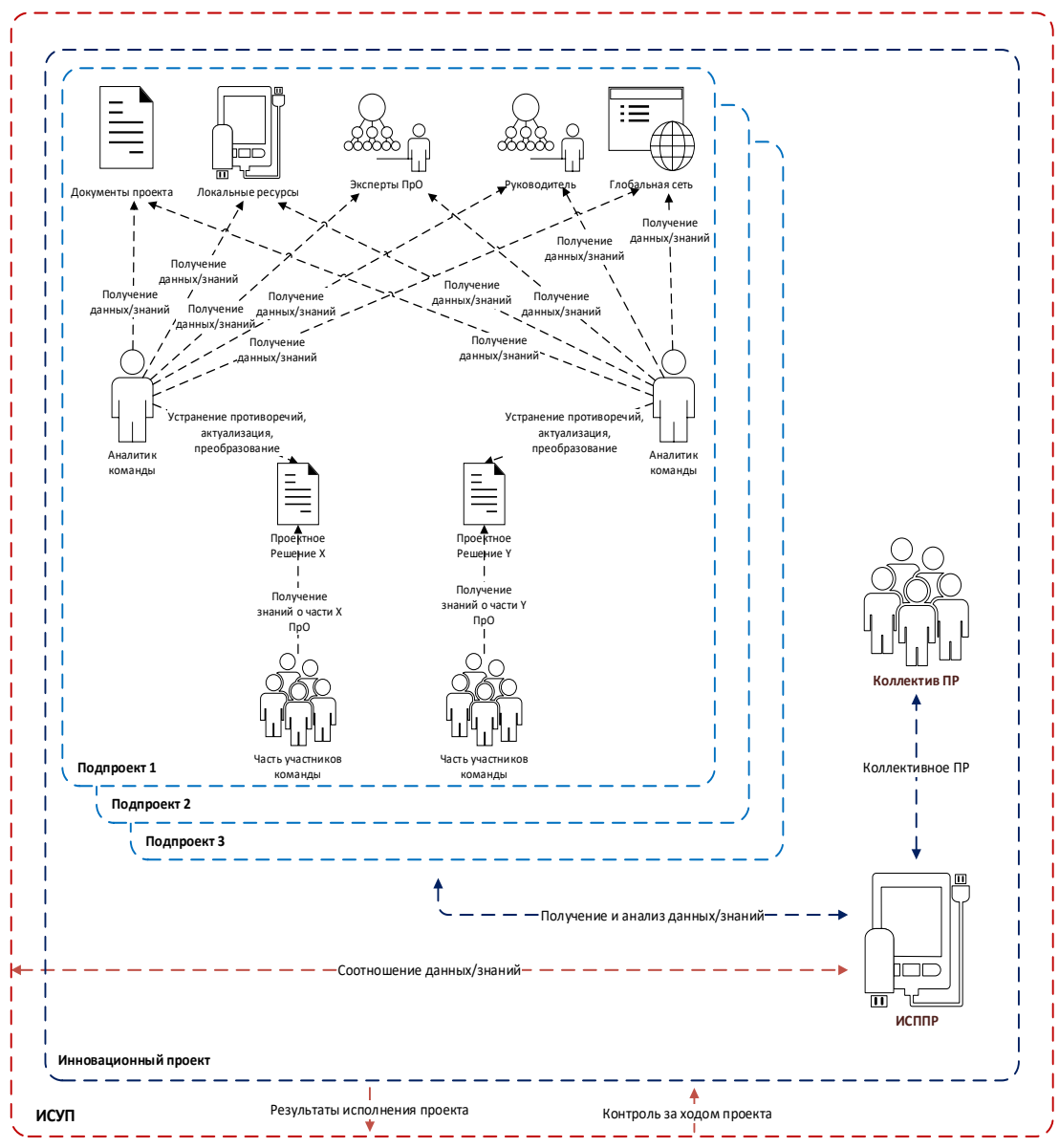

Рис. 2.12. Схема взаимодействия коллективов ЛПР инновационного проекта с использованием ИСППР 
Исследования, посвященные разработке всеобъемлющей справочной онтологии производства [73-75], показали эффективность ее применения для повышения качества функционирования производственно-экономических систем в случае выполнения регулярных бизнеспроцессов, имеющих устойчивые характеристики, в том числе, четкую последовательность операций.

С другой стороны, существует множество методик, адаптирующих стандарты проектного управления к решению реальных задач $[35,76]$. Авторы предлагают использовать подобный подход для агрегирования разнородной информации по более сложным, динамически меняющимся объектам - инновационным проектам, которые реализуются в производственно-экономических системах наряду с текущим ходом производственной деятельности. Из информационной системы управления проектами можно получить информацию обо всех параметрах комплексного проекта и составляющих его подпроектов - плановых и фактических значениях трудозатрат, стоимости ресурсов, сроках и очередности выполнения работ и т.д. Локальные ресурсы проектов, включая информационные системы различного назначения, отражают данные о выполнении бизнес-процессов, необходимых для достижения целей проектов, и содержат сведения о предметных областях проектов. Комплексный анализ полученных данных позволяет коллективу ЛПР оценить вероятность возникновения проблемных ситуаций на различных этапах и в различных областях инновационного проекта и тяжесть последствий принятых решений.

Ни один инновационный проект не может быть успешно реализован без применения в той или иной степени средств, методов и продуктов информационных технологий. Это положение вытекает как из самого определения инновационного проекта, так и перехода к цифровой экономике во всех сферах человеческой деятельности [77]. В связи с этим в лучшем положении оказываются те предприятия, в организационной структуре которых присутствуют соответствующие службы, хорошо знакомые со спецификой бизнес-процессов ПЭС. Это позволяет на стадии инициации проекта не тратить время на поиск партнера, способного оказать услуги по внедрению и поддержке информационных технологий, с помощью которых будет реализован инновационный проект. Известен и другой вариант, когда ИТкомпания имеет долгосрочное сотрудничество с крупным заказчиком, 
для инновационных проектов которого выполняется информационнотехнологическая поддержка. Чаще всего такая ИТ-компания имеет статус системного интегратора, поскольку необходимо решать задачи совместного использования различных информационных систем, обеспечивающих выполнение бизнес-процессов заказчика.

В любом случае при разработке ИСППР, аккумулирующей опыт и знания специалистов в области проектного менеджмента, предметной области и функционала информационных систем, обеспечивающих выполнение проектов, рекомендуется применять предлагаемую авторами методику. Организация информационно-аналитической поддержки принятия коллективных решений для проектных команд инновационного проекта, результатом которой является ИСППР, включает следующие этапы:

1) онтологический анализ проектов, входящих в состав инновационного проекта. Онтология проекта включает описание существенных аспектов предметной области каждого проекта - исходных данных, получаемых результатов, основных этапов жизненного цикла, состава участников;

2) онтологический анализ средств информационных технологий и информационных систем, поддерживающих выполнение бизнеспроцессов предметной области каждого проекта. Онтология ИТ и ИС включает описание функциональности программных продуктов, состав пользователей, комплекс технических средств и специалистов, обеспечивающий их функционирование;

3 ) определение силы влияния взаимодействующих проектов и расстановка приоритетов в случае выявления конфликтов за выделяемые ресурсы;

4) выработка правил распределения ресурсов с учетом специфики каждого проекта и текущей ситуации;

5) разработка интегрированной онтологии инновационного проекта с учетом классификации проектов и организационной структуры коллектива лиц, принимающих решения;

6) разработка ИСППР, основу которой составляют правила принятия решений коллективом участников проектных команд и прецеденты принятия решений, зафиксированные в информационной системе управления проектами, исходя из опыта реализации проектов в рамках рассматриваемой ПЭС. 


\section{5. Методическое и алгоритмическое обеспечение интеллектуальной системы поддержки принятия решений}

\subsection{1. Разработка структуры интеллектуальной системы поддержки принятия решений при управлении инновационным проектом}

Для инновационной проектной деятельности характерна высокая степень неопределенности при принятии решений, связанных, в том числе, с распределением ресурсов между отдельными коллективами исполнителей, работающими на достижение общей цели. Снизить степень неопределенности позволит разработка и применение при реализации проектов интеллектуальной системы поддержки принятия решений, которая содержит в себе правила и прецеденты принятия решений, основанные на знаниях о предметной области и управленческом опыте принятия решений в различных проблемных ситуациях, возникающих в ходе инновационного проектирования.

Несмотря на то, что в течение последних лет активно обсуждаются проблемы управления знаниями в проектной деятельности, что привело, например, ко включению процессов управления знаниями в стандарты по проектному управлению $[4,34]$, в реальности порядок использования накопленных интеллектуальных активов ПЭС описан только для отдельных проектов. Отсутствие четких методик, позволяющих выстроить такую систему на любом экономическом объекте, влияет на эффективность разрабатываемых СППР - их каждый раз нужно проектировать «с нуля», отталкиваясь от конкретных задач конкретного проекта. При этом, с одной стороны, в практике разработки информационных систем существует множество типовых решений, которые после определенной адаптации могут быть успешно внедрены на предприятии. С другой стороны, в работах [7, 78, 79] предлагаются решения, связанные с использованием онтологического анализа при проектировании программного обеспечения.

Авторы полагают, что можно предложить подобные методы типового проектирования и при разработке интеллектуальных СППР, основанных на использовании накопленного опыта и знаний. Такая ИСППР при поиске решений по запросу пользователей сможет опираться на лучшие практики из области проектного управления, спроецированные на конкретную предметную область реализуемого инновационного проекта. 
Для этого требуется совместить онтологический подход к описанию предметной области инновационного проекта, выполняемого в рамках ПЭС, и объектно-ориентированный подход к разработке ИСППР. Оригинальность подхода заключается в синтезе онтологических моделей предметной области и функционала информационных систем, обеспечивающих выполнение отдельных проектов, входящих в состав комплексного инновационного проекта. Интеллектуальная система поддержки принятия решений реализуется как сложный программный комплекс, состоящий из ряда взаимодействующих интеллектуальных модулей, обслуживающих функции принятия решений на разных этапах и уровнях управления инновационным проектом (рис. 2.13).

Структура ИСППР может быть определена как набор следующих компонентов:

$$
\text { IDSS }=<\text { Onto, KB }\{\text { Rule,Case }\}, M, S(M), \text { Dec }>,
$$

где Onto - интегрированная онтология управления знаниями; $K B\{$ Rule,Case $\}$ - база знаний, содержащая модуль правил Rule и модуль прецедентов Case; $M=\left\{M_{1}, M_{2}, \ldots, M_{N}\right\}$ - множество аналитических, имитационных, логических и формальных моделей, реализующих функции моделирования процесса принятия решений; $S(M)$ - модуль, реализующий функцию выбора необходимой модели (моделей) для рассматриваемой задачи; Dec - модуль формирования решений на основе базы знаний и математического моделирования.

В основу интеграции модулей и формирования единой системы положена технология Semantic Web. Реализация ИСППР в соответствии с методологией Semantic Web позволяет осуществлять доступ к данным через корпоративную Intranet-сеть, что является важным условием эффективного информационного обеспечения, накопления корпоративных знаний и взаимодействия коллективов проектных команд.

ИСППР является центральным звеном интегрированной среды управления, выполняющим функции поддержки принятия решений в процессах инновационного проектирования на основе разработанной базы знаний. В зависимости от модели представления знаний результаты работы ИСППР могут быть представлены как в виде набора прецедентов, максимально удовлетворяющих описанию текущей проблемной ситуации, так и в виде готового решения, выведенного на основании заложенных в базу знаний продукционных правил. 


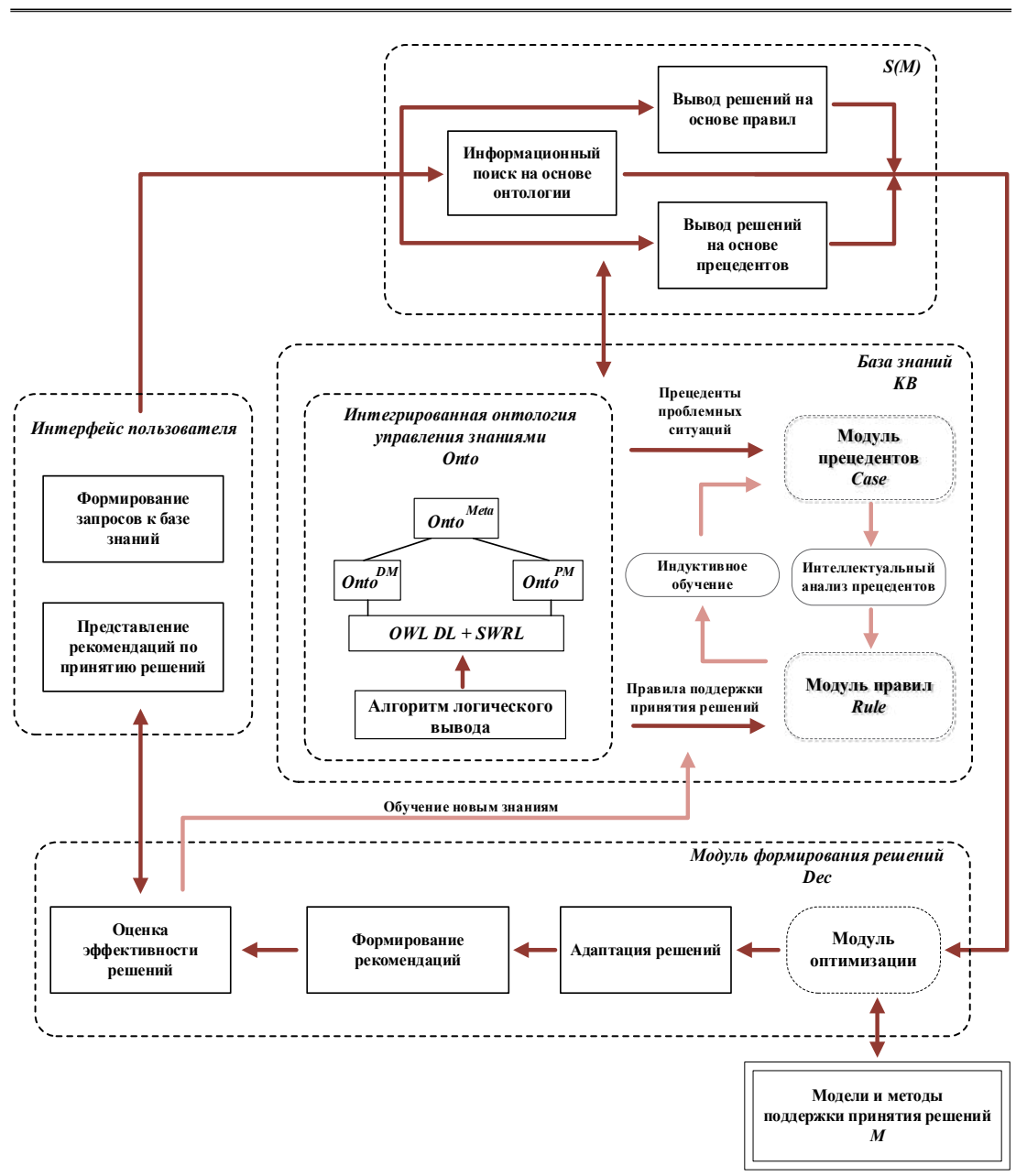

Рис. 2.13. Структура взаимодействия компонентов ИСППР

В рамках реализации инновационного проекта возникают проблемные ситуации, описание которых используется при формировании запроса к базе знаний. Использование ИСППР обычно не предполагает работу с ней в режиме реального времени в задачах, требующих быстрой реакции ЛПР на возникновение проблемных ситуаций. 
Тем не менее, скорость принятия обоснованных, взвешенных решений играет далеко не последнюю роль в эффективном управлении проектом. Поэтому одной из задач при проектировании и реализации ИСППР является разработка удобного пользовательского интерфейса, требующего минимальных затрат времени на ввод информации о проблемной ситуации и оценку полученных результатов.

Оценка эффективности поддержки принятия решений, реализуемой ИСППР, осуществляется по результатам контроля эффективности решений, принятых в результате выполнения рекомендаций, данных системой. Результатом проведенной оценки является обучение базы знаний новым знаниям.

Реализация предлагаемой структуры ИСППР должна сопровождаться разработкой методов и алгоритмов, целью которых является всесторонняя оценка работы системы с различных точек зрения на инновационный проект, а также различных аспектов работы ИСППР в рамках его реализации. Как и любая информационная система, ИСППР должна быть построена по модульному принципу. В зависимости от решаемой задачи в нее включаются те или иные компоненты, реализующие различные алгоритмы и методы обработки данных и знаний. Ниже предлагается описание компонентов алгоритмического и методического обеспечения ИСППР, предназначенных для решения различных задач управления инновационными проектами.

Разработанный алгоритм поиска решений на основе правил и прецедентов в базе знаний ИСППР предназначен для описания процедур работы пользователя с системой в процессе принятия решений в проблемных ситуациях, возникающих при управлении проектом.

Разработанное методическое обеспечение интеллектуального анализа данных мониторинга реализации инновационных проектов позволяет проводить классификацию инновационных проектов с учетом их характеристик и значимости для экономики региона с применением разработанной онтологии поддержки принятия решений.

Применение разрабатываемой ИСППР также рассматривается с точки зрения получения оценки прогноза эффективности реализации инновационного проекта, а также анализа влияния изменений конкретных характеристик состояния проекта на достижение целей проекта. 


\subsection{2. Алгоритм поиска решений на основе правил и прецедентов в базе знаний ИСППР}

Алгоритм поддержки принятия решений выполняет процедуру поиска решений на основе правил и прецедентов принятия решений, сформированных в онтологической базе знаний, и, используя систему логического вывода, выдает рекомендации по принятию решений в проблемных ситуациях, возникающих в процессах управления инновационными проектами (рис. 2.14).

В случае возникновения проблемной ситуации ЛПР обращается к ИССПР посредством интерфейса пользователя. На начальных этапах формирования запроса к интеллектуальной системе поддержки принятия решений ИСППР запрашивает у пользователя необходимые параметры запроса, включенные в условную часть правил и прецедентов, значения этих параметров, а также ЛПР предлагается указать его роль при реализации инновационного проекта, поскольку от этого напрямую зависит приоритет вывода правил и прецедентов принятия решений. При недостаточности данных, введенных для поиска решений в базе правил, система оповещает пользователя о необходимости уточнения параметров запроса. Как уже было отмечено ранее, правила и прецеденты классифицированы в базе знаний ИСППР с позиции отнесения их к определенным этапам, процессам и областям знаний инновационного проектирования, поэтому пользователю также предлагается уточнить данные параметры запроса.

Непосредственно алгоритм поиска решений включает процедуры информационного поиска на основе интегрированной онтологии управления знаниями, поиска решений в модуле правил, а также поиска решений в модуле прецедентов онтологической базы знаний. ИСППР производит поиск правил и прецедентов, в которые входят либо все переменные с определенными пользователем значениями, либо их часть. Алгоритм поиска решений формирует рекомендации на основе онтологической базы знаний, что позволяет обеспечить однозначное понимание рекомендаций всеми пользователями, участвующими в инновационном проектировании, включая комплексные проекты.

По завершении операции поиска пользователю предоставляются рекомендации по разрешению проблемной ситуации. Если решение не найдено, прецедент возникновения неразрешенной проблемной ситуации также фиксируется в онтологической базе знаний ИСППР. 
Глава 2
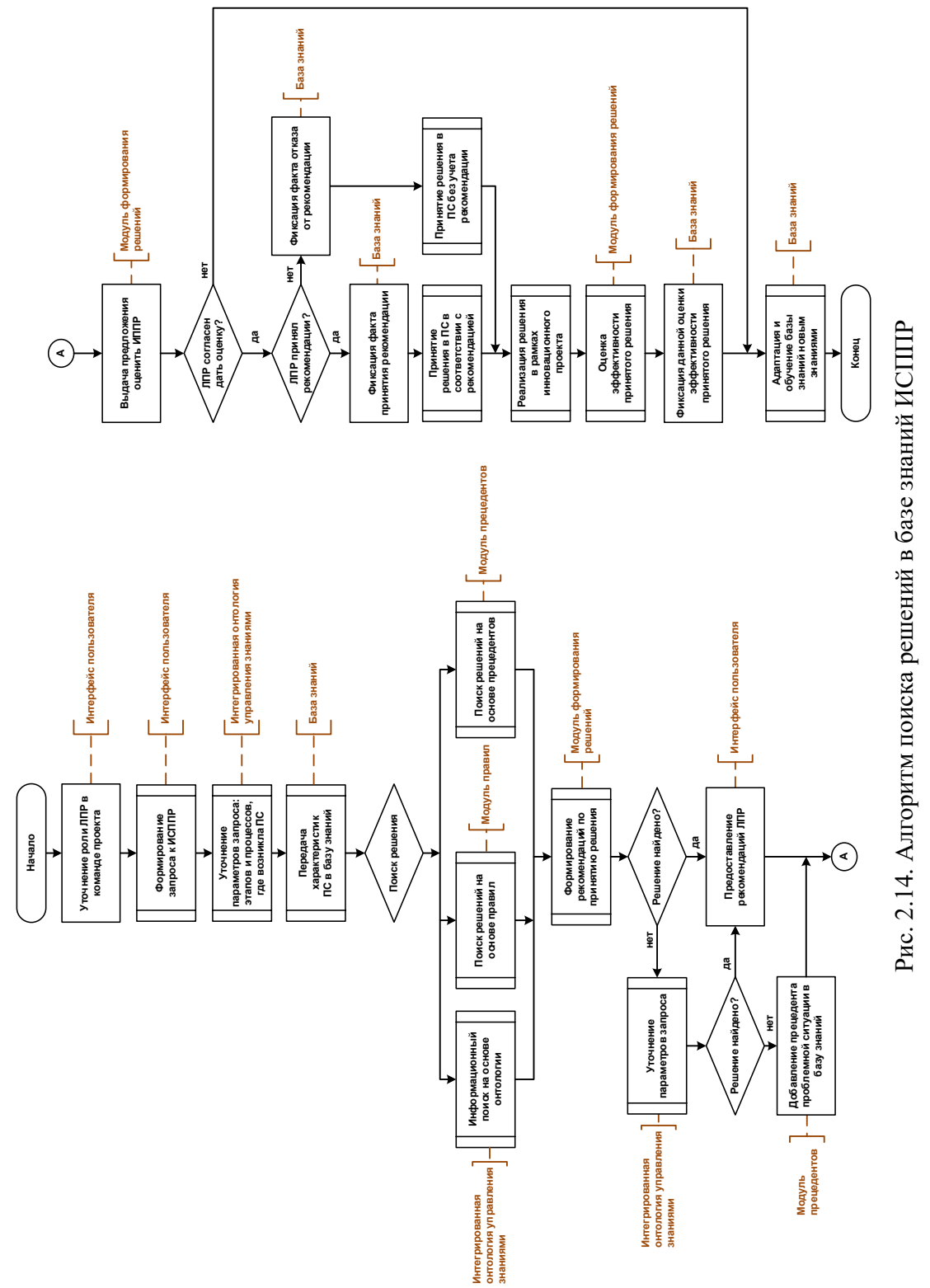
Пользователю предлагается также оценить качество предоставляемой интеллектуальной поддержки принятия решений.

Процедура оценки качества поддержки заключается в следующем:

1) пользователь фиксирует в ИСППР факт согласия с предоставленными рекомендациями или отказа от них;

2) пользователь дает оценку эффективности решения, принятого им с учетом предоставленных рекомендаций или самостоятельно;

3) оценивается близость (совпадение) реально полученных результатов с результатами, которые предполагалось получить в случае следования рекомендациям ИСППР.

По результатам оценки качества рекомендаций происходит дальнейшая адаптация и пополнение базы знаний новыми знаниями с использованием индукционного обучения, основанного на интеллектуальном анализе прецедентов и переводе их в правила принятия решений.

\subsection{3. Методическое обеспечение интеллектуального анализа данных мониторинга реализации инновационных проектов}

Важным моментом при реализации предложенной методологи интеллектуальной поддержки принятия решения является классификация инновационных проектов относительно приоритетов выделения ресурсов (в первую очередь финансовых) на те или иные проекты в те или иные периоды времени с учетом их характеристик и значимости для экономики региона. В проводимых исследованиях подобную классификацию предлагается проводить за счет применения методов и технологий интеллектуального анализа данных.

Инновационные проекты обладают индивидуальными характеристиками, которые необходимо учитывать при их планировании и реализации. Вместе с тем существуют общие принципы, подходы и методы обеспечения эффективности управления, присущие множеству проектов. Для выявления сходства инновационных проектов и объединения их в классы традиционно используется такой метод интеллектуального анализа данных, как классификация. В настоящем исследовании выборка данных создана на основе Перечня приоритетных инвестиционных проектов Республики Башкортостан на 01.10.2020 г., включающего проекты со сроком реализации в период с 2004 г. до 2035 г, Единого реестра инновационных проектов Республики Башкортостан, представленного 
Министерством экономического развития и инновационной политики Республики Башкортостан, отчетов Территориального органа Федеральной службы государственной статистики по Республике Башкортостан (раздел «Наука, инновации и информационное общество») и других источников информации, где представлены основные показатели инновационной активности организаций $[80,81]$.

Эти данные содержат информацию, необходимую для классификации текущих проектов и последующего распознавания и прогнозирования инновационного потенциала новых проектов. Для анализа были использованы сведения о характеристиках 200 проектов, выполняющихся на базе производственных предприятий. Примером применения методики служат правила принятия решений для управления проектом в проблемных ситуациях, сформированные для инновационного проекта «Реконструкция и техническое перевооружение производственной базы ПАО «ОДК-УМПО» для производства компонентов и агрегатов вертолетных двигателей типа ТВ3-117 и ВК-2500» [71]. В качестве методов исследования были применены онтологический анализ предметной области для формализации данных об инновационных проектах и управлении ими, метод символьного индуктивного обучения «с учителем» для построения деревьев решений, методы и средства инженерии знаний.

В интеллектуальном анализе данных обычно используются модели деревьев решений (ДР) для изучения данных, которые будут использоваться для классификации или прогнозирования. Для построения ДР могут быть использованы различные алгоритмы, включая ID3 (Interactive Dichotomizer), CHAID (Chi-squared Automatic Interaction Detection), CART (Classification and Regression Tree) и другие инструменты анализа (см. табл. 2.1) [82]. Для проведения интеллектуального анализа данных об инновационных проектах выбран алгоритм ID3, реализующий метод символьного индуктивного обучения «с учителем». Признаками классификации определены: срок реализации, объем инвестиций в проект, количество новых рабочих мест. Уровни инновационного потенциала проектов определены экспертами как низкий (1 класс), средний (2 класс), выше среднего (3 класс), высокий (4 класс). Экспертные оценки определены с учетом области применения предлагаемого в проекте продукта, типа инновации, масштабности проектов, реализация которых влияет на экономическую, социальную и экологическую ситуацию в регионе. 
В результате применения алгоритма ID3 построено ДРиерархическая модель контролируемого обучения (обучения «с учителем»), в которой локальная область идентифицируется в последовательности рекурсивных разбиений $[83,84]$. ДР состоит из внутренних узлов принятия решений и конечных листьев. Каждый внутренний узел принятия решений $m$ реализует тестовую функцию $f_{m}(x)$ с исходами, обозначающими ветви. Учитывая входные данные, в каждом узле применяется $f_{m}(x)$, и одна из ветвей выбирается в зависимости от результата. Этот процесс начинается в корне и повторяется рекурсивно до тех пор, пока не будет достигнут листовой узел, в котором записанное в лист значение составляет выходную переменную.

Таким образом, каждый листовой узел имеет выходную метку, которая в случае классификации является кодом класса. Каждый $f_{m}(x)$ определяет дискриминант в $d$-мерном входном пространстве, разделяя его на более мелкие области, которые далее подразделяются по мере прохождения пути от корня вниз; $f_{m}(x)$ - это простая функция, и при записи в виде ДР сложная функция разбивается на ряд простых решений. Границы областей определяются дискриминантами, которые кодируются во внутренних узлах на пути от корневого к листовому узлу.

Преимуществом применения ДР является возможность интерпретации, поскольку ДР можно преобразовать в набор правил ЕСЛИ-ТО. Для реализации алгоритма ID3 выбрано программное средство See5. В peзультате интеллектуального анализа данных были получены ДР, определяющие класс инновационного проекта в зависимости от значений признаков. Ошибка классификации находится в диапазоне $11,5 \%-24 \%$.

Для реализации интеллектуального анализа данных в онтологии поддержки принятия решений (рис. 2.15) были созданы базовые объектные отношения между классами: \{Прецедент, Интеллектуальный анализ данных (ИАД), Правило, Рекомендация, ЛПР, Решение, Действие . Цепочка отношений включает следующие объектные отношения:

hasFollow(Прецедент, ИАД) о hasFollow(ИАД, Правило) o hasFollow(Правило, Рекомендация) o hasFollow(Рекомендация, ЛПР) o hasFollow ( ЛПР, Решение) o hasFollow(Решение, Действие).

На основе композиции базовых отношений получено новое отношение (Прецедент, Решение), отображающее методику поддержки принятия решений для ЛПР на основе применения интеллектуального анализа данных. 


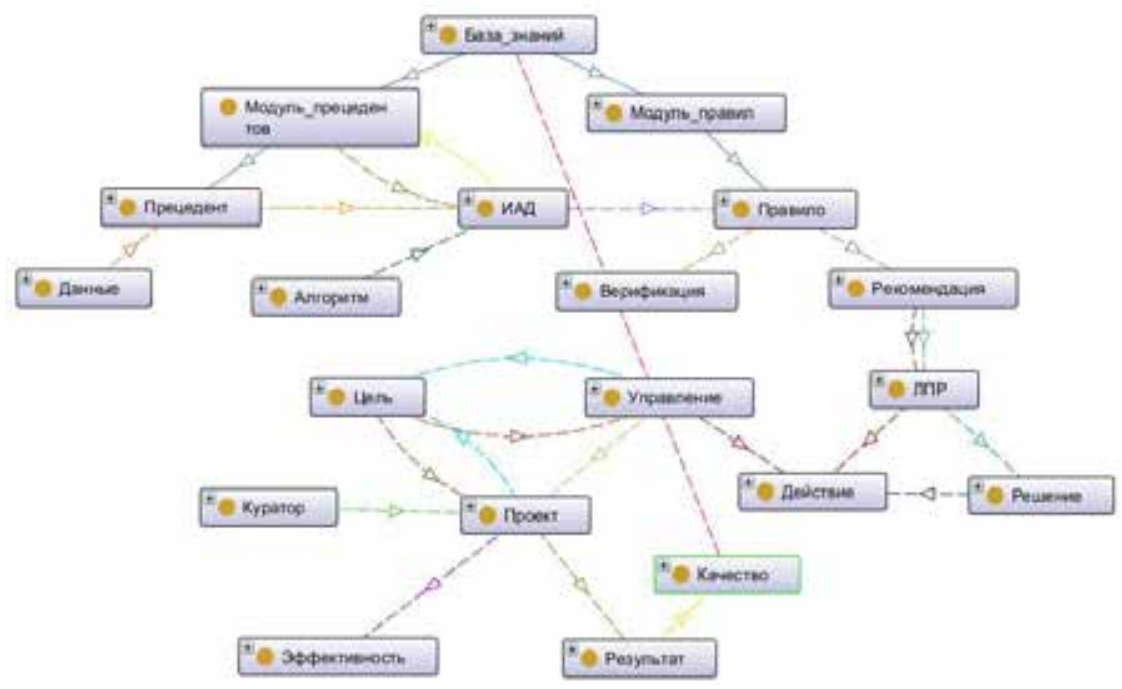

Рис. 2.15. Фрагмент семантической сети структуры знаний в онтологии ППР

Результатом интеллектуального анализа данных являются правила классификации проектов, сгенерированные методом индукции на основе описаний 200 проектов [81] с применением See5 [85]. На рис. 2.16 представлен фрагмент множества правил классификации проектов, трансформированных во встроенные в онтологию правила на языке Semantic Web Rule Language (SWRL).

Правила, встроенные в онтологию, способствуют обмену знаниями между участниками процесса инновационной деятельности. Полученные правила применены для классификации и оценки инновационного потенциала проектов, реализация которых началась в 2020 году.

Классификация проектов на основе правил дает возможность обосновывать управленческие решения относительно приоритетов финансирования инновационных проектов в те или иные периоды времени с учетом их характеристик и значимости для экономики региона. В перспективе, с накоплением прецедентов принятия решений, возможно формирование базы типовых решений, использование которой позволит сократить сроки принятия решений о выделении финансовых средств для реализации инновационных проектов и распределении других видов ресурсов. 


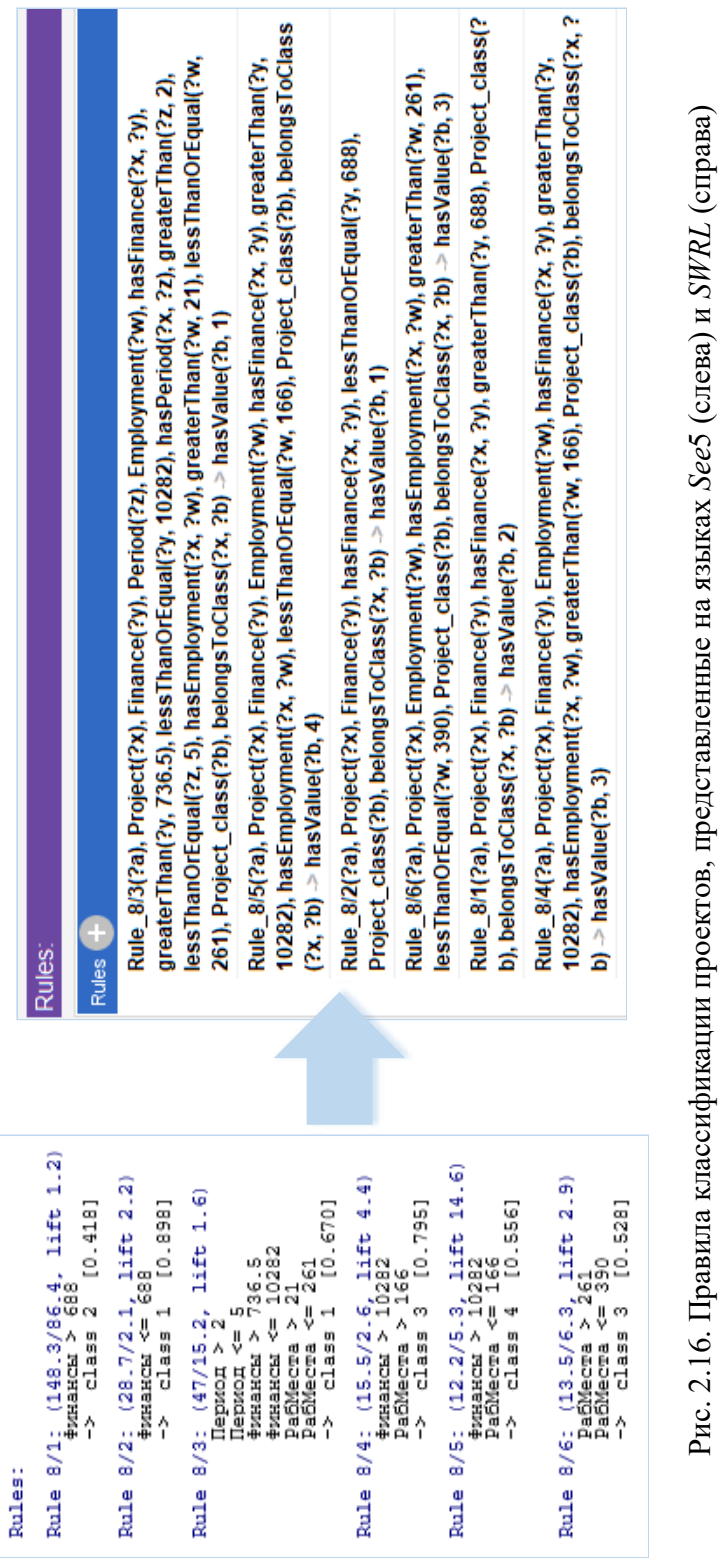




\subsection{4. Оценка эффрективности инновационного проекта методом параметрического прогнозирования}

Как правило, в состоянии нестабильной социально-экономической среды задача планирования проектной деятельности и прогнозирования ее результатов является одной из самых сложных и неоднозначных. Поэтому лица, принимающие решения опираются как на математические методы анализа ситуации и прогнозирования, так и на субъективный опыт, знания и оценки экспертов и руководителя проекта. В [86] подчеркивается, что эффективной стратегией управления деятельностью организации является управление на основе прогнозных оценок. Таким образом, разработка методов оценки ограничений на характеристики реализации проектов на основе прогноза состояния проекта является необходимой предпосылкой эффективной деятельности организаций.

Термин «прогнозирование» в научной литературе используется в разных смыслах, в данном случае используется следующее определение: «Прогнозирование - специальное научное исследование конкретных перспектив развития изучаемого объекта» [87]. Предсказание варианта развития в будущем содержит большой элемент неопределенности, и это вынуждает ограничиваться утверждениями преимущественно качественного характера в сочетании с экстраполяцией наиболее обобщенных параметров проекта в целом. Для определения научно-обоснованных предпосылок применения того или иного метода прогнозирования необходим анализ не только применяемого математического аппарата, но и рассмотрение характеристик класса объектов прогнозирования. В современных исследованиях по управлению сложными системами и принятию решений [88-90] устанавливается, что актуальной тенденцией развития систем поддержки принятия решений является их интеллектуализация, ориентированная на способность выбора метода решения задач прогнозирования, наиболее адекватного структурированности исходной информации. К методам искусственного интеллекта относятся методы нейросетевого анализа, методы параметрического прогнозирования с применением нечетких правил, методы онтологического анализа и другие $[7,90]$.

Инновационные проекты характеризуются повышенной неопределенностью и риском, поэтому целью проведенных исследований также являлся поиск методов инженерии знаний для снижения степени неопределенности и прогнозирования проблемных ситуаций. В каче- 
стве методов исследования были применены онтологический анализ задач и методов принятия решений и метод параметрического прогнозирования. В соответствии с данным подходом к прогнозированию проблемных ситуаций структура ИСППР может быть расширена компонентом нейро-нечеткой системы прогнозирования (рис. 2.17).

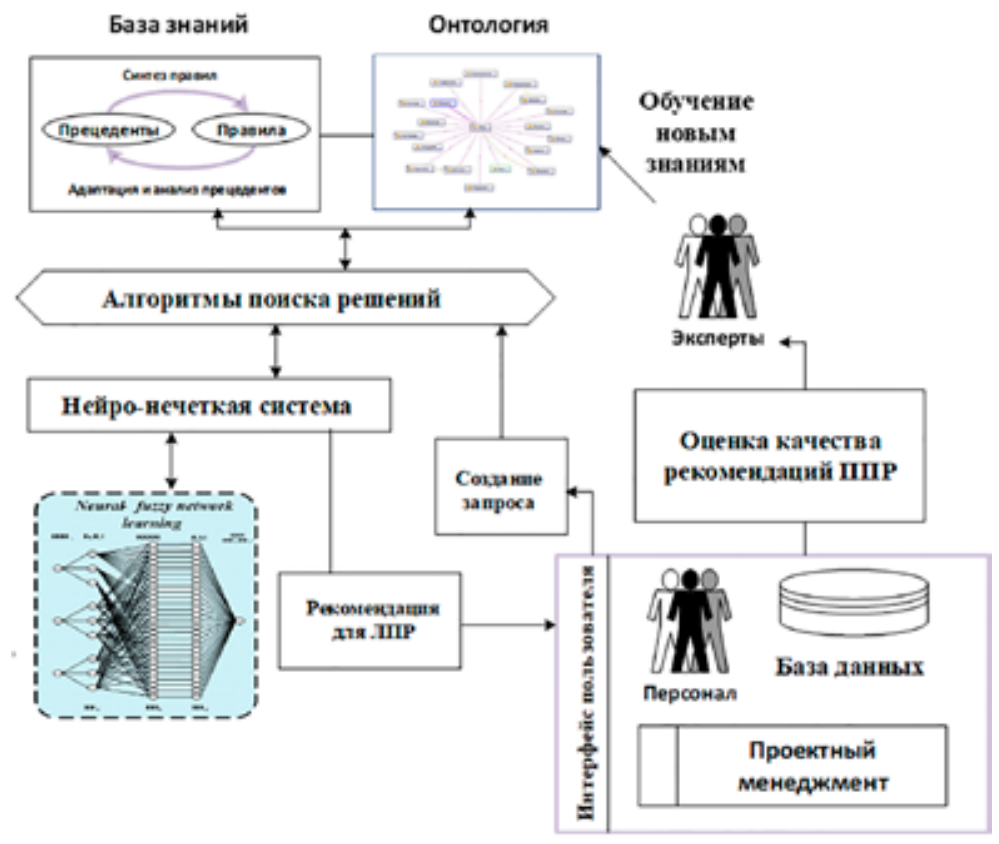

Виешине факторы

Рис. 2.17. Схема взаимодействия компонентов ИСППР в рамках параметрического прогнозирования проблемных ситуаций

Успешность анализа эффективности результатов инновационных проектов определяется знанием зависимостей между классами объектов, участвующих в проектах. Для этого проведен онтологический анализ задач и методов принятия решений с применением онтологического редактора Protege 5.5 и языка моделирования онтологий $W e b$ Ontology Language [63, 92, 93]. Классы и экземпляры классов методов прогнозирования представлены в онтологии поддержки принятия решений (рис. 2.18). 


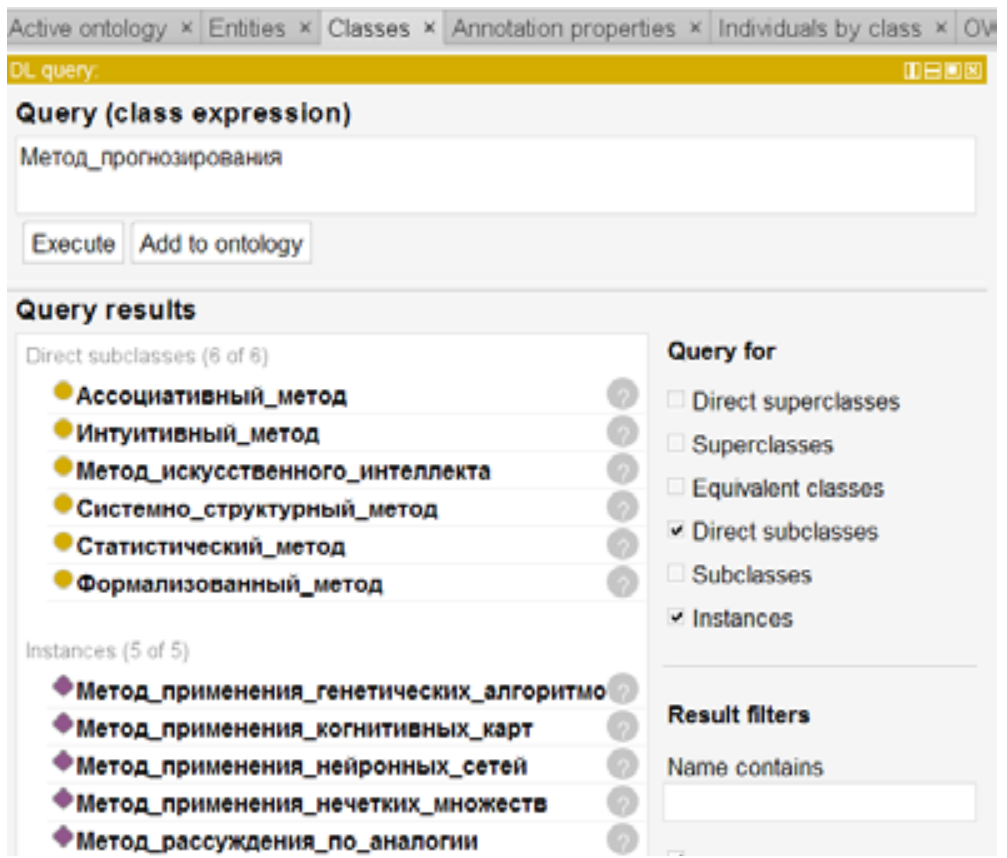

Рис. 2.18. Результаты логического поиска методов прогнозирования в онтологии ППР

Метод прогнозирования выбран с учетом потребности в интеллектуализации управления проектами, а также оценок уровня сложности задачи прогнозирования, недостаточности исходных данных, возможности количественной оценки выходных данных. Наиболее подходящим методом для решения задачи прогнозирования представляется метод параметрического прогнозирования с применением системы нечеткого вывода (Fuzzy Inference Sytem). Нечеткая база знаний представляет собой совокупность нечетких правил $R^{(r)}$ следующего вида [94]:

$$
\begin{aligned}
& R^{(r)}: \text { ЕСЛИ }\left(x_{1} \text { eсть } A_{1}^{r} \text { И } x_{2} \text { ecmь } A_{2}^{r} \ldots И x_{n} \text { ecmь } A_{n}^{r}\right. \\
& \text { TO } y_{k}=f^{(r)}\left(x_{1}, x_{2} \ldots x_{n}\right)
\end{aligned}
$$

Здесь $R^{(r)}$ есть $r$-е правило, $x_{i}-i$-я входная переменная, $i=1, \ldots, n$, $A_{i}^{r}-i$-е нечеткое подмножество в $r$-м правиле, определяемое функциями принадлежности, $y_{r}-$ выход $r$-го правила. 
Входные лингвистические переменные описываются гауссовыми функциями принадлежности, т.е.:

$$
\mu_{A_{i}^{k}}\left(x_{i}\right)=\exp \left[-\left(\frac{x_{i}-\bar{x}_{i}^{r}}{\sigma_{i}^{r}}\right)^{2}\right]
$$

Выходной сигнал FIS по Сугено при $M$ правилах вывода представляет собой агрегирование выходного результата сети:

$$
y(x)=\frac{1}{\sum_{n=1}^{N} w_{k}} \sum^{M} w_{k} y_{k}(x), \quad y_{k}(x)=p_{0}+\sum_{j=1}^{N} P_{k j} x_{j}
$$

В выражении (2.7) веса $w_{k}$ интерпретируются как значимость компонентов $\mu_{A}^{K}(x)$ определенных в форме гауссовых функций принадлежности (2.6). Значение функции принадлежности $\mu_{A_{i}^{k}}$, относящееся к уровню импликации правила, интерпретируется с применением нечеткой $t$-нормы типа min-конъюнкции. Нечетким расширением операции логического вывода является $s$-норма $[95,96]$.

Для моделирования системы выбраны три непрерывные входные переменные: $X_{1}$ - «Отклонение от срока выполнения работ», $X_{2}-$ «Качество работ», $X_{3}-$ «Затраты». Выходной переменной является $Y-$ оценка эффективности реализации работ по проекту. Нечеткие подмножества отображают приращения значений входных переменных при переходе от одного состояния исследуемого объекта к другому. Для переменной $X_{1}$ использовано терм-множество $T_{1}=\{$ «сильно падает», «слабо падает», «стабильно», «слабо растет», «сильно растет»\}; для переменной $X_{2}$ использовано терм-множество $T_{2}=\{$ «сильно ухудшается», «слабо ухудшается», «стабильно», «слабо улучшается», «сильно улучшается»\}, для переменной $X_{3}$ использовано терммножество $T_{3}=\{$ «сильно падают», «слабо падают», «стабильно», «слабо растут», «сильно растут»\}. Определение количества термов - это результат поиска компромисса между адекватностью модели прогнозирования и сложностью ее реализации. В табл. 2.3 приведены некоторые примеры правил оценки эффективности.

Моделирование нейро-нечеткой системы выполнено с применением программной системы MATLAB [97]. 
Правила оценки эффективности

\begin{tabular}{|c|c|c|}
\hline $\begin{array}{c}\text { № } \\
\text { правила }\end{array}$ & Если & To \\
\hline 1 & $X_{1}$ сильно падает $\mathbf{И} X_{2}$ сильно улучшается И $X_{3}$ сильно падают & Y есть 110 \\
\hline 2 & $X_{1}$ сильно падает $\mathbf{И} X_{2}$ слабо улучшается $\mathbf{И} X_{3}$ слабо падают & Y есть 95 \\
\hline 3 & $X_{1}$ слабо падает $\mathbf{И} X_{2}$ стабильно И $X_{3}$ сильно падают & Y ecmb 105 \\
\hline 4 & $X_{1}$ слабо падает $\mathbf{И} X_{2}$ слабо ухудшается $\mathbf{И} X_{3}$ слабо падают & Y ecmb 100 \\
\hline 5 & $X_{1}$ стабильно И $X_{2}$ сильно улучшается И $X_{3}$ сильно падают & Y ecmb 95 \\
\hline 6 & $X_{1}$ стабильно И $X_{2}$ сильно ухудшается И $X_{3}$ слабо падают & Y есть 110 \\
\hline 7 & $X_{1}$ сильно растет $\mathbf{И} X_{2}$ сильно улучшается $\mathbf{И} X_{3}$ сильно падают & Y ecmb 105 \\
\hline
\end{tabular}

При необходимости выполнения подобных экспериментов удаленными пользователями возможно применение MATLAB Mobile. На рис. 2.19 представлен график поверхности нечеткого вывода рассматриваемой модели для переменных «Качество» и «Затраты».

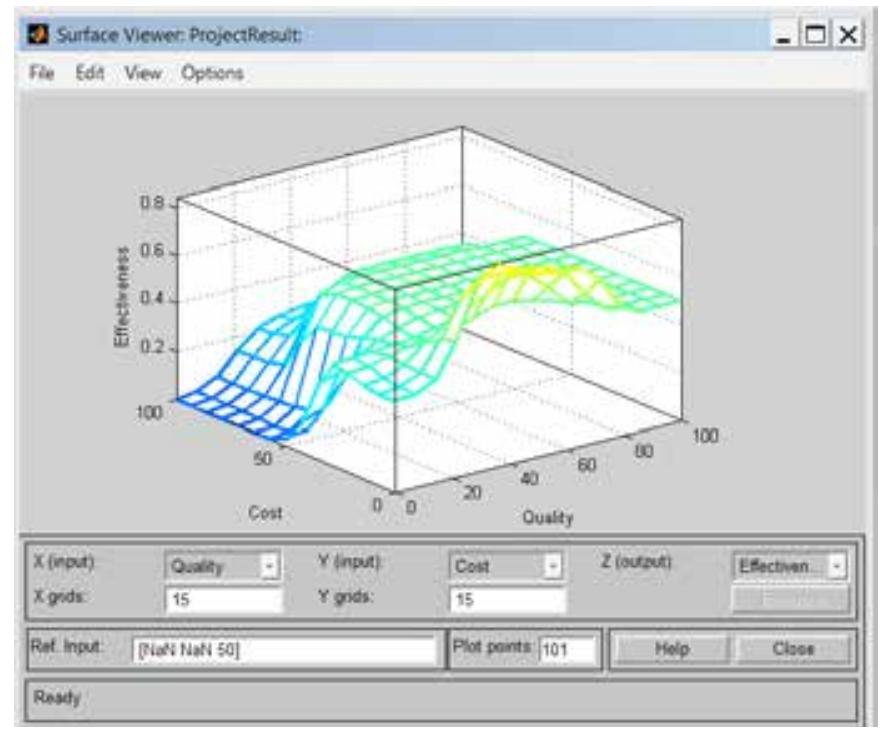

Рис. 2.19. Визуализация поверхности нечеткого вывода для переменных «Качество» и «Затраты» 
Формирование базы правил выполнено с применением экспертных знаний. Далее следует обучение сети ANFIS по экспериментальным данным, в результате которого настраиваются нелинейные параметры нейронов первого слоя и линейные веса нейронов третьего слоя сети. Тем самым осуществляется дополнение экспертных знаний, используемых при формировании правил, коррекцией параметров $A N F I S$ в результате обучения сети на основе объективных данных (84 примера проблемных ситуаций), накопленных в ходе реализации проекта.

Структура $A N F I S$, созданной в соответствии с базой правил, представлена на рис. 2.20.

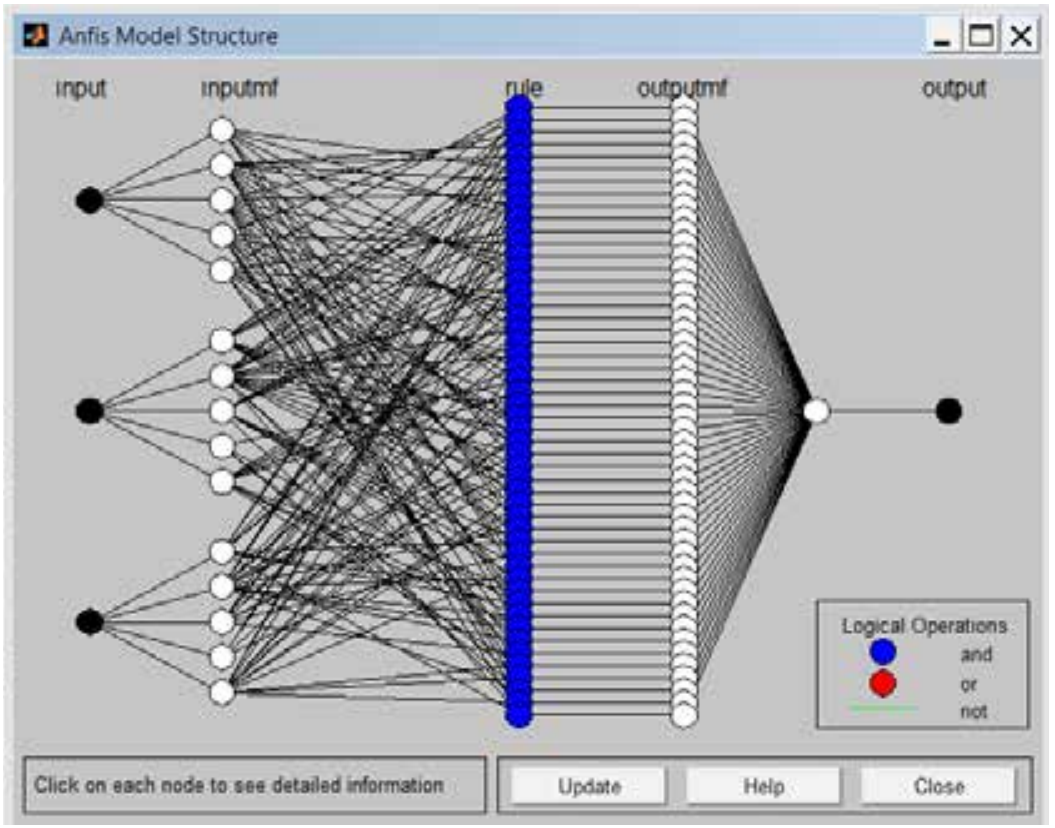

Рис. 2.20. Структура адаптивной нейро-нечеткой сети

При обучении $A N F I S$ гибридным методом количество циклов обучения было задано равным 300, значение погрешности 0,092 (рис. 2.21).

Оценивание порядка прогнозирования осуществлялось по двум критериям: количеству параметров функций принадлежности $p$ и среднеквадратичному отклонению. 


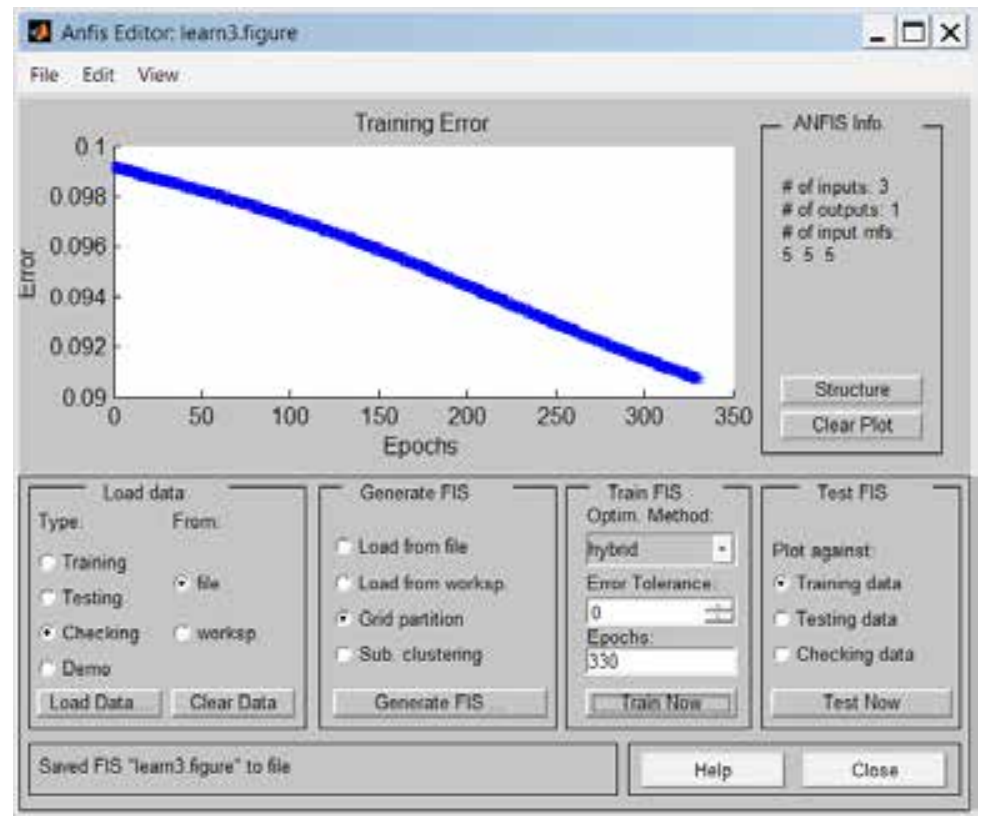

Рис. 2.21. График зависимости ошибки обучения от количества циклов обучения

Для оценивания нейро-нечеткой системы был приведен информационный критерий, предложенный Акаике (англ. Akaike Information Criterion), который вычисляется по формуле:

$$
\operatorname{AIC}\left(p, Q_{p}\right)=M \ln Q_{p}+2,
$$

где $p$ - количество параметров системы (т.е., количество параметров всех функций принадлежности плюс количество весов правил); $Q_{p}$ - мера погрешности, установленная в ходе экспериментов, $m-$ количество выборок в обучающей последовательности.

В результате эксперимента были определены значения погрешности функционирования системы и количеством параметров, подлежащих обучению, которые свидетельствуют, что учет весов, отражающих важность правил и важность лингвистических переменных в суждениях правил, повышают эффективность функционирования нейронечетких систем. 
Таким образом, разработка и применение ИСППР позволит получать оценки прогноза эффективности реализации инновационного проекта, а также проанализировать влияние изменений конкретных характеристик состояния проекта на достижение целей проекта.

\subsection{5. Оценка эффрективности интеллектуальной поддержки принятия решений на основе имитационного моделирования процессов решения задач, возникающих в процессе управления инновационным проектом}

Оценка эффективности интеллектуальной поддержки принятия решений, осуществляемой ИСППР, является важнейшим этапом, нашедшим отражение как на структурной модели ИСППР, так и в алгоритме поиска решений на ее основе. Главным назначением данного этапа является качественная оценка решений, предлагаемых ИСППР для различных стадий, процессов и областей знаний инновационного проекта, а также с учетом различных интересов заинтересованных сторон инновационного проекта.

Участники инновационного проекта (заказчик, руководитель проекта, проектировщик, подрядчик, консультант), а также представители финансовых, юридических, государственных организаций реализуют различные интересы в процессе осуществления проекта, формируют свои требования в соответствии со своими локальными целями и оказывают влияние на реализацию проекта. Для каждого их них в базе знаний ИСППР должны быть предусмотрены решения, наиболее адекватно отвечающие представляемым требованиям к поддержке принятия решений.

Однако, на стадии разработки и принятия управленческого решения можно дать только ориентировочную оценку его эффективности. Эффективность управленческого решения зависит не только от его абсолютной правильности, но и от того, что только будучи реализовано последовательно и в срок, оно достигнет поставленной цели. Следовательно, эффективность управленческого решения зависит как от качества самого решения, так и от качества его осуществления. Оценку эффективности интеллектуальной поддержки принятия решений предлагается осуществлять на основе имитационного моделирования процессов решения основных задач, возникающих в процессе управления инновационным проектом. Имитационное моделирование 
проектных задач позволяет на начальных этапах разработки ИСППР проводить адаптацию базы знаний системы - отсекать ненужные или ошибочные правила и прецеденты, добавлять новые знания.

В настоящее время для настройки и адаптации популярных в сфере менеджмента организаций систем управления бизнес-процессами активно применяются инструментальные средства имитационного моделирования. Их можно использовать и для настройки проектных решений под нужды и особенности конкретного предприятия. Результаты имитационного моделирования дают возможность более точно распределить функции между участниками процессов, а также обосновать необходимость внедрения средств интеллектуальных информационных технологий на их отдельных этапах.

Рассмотрим применение средств имитационного моделирования для решения задач, связанных с процессом обеспечения инновационного проекта квалифицированным персоналом.

Развитие человеческого потенциала является одним из решающих факторов успешного инновационного проектирования. Осуществляемые в рамках производственно-экономических систем инновационные проекты должны опираться на коллектив высококвалифицированных, мотивированных на дальнейшее развитие участников, ведь люди - это важнейший ресурс любой деятельности. Обучение является одним из важнейших бизнес-процессов, осуществляемых в рамках управления человеческими ресурсами проекта $[4,36]$, удовлетворяющим требования к конечному результату инновационного проекта всех его участников. Обучение является необходимым действием по развитию команды проекта - обучение в целях повышения знаний членов команды повышает их результативность.

Согласно [36] обучение включает в себя все операции, направленные на повышение компетенций членов команды проекта. Если члены команды проекта не обладают достаточными управленческими или техническими навыками, то развитие таких навыков можно предусмотреть как часть работ проекта. Запланированное обучение осуществляется согласно плану управления человеческими ресурсами. Внеплановое обучение проводится по результатам наблюдения, обсуждения и оценки исполнения проекта, выполняемых во время процессов контроля управления командой проекта. Стоимость обучения может быть включена в бюджет проекта или оплачена исполняющей организацией, если приобретенные навыки помогут в ходе будущих проектов. 
В соответствии с текущей социально-экономической обстановкой в стране и мире все большее внимание уделяется развитию дистанционного обучения, для осуществления которого необходимо использование современных информационных технологий, функционирующих в единой информационной образовательной среде. Непременным условием для успешного обучения в любом формате является своевременное выполнение вспомогательных процессов, таких как сбор заявок на обучение, формирование групп, обработка сопроводительных документов и т.д. В современных условиях данные процессы также рекомендуется проводить дистанционно с использованием имеющихся информационных технологий и возможностей. При этом потребность в координации действий сотрудников только растет, а у лиц, принимающих решения, одной из самых насущных проблем является необходимость решать большое число задач в условиях ограниченного рабочего времени с привлечением множества разнородных инструментальных средств. Помимо указанной проблемы в работе руководителя любого уровня возникают и другие [98]:

- необходимость обработки огромного количества документов, которые требуют реакции, согласования, исполнения и отслеживания;

- одновременное исполнение нескольких ролей в бизнес-процесcax - ответственного исполнителя, контролера, инициатора;

- анализ и отслеживание разнородной информации, необходимой для принятия решений, связанных с исполнением должностных обязанностей, причем объем этой информации постоянно растет.

С каждым днем в процессах организации обучения все большее значение приобретает оперативность принятия решений, отслеживание их исполнения, рациональное использование собранной информации, анализ и обобщение корпоративного опыта и знаний.

Базой для проведения исследований послужил учебно-научный центр (УНЦ) крупного научно-производственного предприятия. Целью образования УНЦ несколько лет назад явилась необходимость обеспечения потребностей предприятия в высококвалифицированных кадрах во всех областях его деятельности. Чтобы обеспечить конкурентоспособность предприятия и развивать текущие инновационные проекты, необходимо поддерживать квалификацию сотрудников на постоянно высоком уровне, соответствующем требованиям профессиональных стандартов, а также нормативно-законодательной базы (федеральных законов, кодексов и т.п.) и внутренних регламентных доку- 
ментов, на основе которых функционирует предприятие. Повышенные требования к квалификации персонала возникают в связи с появлением в рамках реализации инновационных проектов нового высокотехнологичного оборудования, неправильная эксплуатация которого может повлечь за собой крупные финансовые потери для предприятия, а также снизить эффективность выполнения проектов. Отслеживание изменений бизнес-процессов и соответствие знаний и навыков сотрудников, задействованных в них, является одной из основных обязанностей специалистов УНЦ и службы управления персоналом предприятия. Другой обязанностью является модернизация программ обучения, связанная с обновлением оборудования и программного обеспечения, а также разработка учебно-методических комплексов по новым технологическим решениям, возникающим в ходе выполнения инновационных проектов.

Деятельность рассматриваемого предприятия относится к одной из самых наукоемких отраслей, что приводит к частым изменениям в выполнении бизнес-процессов, связанным с появлением новых технологий, материалов и оборудования [69]. Этим обстоятельством обусловлен наблюдаемый за последние годы рост количества заявок на повышение квалификации и заявок на подтверждение соответствующих уровней допуска к различному оборудованию. Сотрудникам УНЦ приходится обрабатывать большое количество заявок в кратчайшие сроки, ошибки при обработке заявок недопустимы.

При всей значимости учебных центров для предприятия, они обычно находились на периферии внимания руководства, поскольку их деятельность напрямую прибыли не приносила. Но такое положение меняется при повышении интенсивности выполнения инновационных проектов, отдача от которых выражается в возможности коммерциализации их результатов. Поэтому одной из задач УНЦ является привлечение сторонних клиентов для обучения новым технологическим решениям. Тем не менее, серьезное расширение круга обязанностей сотрудников УНЦ, как правило, не приводит к увеличению штатной численности этого подразделения, в связи с чем существует ограничение на количество сотрудников, обеспечивающих поддержку учебного процесса. С учетом того, что стандарты профессионального образования, а также требования законодательства в области регулирования деятельности образовательных учреждений в последние годы меняются стремительно, и эти изменения влекут 
за собой лавинообразное увеличение количества документов, требующих своевременного изучения и соблюдения заявленных в них требований, становится необходимой информационная поддержка персонала УНЦ.

Диагностика системы организации работы УНЦ показала, что процессы, сопровождающие учебный процесс, автоматизированы лишь частично. Процессы, поддерживающие выполнение образовательного процесса (регистрация обучаемых, формирование групп и подготовка организационно-распорядительной документации), выполняются с использованием $C R M$-системы, но это возможно только для сотрудников предприятия. Для сторонних организаций эти процессы выполняются вручную. Обучение полностью или частично (в программах, где это возможно) реализуется с использованием системы дистанционного обучения Moodle, интегрированной с $C R M$-системой. Процесс сбора и первичной обработки заявок на обучение не автоматизирован, именно этот процесс является «узким местом»- одной из причин, приводящих впоследствии к срыву обучения.

Проблемные ситуации, возникающие на этапе приема заявок, могут быть поделены на два вида - проблемы, связанные с содержанием заявки и технические проблемы (табл. 2.4).

Таблица 2.4

Классификация проблемных ситуаций, возникающих на этапе приема заявок

\begin{tabular}{|l|l|}
\hline \multicolumn{1}{|c|}{$\begin{array}{l}\text { Проблемы, связанные } \\
\text { содержанием заявки }\end{array}$} & \multicolumn{1}{c|}{ Технические проблемы } \\
\hline Отсутствие данных в полях заявки & $\begin{array}{l}\text { Проблема, связанная с подключением } \\
\text { к сети Интернет }\end{array}$ \\
\hline $\begin{array}{l}\text { Неверно указанная информация } \\
\text { по программе обучения }\end{array}$ & $\begin{array}{l}\text { Проблема, связанная с программным } \\
\text { обеспечением информационных систем }\end{array}$ \\
\hline $\begin{array}{l}\text { Неверно указанная информация по за- } \\
\text { казчику }\end{array}$ & $\begin{array}{l}\text { Ошибки при работе с периферийными } \\
\text { устройствами }\end{array}$ \\
\hline $\begin{array}{l}\text { Отсутствие подписей ответственных } \\
\text { лиц }\end{array}$ & $\begin{array}{l}\text { Проблема, связанная с появлением вре- } \\
\text { доносного ПО, компрометация храни- } \\
\text { мых и обрабатываемых данных }\end{array}$ \\
\hline $\begin{array}{l}\text { Несоответствие программы обучения } \\
\text { форме ее проведения }\end{array}$ & $\begin{array}{l}\text { Проблема, связанная со сбоями в подаче } \\
\text { электроэнергии }\end{array}$ \\
\hline
\end{tabular}


Таким образом, целью дальнейшего исследовании является определить на каких этапах данного процесса и для каких проблемных ситуаций возможно применение технологии искусственного интеллекта и онтологического инжиниринга, в том числе, внедрение программного робота.

Автоматизация любой деятельности предполагает ее моделирование, которое позволит оценить имеющиеся проблемы и возможные пути их решения. Моделирование процесса приема заявок на обучение было выполнено в нотации BPMN (business process management notation) с применением программного продукта ELMA [99]. На рис. 2.22 представлен фрагмент $B P M N$-модели процесса сбора и обработки заявок на обучение - подпроцесс «Оформление заявки». Исполнителем процесса является сотрудник учебного центра в должности инженера по кадрам, принимающий заявки, отправленные заказчиками на корпоративную электронную почту учебного центра, или поступающие автоматически в $C R M$-систему из подразделений предприятия.

$B P M N$-модель процесса оформления заявок отражает факт наличия значительно количества операций, выполнение которых может быть передано программному роботу (RPA, Robotic Process Automation) - прием заявок, отправка логинов и паролей обучаемым, отправка приглашений на аттестацию, подготовка документации. Программные роботы могут выполнять однотипные повторяющиеся задачи, не требующие принятия решений человеком. К таким задачам относятся заполнение форм, отправка запросов, составление расписания с учетом множества факторов и т.д. Основные преимущества RPA по сравнению с деятельностью человека заключаются в быстрой безошибочной неустанной работе, интеграции со множеством существующих систем и приложений, способности выполнять задачи в режиме $24 \times 7$, и как следствие в сокращении операционных затрат на 50-70\%.

В процессе предварительного сбора и оформления заявок на обучение программный робот может отслеживать по каналам связи поступающие заявки, проверять соблюдение требований к оформлению заявок, составлять расписание групповых занятий в соответствии с программами обучения, рассылать уведомление преподавателям и слушателям. В настоящее время технология $R P A$ получают всё большее распространение, что позволяет надеяться на существенное снижение стоимости продукта и развитие интеллектуальных способностей программных роботов. 


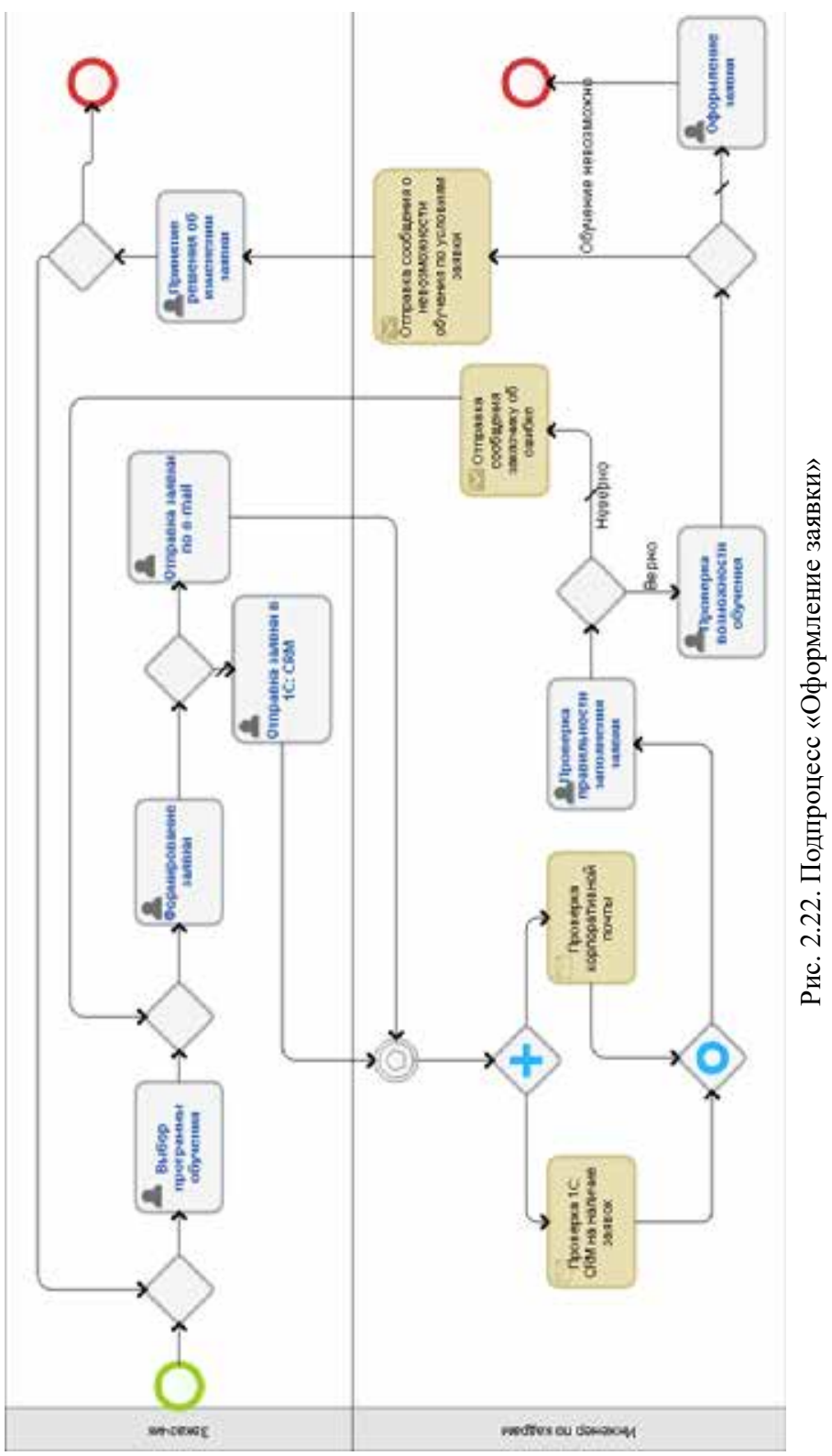


Но, прежде чем внедрять новую технологию в текущий бизнеспроцесс, необходимо провести имитационное моделирование с целью обоснования необходимости сокращения штатной численности сотрудников УНЦ. Для этого была построена имитационная модель процесса сбора и первичной обработки заявок на обучение с использованием системы имитационного моделирования AnyLogic [100]. Этот продукт пользуется заслуженной популярностью среди специалистов- аналитиков различных предметных областей, так как позволяет получать детальное представление о бизнес-процессах и оптимизировать их. Имитационная модель затрагивала только деятельность инженера по кадрам УНЦ, обязанностью которого является обработка заявок и документационное сопровождение образовательного процесса. Кроме того, из процесса обработки заявок в имитационную модель были включены только ряд задач - проверка почтового ящика на наличие заявок на обучение, открытие писем и проверка правильности оформления заявки согласно принятым в УНЦ шаблонам, распечатка правильно оформленных заявок и отправка сотруднику УНЦ неверно оформленных заявок для дальнейшего принятия решений и связи с заказчиком обучения. Основные параметры моделирования приведены в табл. 2.5.

Количественные оценки времени, необходимого для решения вышеуказанных задач, получены методом наблюдения и хронометража в течение 1 месяца.

Таблица 2.5

Параметры имитационной модели процесса обработки заявок

\begin{tabular}{|l|c|}
\hline \multicolumn{1}{|c|}{ Параметр } & Значение \\
\hline Количество обучаемых & 5000 чел. \\
\hline Количество инженеров по кадрам, обрабатывающих заявки & 3 чел. \\
\hline Минимальное время обработки одной заявки & 2,5 мин. \\
\hline Максимальное время обработки одной заявки & 9 мин. \\
\hline Среднее время обработки одной заявки & 6 мин. \\
\hline
\end{tabular}

На основании исходных данных в среде AnyLogic была построена имитационная модель (рис. 2.23). Результаты имитационного моделирования показали, что для обработки заданного количества заявок потребуется примерно 563 часа. 


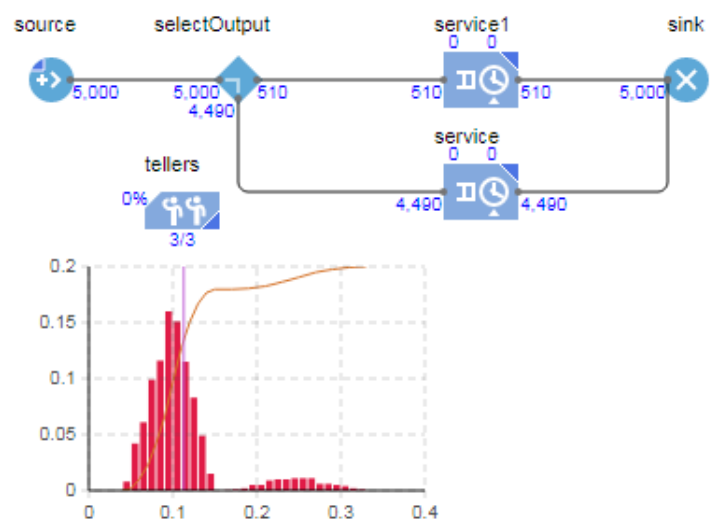

Время работы инженеров 0.11

timelnSystemDistr

Макс $\quad 0.329$

Среднеквадр. отклонение 0.051

Доверит. интервал для среднего 0.001

Cyмua $\quad 562.946$

Рис. 2.23. Модель обработки заявок на обучение при участии трех сотрудников

Для оценки возможности и целесообразности применения программного робота была разработана модель обработки заявок с его участием. В модели были приняты следующие допущения (табл. 2.6).

Таблица 2.6

Параметры имитационной модели процесса обработки заявок с участием программного робота

\begin{tabular}{|l|c|}
\hline \multicolumn{1}{|c|}{ Параметр } & Значение \\
\hline Количество обучаемых & 5000 чел. \\
\hline Минимальное время обработки одной заявки роботом & 0,8 мин \\
\hline Максимальное время обработки одной заявки роботом & 3,5 мин \\
\hline Среднее время обработки одной заявки роботом & 1,5 мин \\
\hline
\end{tabular}

Результаты имитационного моделирования показали, что для обработки заданного количества заявок программным роботом потребуется примерно 162 часа (рис. 2.24). 

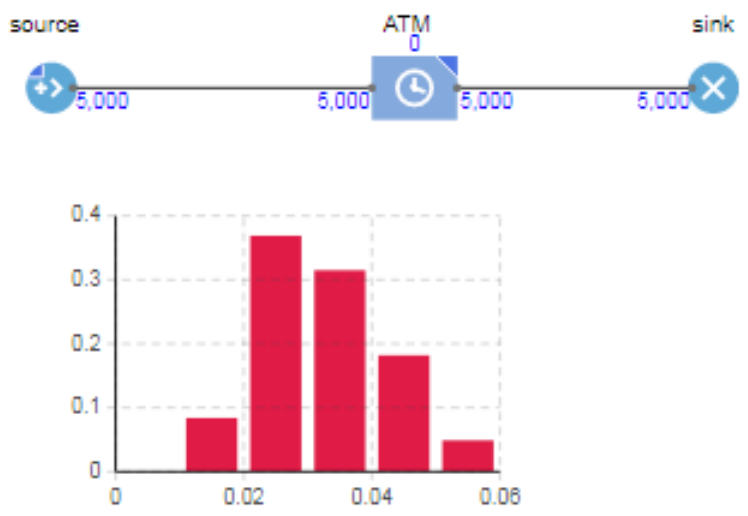

Время работы робота 0.03

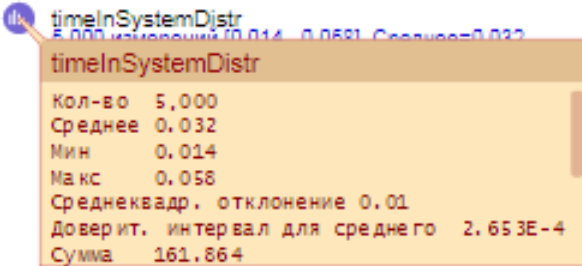

Рис. 2.24. Модель обработки заявок на обучение с использованием программного робота

Для программирования робота целесообразно использовать правила, отнесенные к рассматриваемой области знаний и группе процессов управления инновационным проектом, содержащиеся в базе знаний интегрированной онтологии. Согласно разработанному подходу к классификации знаний в базе знаний ИСППР (см. рис. 2.13) процессы организации обучения сотрудников связаны с областью знаний по управлению ресурсами проекта, относящейся к третьей группе и охватывающей группы процессов планирования, исполнения, а также процессы мониторинга и контроля проекта. Как уже было отмечено ранее, знания в этих областях необходимы для решения реальных задач, ежедневно возникающих в ходе выполнения проекта.

Однако, в ходе анализа процесса было установлено, что обработка заявок только лишь программным роботом нецелесообразна, так как 
были выявлены случаи возникновения проблемных ситуаций, с которыми робот справиться не может. К ним относятся: нарушение заказчиком правил оформления и подачи заявок, отсутствие четких правил формирования групп в случае совмещения очной и дистанционной формы обучения слушателей в одной программе обучения, сбои программного обеспечения и вычислительной техники.

В данных случаях специалистам УНЦ также предлагается обращаться к базе знаний интегрированной онтологии для изучения имеющихся прецедентов принятия решений. Формализация описаний ситуаций в онтологической базе прецедентов отражает накопленный опыт принятия решений в рассматриваемой области знаний в ходе реализации инновационных проектов в рамках сложных производственноэкономических систем.

В ходе исследований было установлено, что примерно $10 \%$ от общего числа заявок требует дополнительного времени на обработку, связанного с решением возникающих проблем. Причем потребовавшееся дополнительное время на решение проблемы зависит от ее тяжести и находится в довольно широком диапазоне - от нескольких минут до нескольких дней. Для оценки времени выполнения процесса была разработана гибридная имитационная модель с совместным участием программного робота и сотрудника УНЦ (рис. 2.25). В модели были приняты допущения, аналогичные приведенным в таблицах 2.5 и 2.6. Результаты имитационного моделирования при условии, что $10 \%$ всех заявок являются проблемными и передаются на обработку сотруднику УНЦ, показали сокращение времени выполнения процесса до 437 часов.

Для уточнения деталей и описания конкретных шагов алгоритма работы программного робота была построена $B P M N$-модель предлагаемого бизнес-процесса «Оформление заявки», в которой было отмечено - какие задачи передаются программному роботу, а какие решения могут быть приняты только человеком (рис. 2.26).

Анализ содержания бизнес-процесса и его имитационное моделирование показало, что оптимальным вариантом его реализации является совмещение деятельности 2 сотрудников УНЦ и программного робота. Выделение 2 сотрудников УНЦ обусловлено характером возникающих проблемных ситуаций: часть их связана с нарушением регламента, а часть - сбоями в работе программно-аппаратного комплекса. 

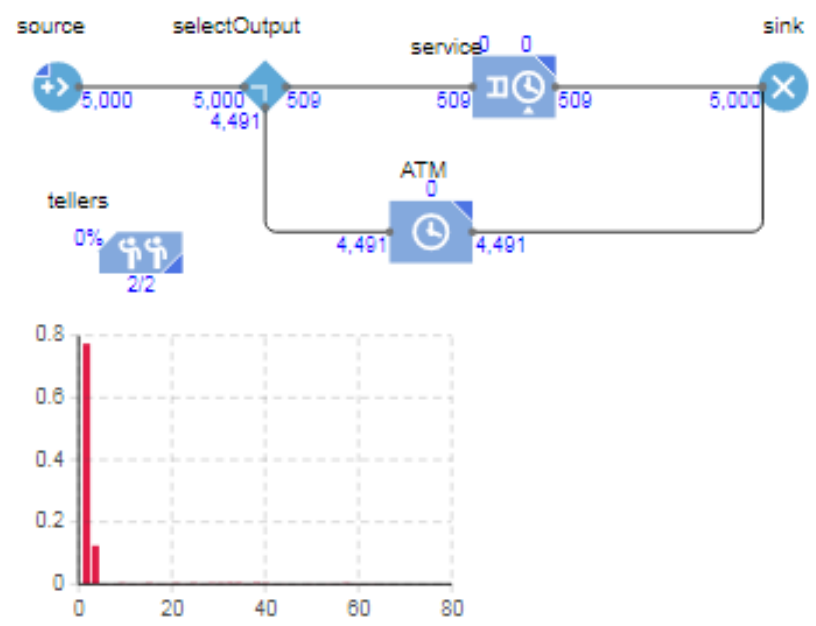

Общцее время работы 5.24

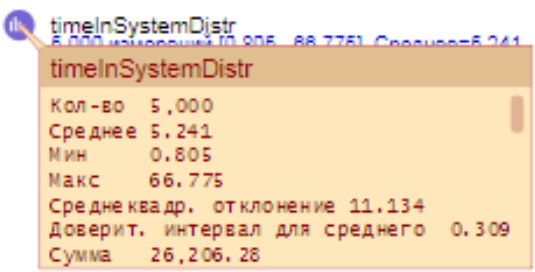

Рис. 2.25. Гибридная имитационная модель обработки заявок на обучение с использованием программного робота и сотрудника УНЦ

Имитационное моделирование проводится для определения частоты проблемных ситуаций, приводящих к привлечению специалистов для решения вопроса, с которым не справился программный робот. Тщательное изучение и формализация описаний проблемных ситуаций позволит обучить робота необходимым действиям и расширит круг его применения. Описание проблемных ситуаций предполагает фиксацию события, приводящего к остановке бизнес-процесса, выявление причин возникновения этого события и (в зависимости от причины) определение тактики по устранению проблемы, а также возможные состояния бизнес-процесса после применения управляющих воздействий. 
Л.Р. Черняховская, В.И. Васильев, В.Е. Гвоздев, Н.О. Никулина, А.И. Малахова, А.М. Вульфин, О.Я. Бежаева

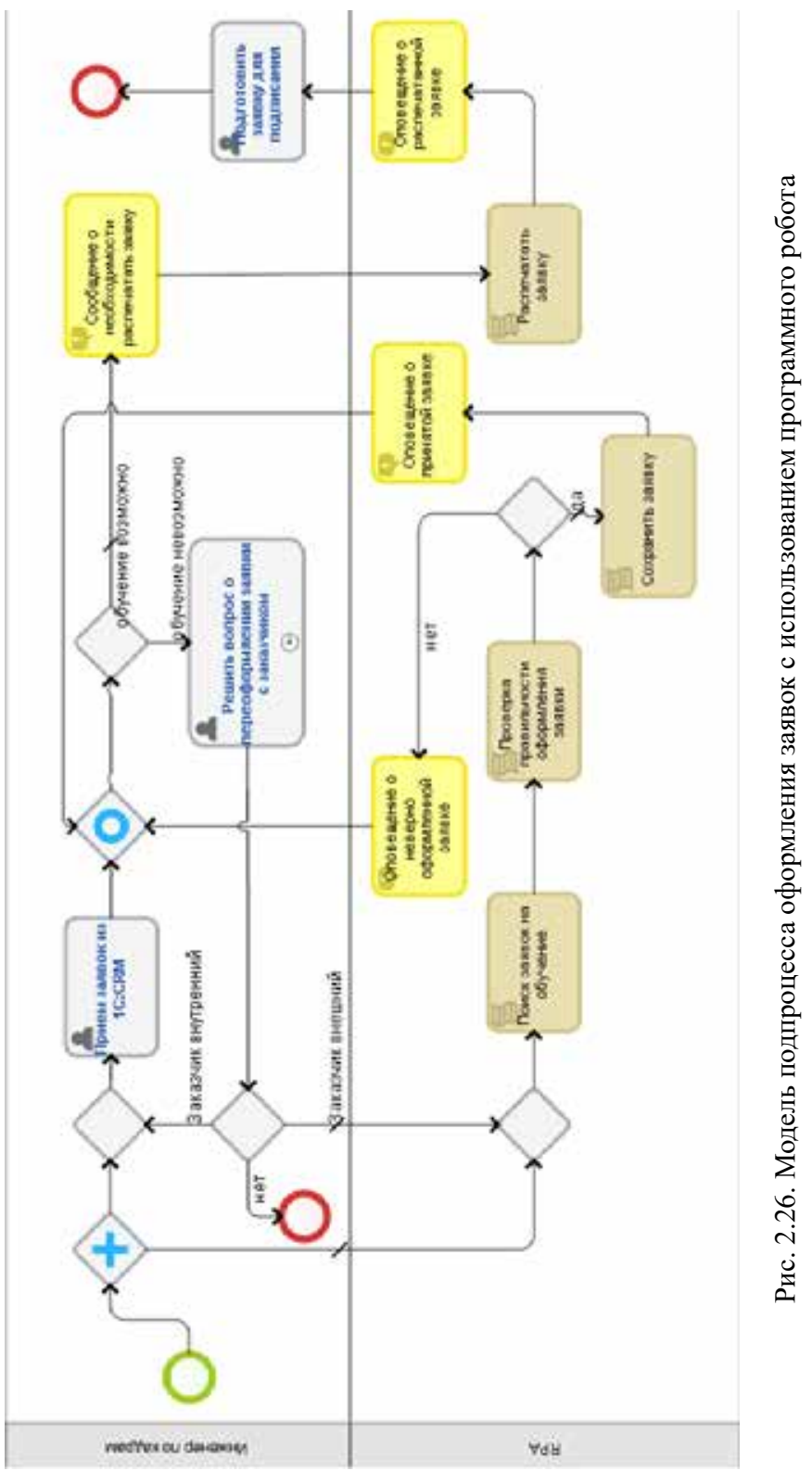


Для формализованного описания проблемных ситуаций используются методы инженерии знаний, в частности онтологический анализ предметной области, дающий возможность сформировать правила принятия решений на основании возникавших ранее прецедентов.

Инновационное проектирование включает множество областей знаний, где появляется возможность передачи функций человека программным роботам. Помимо рассмотренного процесса обработки заявок на обучение, такими претендентами на автоматизацию оказываются процессы формализованного взаимодействия с поставщиками, контроля и мониторинга проектных ресурсов и рисков, формирования отчетности на том или другом этапе реализации инновационного проекта. 


\section{ГЛАВА 3 \\ АНАЛИЗ И УПРАВЛЕНИЕ РИСКАМИ ИННОВАЦИОННЫХ ПРОЕКТОВ И ПРОМЫШЛЕННЫХ ОБЪЕКТОВ С ПОМОЩЬЮ ТЕХНОЛОГИЙ КОГНИТИВНОГО МОДЕЛИРОВАНИЯ}

\section{1 Моделирование процессов управления инновационной деятельностью в регионе с применением нечетких когнитивных карт}

Необходимость создания и развития инновационного пространства [101] как системной формы организации объектов инновационной деятельности, включающей научно-образовательные и производственные направления, нашла отражение в национальном проекте «Наука», разработанном на основе Указа Президента РФ от 7 мая 2018 г. № 204. В нем установлены сроки реализации национального проекта, перечень мероприятий, целевые показатели и объемы финансирования для реализации в 2019-2024 гг. трех федеральных проектов:

- развитие научной и научно-производственной кооперации;

- развитие передовой инфраструктуры для проведения исследований и разработок в Российской Федерации;

- развитие кадрового потенциала в сфере исследований и разработок.

В рамках данного проекта запланировано создание 15 научно-образовательных центров мирового уровня в регионах РФ. Научно-образовательный центр (НОЦ) представляет собой структурное подразделение научной, научно-производственной или образовательной организации, осуществляющее проведение исследований по общему научному направлению, подготовку кадров высшей научной квалификации [102]. Процедура создания НОЦ представлена в Постановлении Правительства Российской Федерации от 30 апреля 2019 г. № 537 «О мерах государственной поддержки создания и развития научно-образовательных центров мирового уровня на основе интеграции образовательных организаций высшего образования и научных организаций и их кооперации с организациями, действующими в реальном 
секторе экономики». Разработаны методические рекомендации по формированию программ деятельности НОЦ [103].

Распоряжением Правительства Республики Башкортостан от 17 июля 2019 г. № 748-р установлены процессы концептуализации, структурирования и развертывания Евразийского НОЦ «Цифровые технологии и новые материалы для повышения эффективности добычи, транспорта и глубокой переработки углеводородного сырья» в регионе. Основная задача, поставленная перед Евразийским НОЦ, - систематизация и актуализация знаний с целью решения задач реального сектора экономики, науки и образования Республики Башкортостан.

Исследовательские миссии Евразийского НОЦ:

- биомедицина, генетика и органика;

- энергетика и цифровые сети;

- цифровая «зеленая» химия;

- инжиниринг и передовые производственные технологии.

Евразийский НОЦ рассматривается как площадка для реализации инновационных проектов, направленных на опережающее развитие региона, и включает компоненты, представленные на рис. 3.1.

Постановлением [104] утверждены Правила предоставления грантов из федерального бюджета в форме субсидий на государственную поддержку НОЦ. Оценка эффективности формирования и развития НОЦ должна выполняться на основе набора целевых показателей, характеризующих каждую структурную компоненту. Предполагается построение качественных и количественных моделей, отражающих зависимости целевых показателей от комплекса факторов, влияющих на эффективность функционирования структурных подразделений и НОЦ в целом. Применение подобных моделей позволит решать задачи повышения эффективности управления и оптимизации финансовых ресурсов (выполнять финансовое планирование) НОЦ.

Перспективным способом учета неопределенности факторов, влияющих на целевые показатели, является применение когнитивного моделирования с помощью нечетких когнитивных карт (НКК) для оказания поддержки принятия решений в задачах управления и оптимизации деятельности НОЦ. Достоинствами методов когнитивного моделирования на основе НКК являются их интерпретируемость и наглядность, возможность выявления и описания структуры причинноследственных связей между элементами сложной системы в условиях неопределенности условий решаемой задачи. 


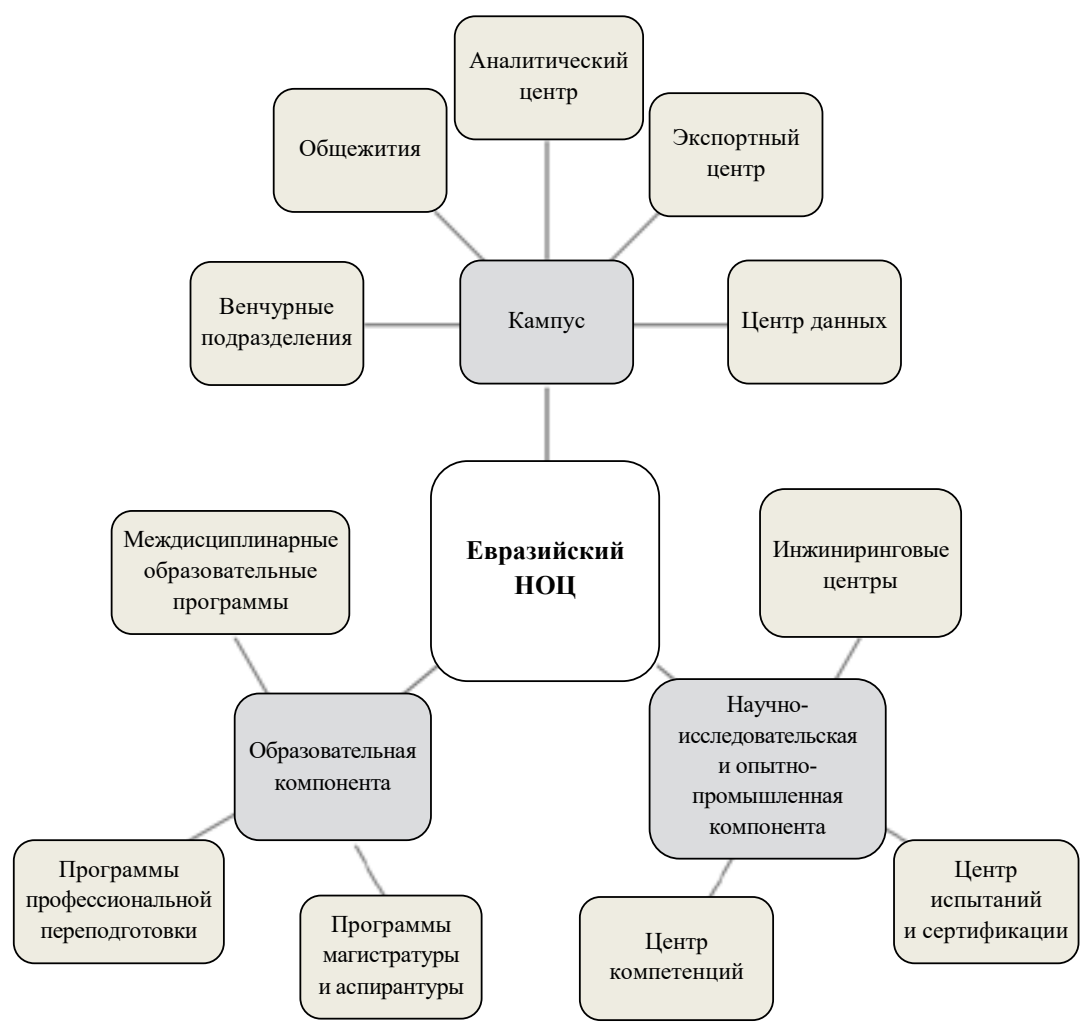

Рис. 3.1. Структурные компоненты Евразийского НОЦ

Далее рассмотрим процесс построения НКК как инструмента моделирования с целью анализа и управления деятельностью Евразийского НОЦ.

Согласно определению Б. Коско [105], нечеткая когнитивная карта - это ориентированный граф, заданный с помощью кортежа:

$$
\mathrm{HKK}=<C, F, W>\text {, }
$$

где $C=\left\{C_{i}\right\}-$ множество концептов (вершин графа) - ключевых факторов, характеризующих деятельность НОЦ; $F=\left\{F_{k}\right\}$ - множество направленных дуг графа - связей между концептами; $W=\left\{W_{i j}\right\}-$ множество весов связей НКК, которые могут быть как положительными 
$\left(W_{i j}>0\right)$, так и отрицательными $\left(W_{i j}<0\right)$, т. е. «усиливающими» или «ослабляющими» влияние концепта $C_{i}$ на концепт $C_{j}$.

Значения весов (силы связей) $W_{i j}$ задаются с помощью нечеткой лингвистической шкалы. Каждому значению лингвистической переменной при этом ставится в соответствие некоторый числовой диапазон, принадлежащий интервалу $[0,1]$ для положительных связей (табл. 4.1) или интервалу $[-1,0]$ для отрицательных связей.

Т а бли ц а 3.1

Оценка силы связей между концептами

\begin{tabular}{|l|l|c|c|}
\hline \multicolumn{1}{|c|}{$\begin{array}{c}\text { Сила связи } \\
\text { (лингвистическое значение) }\end{array}$} & \multicolumn{1}{|c|}{$\begin{array}{c}\text { Обозначение } \\
\text { терма }\end{array}$} & $\begin{array}{c}\text { Числовой } \\
\text { диапазон }\end{array}$ & $\begin{array}{c}\text { Точечная } \\
\text { оценка }\end{array}$ \\
\hline Не_влияет & $Z($ Zero $)$ & 0 & 0 \\
\hline Очень_слабо_влияет & $V L($ Very Low $)$ & $(0 ; 0,2]$ & 0,1 \\
\hline Слабо_влияет & $L($ Low $)$ & $(0,2 ; 0,4]$ & 0,3 \\
\hline Средне_влияет & $M($ Medium $)$ & $(0,4 ; 0,6]$ & 0,5 \\
\hline Сильно_влияет & H(High) & $(0,6 ; 0,8]$ & 0,7 \\
\hline Очень_сильно_влияет & VH(Very High) & $(0,8 ; 1]$ & 0,9 \\
\hline
\end{tabular}

Состояния концептов $C_{i}$ определяются нормированными (безразмерными) переменными $X_{\mathrm{i}}[0,1]$ :

$$
X_{i}=\frac{\tilde{X}_{i}-\tilde{X}_{i \min }}{\tilde{X}_{i \max }-\tilde{X}_{i \min }}, i=1,2, \ldots, n,
$$

где $\tilde{X}_{i \min }$ и $\tilde{X}_{i \max }$ соответственно базовые минимальное и максимальное значения исходной переменной $\tilde{X}_{i} \in\left[\tilde{X}_{i \min }, \tilde{X}_{i \max }\right]$, характеризующей состояние концепта $C_{i}$.

Обобщенная нечеткая когнитивная карта для моделирования процессов оптимизации и управления деятельностью НОЦ представлена на рис. 3.2.

Основные концепты когнитивной карты приведены в табл. 3.2.

Таблица включает следующие группы концептов, сформированные на основе [103], анализа развития региональных инновационных проектов [106, 107] и отчета о деятельности созданных НОЦ [108]:

- концепт-драйвер $C_{1}$, который характеризует исходное финансирование проекта; 
- концепты слоя «Финансовые ресурсы», характеризующие распределение финансирования по основным структурным компонентам НОЦ (концепты $C_{2}-C_{9}$ );

- концепты слоя «Инструменты и средства реализации», они характеризуют основные способы и средства реализации программы деятельности НОЦ всеми участниками программы $\left(C_{10}-C_{19}\right)$;

- концепты слоя «Целевые индикаторы», которые характеризуют каждую структурную компоненту НОЦ и являются формальными показателями, по которым осуществляется отчетность о реализации программы (концепты $C_{20}-C_{28}$ );

- концепты слоя «Интегральные целевые индикаторы», которые позволяют комплексно оценить степень реализации научного, кадрового и инновационно-промышленного потенциала НОЦ (концепты $C_{29}-C_{31}$ );

- выходной концепт НКК «Эффективность деятельности НОЦ», который является комплексным индикатором, позволяющим оценить деятельность НОЦ в целом (концепт $C_{32}$ ).

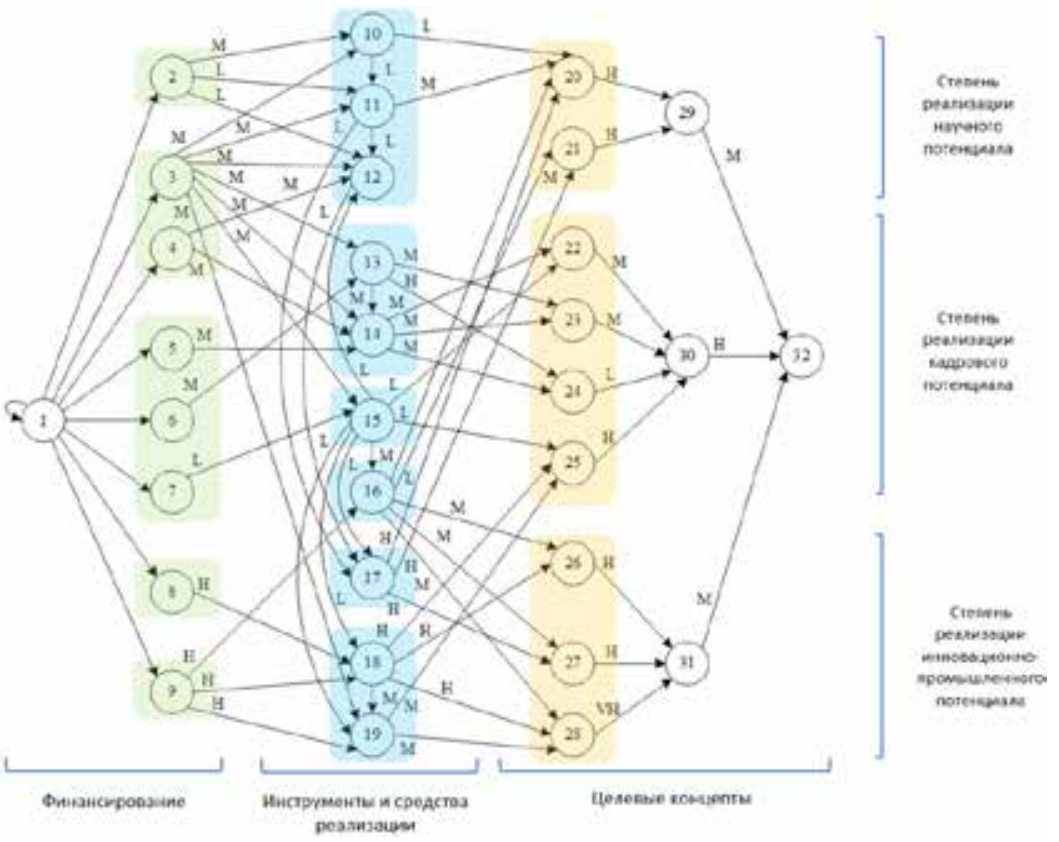

Рис. 3.2. Когнитивная карта для моделирования процессов оптимизации и управления деятельностью НОЦ 
Список концептов когнитивной карты

\begin{tabular}{|c|c|c|c|}
\hline № & Концепт & $\begin{array}{c}\text { Единица } \\
\text { измерения }\end{array}$ & $\begin{array}{c}\text { Группа } \\
\text { концептов }\end{array}$ \\
\hline 1 & $\begin{array}{l}\text { Финансовое обеспечение программы дея- } \\
\text { тельности центра за счет средств гранта }\end{array}$ & млн. руб. & - \\
\hline 2 & Оплата патентных сервисов & млн. руб. & $\begin{array}{l}\text { «Финансирование } \\
\text { патентных сервисов» } \\
(\text { Группа } 1)\end{array}$ \\
\hline 3 & $\begin{array}{l}\text { Оплата труда работников (участников) } \\
\text { центра }\end{array}$ & \multirow[t]{2}{*}{ млн. руб. } & \multirow{2}{*}{$\begin{array}{l}\text { «Оплата труда и } \\
\text { командировки» } \\
\text { (Группа 2) }\end{array}$} \\
\hline 4 & $\begin{array}{l}\text { Транспортные и командировочные расхо- } \\
\text { ды работников (участников) центра }\end{array}$ & & \\
\hline 5 & $\begin{array}{l}\text { Оплата стажировок и освоения дополни- } \\
\text { тельных профессиональных программ }\end{array}$ & \multirow[t]{3}{*}{ млн. руб. } & \multirow{3}{*}{$\begin{array}{l}\text { «Финансирование } \\
\text { совершенствования } \\
\text { образовательных } \\
\text { программ» } \\
\text { (Группа 3) }\end{array}$} \\
\hline 6 & $\begin{array}{l}\text { Разработка и внедрение образовательных } \\
\text { и дополнительных профессиональных про- } \\
\text { грамм, реализация мер по академической } \\
\text { мобильности, привлечение молодых иссле- } \\
\text { дователей и педагогических работников }\end{array}$ & & \\
\hline 7 & $\begin{array}{l}\text { Содержание и деятельность Центра раз- } \\
\text { вития компетенций руководителей проек- } \\
\text { тов и лабораторий }\end{array}$ & & \\
\hline 8 & $\begin{array}{l}\text { Мероприятия, связанные с развитием ин- } \\
\text { фраструктуры Центра }\end{array}$ & млн. руб. & $\begin{array}{l}\text { «Финансирование } \\
\text { развития } \\
\text { инфраструктуры» } \\
\text { (Группа 4) } \\
\end{array}$ \\
\hline 9 & $\begin{array}{l}\text { Приобретение изделий, комплектующих, } \\
\text { материалов, оборудования, ПО }\end{array}$ & млн. руб. & $\begin{array}{l}\text { «Финансирование } \\
\text { развития } \\
\text { материальной базы» } \\
\text { (Группа 5) }\end{array}$ \\
\hline 10 & $\begin{array}{l}\text { Ведение реестра результатов интеллекту- } \\
\text { альной деятельности }\end{array}$ & \multirow{3}{*}{$\begin{array}{c}\text { Экспертная } \\
\text { оценка } \\
{[0 ; 1]}\end{array}$} & \multirow{3}{*}{$\begin{array}{l}\text { «Правовая поддержка } \\
\text { и сопровождение } \\
\text { интеллектуальной } \\
\text { деятельности» } \\
\text { (Группа 6) }\end{array}$} \\
\hline 11 & $\begin{array}{l}\text { Информационная и консультационная } \\
\text { поддержка по вопросам сертификации } \\
\text { и стандартизации }\end{array}$ & & \\
\hline 12 & $\begin{array}{l}\text { Мероприятия, направленные на поддерж- } \\
\text { ку экспорта }\end{array}$ & & \\
\hline
\end{tabular}


Продолжение табл. 3.2

\begin{tabular}{|c|c|c|c|}
\hline № & Концепт & $\begin{array}{c}\text { Единица } \\
\text { измерения }\end{array}$ & $\begin{array}{c}\text { Группа } \\
\text { концептов }\end{array}$ \\
\hline 13 & $\begin{array}{l}\text { Разработка и внедрение образовательных } \\
\text { и дополнительных профессиональных } \\
\text { программ }\end{array}$ & \multirow{2}{*}{$\begin{array}{c}\text { Экспертная } \\
\text { оценка } \\
{[0 ; 1]}\end{array}$} & \multirow{2}{*}{$\begin{array}{l}\text { «Совершенствование } \\
\text { образовательных } \\
\text { программ» } \\
\text { (Группа 7) }\end{array}$} \\
\hline 14 & $\begin{array}{l}\text { Реализация программ академической мо- } \\
\text { бильности, мер по привлечению моло- } \\
\text { дых исследователей и педагогических } \\
\text { работников }\end{array}$ & & \\
\hline 15 & $\begin{array}{l}\text { Создание и функционирование центров } \\
\text { развития компетенций руководителей } \\
\text { проектов и лабораторий }\end{array}$ & $\begin{array}{c}\text { Экспертная } \\
\text { оценка } \\
{[0 ; 1]}\end{array}$ & $\begin{array}{l}\text { «Развитие центров } \\
\text { компетенций» } \\
(\text { Группа } 8)\end{array}$ \\
\hline 16 & $\begin{array}{l}\text { Участие в реализации комплексных науч- } \\
\text { но-технических проектов (НТП) и про- } \\
\text { грамм инновационного цикла }\end{array}$ & $\begin{array}{c}\text { Экспертная } \\
\text { оценка } \\
{[0 ; 1]}\end{array}$ & $\begin{array}{l}\text { «Реализация } \\
\text { комплексных НТП» } \\
(\text { Группа 9) }\end{array}$ \\
\hline 17 & $\begin{array}{l}\text { Коммерциализация результатов интеллек- } \\
\text { туальной деятельности и увеличения объ- } \\
\text { ема высокотехнологичной продукции }\end{array}$ & $\begin{array}{c}\text { Экспертная } \\
\text { оценка } \\
{[0 ; 1]}\end{array}$ & $\begin{array}{l}\text { «Коммерциализация } \\
\text { результатов } \\
\text { интеллектуальной } \\
\text { деятельности» } \\
(\text { Группа 10) } \\
\end{array}$ \\
\hline 18 & $\begin{array}{l}\text { Формирование и использование научной, } \\
\text { производственной и технологической ин- } \\
\text { фраструктуры Центра }\end{array}$ & \multirow[t]{2}{*}{$\begin{array}{c}\text { Экспертная } \\
\text { оценка } \\
{[0 ; 1]}\end{array}$} & \multirow[t]{2}{*}{$\begin{array}{l}\text { «Совершенствование } \\
\text { инфраструктуры» } \\
\text { (Группа 11) }\end{array}$} \\
\hline 19 & Предоставление инжиниринговых услуг & & \\
\hline 20 & Количество патентов на изобретения & \multirow[t]{2}{*}{ ед. } & \multirow{2}{*}{$\begin{array}{l}\text { «Публикационная } \\
\text { активность» } \\
\text { (Группа 12) }\end{array}$} \\
\hline 21 & $\begin{array}{l}\text { Количество статей в областях в научных } \\
\text { изданиях, индексируемых в международ- } \\
\text { ных базах данных Scopus и Web of Science }\end{array}$ & & \\
\hline 22 & $\begin{array}{l}\text { Доля исследователей в возрасте до } 39 \text { лет } \\
\text { в общей численности исследователей }\end{array}$ & $\%$ & \multirow[t]{2}{*}{$\begin{array}{l}\text { «Кадровая база» } \\
(\text { Группа 13) }\end{array}$} \\
\hline 23 & $\begin{array}{l}\text { Доля работников, прошедших обучение } \\
\text { по дополнительным профессиональным } \\
\text { программам }\end{array}$ & $\%$ & \\
\hline 24 & $\begin{array}{l}\text { Количество иногородних и иностранных } \\
\text { студентов, обучающихся по образователь- } \\
\text { ным программам высшего образования }\end{array}$ & чел. & \multirow[t]{2}{*}{$\begin{array}{l}\text { «Кадровая база» } \\
(\text { Группа 13) }\end{array}$} \\
\hline 25 & $\begin{array}{l}\text { Количество новых высокотехнологиче- } \\
\text { ских рабочих мест }\end{array}$ & ед. & \\
\hline
\end{tabular}


Окончание табл. 3.2

\begin{tabular}{|c|c|c|c|}
\hline № & Концепт & $\begin{array}{c}\text { Единица } \\
\text { измерения }\end{array}$ & $\begin{array}{c}\text { Группа } \\
\text { концептов }\end{array}$ \\
\hline 26 & $\begin{array}{l}\text { Объем работ и услуг, завершившихся из- } \\
\text { готовлением и испытаниями опытного } \\
\text { образца }\end{array}$ & млн. руб. & \multirow[t]{3}{*}{$\begin{array}{l}\text { «Инновационная } \\
\text { активность» } \\
\text { (Группа } 14)\end{array}$} \\
\hline 27 & $\begin{array}{l}\text { Количество разработанных и переданных } \\
\text { для внедрения в производство проектов }\end{array}$ & ед. & \\
\hline 28 & $\begin{array}{l}\text { Доля новой и усовершенствованной вы- } \\
\text { сокотехнологичной продукции в объеме } \\
\text { отгруженной продукции }\end{array}$ & $\%$ & \\
\hline 29 & $\begin{array}{l}\text { Степень реализации научного потенциала } \\
\text { НОЦ }\end{array}$ & $\%$ & - \\
\hline 30 & $\begin{array}{l}\text { Степень реализации кадрового потенциа- } \\
\text { ла НОЦ }\end{array}$ & $\%$ & - \\
\hline 31 & $\begin{array}{l}\text { Степень реализации инновационно-про- } \\
\text { мышленного потенциала НОЦ }\end{array}$ & $\%$ & - \\
\hline 32 & Эффективность деятельности НОЦ & $\%$ & - \\
\hline
\end{tabular}

Будем полагать далее, что целью моделирования с помощью НКК является анализ эффективности распределения финансовых ресурсов, а также способов и средств реализации программы деятельности НОЦ с учетом требований существующих нормативных документов. Задача анализа процессов управления деятельностью НОЦ с помощью НКК решается при этом в 2 этапа, с использованием двух вариантов НКК.

Эman 1. Производится экспертная оценка степени взаимного влияния концептов НКК друг на друга, т. е. весов связей НКК на рис. 3.2. Предполагается, что значения весов связей $W_{1, j},(j=1,2, \ldots, 9)$, характеризующих способ распределения выделенных финансовых ресурсов, а также состояния целевых индикаторов (концепты $C_{20}-C_{28}$ ), выбираются с учетом требований федеральных органов, регламентирующих деятельность НОЦ. В данном случае полагаем, что веса связей $W_{i, j}$, $(j=2,3, \ldots, 9)$ принимают одинаковые значения «Средне_влияет», т. е. $W_{1,2}=W_{1,3}=\ldots=W_{1,9}=0,5$ Лингвистические значения весов других связей НКК, определенные экспертами в ходе проведения форсайт-сессий, указаны на рис. 3.2 (соответствующие точечные значения этих весов приведены в табл. 3.1). 
Уравнения динамики НКК, характеризующие изменение переменных состояния $X_{i}$ во времени, принимают вид:

$$
X_{i}(t+1)=f\left(X_{i}(t)+\sum_{j=1}^{31} W_{j i} X_{j}(t)\right), \quad i=2,3, \ldots, 32,
$$

где $t=0,1,2, \ldots$ - дискретное время; $f($.$) - функция гиперболического$ тангенса, принимающая значения в интервале $[0,1)$ при $S_{i} \geq 0$ :

$$
f\left(S_{i}\right)=\left(1-e^{-S_{i}}\right) /\left(1+e^{-S_{i}}\right) .
$$

Начальные условия: $X_{1}(0)=1 ; X_{2}(0)=\ldots=X_{32}(0)=0$.

Результаты расчетов с помощью уравнения (3.3) представлены на рис. 3.3, где по оси ординат отложены значения переменных состояния НКК, а по оси абсцисс - дискретное время (в месяцах календарного года).

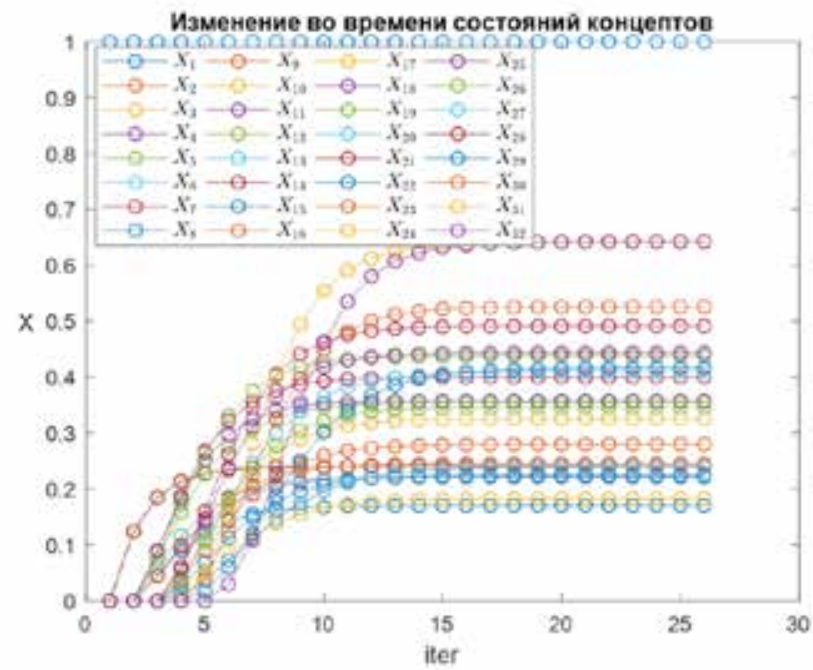

Рис. 3.3. Изменение во времени переменных состояния концептов НКК

Как следует из рис. 3.3, установившиеся (максимальные) значения целевых показателей $X_{29}^{*}, X_{30}^{*}, X_{31}^{*}$ соответственно равны 0,$416 ; 0,526$ и 0,641 , а общий показатель эффективности $X_{32}^{*}$ достигает значения 0,643 . Время установления переходных процессов $t_{\text {уст }}=18$ мес. 
Эman 2. Рассмотрим на данном этапе задачу оптимизации весов $W_{1, j},(j=2,3, \ldots, 9)$ НКК, отвечающих за распределение финансовых ресурсов между различными направлениями деятельности НОЦ. Будем полагать, что целевая функция $J(W)$ в данном случае принимает вид:

$$
J(W)=X_{32}^{*} \rightarrow \max ,
$$

где $X_{32}^{*}$ - установившееся значение переменной $X_{32}$, т. е. результирующий показатель эффективности НОЦ; $W=\left(W_{1,2}, W_{1,3}, \ldots, W_{1,2}\right)^{T}-$ вектор весов указанных связей НКК (веса остальных связей НКК полагаем неизменными).

Для решения задачи воспользуемся генетическим алгоритмом (ГА). Обозначим полученную НКК как НКК + ГА. Значения весов $W_{1, j}$, $(j=2,3, \ldots, 9)$, полученные в результате решения задачи оптимизации, приведены в табл. 3.3.

Та блица 3.3

Веса связей НКК + ГА между концептами $C_{1}$ и $C_{2}-C_{9}$ после применения ГА

\begin{tabular}{|l|c|c|c|c|c|c|c|c|}
\hline \multicolumn{1}{|c|}{ Вес связи } & $\boldsymbol{W}_{\mathbf{1 2}}$ & $\boldsymbol{W}_{\mathbf{1 3}}$ & $\boldsymbol{W}_{14}$ & $\boldsymbol{W}_{15}$ & $\boldsymbol{W}_{\mathbf{1 6}}$ & $\boldsymbol{W}_{17}$ & $\boldsymbol{W}_{\mathbf{1 8}}$ & $\boldsymbol{W}_{\mathbf{1 9}}$ \\
\hline Лингвистическое значение & $V H$ & $M$ & $V L$ & $V H$ & $L$ & $V L$ & $V H$ & $V L$ \\
\hline Численное значение & 0,125 & 0,975 & 0,429 & 0,975 & 0,125 & 0,125 & 0,555 & 0,498 \\
\hline
\end{tabular}

Результаты моделирования НКК + ГА приведены на рис. 3.4.

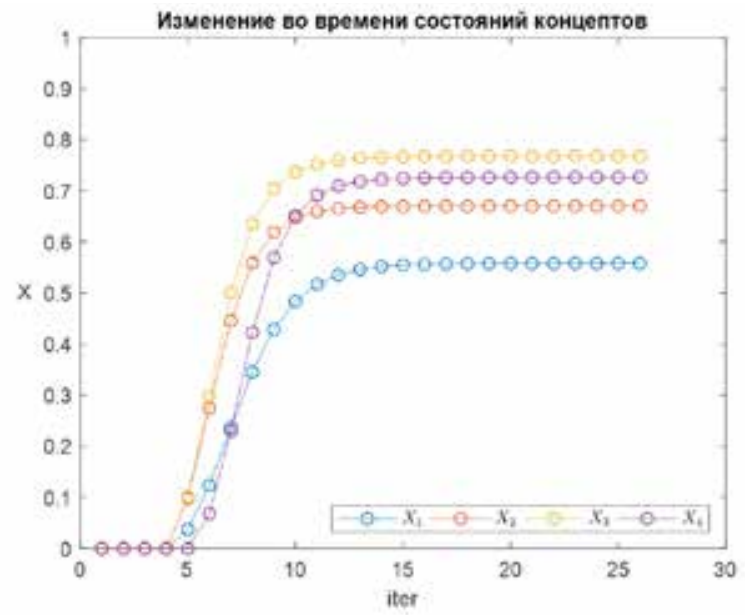

Рис. 3.4. Изменение во времени состояний концептов НКК + ГА 
Как видно из рис. 3.4, установившиеся значения целевых показателей $X_{29}^{*}, X_{30}^{*}, X_{31}^{*}, X_{32}^{*}$ составляют соответственно 0,$558 ; 0,670 ; 0,768$ и 0,726 , а время установления переходных процессов $t_{\text {уст }}=15$ мес. Следовательно, когнитивное моделирование с учетом оптимизации весовых коэффициентов НКК, обуславливающих распределение финансовых ресурсов, а также способов и средств реализации программы деятельности НОЦ, позволило выявить такой сценарий развития НОЦ, при котором срок выхода на устойчивые показатели сократился на 3 мес., а повышение общей эффективности составило более 8\%. Прирост эффективности по отношению к группам 12 («Публикационная активность»), 13 («Кадровая база») и 14 («Инновационная активность») на основе значений формальных целевых концептов составляет более $25 \%$.

Дополнительные возможности предоставляет анализ структуры графа НКК + ГА (рис. 3.5) с целью выявления наиболее «загруженных» путей от входного концепта-драйвера $C_{1}$ к выходному концепту $C_{32}$, т. е. в конечном итоге тех критических факторов (концептов), которые вносят наиболее весомый вклад в обеспечение достигнутого показателя эффективности $X_{32}^{*}$.

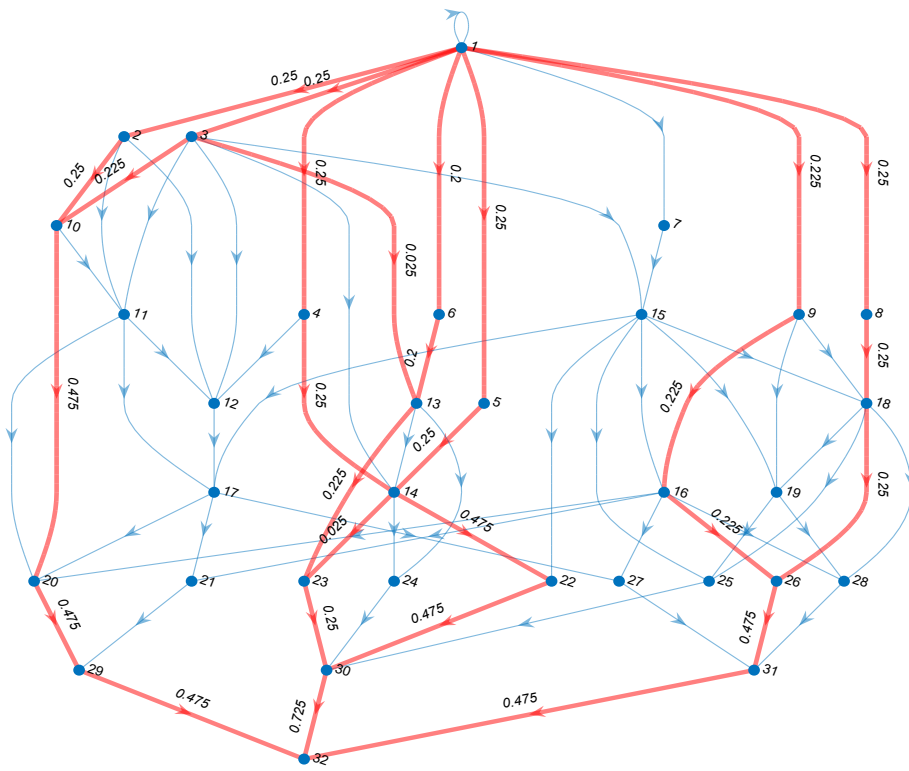

Рис. 3.5. Максимальный поток в графе НКК 
На рис. 3.5 показана карта указанных путей, полученная с помощью алгоритма Форда - Фалкерсона. Как видно из рис. 3.5, ключевыми факторами обеспечения эффективности НОЦ являются группы концептов «Финансирование развития инфраструктуры», «Финансирование развития материальной базы», «Реализация комплексных НТП», «Правовая поддержка и сопровождение этапов интеллектуальной деятельности», «Совершенствование образовательных программ». Ключевыми концептами слоя «Целевые показатели» в порядке убывания значимости являются $C_{26}, C_{20}, C_{22}, C_{23}$.

Таким образом, построение и анализ НКК + ГА позволяет найти сценарий развития НОЦ с наименьшим временем выхода на устойчивые целевые показатели и максимальным значением общего показателя эффективности за счет оптимизации распределения финансовых ресурсов, способов и средств реализации программы деятельности НОЦ. Дополнительный анализ структуры графа НКК + ГА позволяет выделить и ранжировать ключевые факторы обеспечения эффективности НОЦ в слое «Целевые показатели».

\section{2 Анализ рисков инновационных проектов с использованием технологии многослойных нечетких когнитивных карт}

Как уже отмечалось, в последние годы все большее распространение для количественной оценки риска неблагоприятных событий при реализации проекта (инновационных рисков) получили методы когнитивного моделирования, основанные на построении и анализе нечетких когнитивных карт (НКК). Вместе с тем на практике стремление получить достаточно подробное, развернутое описание исследуемой системы приводит к чрезмерному усложнению структуры НКК. В табл. 3.4 приведены известные в литературе примеры построения НКК оценки рисков инновационного проекта (ИП), где в последнем столбце даны значения общего количества концептов НКК и числа связей между ними.

Выходом из сложившейся ситуации является построение НКК в классе многослойных НКК, основанных на декомпозиции исходной (укрупненной) НКК. Такая карта представляется в виде совокупности вложенных друг в друга частных НКК, содержащих локальную информацию о концептах, составляющих исходную НКК [116-119]. 
НКК оценки рисков ИП

\begin{tabular}{|c|l|l|c|}
\hline \multirow{2}{*}{ № } & \multicolumn{1}{|c|}{ Aвторы } & \multicolumn{1}{|c|}{ Назначение НкК } & $\begin{array}{l}\text { Количество } \\
\text { концептов/ } \\
\text { число } \\
\text { связей НКк }\end{array}$ \\
\hline 1 & $\begin{array}{l}\text { Al-Shebab A.J., Hughes R.T., } \\
\text { Winstanley G. [109] }\end{array}$ & $\begin{array}{l}\text { НКК анализа рисков ИП создания } \\
\text { информационных систем }\end{array}$ & $14 / 20$ \\
\hline 2 & $\begin{array}{l}\text { Rodriguez-Repiso L., } \\
\text { Setchi R., Salmeron J.L. [110] }\end{array}$ & $\begin{array}{l}\text { НКК оценки рисков ИП создания } \\
\text { мобильной платежной системы }\end{array}$ & $24 / 35$ \\
\hline 3 & $\begin{array}{l}\text { Миннибаев Д.M., } \\
\text { Зайцева Ж.В. [111] }\end{array}$ & $\begin{array}{l}\text { НКК для управления рисками пред- } \\
\text { приятия строительного комплекса }\end{array}$ & $14 / 25$ \\
\hline 4 & Горелова Г.В. [112] & $\begin{array}{l}\text { НКК анализа механизмов и стра- } \\
\text { тегии развития социально-эконо- } \\
\text { мической системы }\end{array}$ & $34 / 63$ \\
\hline 5 & $\begin{array}{l}\text { Градусов Д.А., } \\
\text { Шутов А.В., } \\
\text { Анцупова Д.П. [113] }\end{array}$ & $\begin{array}{l}\text { НКК механизма внедрения инте- } \\
\text { грированной системы управления } \\
\text { предприятием }\end{array}$ & $28 / 42$ \\
\hline 6 & Сазе D.М., Stylios С.D. [114] & НКК оценки сроков выполнения ИП & 41/102 \\
\hline 7 & $\begin{array}{l}\text { Проценко Е.В., } \\
\text { Александрова А.В. [115] }\end{array}$ & $\begin{array}{l}\text { НКК оценки рисков ИП модифика- } \\
\text { ции продукции при размещении за- } \\
\text { каза авиастроительной компанией }\end{array}$ & $32 / 36$ \\
\hline 8 & $\begin{array}{l}\text { Ковалев С.М., } \\
\text { Колоденкова А.Е. [116] }\end{array}$ & $\begin{array}{l}\text { НКК оценки рисковых ситуаций } \\
\text { на этапе проектирования сложных } \\
\text { технических систем }\end{array}$ & $15 / 36$ \\
\hline
\end{tabular}

Учитывая, что данный этап изложен в литературе достаточно поверхностно, рассмотрим далее подробнее методику построения многослойной НКК. Будем полагать для определенности, что как исходная, так и частные НКК представляют собой нечеткие серые когнитивные карты (НСКК).

\subsection{1. Методика построения многослойных нечетких когнитивных карт}

На практике изучение реального сложного объекта с помощью нечеткого когнитивного моделирования нередко встречается с рядом труднопреодолимых факторов (высокая размерность пространства состояний исследуемой системы, неоднозначность выбора состава кон- 
цептов и выявления наиболее существенных (значимых) связей между ними, неопределенность в оценке силы этих связей и т.д.) - все то, что составляет «проклятие размерности». Попытки разрешить эту ситуацию, как правило, связаны с представлением исходной нечеткой когнитивной карты (НКК) системы в виде совокупности из нескольких, более простых с точки зрения анализа НКК, взаимодействующих между собой по вертикали или по горизонтали. В качестве инструмента для исследования сложных систем при этом применяются такие модификации НКК, как иерархические НКК [120], многоагентные НКК [121], вложенные НКК [119, 122, 123].

Общую идею построения многослойной НКК поясняет рис. 3.6.

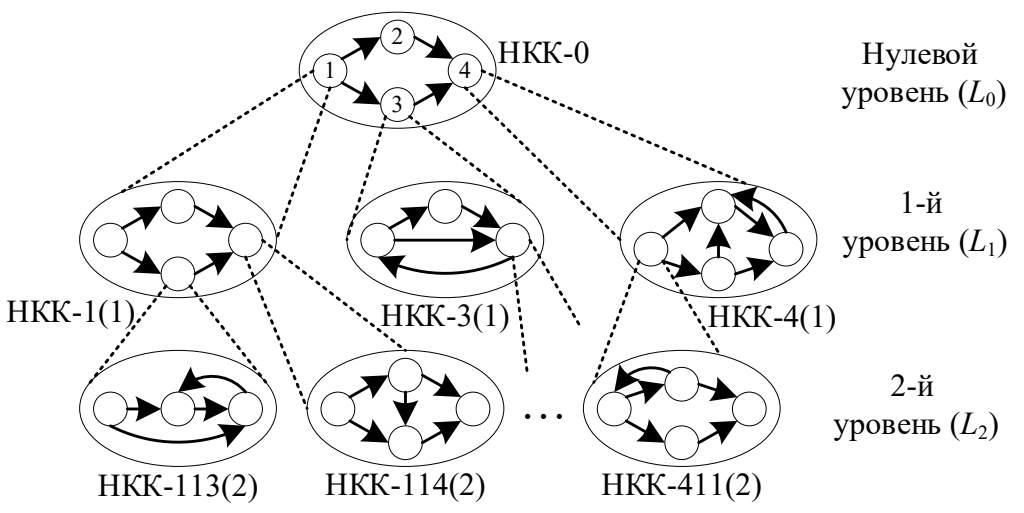

Рис. 3.6. Архитектура многослойной НКК

Здесь НКК-0 - исходная (укрупненная) НКК, соответствующая нулевому (концептуальному) уровню представления исследуемой проблемы; 1, 2, 3, 4 - базовые концепты, образующие исходную НКК-0; НКК-1(1), НКК-3(1), НКК-4(1) - нечеткие когнитивные карты первого уровня декомпозиции исходной нечеткой когнитивной карты НКК-0, раскрывающие содержание (внутреннюю структуру) своих «родительских» концептов 1, 3, 4; НКК-113(2), НКК-114(2), НКК-411(2) - нечеткие когнитивные карты 2-го уровня декомпозиции, раскрывающие (детализирующие) содержание концептов НКК-1(1), НКК-4(1) и т.д. Таким образом, верхний слой (нулевой уровень декомпозиции) НКК-0 отвечает за предоставление глобальной информации об исследуемой 
проблеме, тогда как последующие, нижележащие слои НКК (1-й, 2-й и т.д. уровни) обеспечивают дополнительную, локальную информацию о взаимодействиях и внутренних зависимостях, характеризующих поведение концептов вышележащего уровня («родительских» концептов).

Согласно [119], разбиение НКК на слои (уровни) производится экспертом или группой экспертов таким образом, что каждый слой $\left(L_{i}\right)$ описывает определенный аспект понимания, глубины изучения проблемы и, следовательно, число слоев $(d)$ многослойной НКК будет определяться числом принимаемых во внимание аспектов. В общем виде, многослойная НКК представляет собой многослойный ориентированный граф $G$, определяемый кортежем множеств:

$$
G=\left\{V_{M}, E_{M}, V, L\right\},
$$

где $V_{M}-$ множество вершин графа (концептов НКК), участвующих в формировании слоев в соответствии с принятым способом декомпозиции НКК; $E_{M}-$ множество дуг, связывающих вершины графа (концепты НКК), входящие в $V_{M} ; V$ - множество всех вершин (концептов НКК); $L$ - множество слоев НКК.

В свою очередь, множества $L, V_{M}, E_{M}$ определяются с помощью следующих отношений:

$$
\begin{gathered}
L=\left\{L_{a}\right\}_{a=0}^{d-1}=L_{0} \times L_{1} \times \ldots \times L_{d-1} ; \\
V_{M} \subseteq V \times L_{0} \times L_{1} \times \ldots \times L_{d-1} ; \\
E_{M} \subseteq V_{M} \times V_{M} .
\end{gathered}
$$

Общее количество концептов, входящих в многослойную НКК, равно $\sum_{a=0}^{d-1}\left|L_{a}\right|$, где $\left|L_{a}\right|$ - число концептов, принадлежащих слою $L_{a}$.

Ключевым вопросом построения многослойных НКК является разбиение исходной (укрупненной) НКК на слои, а также изучение взаимодействия между концептами как внутри слоя, так и между слоями. Рассмотрим подробнее методику построения многослойных НКК для анализа рисков ИП, предоставляющую в значительной степени ответы на указанный вопрос.

1. Нулевой уровень декомпозищии (слой $\left.L_{0}\right) H K K$

Составляется исходная (укрупненная) НКК-0, которая включает в себя в качестве концептов наиболее значимые (существенные) факторы рисков ИП с указанием выявленных экспертами взаимосвязей между этими концептами (факторами). 
В качестве рекомендаций общего характера при реализации данного этапа можно воспользоваться информацией, приведенной в [124], а также (с учетом специфики анализа рисков ИП) в [110, 113]. Оценка силы связей НКК-0 при этом является предварительной (приближенной), уточнение силы связей между концептами откладывается до следующего этапа построения НКК.

\section{2. Первый уровень декомпозиции (слой $\left.L_{1}\right) H K K$}

На данном этапе производится «раскрытие» всех или части концептов, входящих в состав укрупненной нечеткой когнитивной карты НКК-0. Рассмотрим, как это делается, на следующем примере. Допустим, что некоторый концепт $C_{1}$, принадлежащий НКК-0, реализует причинноследственную (каузальную) связь ЕСЛИ $A_{1}$ И $A_{2}$, ТО $F$ (рис. 3.7, а). Здесь $A_{1}, A_{2}, F$ - события, которые могут произойти с определенной степенью вероятности (уверенности). Будем полагать, что вероятности наступления указанных событий определяются параметрами $X_{1}, X_{2}, X_{3}$ (переменными состояния), принадлежащими интервалу [0, 1].

Предположим теперь, что мы рассматриваем отношение $\left(A_{1} И_{2}\right) \rightarrow F$ как сложное событие, которое можно представить в виде цепочки последовательных элементарных событий: $A_{1} \rightarrow B_{1} ; A_{2} \rightarrow B_{2} ;\left(B_{1}\right.$ И $\left.B_{2}\right) \rightarrow D_{1}$; $B_{2} \rightarrow D_{2} ;\left(D_{1}\right.$ И $\left.D_{2}\right) \rightarrow F$. Тогда родительский концепт $C_{1}$ замещается частной НКК, состоящей из 5 концептов $C_{1}^{1}, C_{1}^{2}, C_{1}^{3}, C_{1}^{4}, C_{1}^{5}$ (рис. 3.7,б).

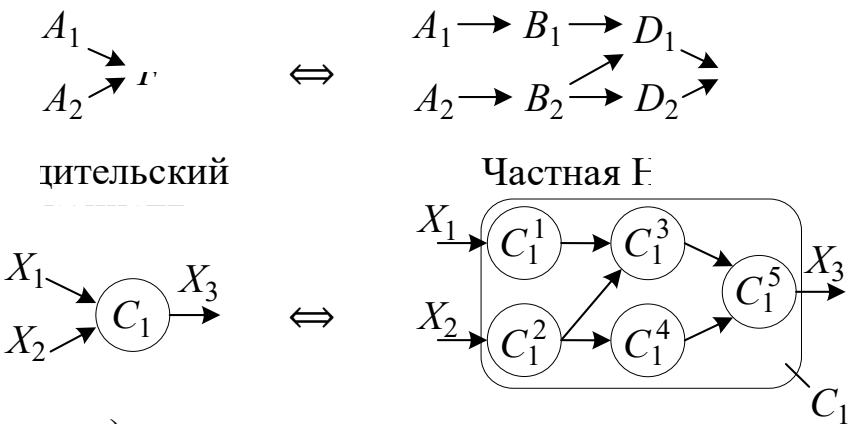

Рис. 3.7. Общая схема декомпозиции:

$\mathrm{a}$ - родительский концепт $C_{1}$; б - частная НКК

В основе данного преобразования лежит отношение эквивалентности [125], согласно которому родительский концепт и замещающая его частная НКК считаются эквивалентными, если они имеют одина- 
ковые входы и выходы, реализуют эквивалентные (т.е. взаимно преобразуемые) схемы логического вывода и одинаково интерпретируемы (хотя и с разной глубиной понимания) в рамках общей (укрупненной) НКК исследуемой проблемы.

На этом же этапе уточняются значения весов связей между концептами (уже применительно к частным НКК) с учетом дополнительной информации, полученной от экспертов.

3. Следующие уровни декомпозищии (слои $L_{2}, L_{3} \ldots$ ) HKK

Аналогично, любой из концептов частных НКК, построенных на предыдущем уровне декомпозиции, может быть, в свою очередь, развернут (детализирован), что в итоге даст возможность еще более глубокого анализа всех аспектов изучаемой проблемной области за счет включения в рассмотрение дополнительных нижележащих слоев $L_{2}, L_{3}$ и т.д. Соответственно, пересматриваются (уточняются) значения весов связей между концептами НКК.

4. Моделирование поведения (динамики) полного набора нечетких когнитивных карт

Для каждой НКК (начиная с частных НКК нижних уровней декомпозиции $L_{1}, L_{2}$ и заканчивая укрупненной НКК самого верхнего уровня $L_{0}$ ) производится расчет динамики изменения состояния концептов. Будем полагать также, что рассматриваемая вложенная НКК строится в класce нечетких серых когнитивных карт (Fuzzy Grey Cognitive Maps, $F G C M)$, предложенных в 2010 г. Хосе Салмероном [126]. Основное отличие нечетких серых когнитивных карт (НСКК) от других классов НКК - использование интервальных значений переменных состояния концептов и весов связей между концептами вместо нечетких чисел или термов лингвистических переменных, как это традиционно делается в классических НКК. Считается, что НСКК лучше соответствуют представлениям экспертов, обладают большей интерпретируемостью и предоставляют больше степеней свободы лицу, принимающему решение (ЛПР) по результатам моделирования.

Веса связей НСКК задаются с помощью «серых» (интервальных) чисел, которые обозначаются как $\otimes W_{i j}$ и определяются следующим образом:

$$
\otimes W_{i j} \in\left[\underline{W}_{i j}, \bar{W}_{i j}\right]
$$

где $\underline{W}_{i j}<\bar{W}_{i j} ;\left[\underline{W}_{i j}, \bar{W}_{i j}\right] \in[-1,1] ; \underline{W}_{i j}$ и $\bar{W}_{i j}-$ соответственно нижняя и верхняя граница серого числа $\otimes W_{i j}$. В частном случае, когда $\underline{W}_{i j}=\bar{W}_{i j}$, получаем $\otimes W_{i j} \in\left[\underline{W}_{i j}, \bar{W}_{i j}\right]-$ «белое» (обычное) число. 
Изменение состояния концептов во времени при этом описывается уравнениями:

$$
\otimes X_{i}(k+1)=f\left(\otimes X_{i}(k)+\sum_{\substack{j=1 \\(j \neq i)}}^{n} \otimes W_{j i} \otimes X_{j}(k)\right),(i=1,2, \ldots, n),(3.9)
$$

где $\otimes X_{i}(k)$ - «серая» (интервальная) переменная состояния $X_{i}$-го концепта НСКК, в каждый момент времени $k=0,1,2, \ldots$, принимающая значение внутри некоторого интервала $\left[\underline{X}_{i}(k), \bar{X}_{i}(k)\right]$ из интервала $[-1,1]$; $f(\cdot)$ - нелинейная функция активации $i$-го концепта, отображающая значения аргумента в интервал $[-1,1]$. Для определенности будем полагать, что в качестве функции активации принимается двухполярная сигмоида (гиперболический тангенс):

$$
f(x)=\left(1-e^{-x}\right) /\left(1+e^{-x}\right)=\operatorname{th}(x / 2) .
$$

Для решения уравнений (3.9) необходимо задать начальные условия для переменных состояния $\otimes X_{i}(0)$, которые также представляют собой серые числа $\otimes X_{i}(0) \in\left[\underline{X}_{i}(0), \bar{X}_{i}(0)\right],(i=1,2, \ldots, n)$.

При выборе серых значений весов $\otimes W_{i j}$ экспертам необходимо ориентироваться на некоторую нечеткую шкалу, наподобие той, которая представлена в табл. 3.5. Здесь значения термов: $Z$ - Zero; VS - Very Small; $S$-Small; $M$-Middle; L - Large; VL-Very Large. При этом осуществляется выбор границ интервала $\left[\underline{W}_{i j}, \bar{W}_{i j}\right]$, определяющего серое значение силы связи $\otimes W_{i j}$. Это могут быть равноотстоящие от центрального значения $W_{i j}^{0}$ числа, например: $\otimes W_{i j} \in\left[W_{i j}^{0}-\delta_{i j}, W_{i j}^{0}+\delta_{i j}\right]$, где $\pm \delta_{i j}$ - разброс оценки относительно центра $W_{i j}{ }_{i j}$.

Та блица 3.5

Оценка силы (весов) связей между концептами

\begin{tabular}{|l|l|l|}
\hline Лингвистическое значение силы связи & \multicolumn{1}{|c|}{ Терм } & Числовой диапазон \\
\hline Не влияет & $Z$ & 0 \\
\hline Очень слабая & $V S$ & $(0 ; 0,15]$ \\
\hline Слабая & $S$ & $(0,15 ; 0,35]$ \\
\hline Средняя & $M$ & $(0,35 ; 0,6]$ \\
\hline Сильная & $L$ & $(0,6 ; 0,85]$ \\
\hline Очень сильная & $V L$ & $(0,85 ; 1]$ \\
\hline
\end{tabular}


После выполнения всех расчетов для частных (локальных) НКК, расположенных на нижних слоях НКК, производится агрегирование полученных результатов моделирования на верхнем уровне НКК (слой $L_{0}$ ), с вычислением интегральных показателей оценки рисков ИП.

4. Сценарное моделирование с использованием НКК

Завершающим этапом когнитивного моделирования является этап сценарного моделирования, на котором производится анализ различных вариантов воздействия факторов риска с оценкой ожидаемых последствий, выбор возможных контрмер для снижения уровня рисков ИП, формирование рекомендаций ЛПР в отношении наиболее предпочтительного варианта реализации ИП.

\subsection{2. Пример оценки и анализа рисков ИП с использованием технологии многослойных НКК}

Рассмотрим в качестве примера ИП (стартап), направленный на создание нового инновационного предприятия по оказанию услуг малому и среднему бизнесу в сфере инфотелекоммуникаций. Предполагается, что инициатор ИП разработал бизнес-план, определил стратегию развития предприятия, провел маркетинговые исследования планируемой ниши рынка, договорился с предполагаемыми инвесторами ИП.

На этой стадии важно правильно произвести оценку рисков реализации ИП, обусловленных наличием таких факторов риска, как

1 - несвоевременное финансирование ИП;

2 - ошибки на этапе предпроектного исследования (в формулировке целей ИП, оценке привлекательности предоставляемых услуг, сроков выхода на рынок, объемов ожидаемого рынка и т.п.);

3 - задержки плановых сроков реализации отдельных этапов ИП (задержки с оформлением документации, сроков согласования ИП, поставок оборудования, ПО и т.п.);

4 - недобросовестные действия со стороны конкурентов;

5 - неэффективная рекламная (маркетинговая) компания.

Перечисленные факторы риска, в свою очередь, приводят к следующим последствиям:

6 - срыв сроков начала реализации ИП;

7 - прекращение финансирования ИП;

8 - отсутствие привлекательности (востребованности) предлагаемого инновационного продукта;

9 - просчеты в оценке рентабельности (окупаемости) вкладываемых средств на реализацию ИП. 
Интегральные показатели риска ИП:

10 - финансовый риск (потеря вложенных средств);

11 - репутационный риск (прекращение деятельности предприятия).

Соответствующая укрупненная НКК (слой $L_{0}$ ), отражающая все перечисленные выше факторы риска, последствия от их реализации и интегральные показатели риска ИП, а также взаимодействия между ними, приведена на рис. 3.8.

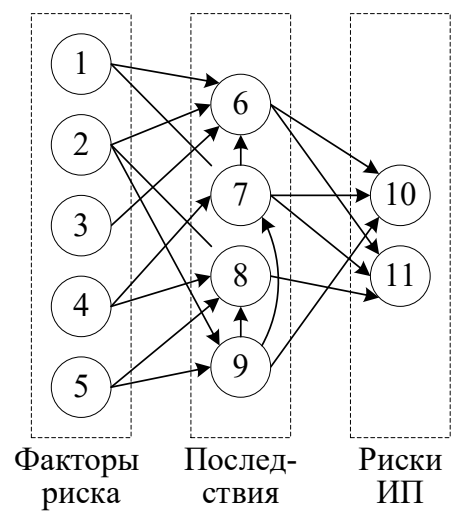

Рис. 3.8. Укрупненная НКК оценки рисков ИП

Перейдем к 1-му уровню декомпозиции НКК (слой $L_{1}$ ). На рис. 3.9 приведена частная НКК, раскрывающая внутреннее содержание родительского концепта $C_{1}$ («Несвоевременное финансирование ИП»).

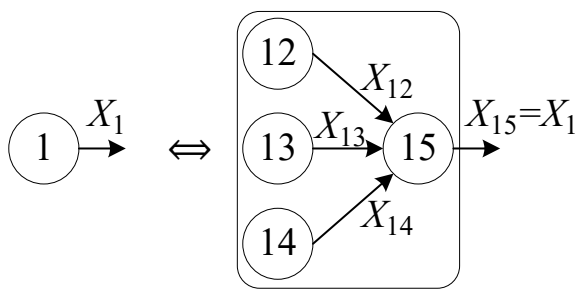

Рис. 3.9. Декомпозиция концепта $C_{1}$ : a - концепт $C_{1} ;$ б - частная НКК

Здесь: 12 - задержки с финансированием со стороны инвестора на предпроектной стадии ИП; 13 - перебои с банковским обслуживанием; 14 - пересмотр условий финансирования ИП (снижение 
суммы контракта); 15 - нарушения графика финансирования ИП; $X_{12}, X_{13}, X_{14}, X_{15}$, - переменные состояния соответствующих концептов $C_{12}, C_{13}, C_{14}, C_{15}$.

Приведем еще несколько вариантов декомпозиции концептов исходной (укрупненной) НКК.

Концепт $C_{6}$ («Срыв сроков начала реализации ИП») представлен на рис. 3.10.

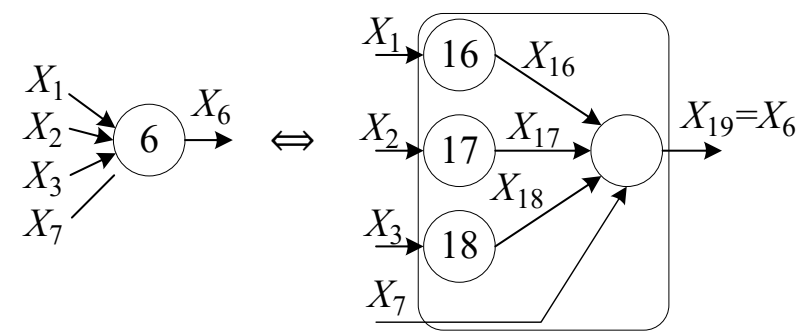

Рис. 3.10. Декомпозиция концепта $C_{6}$ : а - концепт $C_{6}$; 6 - частная НКК

Здесь: 16 - привлечение дополнительного инвестора; 17 - необходимость выполнения дополнительных работ; 18 - невыполнение запланированного графика работ над ИП; 19 - срыв сроков начала реализации ИП.

Концепт $C_{7}$ («Прекращение финансирования ИП») приведен на рис. 3.11.

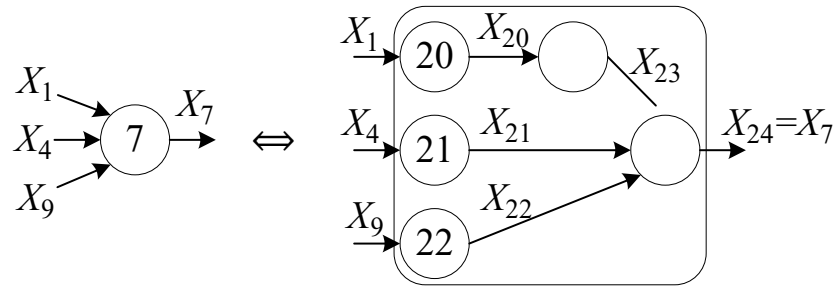

Рис. 3.11. Декомпозиция концепта $C_{7}$ : a - концепт $C_{7}$; б - частная НКК

Здесь: 20 - низкая исполнительская дисциплина участников ИП; 21 - декомпозиция инвестора и потребителей инновационного продукта; 22 - отсутствие преимуществ инновационного продукта по сравнению с аналогами; 23 - низкое качество ИП; 24 - прекращение финансирования ИП. 
Концепт $C_{10}$ («Финансовый риск») изображен на рис. 3.12.

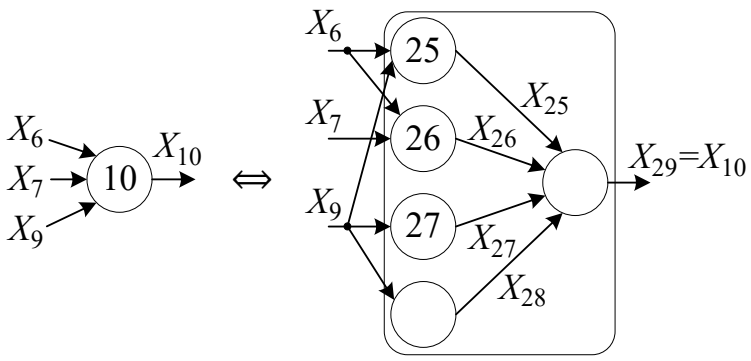

Рис. 3.12. Декомпозиция концепта $C_{10}$ : a - концепт $C_{10}$; б - частная НКК

Здесь: 25 - невыход инновационного продукта на рынок; 26 - срыв обязательств перед заказчиком (инвестором); 27 - невыполнение ожиданий потребителя (уменьшение числа заказов); 28 - прекращение реализации ИП (с возвратом полностью или части вложенных средств инвестору); 29 - потеря финансовых средств (убыток предприятия).

Концепт $C_{11}$ («Репутационный риск») представлен на рис. 3.13.

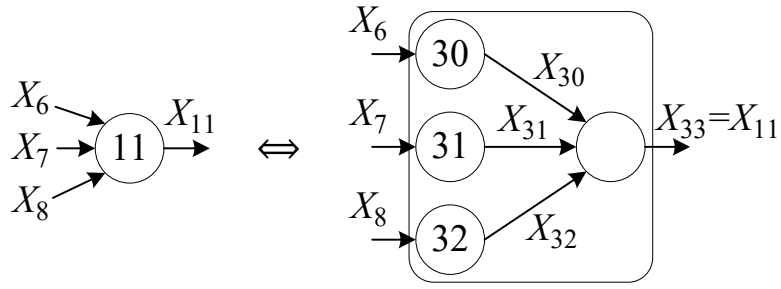

Рис. 3.13. Декомпозиция концепта $C_{11}$ : а - концепт $C_{11}$; б - частная НКК

Здесь: 30 - потеря интереса к инновационному предприятию со стороны потребителей; 31 - прекращение деловых контактов с инвестором; 32 - потеря планируемой доли рынка; 33 - снижение уровня (имиджа) предприятия по отношению к партнерам (деловому сообществу).

Аналогичным образом можно (при необходимости) провести декомпозицию всех оставшихся концептов укрупненной НКК (рис. 3.8), а также произвести более детальную декомпозицию полученных частных НКК (слои $L_{2}, L_{3}, \ldots$ ) с учетом располагаемой дополнительной информации о внутренней структуре и характеристиках соответствующих концептов. 


\subsection{3. Результаты когнитивного моделирования с использованием НСКк}

Будем полагать, что укрупненная НСКК принимает вид, изображенный на рис. 3.8. Рассмотрим в качестве примера один из вариантов сценарного моделирования, связанный с оценкой финансового и репутационного рисков (переменные $X_{10}$ и $X_{11}$ ), которые вызваны задержками финансирования со стороны инвестора на предпроектной стадии ИП (входной концепт $C_{12}$ в составе частной НСКК на рис. 3.9). Определим значения переменной состояния $X_{12}(k)$ указанного концепта как $\otimes X_{12}(k) \in[0,9 ; 1]$ для всех моментов времени $k=0,1,2, \ldots$; начальные условия для всех остальных переменных состояния (как исходной НСКК, так и частных НСКК) принимаем нулевыми, т. е. равными [0;0].

Изменение во времени переменных состояния НСКК будет определяться уравнениями динамики (3.9). Однако заметим, что в рассматриваемом случае из общего числа 11 концептов лишь 5 концептов $\left(C_{1}, C_{6}, C_{7}, C_{10}\right.$ и $\left.C_{11}\right)$ являются активными, т. е. участвуют в процедуре оценки искомых рисков. Влияние остальных 6 концептов $\left(C_{2}, C_{3}, C_{4}\right.$, $C_{5}, C_{8}, C_{9}$ ) на показатели рисков $X_{10}$ и $X_{11}$ здесь не учитывается, т.к. переменные состояния этих концептов сохраняют нулевые значения для всех $k=0,1,2, \ldots$ Соответствующие частные (детализированные) НСКК для указанных активных концептов $C_{1}, C_{6}, C_{7}, C_{10}, C_{11}$ приведены на рис. 3.9-3.13. Допустим далее, что эксперты определили значения весов связей внутри каждой из частных НСКК следующим образом (табл. 3.6-3.10).

Полагаем, что решение уравнений динамики (3.7) осуществляется последовательно для перечисленных выше частных НСКК. При этом нас интересуют только установившиеся значения переменных состояния $\otimes X_{1}^{*}, \otimes X_{6}^{*}, \otimes X_{7}^{*}, \otimes X_{10}{ }^{*}, \otimes X_{11}{ }^{*}$. Общую схему вычислений указанных переменных можно представить в виде, приведенном на рис. 3.14.

Таблица 3.6

Веса связей частной НСКК для концепта $C_{1}$

\begin{tabular}{|l|c|c|c|}
\hline \multicolumn{1}{|c|}{ Вес связи } & $\boldsymbol{W}_{\mathbf{1 2 , 1 5}}$ & $\boldsymbol{W}_{\mathbf{1 3 , 1 5}}$ & $\boldsymbol{W}_{\mathbf{1 4 , 1 5}}$ \\
\hline Терм & $V L$ & $L$ & $V L$ \\
\hline Числовой диапазон & {$[0,9 ; 1]$} & {$[0,7 ; 0,8]$} & {$[0,9 ; 1]$} \\
\hline
\end{tabular}


Гиава 3

Т а бли ц а 3.7

Веса связей частной НСКК для концепта $C_{6}$

\begin{tabular}{|c|c|c|}
\hline Вес связи & Терм & Числовой диапазон \\
\hline$W_{1,16}$ & $M$ & {$[0,5 ; 0,6]$} \\
\hline$W_{2,17}$ & $L$ & {$[0,75 ; 0,85]$} \\
\hline$W_{3,18}$ & $V L$ & {$[0,9 ; 1]$} \\
\hline$W_{4,19}$ & $V L$ & {$[0,9 ; 1]$} \\
\hline$W_{16,19}$ & $L$ & {$[0,7 ; 0,8]$} \\
\hline$W_{17,19}$ & $L$ & {$[0,75 ; 0,85]$} \\
\hline$W_{18,19}$ & $V L$ & {$[0,9 ; 1]$} \\
\hline
\end{tabular}

Табли ца 3.8

Веса связей частной НСКК для концепта $C_{7}$

\begin{tabular}{|c|c|c|}
\hline Вес связи & Терм & Числовой диапазон \\
\hline$W_{1,20}$ & $L$ & {$[0,6 ; 0,8]$} \\
\hline$W_{4,21}$ & $M$ & {$[0,4 ; 0,5]$} \\
\hline$W_{9,24}$ & $L$ & {$[0,7 ; 0,8]$} \\
\hline$W_{20,23}$ & $V L$ & {$[0,85 ; 0,9]$} \\
\hline$W_{21,24}$ & $S$ & {$[0,25 ; 0,35]$} \\
\hline$W_{22,24}$ & $V L$ & {$[0,85 ; 1]$} \\
\hline$W_{23,24}$ & $L$ & {$[0,75 ; 0,85]$} \\
\hline
\end{tabular}

Т а бли ц а 3.9

Веса связей частной НСКК для концепта $C_{10}$

\begin{tabular}{|c|c|c|}
\hline Вес связи & Терм & Числовой диапазон \\
\hline$W_{6,25}$ & $M$ & {$[0,5 ; 0,6]$} \\
\hline$W_{7,26}$ & $V L$ & {$[0,85 ; 1]$} \\
\hline$W_{9,25}$ & $L$ & {$[0,7 ; 0,8]$} \\
\hline$W_{9,27}$ & $M$ & {$[0,4 ; 0,6]$} \\
\hline$W_{9,28}$ & $L$ & {$[0,8 ; 0,85]$} \\
\hline$W_{25,29}$ & $V L$ & {$[0,9 ; 1]$} \\
\hline$W_{26,29}$ & $L$ & {$[0,75 ; 0,85]$} \\
\hline$W_{27,29}$ & $L$ & {$[0,7 ; 0,8]$} \\
\hline$W_{28,29}$ & $V L$ & {$[0,9 ; 1]$} \\
\hline
\end{tabular}


Та блица 3.10

Веса связей частной НСКК для концепта $C_{11}$

\begin{tabular}{|c|c|c|}
\hline Вес связи & Терм & Числовой диапазон \\
\hline$W_{6,30}$ & $M$ & {$[0,5 ; 0,6]$} \\
\hline$W_{7,31}$ & $V L$ & {$[0,9 ; 1]$} \\
\hline$W_{8,32}$ & $L$ & {$[0,8 ; 0,85]$} \\
\hline$W_{30,33}$ & $L$ & {$[0,7 ; 0,8]$} \\
\hline$W_{31,33}$ & $L$ & {$[0,6 ; 0,8]$} \\
\hline$W_{32.33}$ & $L$ & {$[0,75 ; 0,85]$} \\
\hline
\end{tabular}

Как видно из рисунка, за $k_{1}$ итераций (этап I) вначале вычисляется значение $\otimes X_{15}{ }^{*}=\otimes X_{1}{ }^{*}$, затем за $\Delta k_{2}=k_{2}-k_{1}$ итераций (этап II) вычисляются значения $\otimes X_{6}^{*}$ и $\otimes X_{7}^{*}$, и наконец, за $\Delta k_{3}=k_{3}-k_{3}$ итераций (этап III) вычисляются искомые значения рисков $\otimes X_{10}{ }^{*}$ (финансовый риск) и $\otimes X_{11}{ }^{*}$ (репутационный риск).

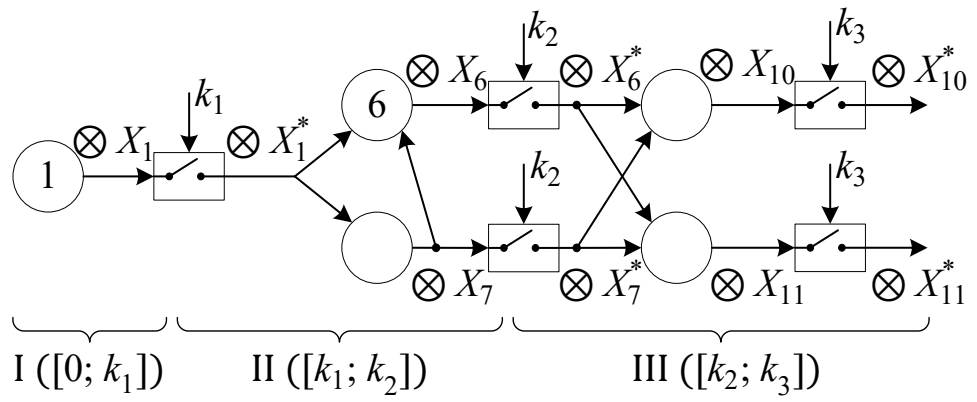

Рис. 3.14. Схема вычисления рисков

(установившихся значений переменных состояния $\otimes X_{10}{ }^{*}$ и $\otimes X_{11}{ }^{*}$ )

Фактически, с учетом принятых ранее нулевых начальных условий (за исключением концепта $C_{12}$ ), будет моделироваться следующая детализированная схема НСКК (рис. 3.15), где $\otimes X_{15}{ }^{*}=\otimes X_{1}^{*}, \otimes X_{19}{ }^{*}=\otimes X_{6}{ }^{*}$, $\otimes X_{24}{ }^{*}=\otimes X_{7}{ }^{*}, \otimes X_{29}{ }^{*}=\otimes X_{10}{ }^{*}, \otimes X_{33}{ }^{*}=\otimes X_{11}{ }^{*}$.

Результаты моделирования: $\otimes X_{1}^{*} \in[0,61 ; 0,69]$ (достигается за $k_{1}=10$ итераций); $\otimes X_{6}^{*} \in[0,35 ; 0,50]$ и $\otimes X_{7}^{*} \in[0,20 ; 0,31]$ (потребовалось $\Delta k_{2}=20$ итераций); $\otimes X_{10}{ }^{*} \in[0,36 ; 0,57]$ и $\otimes X_{11}{ }^{*} \in[0,22 ; 0,41]$ (потребовалось $\Delta k_{3}=15$ итераций). 


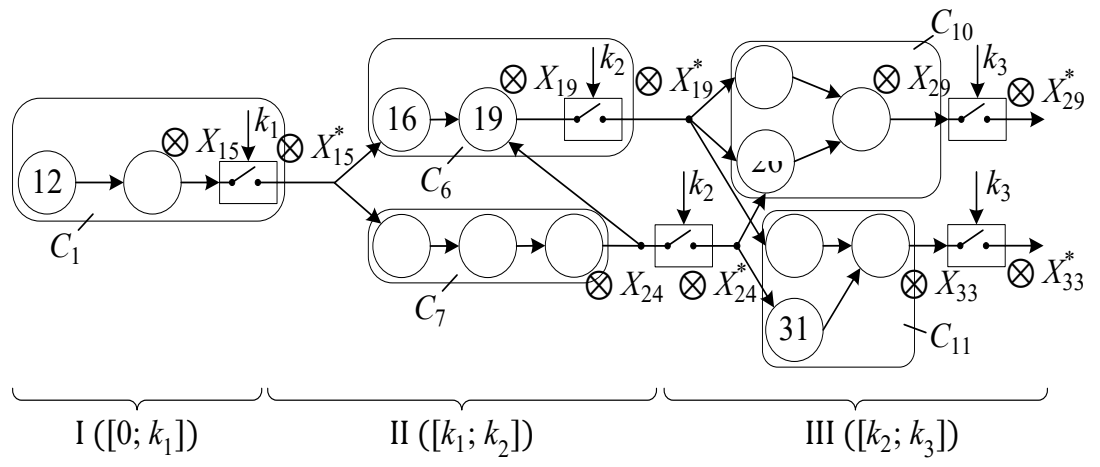

Рис. 3.15. Детализированная схема вычисления рисков ИП

Допустим в качестве еще одного сценария, что за счет применения заранее продуманных организационных контрмер, по мнению экспертов, удается снизить влияние отдельных факторов риска на результирующие значения прогнозируемых рисков (что сказывается на изменении весов частных НСКК): $W_{1,16} \rightarrow \widetilde{W}_{15,16} ; W_{16,19} \rightarrow \widetilde{W}_{16,19} ; W_{7,19} \rightarrow \widetilde{W}_{24,19}$; $W_{1,20} \rightarrow \widetilde{W}_{15,20} ; W_{20,23} \rightarrow \widetilde{W}_{20,23} ; W_{23,24} \rightarrow \widetilde{W}_{23,24}$. Новые значения скорректированных весов приведены в табл. 3.11.

Таблица 3.11

Скорректированные значения весов связей

\begin{tabular}{|c|c|c|}
\hline Вес связи & Терм & Числовой диапазон \\
\hline$\widetilde{W}_{15,16}$ & $S$ & {$[0,25 ; 0,3]$} \\
\hline$\widetilde{W}_{16,19}$ & $M$ & {$[0,45 ; 0,5]$} \\
\hline$\widetilde{W}_{24,19}$ & $M$ & {$[0,45 ; 0,5]$} \\
\hline$\widetilde{W}_{15,20}$ & $M$ & {$[0,45 ; 0,5]$} \\
\hline$\widetilde{W}_{20,23}$ & $M$ & {$[0,55 ; 0,6]$} \\
\hline$\widetilde{W}_{23,24}$ & $S$ & {$[0,25 ; 0,3]$} \\
\hline
\end{tabular}


Результаты моделирования для данного сценария: $\otimes X_{1}^{*} \in[0,61 ; 0,69]$; $\otimes X_{6}^{*} \in[0,08 ; 0,12] ; \otimes X_{7}^{*} \in[0,04 ; 0,05] ; \otimes X_{10}{ }^{*} \in[0,07 ; 0,11] ;$ $\otimes X_{11}{ }^{*} \in[0,03 ; 0,06]$. Таким образом, применение указанных контрмер позволило уменьшить финансовый риск, определяемый показателем $\otimes X_{10}{ }^{*}$, в среднем в 5,1 раз, а репутационный риск, оцениваемый показателем $\otimes X_{11}^{*}$, в среднем в 7 раз.

Аналогичным образом можно рассмотреть другие варианты сценариев с использованием предложенной методики когнитивного моделирования, оценивая уровень рисков ИП от воздействия других дестабилизирующих факторов и эффективность принятия тех или иных мер по их снижению.

\section{3 Оценка рисков кибербезопасности АСУ ТП промышленных объектов на основе вложенных нечетких когнитивных карт}

Согласно данным «Лаборатории Касперского» [127], общий процент промышленных компьютеров в мире, на которых было обнаружено и заблокировано вредоносное ПО, в первом полугодии 2019 г. составил $41,21 \%$, т.е. практически каждый второй компьютер подвергся атаке. В России аналогичный показатель составил 44,8\%. Атакам в равной степени подвергались предприятия энергетики, машиностроения, нефтегазового сектора и других не менее важных отраслей, что, безусловно, свидетельствует об остроте складывающейся ситуации и необходимости принятия неотложных мер для ее улучшения. Более половины выявленных в системах АСУ ТП уязвимостей получили при этом более 7 баллов по шкале CVSS версии 3.0, что соответствует высокой и критической степени риска.

Задачи обеспечения кибербезопасности промышленных автоматизированных систем принципиально отличаются от классических задач обеспечения информационной безопасности $[128,129]$. С точки зрения кибербезопасности, главным защищаемым ресурсом в АСУ ТП является сам технологический процесс, и основная цель - это обеспечить его непрерывность (т.е. доступность всех узлов) и целостность (в том числе передаваемой между узлами информации). В корпоративных информационно-вычислительных системах главный ресурс - это информация, которая обрабатывается, передается и хранится в системе, а основная цель - обеспечение ее конфиденциальности. Таким образом, поле потенциальных рисков и угроз для АСУ ТП, по сравнению 
с корпоративными информационными системами, расширяется рисками потенциального ущерба жизни и здоровью персонала, населения и окружающей среде.

Отсюда понятен тот интерес к решению проблемы обеспечения кибербезопасности АСУ ТП, включая создание нормативно-правовой и методической базы (краткую характеристику современного состояния и полученных результатов в этой области можно найти в [130]). Одним из перспективных путей решения данной проблемы является разработка и поэтапное принятие серии международных стандартов ISA/IEC 62443 [131]. Всего в этой серии запланирован выпуск 13 руководящих документов, 3 из которых уже переведены на русский язык и утверждены в России (ГОСТ Р 62443-3-3-2016). В основе развиваемого в этих стандартах риск-ориентированного подхода используется методология формирования требований по обеспечению кибербезопасности АСУ ТП в зависимости от уровня рисков предприятия подвергнуться кибератакам. В стандартах подчеркивается необходимость применения для этих целей не только критериев качественной оценки уровня безопасности АСУ ТП, но и разработки количественных методов оценки безопасности на основе математических моделей риска, угроз и инцидентов безопасности.

В качестве одного из возможных подходов к решению данной задачи может использоваться технология когнитивного моделирования и в частности математический аппарат «вложенных» нечетких серых когнитивных карт.

\subsection{1 Нечеткие когнитивные карты и принцип вложения}

В отличие от иерархических и многоагентных НКК, основной упор при построении вложенных НКК (Nested FCM) делается на последовательное раскрытие неопределенностей - каждый последующий (нижележащий) слой содержит более детальную (локальную) информацию о внутренней структуре (топологии) базовых концептов исходной НКК. Ниже нами будет рассматриваться именно этот класс нечетких когнитивных моделей, в основе которых используется принцип вложения (nesting principle).

В качестве базового подхода к построению вложенных НКК можно воспользоваться предложенной в [125] теорией декомпозиции больших НКК. Согласно данной теории, процедура когнитивного моделирования начинается с построения подробной (развернутой) НКК ис- 
следуемой системы, которая принимается в качестве исходной. Затем производится разбиение множества вершин (концептов) данной НКК на ряд отдельных блоков в соответствии с отношением эквивалентности. Каждый из этих блоков содержит локальную информацию о взаимодействиях и внутренних зависимостях между концептами в пределах данного блока. Рассматривая полученные блоки в качестве вершин укрупненной (обобщенной) НКК (которую авторы [125] назвали Quotient Fuzzy Cognitive Map), получим блочное представление НКК.

На рис. 3.16 показан пример подобной декомпозиции НКК (слева - исходная НКК, состоящая из 6 индивидуальных блоков (частных НКК), определенным образом связанных между собой; справа укрупненная НКК, каждая из вершин (концептов) которой отображает множество вершин (концептов) соответствующей частной НКК.

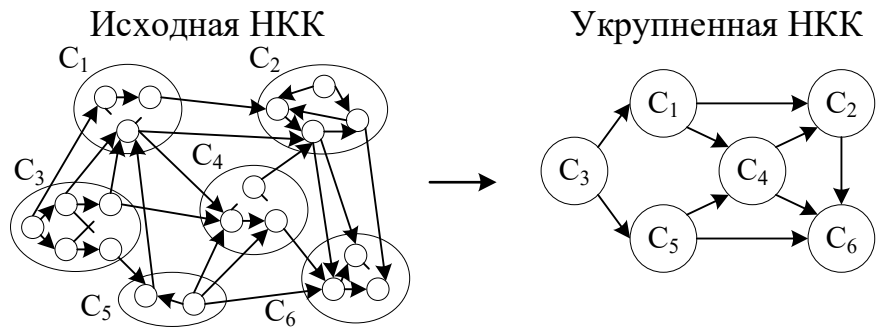

Рис. 3.16. Пример декомпозиции НКК

Заметим, что в отличие от описанной выше процедуры преобразования НКК [125] путем ее «сворачивания» (т.е. от частного к общему), мы, наоборот, будем строить вложенную НКК путем ее «развертывания», детализации (от общего к частному).

\subsection{2. Методика анализа рисков с помощью нечетких серых когнитивных карт}

Рассмотрим методику анализа рисков обеспечения кибербезопасности АСУ ТП на следующем примере. В качестве объекта защиты будем рассматривать автоматизированную информационную систему (АИС) сбора, хранения и обработки телеметрической информации (ТМИ) предприятия-изготовителя изделий авиационной техники. Текущая информация о параметрах состояния бортовых систем собирается в течение всего периода их эксплуатации наземными службами 
технического обслуживания. Детальный анализ этой информации позволяет в последующем принимать правильные управленческие и конструкторские решения о дальнейшей эксплуатации и модификации бортовых систем летательного аппарата. Поэтому задача обеспечения целостности ТМИ в условиях воздействия на нее потенциальных внешних и внутренних угроз имеет важное значение.

Обобщенная структура перспективной территориально распределенной АИС сбора, хранения и обработки ТМИ на станциях технического обслуживания приведена на рис. 3.17.

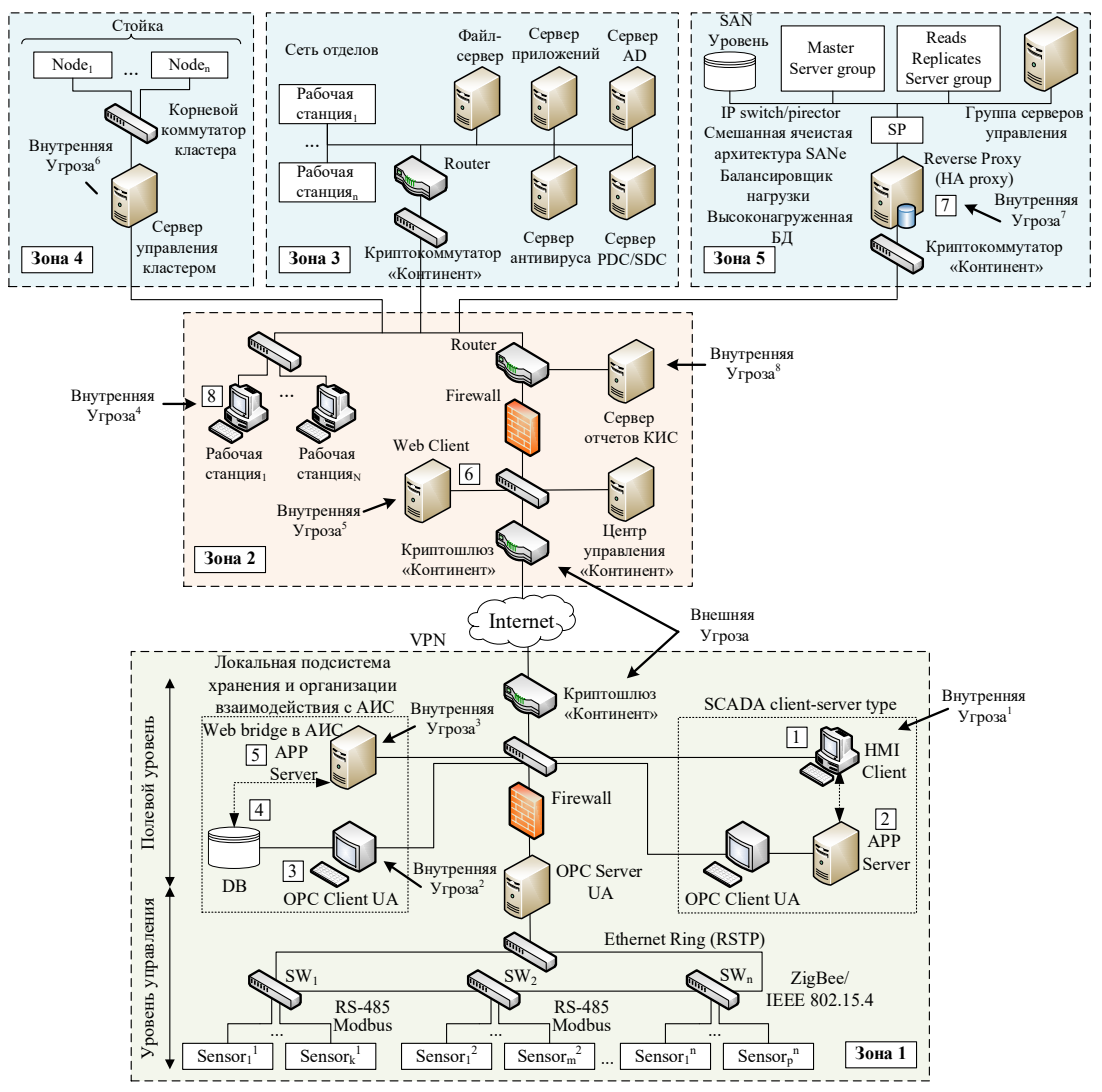

Рис. 3.17. Структурная схема АИС сбора, хранения и обработки ТМИ 
В составе АИС при этом можно выделить следующие подсистемы (зоны), объединяемые по принципу единства выполняемых функций и требований к безопасности их реализации:

1) подсистема сбора и хранения первичных данных на станц̧иях технического обслуживания (зона 1), в состав которой входят:

- элемент 1 - клиентская часть Web-base SCADA системы;

- элемент 2 - серверная часть Web-base SCADA системы;

- элемент 3 - OPC UA клиент;

- элемент 4 - временное хранилище для размещения оперативных данных телеметрии, накапливаемых на объекте;

- элемент 5 - серверная часть системы передачи накопленных данных в хранилище предприятия-изготовителя (ПИ) авиационной техники;

2) ядро корпоративной информащионной сети (КИС) ПИ (зона 2), где:

- элемент 6 - клиентская часть для организации доступа к серверу станции обслуживания с целью передачи накопленных оперативных данных ТМИ в хранилище ПИ;

- элемент 8 - АРМ администратора и обслуживающего персонала ядра КИС ПИ;

3) подсистема хранения ТМИ с функциями обеспечения отказоустойчивости (зона 3), где:

- элемент 7 - узел доступа к хранилищу данных ТМИ на ПИ;

- Cluster management server - сервер управления вычислительным кластером и консоль управления системой мониторинга целостности;

- Core switch - базовый коммутатор вычислительного кластера;

4) подсистема обработки данных ТМИ с помощью иерархии математических моделей изделий авиационной техники (зона 4);

5) подсистема поддержки и реализации бизнес-процессов ПИ (зона 5).

Соответствующие подсистемы (зоны безопасности) связаны между собой с помощью каналов телекоммуникаций (трактов).

Используя в качестве инструмента моделирования аппарат НСКК, обратимся к задаче анализа рисков, связанных с обеспечением целостности ТМИ в рассмотренной выше АИС. Укрупненная НСКК для оценки рисков АИС, выступающая в данном случае как когнитивная модель АИС начального приближения (нулевой уровень декомпозиции), представлена на рис. 3.18. 


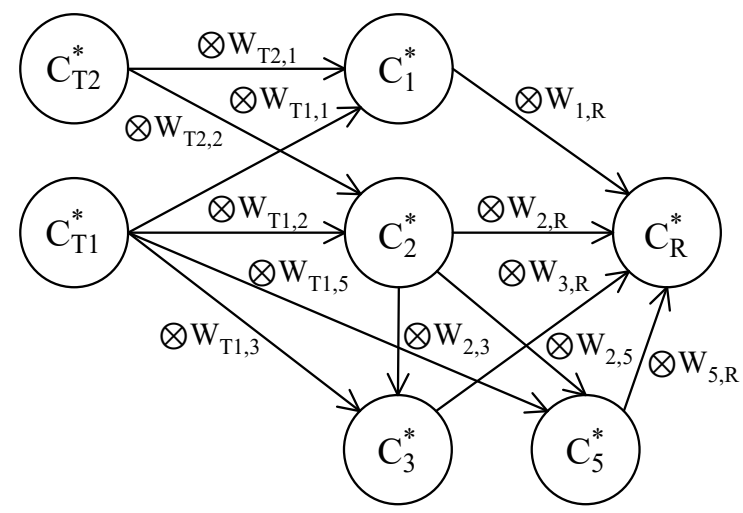

Рис. 3.18. Укрупненная (исходная) НСКК для оценки рисков АИС

Здесь используются следующие обозначения: верхний индекс (маркер «*») обозначает принадлежность концепта $C_{p}^{*}$ укрупненной НСКК, нижний индекс ( $p)$ обозначает номер концепта текущего уровня. Список концептов укрупненной НСКК приведен в табл. 3.12.

Таблица 3.12

Список концептов укрупненной НСКК

\begin{tabular}{|c|l|}
\hline Концепт & \multicolumn{1}{|c|}{ Наименование концепта } \\
\hline$C_{T_{1}}^{*}$ & $\begin{array}{l}\text { Внутренняя угроза целостности ТМИ (вследствие сбоев или ошибоч- } \\
\text { ных действий персонала) }\end{array}$ \\
\hline$C_{T_{2}}^{*}$ & $\begin{array}{l}\text { Внешняя угроза целостности ТМИ (вследствие попытки несанкцио- } \\
\text { нированного доступа извне к информации) }\end{array}$ \\
\hline$C_{1}^{*}$ & Модификация данных ТМИ в Зоне 1 \\
\hline$C_{2}^{*}$ & Модификация данных ТМИ в Зоне 2 \\
\hline$C_{3}^{*}$ & Модификация данных ТМИ в Зоне 3 \\
\hline$C_{5}^{*}$ & Модификация данных ТМИ в Зоне 5 \\
\hline$C_{R}^{*}$ & $\begin{array}{l}\text { Риск (потенциальный ущерб), вызванный нарушением целостности } \\
\text { ТМИ в АИС }\end{array}$ \\
\hline
\end{tabular}

Выбор серых значений весов связей $\otimes W_{i j}$ для НСКК на рис. 3.18 должен производиться экспертом с учетом его опыта и субъективных оценок вероятностей использования уязвимостей АИС, что на практи- 
ке весьма затруднительно. Учитывая, что каждое из указанных событий представляет собой сложное событие, состоящее из цепочки следующих друг за другом элементарных событий, целесообразно декомпозировать изображенную на рис. 3.18 НСКК, представив ее в виде набора вложенных НСКК для отдельных концептов (т.е. зон безопасности, содержащих целевые объекты атаки на ТМИ через соответствующие уязвимости АИС) (рис. 3.19).

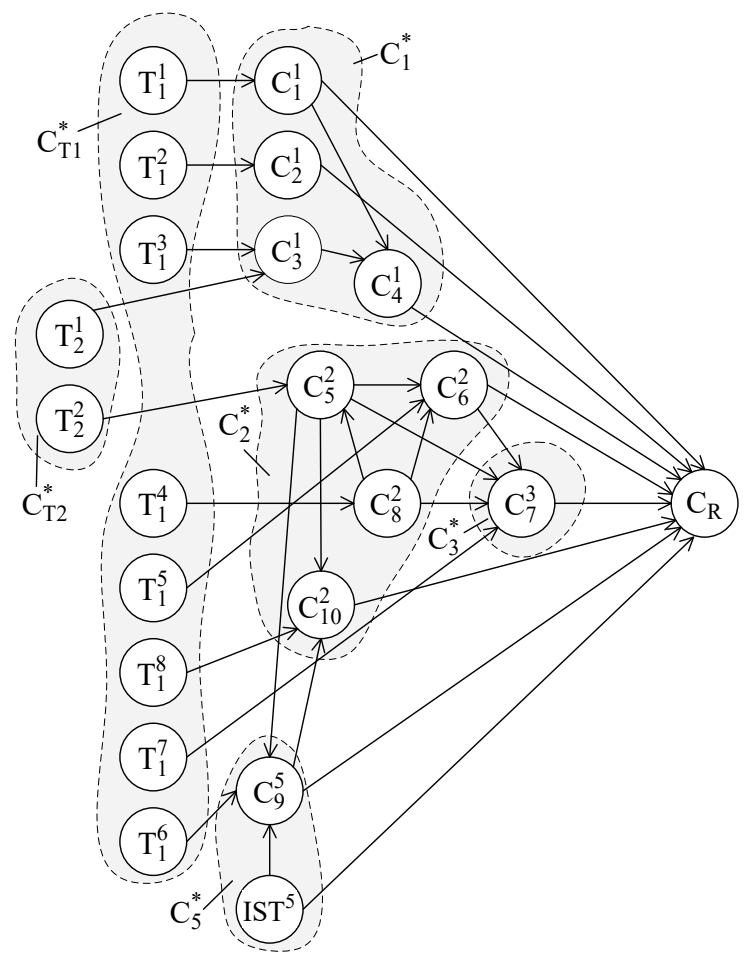

Рис. 3.19. Первый уровень декомпозиции НСКК для оценки рисков АИС

Первый уровень декомпозиции исходной (укрупненной) НСКК представлен на рис. 3.19. Здесь используются следующие обозначения: верхний индекс (маркер «q») концепта $C_{p}{ }^{q}$ указывает на его принадлежность к концепту $C_{q}^{*}$ укрупненной НСКК; нижний индекс $(p)-$ номер концепта в НСКК первого уровня декомпозиции. 
В табл. 3.13 приведены концепты первого уровня декомпозиции НСКК с указанием принадлежности к родительскому концепту.

Таблица 3.13

Список концептов первого уровня декомпозиции НСКК

\begin{tabular}{|c|c|c|}
\hline Концепт & Наименование концепта & $\begin{array}{l}\text { Родительский } \\
\text { концепт }\end{array}$ \\
\hline$T_{1}^{1}, \ldots, T_{1}^{8}$ & $\begin{array}{l}\text { Внутренние угрозы целостности ТМИ (т.е. точки } \\
\text { потенциальной реализации угрозы нарушения це- } \\
\text { лостности ТМИ внутренним субъектом) }\end{array}$ & $T_{1}^{*}$ \\
\hline$T_{2}^{1}, T_{2}^{2}$ & $\begin{array}{l}\text { Внешние угрозы целостности ТМИ (декомпозиция } \\
\text { концепта } T_{2}^{*} \text { ) }\end{array}$ & $T_{2}^{*}$ \\
\hline$C_{1}^{1}$ & $\begin{array}{l}\text { Доступ к данным ТМИ в клиент-серверной } S C A D A \\
\text { web-base до внесения в БД оперативного хранилища } \\
\text { ТМИ }\end{array}$ & \multirow[t]{4}{*}{$C_{1}^{*}($ Зона 1$)$} \\
\hline$C_{2}{ }^{1}$ & Доступ к БД оперативного хранения данных ТМИ & \\
\hline$C_{3}{ }^{1}$ & Доступ к сетевому оборудованию & \\
\hline$C_{4}{ }^{1}$ & $\begin{array}{l}\text { Доступ к модулю } W e b \text {-сервера отправки данных } \\
\text { ТМИ в долгосрочное хранилище ПИ }\end{array}$ & \\
\hline$C_{5}^{2}$ & Доступ к сетевой инфраструктуре & \multirow[t]{4}{*}{$C_{2}^{*}$ (Зона 2) } \\
\hline$C_{6}^{2}$ & 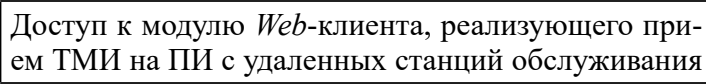 & \\
\hline$C_{8}^{2}$ & $\begin{array}{l}\text { Несанкционированный доступ к рабочей станции } \\
\text { ядра КИС ПИ }\end{array}$ & \\
\hline$C_{10}^{2}$ & $\begin{array}{l}\text { Доступ к серверу отчетов о состоянии оборудова- } \\
\text { ния, формируемых для пользователей Зоны } 4\end{array}$ & \\
\hline$C_{7}^{3}$ & $\begin{array}{l}\text { Получение доступа к ТМИ в долгосрочном храни- } \\
\text { лище }\end{array}$ & $C_{3}^{*}$ (Зона 3) \\
\hline$C_{9}^{5}$ & $\begin{array}{l}\text { Доступ к серверу управления вычислительным кла- } \\
\text { стером Зоны } 5\end{array}$ & \multirow[t]{2}{*}{$C_{5}^{*}($ Зона 5) } \\
\hline$I S T^{5}$ & Модуль контроля целостности ТМИ & \\
\hline
\end{tabular}

На рис. 3.20 представлен второй уровень декомпозиции для концепта $C_{1}^{*}$, позволяющий уточнить воздействие угроз на рассматриваемый концепт, в данном случае - для оценки рисков АИС в зоне 1 .

На схеме используются следующие обозначения концептов $C_{r}^{q, p}$ второго уровня декомпозиции НСКК: верхний индекс (маркер «q») - номер 
концепта (родительский концепт нулевого уровня декомпозиции) укрупненной НСКК, в состав которого входит данный элемент; индекс $p$ - номер родительского концепта первого уровня декомпозиции; нижний индекс $(r)$ - номер концепта текущего уровня. Список концептов второго уровня декомпозиции НСКК для зоны 1 приведен в табл. 3.14 .

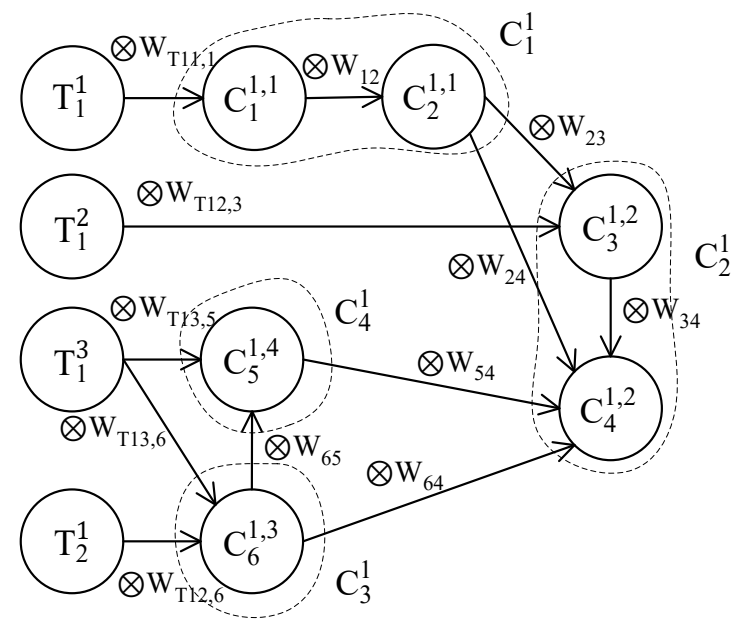

Рис. 3.20. Второй уровень декомпозиции НСКК

Та блица 3.14

Список концептов второго уровня декомпозиции НСКК для зоны 1

\begin{tabular}{|c|l|c|}
\hline Концепт & \multicolumn{1}{|c|}{ Наименование концепта } & $\begin{array}{c}\text { Родительский } \\
\text { концепт }\end{array}$ \\
\cline { 1 - 2 }$C_{1}^{1,1}$ & Доступ к HMI client SCADA & \multirow{2}{*}{$C_{1}^{1}$} \\
\cline { 1 - 2 }$C_{2}^{1,1}$ & $\begin{array}{l}\text { Доступ к оперативным данным ТМИ на client-server } \\
\text { части SCADA до внесения в оперативное хранилище }\end{array}$ & \multirow{2}{*}{$C_{2}^{1}$} \\
\cline { 1 - 2 }$C_{3}^{1,2}$ & $\begin{array}{l}\text { Доступ к клиенту для взаимодействия с сервером } \\
\text { OРC UA }\end{array}$ & \multicolumn{1}{|c|}{} \\
\cline { 1 - 2 }$C_{4}^{1,2}$ & Доступ к БД хранения оперативных данных ТМИ & \\
\hline
\end{tabular}


Дальнейшая декомпозиция второго уровня позволяет перейти к еще более детальной НСКК, позволяющей учитывать влияние отдельных уязвимостей на потенциальное нарушение целостности ТМИ в промежуточных элементах обработки информации. Рассмотрим численный пример оценки рисков для концепта $C_{1}^{*}$ (рис. 3.20). Будем полагать, что при выборе серых значений весов НСКК необходимо ориентироваться на нечеткую шкалу, определяющую силу связей между собой различных концептов (табл. 3.1). Допустим далее, что эксперт оценил значения весов связей НСКК на рис. 3.20 следующим образом (табл. 3.15).

Таблица 3.15

Значения весов связей НСКК

\begin{tabular}{|c|c|c|}
\hline Вес связи & Значение веса связи & Серость (разброс оценки) \\
\hline$\otimes W_{T 11,1}$ & {$[0,6 ; 0,75]$} & 0,075 \\
\hline$\otimes W_{T 12,3}$ & {$[0,5 ; 0,7]$} & 0,1 \\
\hline$\otimes W_{T 13,5}$ & {$[0,5 ; 0,7]$} & 0,1 \\
\hline$\otimes W_{T 13,6}$ & {$[0,15 ; 0,3]$} & 0,075 \\
\hline$\otimes W_{T 21,6}$ & {$[0,55 ; 0,65]$} & 0,05 \\
\hline$\otimes W_{12}$ & {$[0,35 ; 0,55]$} & 0,1 \\
\hline$\otimes W_{23}$ & {$[0,55 ; 0,65]$} & 0,05 \\
\hline$\otimes W_{24}$ & {$[0,3 ; 0,5]$} & 0,1 \\
\hline$\otimes W_{34}$ & {$[0,15 ; 0,3]$} & 0,075 \\
\hline$\otimes W_{54}$ & {$[0,2 ; 0,45]$} & 0,125 \\
\hline$\otimes W_{64}$ & {$[0,24 ; 0,35]$} & 0,055 \\
\hline$\otimes W_{65}$ & {$[0,22 ; 0,37]$} & 0,075 \\
\hline
\end{tabular}

Используя для расчетов программное средство «Cognitive Map Constructor» (см. раздел 3.3.3), выполним оценку изменения верхней и нижней границы переменной состояния концептов НСКК во времени $k=1,2,3, \ldots$ (табл. 3.16-3.17). Состояния входных концептов $T_{1}^{1}$, $T_{1}^{2}, T_{1}^{3}, T_{2}^{1}$ при этом были заданы как $[0,8 ; 1]$ для всех $k=0,1,2, \ldots$ начальные условия для переменных состояния других концептов приняты нулевыми, т.е. равны [0;0]. 
Л.Р. Черняховская, В.И. Васильев, В.Е. Гвоздев, Н.О. Никулина, А.И. Малахова, А.М. Вульфин, О.Я. Бежаева

Таблица 3.16

Верхние границы оценок состояния концептов

\begin{tabular}{|c|c|c|c|c|c|c|c|c|c|}
\hline $\bar{X}_{i}$ & 1 & 2 & 3 & 4 & 5 & 6 & 7 & 8 & 9 \\
\hline $\bar{X}_{1}^{1,1}$ & 0,36 & 0,50 & 0,56 & 0,57 & 0,58 & 0,58 & 0,58 & 0,58 & 0,58 \\
\hline $\bar{X}_{2}^{1,1}$ & 0 & 0,10 & 0,19 & 0,24 & 0,27 & 0,29 & 0,29 & 0,30 & 0,30 \\
\hline $\bar{X}_{3}^{1,2}$ & 0,34 & 0,48 & 0,55 & 0,60 & 0,62 & 0,63 & 0,64 & 0,64 & 0,65 \\
\hline $\bar{X}_{4}^{1,2}$ & 0 & 0,10 & 0,19 & 0,26 & 0,31 & 0,33 & 0,35 & 0,36 & 0,36 \\
\hline $\bar{X}_{5}^{1,4}$ & 0,20 & 0,29 & 0,33 & 0,35 & 0,36 & 0,36 & 0,36 & 0,36 & 0,36 \\
\hline $\bar{X}_{6}^{1,3}$ & 0,27 & 0,39 & 0,44 & 0,46 & 0,47 & 0,47 & 0,48 & 0,48 & 0,48 \\
\hline
\end{tabular}

Та блица 3.17

Нижние границы оценок состояния концептов

\begin{tabular}{|c|c|c|c|c|c|c|c|c|c|}
\hline$\underline{X}_{i}$ & 1 & 2 & 3 & 4 & 5 & 6 & 7 & 8 & 9 \\
\hline$\underline{X}_{1}^{1,1}$ & 0,24 & 0,34 & 0,39 & 0,41 & 0,42 & 0,42 & 0,42 & 0,42 & 0,42 \\
\hline$\underline{X}_{2}^{1,1}$ & 0 & 0,04 & 0,08 & 0,11 & 0,13 & 0,13 & 0,14 & 0,14 & 0,14 \\
\hline$\underline{X}_{3}^{1,2}$ & 0,20 & 0,29 & 0,34 & 0,37 & 0,39 & 0,41 & 0,41 & 0,42 & 0,42 \\
\hline$\underline{X}_{4}^{1,2}$ & 0 & 0,28 & 0,51 & 0,63 & 0,68 & 0,70 & 0,71 & 0,71 & 0,71 \\
\hline$\underline{X}_{5}^{1,4}$ & 0,34 & 0,48 & 0,53 & 0,55 & 0,55 & 0,56 & 0,56 & 0,56 & 0,56 \\
\hline$\underline{X}_{6}^{1,3}$ & 0,44 & 0,60 & 0,65 & 0,66 & 0,67 & 0,67 & 0,67 & 0,67 & 0,67 \\
\hline
\end{tabular}

В результате установившееся значение серого вектора состояния $\otimes X$ для НСКК на рис. 3.20 (т.е., для декомпозиции концепта $C_{1}^{*}$ ) находится как $\otimes X=\{[0,42 ; 0,58],[0,14 ; 0,30],[0,42 ; 0,65],[0,36 ; 0,71],[0,36 ; 0,56],[0,48 ; 0,67]$, а искомое значение для состояния целевого концепта $C_{4}^{1,2}$ определяется серым числом $[0,36 ; 0,71]$. 
Рассмотрим состояние целевого концепта $C_{R}{ }^{*}$ (рис. 3.18), т.е. ущерба, вызванного потенциальным нарушением целостности ТМИ в АИС, после уточнения значений всех весовых коэффициентов по уровням декомпозиции исходной НСКК. Предположим, что активной является внутренняя угроза $T_{1}^{*}$ нарушения целостности ТМИ, уровень которой определяется серым числом $\otimes X_{T_{1}}^{*} \in[0,6 ; 0,95]$. Тогда получаем установившееся значение для оценки рисков вследствие нарушения целостности информации ТМИ: $\otimes X_{R}^{*} \in[0,19 ; 0,28]$.

Допустим далее, что в качестве возможной контрмеры для снижения ущерба от нарушения целостности ТМИ применяется дополнительная система мониторинга, развернутая в виде защищенного контейнера в Зоне 5. На рис. 3.17 данная система обозначена как модуль контроля целостности ТМИ - концепт IST ${ }^{5}$. Защищенный контейнер обеспечивает мониторинг целостности ТМИ в режиме онлайн и офлайн путем анализа оперативных данных и данных, собранных в хранилище (зона 3).

Как показали расчеты, оценка рисков вследствие нарушения целостности информации ТМИ после применения дополнительной контрмеры составляет $\left.\otimes X_{R}^{*}\right|_{A} \in[0,07 ; 0,15]$, т.е. величина риска снижается в среднем в 2,3 раза.

\subsection{3. Автоматизация процедуры анализа и управления рисками на основе технологии когнитивного моделирования}

$\mathrm{C}$ целью повышения эффективности анализа и управления рисками с использованием НСКК использовалось специально разработанное программное средство «Cognitive Map Constructor». Оно позволяет строить и редактировать НСКК, проводить с их помощью анализ рисков и обосновывать выбор необходимых контрмер из заданного пользователем набора. В итоге строится диаграмма оценки рисков при различных сценариях внедрения контрмер и реализации угроз.

Помимо поддержки НСКК с установкой весов связей в виде верхних и нижних границ, программа допускает использование лингвистических термов нечеткой логики, а также задание весов в виде «белых» (четких) чисел. Программа имеет интерфейс, реализованный на языке гипертекстовой разметки $H T M L$ с применением $C S S$, позволяющий отображать НСКК и необходимую сопроводительную информацию по концептам и связям, а также способна работать на любой графической операционной системе, в которой имеется актуальный веб-браузер. 
На рис. 3.21 приведен пример НСКК оценки рисков подсистемы сбора и хранения данных АИС, построенной в «Cognitive Map Constructor».

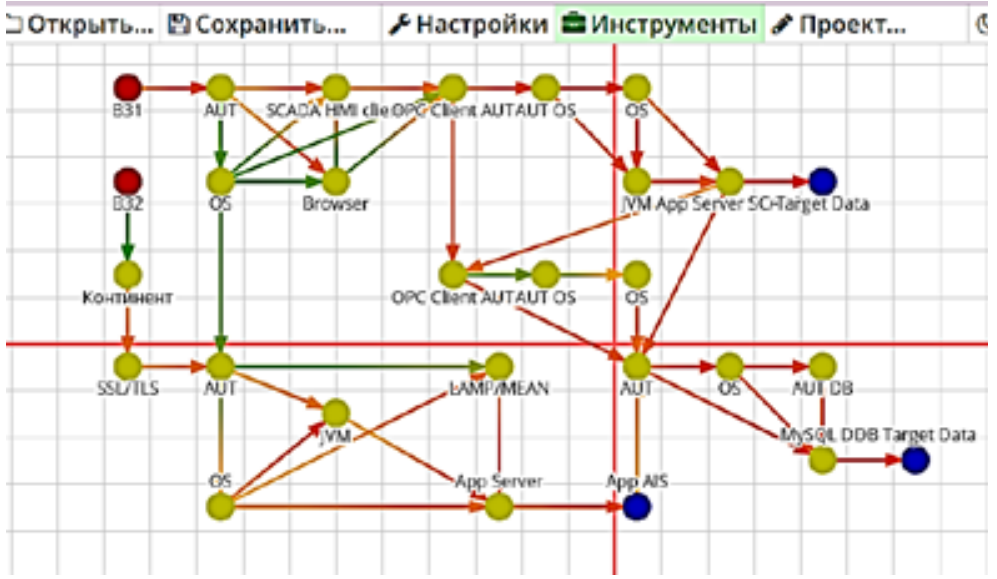

Рис. 3.21. НСКК для оценки рисков подсистемы сбора и хранения данных на станциях обслуживания (зона 1)

Результаты оценки рисков для целевых концептов и оценка суммарного риска до и после реализации контрмер и состояние целевых концептов НСКК приведены на рис. 3.22.

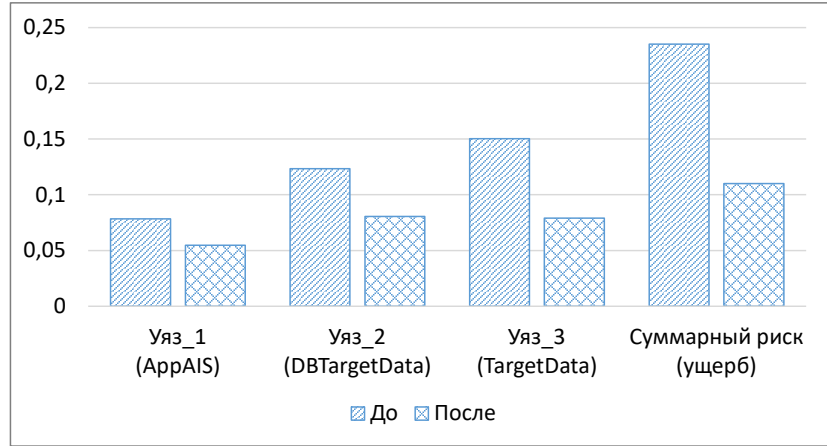

Рис. 3.22. Результаты оценки рисков для целевых концептов и суммарного риска до и после реализации контрмер 
Здесь: AppAIS - Эксплуатация уязвимости Web-приложения для запуска модуля доступа к БД оперативного хранения ТМИ на станциях обслуживания ЛА; DB Target Data - модификация оперативных данных ТМИ в БД хранения; Target Data - модификация ТМИ в долгосрочном хранилище.

\section{4 Анализ рисков кибербезопасности промышленных объектов \\ с помощью ансамбля нечетких когнитивных карт}

Как уже отмечалось, одной из центральных задач при построении когнитивных моделей изучаемого объекта является задача оценки силы связей (весов) НКК. В качестве возможных путей решения данной проблемы различными авторами были предложены специальные конструкции (расширения) НКК, связанные с представлением силы связей НКК в виде некоторых интервальных оценок. К числу подобных структур НКК относятся такие разновидности НКК, как уже упоминавшиеся серые НКК (Grey FCM) [132], а также интервально-значные НКК (Interval-Valued FCM) [133], грубые НКК (Rough FCM) [134], интуиционистские НКК (Intuitionistic FCM) [135].

Ниже будут рассмотрены особенности применения, помимо классической НКК, двух вариантов расширения НКК, а именно - серой и интуиционистской НКК (будем называть их обобщенными НКК), для решения задачи оценки рисков кибербезопасности АСУ ТП промышленных объектов. Главное внимание будет уделено их совместному использованию в составе ансамбля НКК с целью повышения эффективности оценки риска за счет использования различных способов формализации знаний и опыта эксперта. Этот вопрос практически не освещен в литературе, за исключением ряда работ [136-139], посвященных главным образом использованию указанных выше когнитивных моделей при построении систем обнаружения атак и оценке связанных с ними информационных рисков.

\subsection{1 Обобщенные нечеткие когнитивные карты}

Переходя к рассмотрению обобщенных НКК, будем полагать, что уравнения состояния НКК в общем виде могут быть записаны как: 


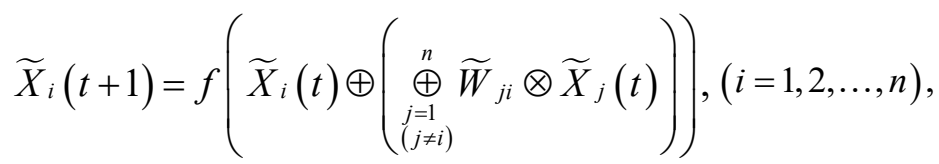

где веса связей $\widetilde{W}_{i}$ и переменные состояния $\widetilde{X}_{i}(t+1), \widetilde{X}_{i}(t)$ представляют собой интервальные числа, определяемые как элементы некоторых нечетких интервальных множеств; $\oplus$ и $\otimes-$ операции сложения и умножения интервальных чисел, заданные на нечетких интервальных множествах; $f$ - функция активации.

В качестве основы для построения НКК могут использоваться различные способы задания интервальных нечетких множеств (НМ).

Серье НКК (СНКК)

Под серым множеством (grey set) $A \subseteq X$ понимается множество:

$$
A=\{<x,[\underline{x}, \bar{x}]>\mid x \in X\},
$$

элементами которого являются серые числа $x \in[\underline{x}, \bar{x}] \leq A$, т.е. числа, которые могут принимать любые значения в пределах некоторого диапазона $[\underline{x}, \bar{x}] \in[0,1]$, где $\underline{x}$ и $\bar{x}-$ соответственно нижняя и верхняя граница серого числа $x ; X$ - универсальное множество. Число $\delta x=\bar{x}-\underline{x}$ называется серостью (greyness) числа $x$, а $x^{0}=(\bar{x}-\underline{x}) / 2-$ «отбеленным» (центральным) значением этого числа.

Веса связей между концептами серой НКК задаются в виде серых чисел $\left[\underline{W}_{i j}, \bar{W}_{i j}\right]$; переменные состояния концептов также представляют собой серые числа $\left[\underline{X}_{i}, \bar{X}_{i}\right]$, вычисляемые с помощью уравнений (3.11).

Интуиционистские НКК (ИНКК)

Понятие интуиционистского нечеткого множества (intuitionistic fuzzy set) было впервые введено в 1986 г. болгарским математиком К. Атанасовым.

Под интуиционистским нечетким множеством при этом понимается множество вида:

$$
A=\left\{<x, \mu_{A}(x), v_{A}(x)>\mid x \in X\right\},
$$

где $\mu_{A}(x)$ и $v_{A}(x)$ определяют соответственно степень принадлежности и степень непринадлежности элемента $x \in X$ (интуиционистского нечеткого числа) множеству $A \subseteq X$; $0 \leq \mu_{A}(x) \leq 1 ; 0 \leq v_{A}(x) \leq 1$. Существенное отличие от «обычных» нечетких множеств заключается в выполнении условия: $\mu_{A}(x)+v_{A}(x) \leq 1$, т.е. допускается случай, 
когда сумма значений $\mu_{A}(x)$ и $v_{A}(x)$ меньше единицы. Таким образом, в рассмотрение вводится еще один параметр, называемый степенью нерешительности (сомнения, неуверенности - hesitancy degree) и определяемый как:

$$
\pi_{A}(x)=1-\mu_{A}(x)-v_{A}(x) ; \quad 0 \leq \pi_{A}(x) \leq 1 .
$$

Имеется в виду, что эксперт зачастую затрудняется определить значения функции принадлежности $\mu_{A}(x)$ и непринадлежности $v_{A}(x)$ элемента $x$ множеству $A$ в силу недостоверности располагаемых им данных или отсутствия у него достаточно полной информации. При этом всегда имеет место равенство $\mu_{A}(x)+v_{A}(x)+\pi_{A}(x)=1$. Очевидно, что если $\pi_{A}(x)=0$, то мы имеем дело с обычным нечетким множеством, где $\mu_{A}(x)+v_{A}(x)=1$.

Веса связей в интуиционистской НКК задаются в виде значений принадлежности и непринадлежности веса $W_{i j}$ соответствующему нечеткому подмножеству, т.е. парой чисел $\left\langle W_{i j}^{\mu}, W_{i j}^{v}\right\rangle$, или с помощью значений принадлежности и степени нерешительности $<W_{i j}^{\mu}, W_{i j}^{\pi}>$. Эти способы задания весов равноценны, поскольку всегда выполняется условие $W_{i j}^{\pi}=1-W_{i j}^{\mu}-W_{i j}^{v}$.

В отношении расчета переменных состояния концептов авторами работы [135] предложены два различных подхода:

1) концепция интуиционистского НМ, основанная на введении понятия степени нерешительности $W_{i j}^{\pi}$, используется только при определении силы взаимного влияния концептов $W_{i j}$ (соответствующий вариант интуиционистской НКК получил в [35] обозначение $i F C M-\mathrm{I})$;

2) интуиционистская оценка нерешительности используется как при определении силы взаимного влияния $\widetilde{W}_{i j}$, так и для определения текущего состояния каждого концепта $C_{i}$ на основе уравнения (3.1), т.е. состояние каждого концепта описывается парой значений $<X_{i}^{\mu}, X_{i}^{v}>$ в терминах принадлежности и непринадлежности соответствующему подмножеству (значению лингвистической переменной $\left.\widetilde{X}_{i}\right),-$ данный вариант интуиционистской НКК авторы [135] назвали $i F C M$-II).

Учитывая более высокую сложность модели $i F C M$-II по сравнению с моделью $i F C M$-I, выберем для дальнейшего анализа более простой вариант интуиционистской НКК - когнитивную карту iFCM-I, уравнения состояния которой принимают в данном случае следующий вид [132]: 


$$
X_{i}(t+1)=f\left(X_{i}(t)+\sum X_{i}(t) W_{j i}^{\mu}\left(1-W_{j i}^{\pi}\right)\right), \quad(i=1,2, \ldots, n) \cdot(3.15)
$$

Заметим, что весовой фактор $W_{j i}^{\mu}\left(1-W_{j i}^{\pi}\right)$ принимает нулевое значение, если два концепта $C_{j}$ и $C_{i}$ не связаны между собой $\left(W_{j i}=0\right)$ или если степень нерешительности $W_{j i}^{\pi}$ становится равной 1 .

Перейдем непосредственно к задаче оценке рисков кибербезопасности АСУ ТП с использованием сценарного моделирования на основе рассмотренных выше разновидностей НКК и их ансамбля.

\subsection{2 Использование аппарата обобщенных НКК для оценки риска кибербезопасности промышленной сети АСУ ТП нефтедобывающего предприятия}

В качестве исследуемого объекта защиты рассматривается АСУ ТП нефтедобывающего предприятия, интегрированная в комплексную систему оперативного контроля и управления в реальном масштабе времени, и позволяющая передавать накапливаемые технологические данные в системы управления производственными процессами вышележащих уровней. Технологическая цепочка включает основные элементы: добыча нефти, сбор нефти, подготовка нефти, транспортировка товарной нефти.

Обобщенная структурная схема территориально распределенной системы обустройства месторождения $[140,141]$ и транспорта товарной нефти (ТТН) представлена на рис. 3.23.

На данном рисунке УПН - установка подготовки нефти; ЦПС центральный пункт сбора; НПС - нефтеперекачивающая станция; ПСП - приемо-сдаточный пункт; ГСС - газосборная сеть; 1 - ВПТ внутри промысловой трубопровод; ДС - добывающие скважины; $\mathrm{HC}$ - нагнетающая скважина; ВС - водозаборная скважина; КС - куст скважин; 2 - водовод; 3 - нефтесборный трубопровод; МН - магистральный нефтепровод; АГЗУ - автоматическая групповая замерная установка; ДНС - дожимная насосная станция; УПСВ - установка предварительного сбора воды; КНС - кустовая насосная станция.

Согласно терминологии ГОСТ 62443-3-3-2016, необходимо реализовать несколько стадий анализа и моделирования объекта защиты. Первой стадией является создание референсной модели объекта защиты, позволяющей выделить основные виды деятельности, техноло- 
гические цепочки и процессы, АСУ и прочие активы, распределенные по 5 логическим уровням.

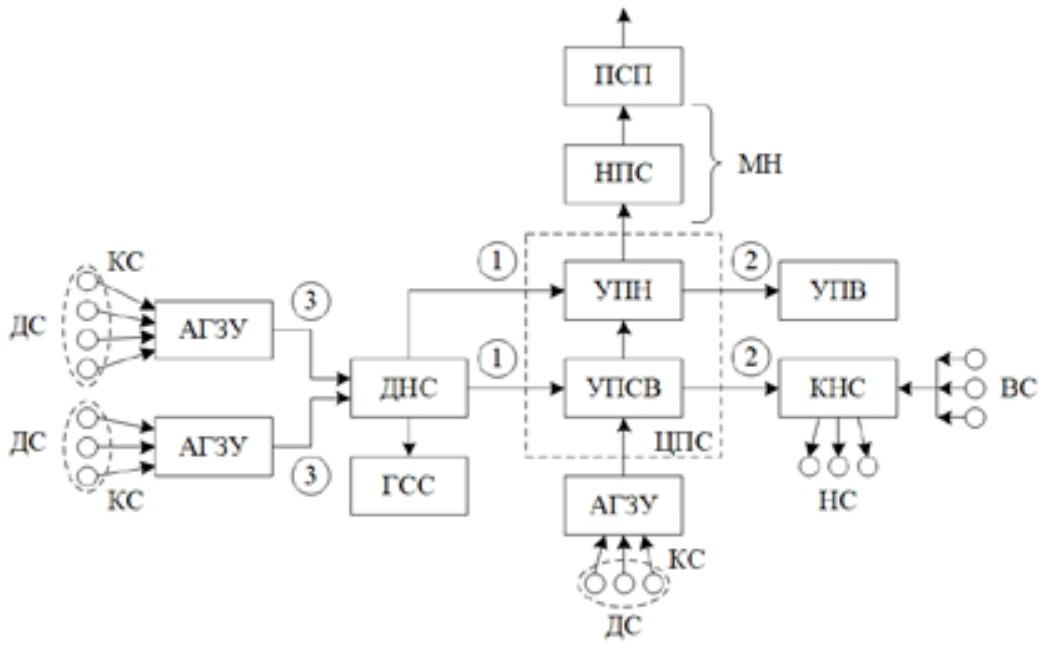

Рис. 3.23. Обобщенная структурная схема территориально-распределенной системы обустройства месторождения и транспорта товарной нефти

Подсистемы АСУ ТП месторождения можно рассматривать как отдельные зоны безопасности, объединяемые по принципу единства выполняемых функций и требований к безопасности их реализации. Ввиду сложности анализируемого объекта, рассмотрим фрагмент референсной модели архитектуры АСУ ТП месторождения, включающий основные элементы АСУ кустовых площадок, телекоммуникационное оборудование, линии связи и т.П. (рис. 3.24).

Основные последствия реализации атак на АСУ кустовых площадок:

- останов кустовой площадки;

- блокировка систем противоаварийной защиты;

- блокировка автоматизированных систем пожаротушения;

- потеря возможности мониторинга параметров оборудования и ТП;

- перевод объекта в аварийный режим.

Согласно отчетам «Лаборатории Касперского» и Positive Technologies [142-144], наиболее часто подвергаются атакам следующие элементы промышленных систем: $S C A D A$-системы, ПЛК, инфраструктура и ОС, сетевые протоколы. 


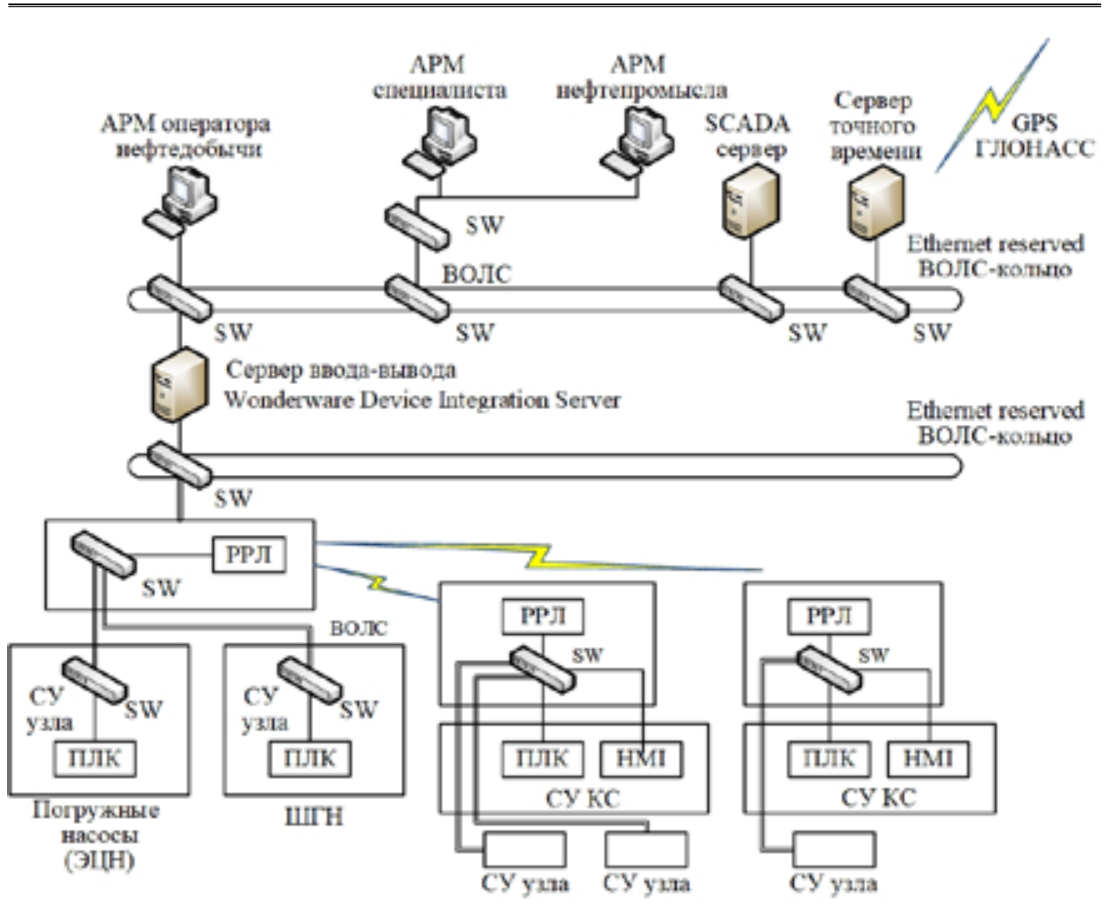

Рис. 3.24. Фрагмент референсной модели архитектуры АСУ ТП кустовых площадок

Для рассматриваемого фрагмента референсной модели архитектуры АСУ ТП кустовых площадок на основе данных BSI [145], предлагается проанализировать возможные векторы атак, реализуемые внутренним злоумышленником (в последнем случае, это такие атаки, как: подмена исполняемые файлов ПО серверов и АРМ, перезапись программируемых логических контроллеров (ПЛК) в ходе работы системы, отказ в обслуживании оборудования).

Исходя из сформированного списка векторов атак и последствий их реализации, рассмотрим задачу анализа рисков кибербезопасности промышленных объектов с учетом воздействия на систему возможных внутренних угроз, используя в качестве инструмента моделирования аппарат когнитивного моделирования. Когнитивная карта для оценки рисков кибербезопасности АСУ ТП кустовых площадок представлена на рис. 3.25. Основные концепты когнитивной карты приведены в табл. 3.18. 


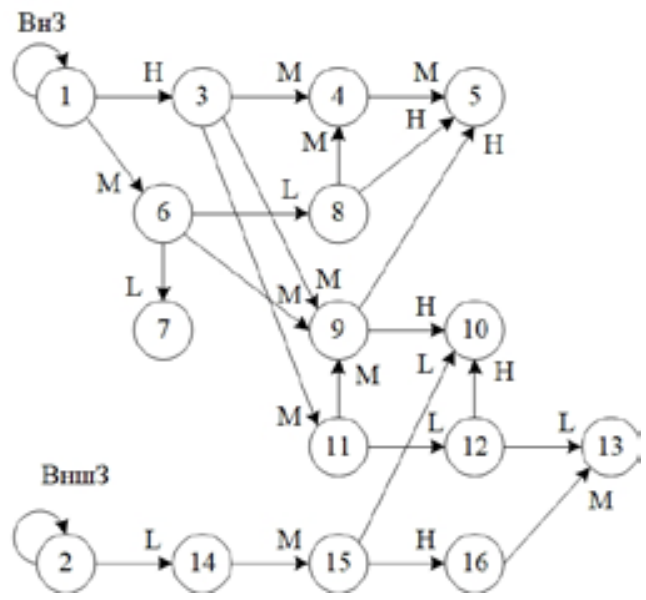

Рис. 3.25. Когнитивная карта для оценки рисков кибербезопасности АСУ ТП

Т аблица 3.18

Список концептов когнитивной карты анализа рисков кибербезопасности промышленного объекта

\begin{tabular}{|c|l|}
\hline Концепт & \multicolumn{1}{|c|}{ Название концепта } \\
\hline$C_{1}$ & Воздействие внутреннего злоумышленника \\
\hline$C_{2}$ & Воздействие внешнего злоумышленника \\
\hline$C_{3}$ & Физический доступ к АРМ оператора \\
\hline$C_{4}$ & Авторизация с правами легитимного пользователя системы \\
\hline$C_{5}$ & $\begin{array}{l}\text { Несанкционированное управление кустовой площадкой. Целевой } \\
\text { концепт }\left(X_{5}\right) .\end{array}$ \\
\hline$C_{6}$ & $\begin{array}{l}\text { Эксплуатация уязвимостей сетевого оборудования и/или ошибок кон- } \\
\text { фигурации }\end{array}$ \\
\hline$C_{7}$ & $\begin{array}{l}\text { Отказ в обслуживании сети нижнего уровня промышленного объекта. } \\
\text { Целевой концепт }\left(X_{7}\right) .\end{array}$ \\
\hline$C_{8}$ & $\begin{array}{l}\text { Прослушивание сетевого трафика и перехват данных учетных запи- } \\
\text { сей пользователей }\end{array}$ \\
\hline$C_{9}$ & $\begin{array}{l}\text { Изменение алгоритма управления объектами промышленной систе- } \\
\text { мы за счет модификации конфигурационных файлов } P L C \text { (использо- } \\
\text { вание протоколов } H T T P+F T P)\end{array}$ \\
\hline
\end{tabular}


Окончание табл. 3.18

\begin{tabular}{|c|l|}
\hline Концепт & \multicolumn{1}{|c|}{ Название концепта } \\
\hline$C_{10}$ & $\begin{array}{l}\text { Нарушение логики работы промышленного объекта. Целевой кон- } \\
\text { цепт }\left(X_{10}\right) .\end{array}$ \\
\hline$C_{11}$ & $\begin{array}{l}\text { Доступ к ОС через протоколы SSH/Telnet (эксплуатация уязвимостей } \\
\text { удаленного доступа) }\end{array}$ \\
\hline$C_{12}$ & $\begin{array}{l}\text { Эксплуатация уязвимостей датчиков сбора параметров технического } \\
\text { объекта (-ов) и подмена конфигурационных файлов }\end{array}$ \\
\hline$C_{13}$ & $\begin{array}{l}\text { Модификация актуальных параметров телеметрии (нарушение це- } \\
\text { лостности). Целевой концепт }\left(X_{13}\right) .\end{array}$ \\
\hline$C_{14}$ & $\begin{array}{l}\text { Подмена сигнала точного времени в зоне приема антенны }(G P S / \\
\text { ГЛОНАСС) }\end{array}$ \\
\hline$C_{15}$ & Установка некорректного времени на сервере точного времени $(N T P)$ \\
\hline$C_{16}$ & $\begin{array}{l}\text { Нарушение последовательности технологических событий, отобра- } \\
\text { жаемых в } S C A D A \text { системе }\end{array}$ \\
\hline
\end{tabular}

Рассмотрим три варианта реализации НКК (обычная НКК, серая НКК и интуиционистская НКК). В табл. 3.19 приведены значения весов связей между концептами, определенные экспертами.

Т а блица 3.19

Веса связей между концептами НКК

\begin{tabular}{|c|c|c|c|c|}
\hline $\begin{array}{c}\text { Вес связи } \\
\boldsymbol{C}_{i} \rightarrow \boldsymbol{C}_{j}\end{array}$ & Обычная НКК & Серая НКК & \multicolumn{2}{|c|}{$\begin{array}{c}\text { Интуиионистская НКК } \\
(\mathbf{i F C M - I})\end{array}$} \\
\hline$\widetilde{W}_{i j}$ & $W_{i j}$ & {$\left[\underline{W}_{i j}, \bar{W}_{i j}\right]$} & $W_{j i}^{\mu}$ & $W_{j i}^{\pi}$ \\
\hline$\widetilde{W}_{11}$ & 1 & {$[1 ; 1]$} & 1 & 0 \\
\hline$\widetilde{W}_{13}$ & 0,725 & {$[0,6 ; 0,85]$} & 0,725 & 0,1 \\
\hline$\widetilde{W}_{16}$ & 0,475 & {$[0,35 ; 0,6]$} & 0,475 & 0,25 \\
\hline$\widetilde{W}_{22}$ & 1 & {$[1 ; 1]$} & 1 & 0 \\
\hline$\widetilde{W}_{214}$ & 0,25 & {$[0,15 ; 0,35]$} & 0,25 & 0,1 \\
\hline$\widetilde{W}_{34}$ & 0,475 & {$[0,35 ; 0,6]$} & 0,475 & 0,25 \\
\hline$\widetilde{W}_{39}$ & 0,475 & {$[0,35 ; 0,6]$} & 0,475 & 0,25 \\
\hline
\end{tabular}


Гиава 3

Окончание табл. 3.19

\begin{tabular}{|c|c|c|c|c|}
\hline $\begin{array}{c}\text { Вес связи } \\
\boldsymbol{C}_{i} \rightarrow \boldsymbol{C}_{j}\end{array}$ & Обычная НКК & Серая НКК & \multicolumn{2}{|c|}{$\begin{array}{c}\text { Интицонистская НКК } \\
\text { (iFCM-I) }\end{array}$} \\
\hline$\widetilde{W}_{311}$ & 0,475 & {$[0,35 ; 0,6]$} & 0,475 & 0,25 \\
\hline$\widetilde{W}_{45}$ & 0,475 & {$[0,35 ; 0,6]$} & 0,475 & 0,25 \\
\hline$\widetilde{W}_{67}$ & 0,25 & {$[0,15 ; 0,35]$} & 0,25 & 0,25 \\
\hline$\widetilde{W}_{68}$ & 0,25 & {$[0,15 ; 0,35]$} & 0,25 & 0,1 \\
\hline$\widetilde{W}_{69}$ & 0,475 & {$[0,35 ; 0,6]$} & 0,475 & 0,25 \\
\hline$\widetilde{W}_{84}$ & 0,475 & {$[0,35 ; 0,6]$} & 0,475 & 0,25 \\
\hline$\widetilde{W}_{85}$ & 0,725 & {$[0,6 ; 0,85]$} & 0,725 & 0,1 \\
\hline$\widetilde{W}_{95}$ & 0,725 & {$[0,6 ; 0,85]$} & 0,725 & 0,1 \\
\hline$\widetilde{W}_{910}$ & 0,725 & {$[0,6 ; 0,85]$} & 0,725 & 0,1 \\
\hline$\widetilde{W}_{119}$ & 0,475 & {$[0,35 ; 0,6]$} & 0,475 & 0,25 \\
\hline$\widetilde{W}_{1112}$ & 0,25 & {$[0,15 ; 0,35]$} & 0,25 & 0,1 \\
\hline$\widetilde{W}_{1210}$ & 0,725 & {$[0,6 ; 0,85]$} & 0,725 & 0,25 \\
\hline$\widetilde{W}_{1213}$ & 0,25 & {$[0,15 ; 0,35]$} & 0,25 & 0,1 \\
\hline$\widetilde{W}_{1415}$ & 0,475 & {$[0,35 ; 0,6]$} & 0,475 & 0,25 \\
\hline$\widetilde{W}_{1510}$ & 0,25 & {$[0,15 ; 0,35]$} & 0,25 & 0,1 \\
\hline$\widetilde{W}_{1516}$ & 0,725 & {$[0,6 ; 0,85]$} & 0,725 & 0,25 \\
\hline$\widetilde{W}_{1613}$ & {$[0,35 ; 0,6]$} & 0,475 & 0,475 \\
\hline
\end{tabular}

Рассмотрим сценарий когнитивного моделирования воздействия внутреннего злоумышленника (активация концепта-драйвера $C_{1}$ ), эксплуатирующего уязвимости программных и аппаратных компонент системы, с применением указанных в $C_{1}$ вариантов построения НКК.

Для НКК и интуиционистской когнитивной карты изменение во времени состояний концептов приведено на рис. 3.26. 
Л.Р. Черняховская, В.И. Васильев, В.Е. Гвоздев, Н.О. Никулина, А.И. Малахова, А.М. Вульфин, О.Я. Бежаева

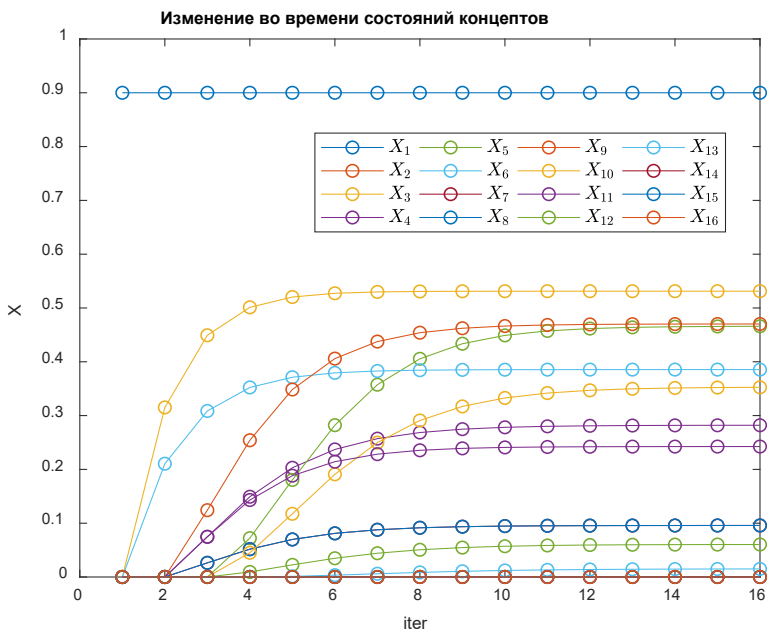

a)

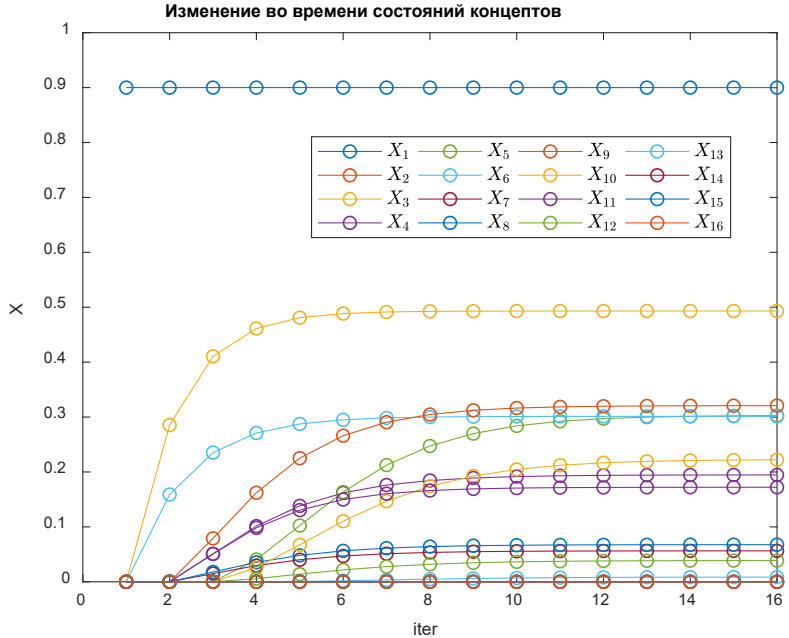

б)

Рис. 3.26. Изменение во времени состояний концептов НКК (а) и ИНКК (б) 
Изменение параметров состояний концептов СНКК («серость» и «белизна» оценки состояния) показаны на рис. 3.27.

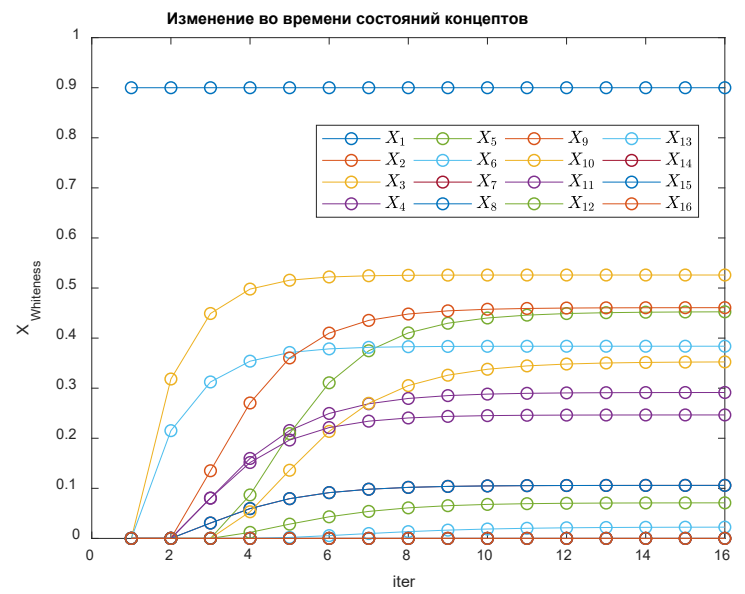

a)

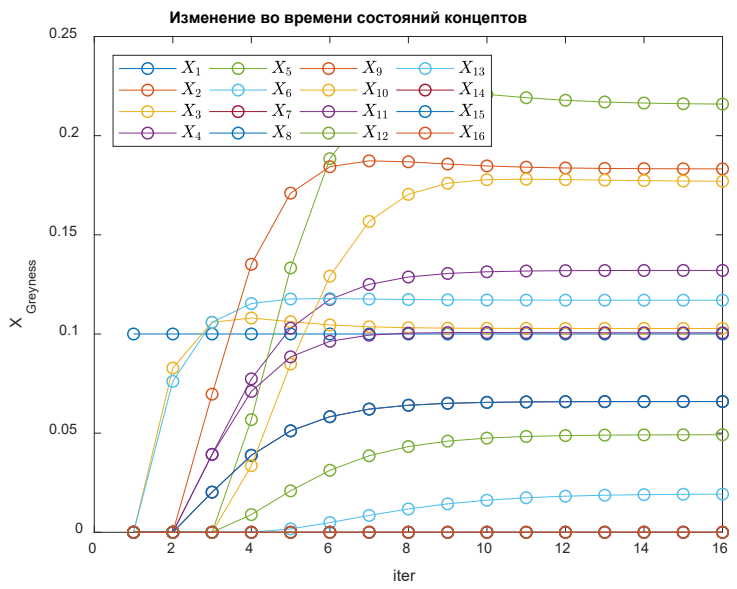

б)

Рис. 3.27. Изменение во времени состояний концептов СНКК:

(а) стабилизация «белого» значения концепта (б) стабилизация «серости» концепта 
В табл. 3.20 и на рис. 3.28 показаны результаты моделирования локальных относительных рисков угроз кибербезопасности промышленного объекта для целевых концептов: $C_{5}, C_{7}, C_{10}, C_{13}$.

Та блица 3.20

Итоговые результаты моделирования локальных относительных рисков угроз кибербезопасности промышленного объекта

\begin{tabular}{|l|c|c|c|c|}
\hline \multicolumn{1}{|c|}{ Тип НКК } & $\boldsymbol{R}_{\mathbf{5}}$ & $\boldsymbol{R}_{\mathbf{7}}$ & $\boldsymbol{R}_{\mathbf{1 0}}$ & $\boldsymbol{R}_{\mathbf{1 3}}$ \\
\hline НКК & 0,466 & 0,096 & 0,353 & 0,015 \\
\hline СНКК & 0,453 & 0,106 & 0,353 & 0,023 \\
\hline ИНКК & 0,303 & 0,057 & 0,223 & 0,009 \\
\hline$\underline{R}_{i}$, СНКК & 0,237 & 0,040 & 0,176 & 0,003 \\
\hline $\bar{R}_{i}$, СНКК & 0,669 & 0,171 & 0,530 & 0,042 \\
\hline Среднее для всех карт & 0,407 & 0,086 & 0,310 & 0,015 \\
\hline Отклонение & 0,070 & 0,020 & 0,058 & 0,005 \\
\hline
\end{tabular}

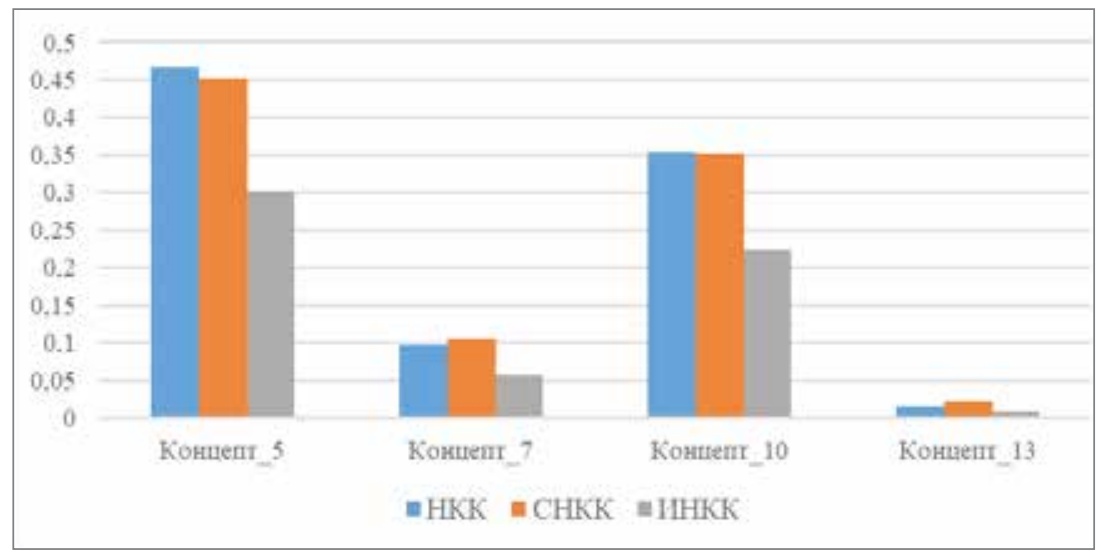

Рис. 3.28. Локальные относительные риски $R_{\mathrm{i}}$ для целевых концептов $C_{5}, C_{7}, C_{10}, C_{13}$

Под локальным относительным риском $R_{\mathrm{i}}$ понимается потенциальный ущерб, наносимый $i$-ому активу АСУ ТП предприятия (в относительных единицах) и приводящей к нарушению целостности телеме- 
трической информации, содержащей сведения о балансе материальных потоков на объекте (дебит жидкости, энергетические затраты и др.), и к нарушению хода самого ТП. Предполагается, что значение риска вычисляется как $R_{i}=X_{i}^{*}$, где $X_{i}^{*}$ - установившееся значение состояния $i$-го целевого концепта $(i=5,7,10,13)$.

Заметим, что средневзвешенная оценка локальных рисков, формируемая с помощью ансамбля когнитивных карт (см. табл. 3.20), более предпочтительна с точки зрения разброса оценок состояния целевых концептов, чем использование отдельных НКК. Разброс оценок состояния концептов ансамбля меньше, чем разброс оценок их серых значений с помощью СНКК, в среднем в 1,5-1,7 раза, что говорит о снижении влияния фактора субъективности на результаты оценки рисков. Как следует из рис. 3.28 и табл. 3.20, наибольшее значение риска $R_{5}=X_{5}^{*}=0,41$ соответствует целевому концепту $C_{5}$ («Несанкционированное управление кустовой площадкой»), что, в свою очередь, указывает на необходимость принятия дополнительных мер по снижению этого показателя. Это может быть сделано в частности посредством применения соответствующих средств защиты информации: межсетевых экранов для сегментирования промышленной сети, локализации сетевого трафика внутри виртуальных сетей и т.п. Основные недостатки существующей конфигурации связаны с использованием учетных записей и параметров промышленных контроллеров и сетевого оборудования, задаваемых производителем по умолчанию. Аналогичные мероприятия, направленные на снижение других показателей риска, позволят обеспечить предъявляемые требования к обеспечению кибербезопасности АСУ ТП. Как показало сценарное моделирование, применение указанных средств защиты и организационных мер позволяет снизить оценку локальных рисков на 10-15\%.

Таким образом, применение предложенной методики позволяет дать обоснованную качественную и количественную оценку показателей рисков обеспечения кибербезопасности АСУ ТП с учетом мнений экспертов -специалистов в рассматриваемой предметной области, что, в свою очередь, может явиться основой для выбора эффективных защитных контрмер в соответствии с требованиями существующих нормативных документов. 


\title{
ГЛАВА 4
}

\section{ИННОВАЦИОННОЕ РАЗВИТИЕ ПРОИЗВОДСТВЕННО-ЭКОНОМИЧЕСКИХ СИСТЕМ НА ПРИМЕРЕ СОЗДАНИЯ «УМНЫХ» ПРЕДПРИЯТИЙ}

\author{
4.1. Влияние доктрины «Индустрия 4.0 » на развитие \\ интеллектуальных информационных технологий \\ управления производственно-экономическими системами
}

\subsection{1. Основные положения доктрины «Индустрия 4.0»}

Бизнесмены и политические деятели в равной степени осознали возможности роста, связанные с цифровизацией, коммуникациями и новыми производственными технологиями. Это явление, вызывающее к жизни инновационные бизнес-модели, поддерживающее эффективное использование ограниченных ресурсов, обеспечивающее получение продукции, ориентированной на индивидуальные запросы потребителей при низкой себестоимости, получило название «Индустрия 4.0» [146]. Практическая реализация положений «Индустрии 4.0» предполагает беспрецедентное изменение, гибкость и скорость перестройки промышленного производства.

Основная цель анализа текущего состояния предприятий в рамках реализации доктрины «Индустрии 4.0» - выявление областей, требующих реализации первоочередных действий с тем, чтобы преобразовать предприятия к виду «умного предприятия». Систематическая идентификация возможностей сильных и слабых сторон предприятия, факторов, препятствующих улучшениям бизнес-процессов, создают базу разработки стратегии их преобразований.

Термин «Индустрия 4.0» используется с 2011 года для описания радикальных преобразований промышленных предприятий на основе широкомасштабной интеграции информационных и коммуникационных технологий с промышленным производством. Однако не следует все сводить лишь к производственной сфере. Реализация четвертой промышленной революции предполагает трансформацию организации и корпоративной культуры предприятия. Развитие информацион- 
ных технологий открывает возможность доступа к новой, ранее недоступной информации и новым знаниям. Глобальная цель преобразований, производимых на предприятии состоит в том, чтобы сделать его обучаемым, способным быстро и гибко перестраиваться в темпе изменения состояния окружающей среды, т.е. обеспечить коэволюцию структуры, параметров и алгоритмов функционирования предприятия и состояния внешней среды.

Многие организации не в полной мере осознают содержание доктрины «Индустрии 4.0». Часто «Индустрия 4.0» ограничивается цифровизацией, либо полной автоматизацией технологических процессов. Более того, многие действия ориентированы на решение локальных задач, вместо постановки глобальной цели, состоящей в извлечении знаний из данных для преобразования предприятия в обучаемую и гибко адаптируемую организацию.

В материалах Федерального Министерства экономики и энергетики Германии (German Federal Ministry of Economics and Energy $B M W i)$ отмечается, что во многом недостаточная эффективность деятельности, направленной на обеспечение соответствия свойств предприятий тем, которые определены в доктрине «Индустрия 4.0», обусловлена отсутствием инструментов для постоянного отслеживания преимуществ, связанных со следованием этой идеологии (в особенности это относится к малым и средним предприятиям). Это, в совокупности с неопределенностью технологических и финансовых целей, является серьезным препятствием для инвестирования в развитие предприятий. В настоящее время единственным мерилом таких преимуществ являются случайные пилотные проекты, фактически направленные на совершенствование технологических возможностей предприятия. Реализация подобных проектов не позволяет продемонстрировать полный потенциал доктрины «Индустрия 4.0», так как при этом остаются вне зоны внимания такие ключевые факторы как организационная структура и корпоративная культура предприятия. К тому же часто не находят должного освещения процессы, протекающие внутри предприятия и представляющие собой потенциальные источники новых знаний, а также актуальные потребности предприятий.

Особенностью современного бизнеса является высокая конкуренция. Как следствие, если предприятие желает оставаться конкурентоспособным, его руководству необходимо быстро принимать правильные решения, адекватные изменениям, происходящим во внешней и вну- 
тренней среде. Сложившаяся к настоящему времени бизнес-практика не способна на это. Процесс принятия решений может растягиваться до недель и месяцев, в основе принимаемых решений лежит интуиция, но не результаты обработки данных и новые знания. Производство основывается на совокупности оформленных в виде документов требований и спецификаций продуктов, которые составляются без всестороннего изучения потребностей пользователей. Изучение нового создает возможности лишь для внесения ограниченных изменений в процессы проектирования и производства, причём эти изменения требуют длительного времени. Многие предприниматели и ЛПР тратят много времени на поиск нужной информации. И это лишь некоторые примеры недостатков существующей системы, которая требует преобразований.

Стратегическим потенциалом доктрины «Индустрия 4.0» является возможность ускорить корпоративные процессы принятия решений и адаптации структуры и параметров предприятия в темпе изменений состояния окружающей среды. Результатом является повышение эффективности процессов проектирования и производства продукции, продаж, маркетинга и послепродажного обслуживания. Кроме того, происходят изменения как в бизнесе в целом, так и в отдельных бизнес-единицах и бизнес-моделях. Признаками «Индустрии 4.0» являются:

- выполнение процессов в реальном времени;

- большие объемы данных;

- одновременное использование в производственных процессах различных материалов;

- взаимодействие киберфизических систем и людей.

Возможность доступа сотрудников предприятия к большим объемам данных, информации и новым знаниям в режиме реального времени создает возможность лучшего понимания устройства окружающего мира, что, в свою очередь, создает базу для сокращения времени принятия обоснованных решений. В совокупности со сбалансированными ресурсной, организационной структурами, а также высокой производственной культурой, это позволяет предприятию быстрее и адекватнее изменять свойства продуктов в соответствии с изменяющимися потребностями покупателей, экспоненциально ускорить выход новых продуктов на рынок. Ключевым требованием в рамках доктрины «Индустрия 4.0», ее отличительным признаком, является взаимопроникно- 
вение (рассмотрение как единого целого) ресурсной, организационной, информационной составляющих и корпоративной культуры. Предприятие сможет реализовать весь потенциал доктрины «Индустрия 4.0» только в том случае, если оно полностью реализует описанное выше во всех бизнес-процессах, а также при условии, что потоки данных и процессы обработки данных будут прозрачными во всей организации [147].

\section{2. Методологическая основа построения «умного» предприятия}

\subsection{1. Основные компоненты методологии построения "умного» предприятия}

Методологическую основу построения обучаемого предприятия составляет системная интеграция проектно-ориентированного и практико-ориентированного подходов. Платформой для реализации этого является проведение семинаров по изучению различных проблемных ситуаций, возникающих при реализации проектов. Изучение ситуаций позволяет исследовать «содержание явления во времени». Такой подход целесообразно использовать в случае, когда трудно установить границы между внешними признаками явления и его внутренним содержанием. Целесообразность интеграции проектно-ориентированного и практико-ориентированного подходов обусловлена тем, что особенность задач, связанных с реализацией доктрины «Индустрия 4.0», состоит в их уникальности. Для снижения неопределенности проводятся семинары, в рамках которых происходит выработка консолидированных решений по урегулированию проблемных ситуаций, обмен опытом между сотрудниками предприятия, являющихся специалистами в своих предметных областях, устранение барьеров, обусловленных различиями семантических пространств специалистов, добровольная кооперация сотрудников. Результатами подобных семинаров и совещаний являются венчурная кооперация сотрудников предприятия, сокращение времени на планирование и реализацию проектов.

На рис. 4.1 представлена методология построения обучаемого предприятия на основе знаний специалистов и анализа практического опыта. 


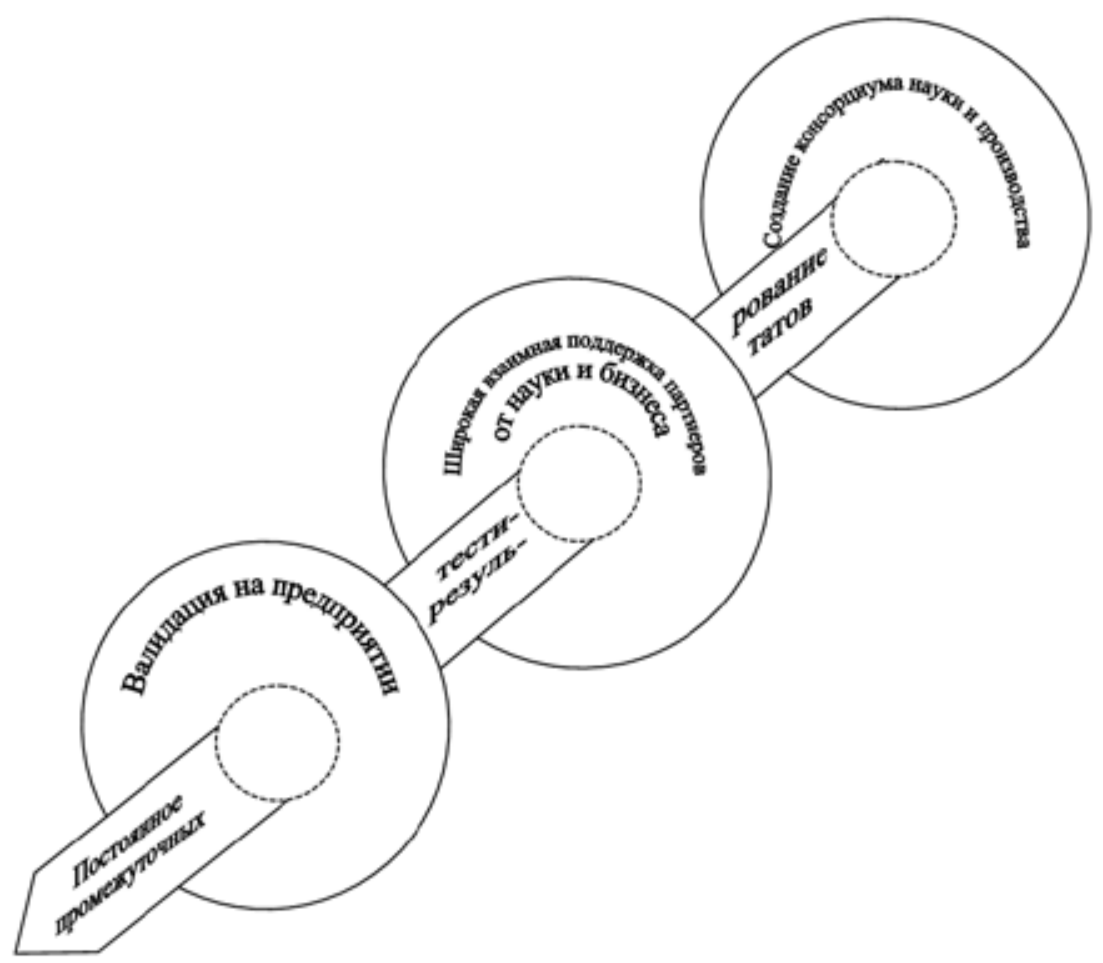

Рис. 4.1. Методология построения обучаемого предприятия

Методология исследований разбивается на четыре компонента, три из которых настраиваются на четвертый - системообразующий компонент, представляющий собой постоянное исследование новшеств и, как стержень, объединяющий все части в единое целое.

Первый компонент «Создание консорциума науки и производства» обеспечивает базу для последующей деятельности. Второй компонент «Широкая взаимная поддержка партнеров от науки и бизнеса» позволяет организовать сбалансированное сотрудничество между ними. Консорциум регулярно проводит тематические обсуждения, на которых участники получают актуальные сведения, позволяющие им оценивать прогресс от их деятельности. Сведения, являющиеся результатом совещаний, в последующем проходят валидацию на предприятии 
(третий компонент). Назначение четвертого компонента - постоянное тестирование промежуточных результатов. Имея целью постоянное совершенствование бизнес-процессов, «находки», обнаруженные в результате проведения совещаний по проекту, используются для совершенствования деятельности всего предприятия.

\subsection{2. Стадии преобразования производственно-экономической системы к виду "умного» предприятия}

Индекс зрелости является параметром, играющим роль индикатора и предназначенного для оценки того, на какой стадии движения к обучаемой и способной гибко перестраиваться производственно-экономической системе находится в настоящее время промышленное предприятие. Оценивание ведётся с точек зрения ресурсной, организационной и производственной культуры. При этом фокусом исследований являются бизнес-процессы.

Путь в «Индустрию 4.0» будет своим у каждого предприятия. Начинать следует с оценки текущего состояния и целей предприятия, задав следующие вопросы:

- каковы стратегические цели на ближайшие 3-5 лет?

- какие технологии и информационные системы используются в настоящее время?

- что является инструментальной базой технологий и платформой построения информационных систем?

Ответы на эти вопросы позволяют определить, какие свойства необходимо приобрести предприятию для того, чтобы соответствовать положениям доктрины «Индустрия 4.0». Важно осознать, что успешные преобразования осуществляются поэтапно. Более того, каждое предприятие должно принять принципиальное решение относительно того, какие именно выгоды оно желает получить, выполнить их приоритезацию и определить последовательность реализации действий по их получению. Результатом является разработка дорожных карт для всех направлений деятельности, что позволит шаг за шагом двигаться к поставленным целям. Наличие дорожных карт способствует пониманию предприятием важности комплексной цифровизации бизнеса как основы реализации стратегических преобразований (рис. 4.2)[148]. 


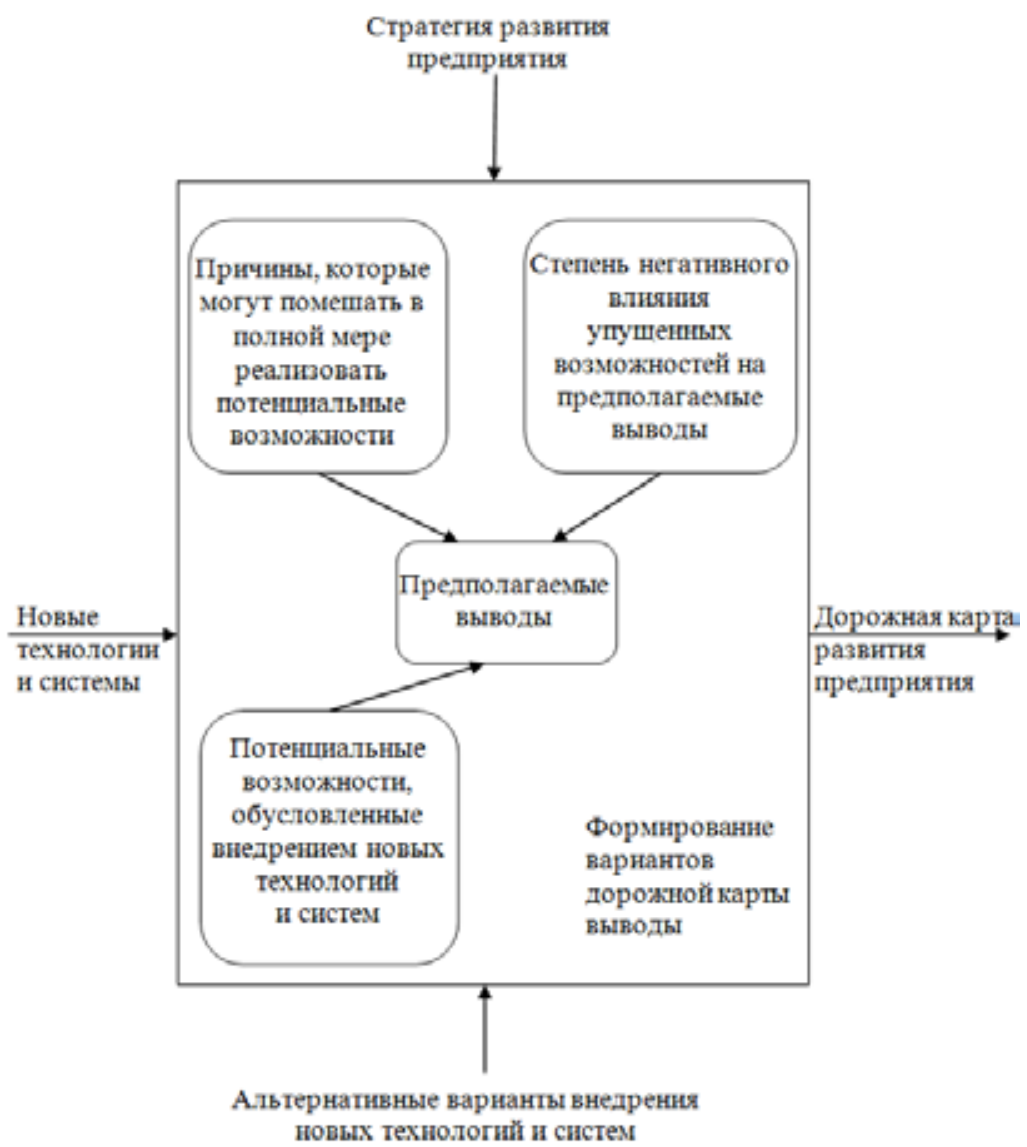

Рис. 4.2. Системные факторы дорожной карты развития предприятия

Реализация каждой стадии обеспечивает переход предприятия на новый уровень развития, что и должен отображать индекс зрелости. Способ реализации каждой стадии определяется предприятием самостоятельно. Каждое предприятие должно само определить приемлемый для неё в настоящий период времени уровень зрелости, при котором обеспечивается наилучшее соотношение между затратами, возможностями и выгодами от того состояния, в котором находится предприятие. 
Изменение предприятия в рамках реализации положений доктрины «Индустрия 4.0» в силу сложности реализуемых преобразований занимает несколько лет. Преобразования должны быть сбалансированы и реализовываться таким образом, чтобы положительный эффект от них был очевиден на каждом шаге.

Типовая схема преобразования включает в себя пять стадий (табл. 4.1). Каждая последующая стадия базируется на результатах предыдущей. Каждой стадии ставятся в соответствие необходимые стартовые условия, без наличия которых невозможно осуществить преобразования. Важно осознавать тот факт, что эти стартовые условия создаются шаг за шагом, т.е. для того чтобы получить выгоды от реализации первой стадии, требуется иметь меньший потенциал по сравнению с тем, который необходим для реализации возможных выгод от второй стадии. Процесс преобразований представляет собой непрерывную последовательность шагов, которые выполняются инкрементально и не требуют точной синхронизации между бизнес-процессами предприятия. Каждое предприятие должно само определить, какая из стадий развития позволяет ему обеспечить наилучший баланс между затратами на преобразование и выгодами от них с учётом текущих условий функционирования. Состояние, соответствующее наилучшему балансу, является целью процесса преобразований.

Таблица 4.1

Стадии преобразования предприятия

\begin{tabular}{|l|l|}
\hline \multicolumn{1}{|c|}{ Наименование этапа } & \multicolumn{1}{|c|}{ Цели } \\
\hline Компьютеризация & $\begin{array}{l}\text { Создание на предприятии информационных систем, } \\
\text { поддерживающих основные бизнес-процессы }\end{array}$ \\
\hline Коммуникации & $\begin{array}{l}\text { Создание инфраструктуры для интеграции локальных } \\
\text { информационных систем }\end{array}$ \\
\hline $\begin{array}{l}\text { Создание цифровой } \\
\text { модели предприятия }\end{array}$ & $\begin{array}{l}\text { Получение сотрудниками полной информации в об- } \\
\text { ласти их профессиональной деятельности о текущем } \\
\text { и прогнозируемом состоянии предприятия }\end{array}$ \\
\hline $\begin{array}{l}\text { Прозрачность } \\
\text { транспарентность) }\end{array}$ & $\begin{array}{l}\text { Создание условий для понимания сотрудниками } \\
\text { предприятия причин, снижающих эффективность их } \\
\text { профессиональной деятельности }\end{array}$ \\
\hline $\begin{array}{l}\text { Предсказуемость } \\
\text { изменения состояния } \\
\text { предприятия }\end{array}$ & $\begin{array}{l}\text { Создание условий для генерации и анализа альтерна- } \\
\text { тивных вариантов перехода от текущего состояния } \\
\text { предприятия к желаемому }\end{array}$ \\
\hline
\end{tabular}


Следует обратить внимание на то, что компьютеризация и развитая коммуникационная платформа являются необходимыми предпосылками реализации положений доктрины «Индустрия 4.0», но не является частью этой доктрины.

Компьютеризация является необходимым условием создания цифровой экосреды. Как правило в настоящее время большинство компаний достаточно хорошо компьютеризировано, причём целью компьютеризации является повышение эффективности решения часто повторяющихся задач. Компьютеризация создает основу для получения серьезных преимуществ, например, снижения стоимости производимой продукции, повышения точности производственных процессов. На современных предприятиях имеется большое число технических устройств, не имеющих цифрового интерфейса (механизмы, управляемые вручную). Результатом «локальной компьютеризации» является неполная автоматизация контроля качества на всех стадиях жизненного цикла продукции. Как результат, достаточно сложно определить, какая работа является источником проблем с качеством. Создание терминальных устройств информационных систем в этом случае будет играть роль своеобразного переходника между бизнес-приложениями и техническими устройствами, что позволит интегрировать «умные» технические объекты в цифровую экосреду предприятия.

Коммуникации являются основой создания цифровой экосреды. При наличии цифровой экосреды бизнес-приложения, соотносимые с основными, вспомогательными и обеспечивающими процессами производства, оказываются информационно взаимосвязанными и являются стержнем гибко настраиваемого промышленного предприятия (см. рис. 4.1).

Информационная интеграция лишь основных процессов не обеспечивает создание цифровой экосистемы. Технологические процессы оказываются информационно взаимосвязанными, но полная интеграция технологий производства продукции и информационных технологий отсутствует. Это обусловлено тем, что не реализованы коммуникации с обеспечивающими и вспомогательными процессами.

Протоколы интернета (Internet Protocol - IP) используются все шире и шире при реализации производственных процессов. В силу того, что действующий протокол IP6 позволяет формировать гораздо более длинные адреса нежели его предшественник IP4, все информа- 
ционные компоненты теперь могут быть соединены без необходимости преобразования перевода сетевых адресов. Это является ключевым требованием для Интернета Вещей (Internet of things-IoI). Связанность означает, что, например, данные, возникшие на этапе проектирования, могут поступать на стадию производства, так что особенности производственного процесса могут быть согласованы с результатами проектирования $(C A D / C A M)$. Как только процесс производства будет завершен, информация об этом автоматически в режиме реального времени поступает в MES (Manufactoring Execution System). Помимо этого, доступность дешевых, позволяющих передавать большие объемы данных каналов создаёт возможность дистанционного обслуживания (ремонта) производителями приобретённых покупателем товаров.

Существующие производства представляют ценность до тех пор, пока они позволяют производить качественные продукты. В настоящее время нельзя признать нормальной ситуацию, когда по 50 и более лет не происходит смены оборудования в цехе. Вместе с тем, неразумно менять оборудование, на котором есть возможность производить пользующуюся спросом продукцию. В силу того, что интернет-технологии позволяют стандартизировать коммуникации, представляется возможность собирать данные, на основе которых можно вынести обоснованное суждение о ценности существующих производственных линий и целесообразности их замены.

Цифровая модель предприятия. Сенсоры позволяют постоянно отслеживать состояние бизнес-процессов, обеспечивая возможность производить измерения во множестве мест. Уменьшение стоимости сенсоров, микрочипов и сетевых технологий означает, что происходящие события и изменения состояний компонент системы могут регистрироваться в режиме реального времени не только в масштабах предприятия, но и во внешней по отношению к предприятию среде. Относительно недавно такое было возможно лишь в локальных областях, например, в отдельных подразделениях предприятий. Отслеживание состояния всего предприятия в режиме реального времени создает возможность в любой момент времени иметь актуальную цифровую модель предприятия, что, в свою очередь, создает условия для увеличения обоснованности принимаемых управленческих решений. Построение цифровой модели предприятия является основой для реализации положений доктрины «Индустрии 4.0». 
Построение цифровой модели - сложная проблема. Одна из причин заключается в отсутствии единого источника информации. Более того, реализация многих функций (производство, логистика, сервисы) порождает небольшое количество детализированных данных. Доступность данных лишь узкому кругу лиц приводит к отсутствию прозрачности об истинном положении дел на предприятии, что часто приводит к злоупотреблениям. Увеличению же числа пользователей препятствуют границы информационной системы и существующие регламенты управления бизнес-процессами.

Для того, чтобы предприятие стало гибко перестраиваемым и обучаемым, необходимо обеспечить сбор и возможность использования сотрудниками данных, дающих полноценное представление о состоянии всего предприятия. Тогда, в случае возникновения непредвиденных обстоятельств, оперативное оповещение руководителей производства, покупателей и поставщиков о смещении сроков поставки в режиме реального времени делает возможным своевременно скорректировать свои планы.

Возникновение цифровой экосистемы требует изменения концепции управления предприятием. Основанием для этого является единая цифровая модель всего предприятия, а не отдельных подсистем, что характерно для автоматизации отдельных процессов.

Прозрачность (транспарентность). Следующим после создания цифровой модели шагом реализации положений доктрины «Индустрия 4.0» является понимание того, что явилось причинами того состояния, в котором находится предприятие. Для выявления и установления причинно-следственных связей между наблюдаемыми симптомами и их коренными причинами требуется обработка собранных данных методами инженерии знаний. Семантическая увязка и агрегирование разнородных данных позволит получить новую информацию, осмысление которой даст новые знания, необходимые для принятия решений, направленных на развитие всей системы.

Важную роль в этом процессе играют технологии обработки больших массивов данных. Термином «Big Data» подчеркивается, что данные того объема, который необходим для формирования цифровой модели предприятия, нельзя обработать посредством тех технологий, которые традиционно используются для обработки данных, ассоциируемых с отдельными бизнес-процессами. Термином «Big Data» обозначают технологии и приложения, которые позволяют выполнить 
разноаспектную обработку исключительно больших по объему и разнородных по составу данных.

Как правило, приложения «Big Data» разворачиваются параллельно с вводом в эксплуатацию $E R P$ - и $M E S$-систем. За счет этого создается платформа для проведения разноаспектного анализа данных с целью выявления неявных связей между характеристиками и параметрами, представленными в цифровой модели предприятия. Одним из приложений в рамках такого анализа является мониторинг состояния машин и оборудования. Установление взаимосвязей между зафиксированными значениями характеристик состояния и событиями, происходящими на предприятии, позволяет на основе измерительных данных сделать обоснованное заключение о состоянии технических систем.

Помимо отмеченного выше, транспарентность создает базу для управления эксплуатацией и обслуживанием сложных технических систем на основе прогнозных оценок (predictive maintenance).

Предсказуемость изменения состояния предприятия. Транспарентность создает базу для симуляции различных сценариев развития текущей ситуации, что создает условия для выбора рационального управленческого решения. Иными словами, цифровая модель вовлечена в проектирование будущего состояния предприятия посредством разработки множества сценариев изменения текущего состояния предприятия и выбора из них наиболее предпочтительного. В силу того, что основу управления по прогнозу составляет реализация заранее проработанного сценария, увеличивается возможность предотвращения и сокращения масштабов негативных последствий. Уменьшение числа неожиданных событий, что достигается учетом в сценариях как штатных, так и нештатных вариантов состояний предприятия (различного рода отказы, либо отклонения от плана), повышает устойчивость бизнеса. Например, прогноз времени поломки детали делает возможным ее заблаговременную замену с тем, чтобы исключить саму возможность поломки.

Достоверность прогнозных оценок состояния предприятия определяется объемом выполненной предварительно работы. Должным образом созданная цифровая модель предприятия в совокупности с грамотно привлекаемыми знаниями при разработке сценариев моделирования обеспечивают гарантию того, что прогнозные оценки и основанные на них рекомендации в совокупности позволяют повысить устойчивость состояния и эффективность функционирования предприятия. 
Автоматизация принятия решений. Наличие формализованных прогностических моделей является обязательным условием построения автоматизированных систем поддержки принятия решений. Способность быстрой адаптации прогностических моделей к изменяющимся условиям окружающей среды позволяет использовать интеллектуальные информационные системы для принятия ряда решений.

Степень автоматизации процедур принятия решений зависит от сложности ситуации, в которой приходится принимать решение, и от соотношения «затраты-прибыль», ассоциируемого с решаемыми задачами. Достаточно часто целесообразно автоматизировать лишь отдельные подпроцессы в общем процессе подготовки и принятия решений. Из этого следует необходимость исследования принципиальной возможности автономной автоматизации повторяющихся процессов. Вместе с тем, необходимо тщательно оценить, насколько автоматизация окажется полезной с точки зрения взаимодействия предприятия с окружающей средой, в том числе, с покупателями и поставщиками. Например, учесть, насколько может повлиять отказ компонентов автоматизированной системы на установленный порядок выполнения операций на предприятии, либо на сроки поставок продукции. Основой автоматизации процедур принятия решений является наличие достоверной актуальной цифровой модели предприятия.

\section{3. Системная модель «умного» предприятия}

Системная модель предназначена для исследования внутреннего устройства предприятия с трех точек зрения (рис. 4.3):

- структура предприятия;

- процессы предприятия;

- направление развития предприятия.

Исследование структуры предполагает выделение компонентов, без которых предприятие не сможет выпускать продукцию и предоставлять сервисы. Исследование процессов основано на выделении цепочек процессов в каждой сфере деятельности предприятия. Исследование направления развития основано на изучении стратегии и операционной деятельности предприятия. Основными структурными компонентами архитектуры «умного предприятия» являются ресурсы, информационные системы, производственная культура, организационная структура. 


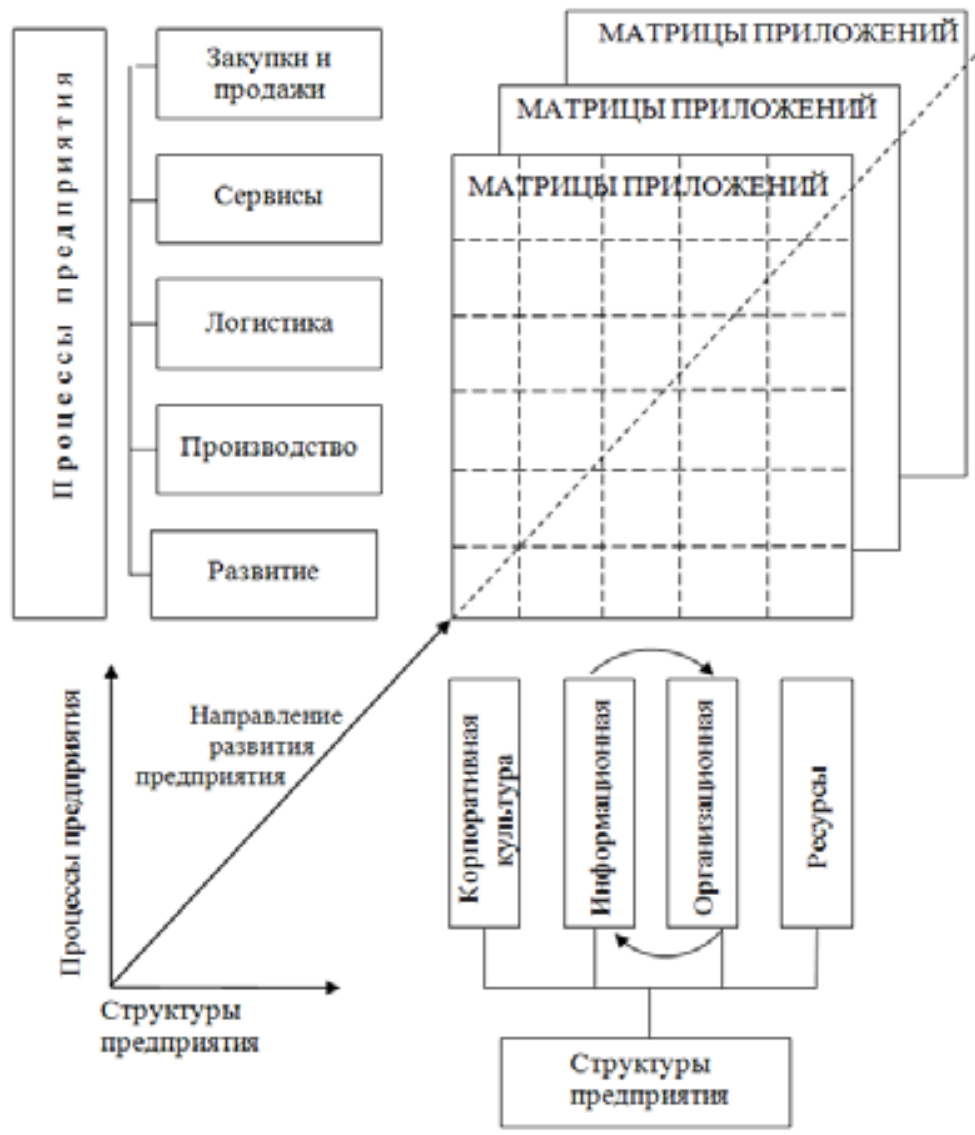

Рис. 4.3. Системная модель предприятия

Изучение структуры предполагает исследование структуры ресурсов, информационной структуры, организационной структуры, структуры производственной культуры. На основе выделенных структур производится оценка возможностей предприятия по следующим признакам:

- обеспечение сбалансированности свойств структур (compensation);

- степень связанности компонентов структур, обеспечение при выделении структур принципа модульности (connectivity); 
- масштаб и обозримость структур (visibility);

- ясность, понимание правил функционирования структуры (transparency);

- прогнозируемость последствий воздействия на компоненты структуры (predictive capacity);

- способность структур к адаптации (adaptibility) при изменении состояния окружающей среды предприятия.

\subsection{1. Ресурсы}

Под ресурсами понимают как материальные (физические), так и человеческие ресурсы (сотрудники предприятия). К физическим ресурсам относятся техника, оборудование, инструменты, материалы (сырье) и конечный продукт. Человеческие ресурсы должны обладать необходимыми компетенциями для того, чтобы реализовать технологические операции, а также создавать информацию, поступающую в цифровую экосистему. Правильно сконфигурированные физические ресурсы позволяют одновременно сократить как объем латентных данных, так и масштабы латентной деятельности. Кроме того, для эффективного функционирования предприятию необходимо стремиться к обеспечению соответствия между фактическими объемами ресурсов и тем, что представлено в цифровой модели. Соответствие объемов фактических ресурсов тому, что отражено в цифровой модели, создаёт основу для управления системой обучающих процессов, результатом чего является повышение способности предприятия оперативно перестраиваться при изменении состояния окружающей среды. Из этого следуют два важных вывода:

1) ресурсы должны соответствовать тому, что обеспечивает способность предприятия существовать и функционировать в цифровом мире. Сотрудники должны уметь выявлять источники данных и определять такие технологии их обработки, которые обеспечивают извлечение наибольшего количества информации и знаний. После того, как обозначены технические ресурсы, необходимо ввести в эксплуатацию технологии, создающие возможность сбора данных и преобразования их в информацию и знания. Иными словами, необходимо иметь технологии преобразования измерительных данных к виду, позволяющему принимать решения, адекватные текущему состоянию предприятия. 


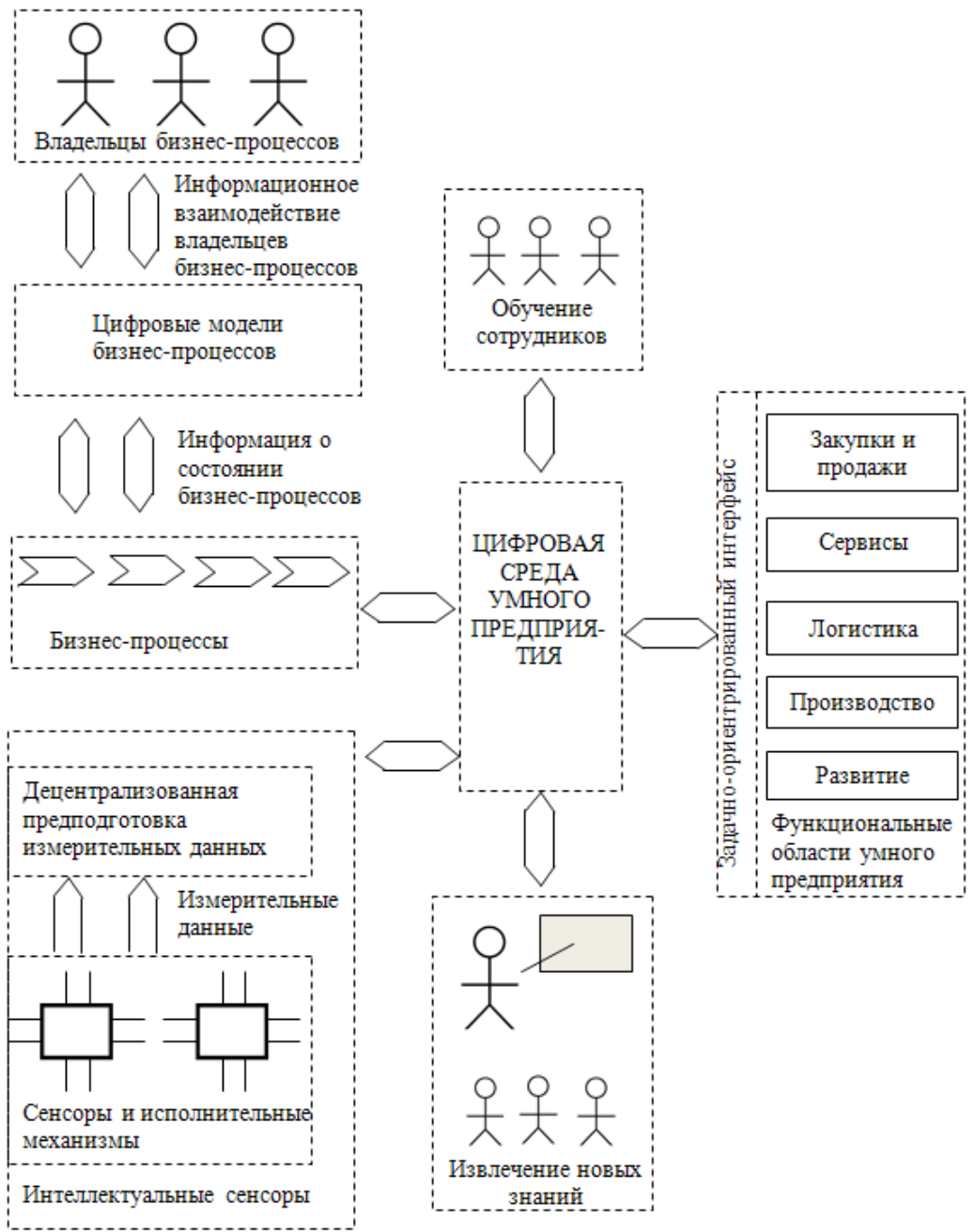

Рис. 4.4. Структурированные коммуникации умного предприятия

Фокус первого вывода: для эффективного управления необходимо знать реальное положение дел «на местах», т.е. данные в совокупности должны давать объективную оценку актуального состояния предприятия. Вместо того, чтобы ориентироваться на целевые показатели 
плана (которые формируются на основе предположений, либо прогнозных оценок) этот подход базируется на анализе обратных связей, характеризующих фактическое положение предприятия в окружающей среде. При этом лишь сотрудники способны оценить, насколько удачно сконфигурирована система, т.е., насколько полно реализуются возможности предприятия при существующих ресурсной, информационной и организационной структурах.

2) целостная и ясная картина формируется за счёт различных комбинаций фрагментов информации. Это требует наличия структурированных интерфейсов, позволяющих формировать различные комбинации информационных фрагментов, а также формировать коммуникационную основу между сотрудниками предприятия, между человеком и машиной, между машинами. Вышеизложенное составляет содержание принципа «структурированная коммуникация» (рис. 4.4).

\subsection{2. Цифровые возможности}

Широкое внедрение информационных и коммуникационных технологий в продукты и процессы вынуждает предприятия внедрять междисциплинарный подход в материальную и нематериальную сферы деятельности, т.е., в то, как они думают, и в то, как они действуют. Сотрудники должны быть как можно глубже вовлечены в инновационные процессы с тем, чтобы сделать знания и опыт как можно более ценными для предприятия. Происходящая поэтапная автоматизация многих процессов означает, что в будущем основным требованием к сотрудникам будет способность использовать мастерство и креативность при принятии решений, влияющих на настоящее и будущее. Мастерства и креативности, необходимых только для решения повседневных задач, при этом окажется недостаточно. Помимо этого, усилится значение персональной ответственности сотрудников за последствия принимаемых решений, что также явится стимулом к обучению как фундамента для принятия решений. Увеличивается значимость возможностей доступа к данным и информации; результативности и эффективности системы сбора данных и информации. Помимо понимания значимости информации в кратко-, средне- и долгосрочной перспективе, сотрудники также должен понимать суть «Индустрии 4.0». В силу широкого распространения информационных систем и коммуникационных технологий предприятия должны создавать условия для форми- 
рования у сотрудников компетенций, основанных на междисциплинарных знаниях, что обеспечивает глубокое понимание ими связи бизнес-процессов и содержания IT-приложений.

Трансформация IT-систем из фактора, обеспечивающего функционирование предприятия, в системообразующий фактор требует осознание сотрудниками фундаментальной значимости IT-безопасности. Критически важно, чтобы процессе подготовки/переподготовки к практической деятельности сотрудники получили полное представление о возможных причинах искажения и потери данных.

Растущая популярность социальных сред обмена информацией и инструментов коллективного использования информации требует разработки новых правил внутренних и внешних коммуникаций. Необходимо учитывать, что, обеспечивая возможность доступа к обширным массивам данным (среди которых находятся и те, которые критически важны для предприятия, необходимо предпринимать меры по обеспечению защиты конфиденциальных данных от доступа к ним третьих лиц. Стандарты серии IEC 62443 содержат описание стратегии обеспечения безопасности распределенных информационных и производственных систем.

Сбор данных с сенсоров и приводных механизмов. По мере роста значимости технологического ресурса машин, оборудования, инструментов и продуктов, приобретают приоритетное значение интеграции этих ресурсов в форме киберфизических систем (cyber-physical systems $C P S)$. $C P S$ создаются за счёт усиления мехатронных компонент посредством подключения к ним сенсоров, исполнительных механизмов, систем обработки информации и возможности доступа к коммуникационной сети. Практика показывает, что компании, пытающиеся внедрить $C P S$, имеют склонность либо к построению локальных замкнутых систем, не взаимодействующих с иными ресурсами, либо ограничиваются использованием меток (штрих-кодов, RFID) лишь для инвентаризации существующих объектов. При таком подходе не используется весь потенциал $C P S$.

Ныне общепринятой практикой является оснащение машин и оборудования значительным числом датчиков. Основным назначением датчиков является наблюдение за стабильностью технологического процесса и корректировка краткосрочных отклонений от штатного режима функционирования оборудования. Дополнительно к задачам мониторинга значений физических параметров, ключевым требованием 
мониторинга бизнес-процессов является возможность оперативного определения местоположения мобильного объекта. В связи с этим особую роль начинает играть формирование требований к точности и периодичности регистрации параметров CPS. Определение требований к данным, наличие которых позволяет оценивать состояние и пространственное положение объекта управления, а также выбор сенсоров, позволяющих получать такие данные, составляют основу построения цифровой модели.

Децентрализованная предподготовка измерительных данных. Подобно сенсорам и исполнительным механизмам встроенные системы передачи данных являются ключевыми компонентами $C P S$. Они обеспечивают связь систем получения и обработки данных и электромеханических компонентов (исполнительных механизмов). Рост вычислительных возможностей и уменьшение размеров чипов делает возможным реализовать распределённую первичную препроцессорную обработку измерительных данных посредством встроенных в технические устройства систем. Это позволяет уменьшить временную задержку, связанную с передачей сигнала о состоянии объекта управления, что создает условия для сокращения времени получения результатов критически важных вычислений.

\subsection{2. Структурированные коммуникации}

Потенциал централизованной системы управления ограничен числом решений, которые она может принять. Рост сложности объекта управления означает рост сложности задач, связанных с принятием и реализацией решений. Это служит основанием для научно-обоснованной адаптации опыта создания децентрализованных систем контроля, давно применяющихся для оптимизации технологических процессов, в область управления распределенными бизнес-процессами. Внедрение децентрализованных систем контроля бизнес-процессов создает условия для повышения их надежности и сбалансированности.

Ключевым требованием для реализации концепции «Индустрия 4.0» является наличие коммуникационных технологий, обеспечивающих возможность создания динамических сетей, позволяющим ресурсам взаимодействовать между собой.

Эффективность коммуникаций. Показателем эффективности коммуникаций между акторами является сокращение потерь времени, 
связанных с поиском и ожиданием предоставления данных и информации. Коммуникации между сотрудниками должны сопровождаться трассируемым документооборотом, быть свободными от избыточной информации, обеспечивать получение сведений и знаний, соответствующих потребностям целевых групп акторов. Трассируемость документооборота означает, что содержание послания известно либо благодаря автоматическому снабжению его ярлыком (тегом), либо благодаря возможности интеграции послания в режиме реального времени с соответствующим посланию бизнес-процессом. Отсутствие информационной избыточности может обеспечиваться наличием централизованного хранилища данных. Если имеется единственный достоверный источник данных, то вместо отправки файлов пользователям достаточно обеспечить им авторизованный доступ к хранилищу данных. Более того, профили ролей и подтверждение личности создают возможность подключать сотрудников к коммуникационному процессу контекстуально и, в случае необходимости, реактивно.

Уже сегодня аналогичные электронные подписи используются для подтверждения принятых решений. Внедрение цифровой подписи ускоряет процедуру подтверждения, делает её более прозрачной. Акторы непосредственно информированы о своем статусе и процедура одобрения может сопровождаться информацией о статусе актора. IT-системы поддерживают тип коммуникации, известный как «продукты совместной деятельности» (groupware).

Профили являются разновидностью структурных иерархических моделей систем обработки данных (СОД). Под профилем понимается полное множество альтернатив (функций, операций пользователей и т.д.) для каждой из которых существует вероятность появления $[149,150]$ и др. Агрегаты профилей являются инструментом информационной поддержки решения задач, связанных с управлением потребительскими свойствами СОД. Концептуальную основу построения профилей составляет стремление разработчиков на ранних стадиях жизненного цикла систем учесть предполагаемые условия их эксплуатации. Обеспечение требуемых потребительских свойств СОД в условиях ограниченных ресурсов проектов обеспечивается за счет избирательного подхода к назначению свойства компонентов системы с учетом роли, которую играют разные компоненты в обеспечении потребительских свойств системы. 
В литературе описано значительное число разных профилей, соответствующих разным подходам к исследованию свойств систем [149]:

- потребительский профиль, предназначенный для исследования целевых групп пользователей;

- профиль системных режимов, предназначенный для исследования возможных условий использования системы;

- функциональный профиль, предназначенный для исследования функций, которые может реализовать система;

- операционный профиль, предназначенный для исследования операций, выполняемых системой и т.д.

Проектирование задачно-ориентированного интерфейса. Человекомашинные взаимодействия, технологии идентификации и визуализации реализуют интерфейс между реальным и цифровым (виртуальным) миром. Поддерживающие системы начинают играть все большую роль по мере роста сложности процессов и увеличения масштабов задач, которые приходится решать сотрудникам. Технологии автоидентификации (Auto-ID) позволяют распознавать объекты и устанавливать их атрибуты. Интерфейсы аппаратной части играют ключевую роль, обеспечивают возможность различным типам технологических ресурсов взаимодействовать между собой. В будущем киберфизическим системам не потребуется обмениваться «самохарактеристиками» между разными уровнями пирамиды управления. Они будут рассматриваться как компоненты динамических сетей. Технологии идентификации позволяют осуществлять взаимное распознавание как технологическим, так и трудовым ресурсам, что позволяет им в последующем договариваться относительно особенностей дополнительной специальной информации. При создании новых систем, основанных на взаимодействии контролируемых компонент и датчиков, взаимодействие может быть обеспечено на базе проводной либо беспроводной связи (в зависимости от того, в каких условиях ведётся развёртывание системы). Преимущество следует отдавать интерфейсам, позволяющим создавать открытые системы с тем, чтобы избежать зависимости от конкретных производителей техники, либо инструментов. Кроме того, в организации должна изменяться соответствующая инфраструктура (например, промышленный интернет). Создаваемые системы должны обеспечивать возможность интеграции подсистем, созданных ранее в рамках превалирующих в то время подходов. При этом должно обеспечиваться не только взаимодействие таких подсистем внутри новой системы, но и взаимо- 
действие с внешним миром посредством интернета. Это требование является принципиальным, поскольку его реализация делает возможным эксплуатацию (сопровождение) системы и планирования производства инвариантным к характеристикам машин и оборудования.

Аналогичный подход может быть реализован по отношению к материалам - если имеется достаточное количество контрольных точек, возможно автоматически отслеживать состояние и движения материальных ценностей либо через медийную среду, либо непосредственно через идентификаторы материальных ценностей. Это создает условия для своевременного удовлетворения потребностей пользователей.

\section{4. Информационные системы как компоненты цифровой экосреды «умного» предприятия}

Информационные системы представляют собой сложные системы, в которых информация возникает как вследствие деятельности людей, так и за счет взаимодействия с другими информационными системами посредством использования инфокоммуникационных технологий. Системы создают, приобретают, систематизируют, обеспечивают хранение, представление и передачу данных и информации. На рис. 4.5 показано место информационной системы как компоненты цифровой экосреды «умного» предприятия.

\subsection{1. Принципы создания цифровой экосреды}

Цифровизация бизнеса обусловлена стремлением создать на промышленных предприятиях условия для своевременного принятия эффективных решений в режиме реального времени на основе цифровой модели предприятия. Существуют две причины, препятствующие этому.

1. Данные не преобразуются в информацию. В силу этого информация не представляется в пригодной для использования сотрудниками предприятия форме и не может использоваться в качестве информационной поддержки их деятельности. Для того, чтобы быть полезными при принятии решений, равно как и для того, чтобы быть пригодными для анализа и преобразования в информацию, свойства данных должны быть сбалансированы с потребностями пользователей. Таким образом, первый основополагающий принцип при создании информационных систем, соответствующих концепции «Индустрия 4.0»-данные должны быть подготовлень и преобразовань таким образом, чтобы обеспечивать поддержку принятия решений сотрудниками предприятия. 
Л.Р. Черняховская, В.И. Васильев, В.Е. Гвоздев, Н.О. Никулина, А.И. Малахова, А.М. Вульфин, О.Я. Бежаева

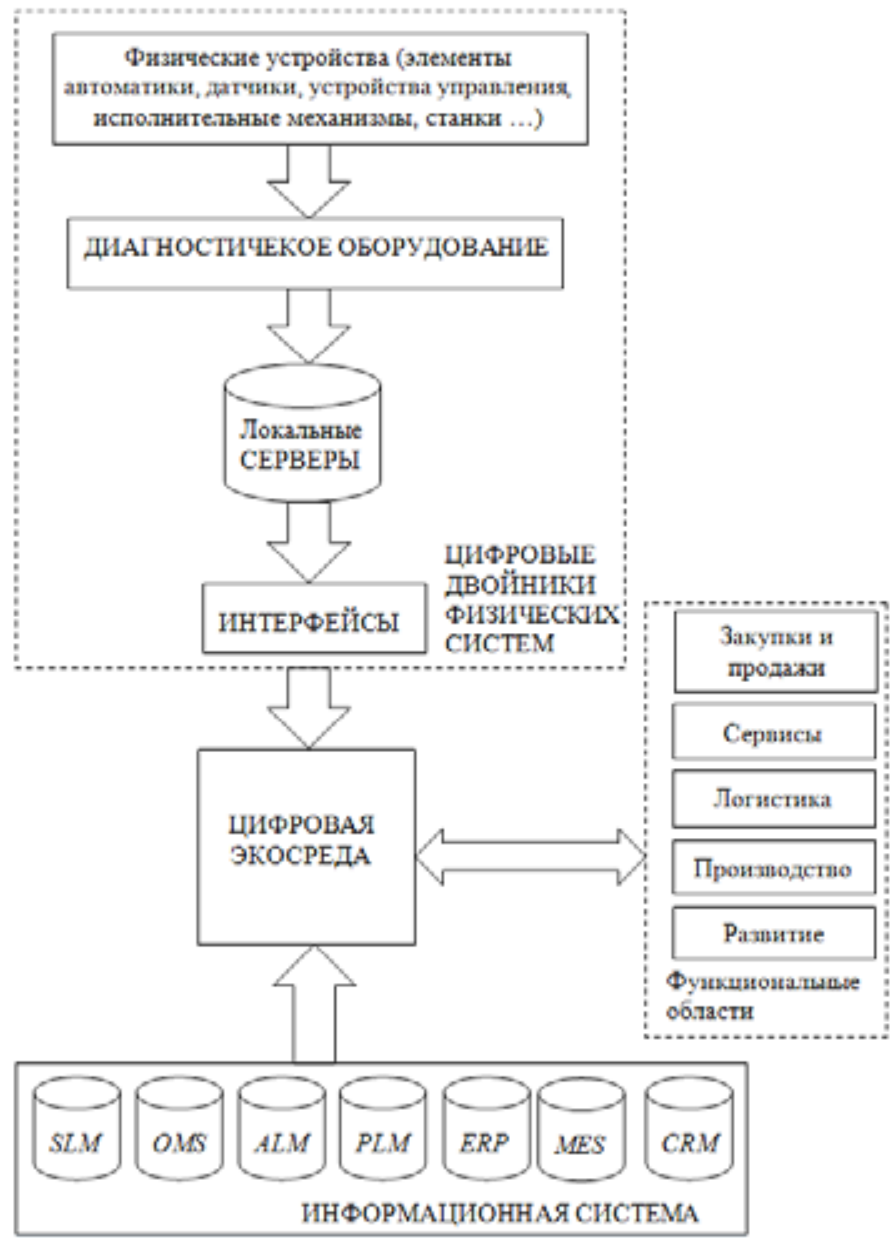

Рис. 4.5. Информационная система

как компонента цифровой экосреды «умного» предприятия

Для того чтобы данные были ориентированы на удовлетворение потребностей пользователей, на предприятии должны быть определены правила доступа к данным и такие их преобразования, которые позволяют рассматривать как единое целое обработку данных и их предоставление потребителям. 
2. Все данные, имеющиеся в хранилищах структурных подразделений, недоступны другим подразделениям предприятия. Информационные подсистемы, существующие в разных подразделениях, должны быть информационно объединены, чтобы можно было использовать данные, представляющие интерес для всех, участвующих в создании ценностей для потребителей. В гибко перестраиваемом предприятии должна существовать центральная платформа, позволяющая соединить IT-системы подразделений друг с другом, что позволит интегрировать имеющиеся в них информационные ресурсы. Такой подход гарантирует, что всем пользователям будут предоставляться достоверные данные из одного и того же заслуживающего доверие источника (в противном случае возможно различие значений одних и тех же данных, хранящихся в разных подсистемах).

Таким образом, второй основополагающий принцип - интегращия есть путь к повышению ценности данных для пользователей и увеличению гибкости предприятия.

Для создания платформы, позволяющей интегрировать различные информационные системы, требуется наличие системы стандартов на организацию интерфейсов, обеспечивающих возможность гибкой настройки подключаемых систем, их открытости, на обеспечение полной безопасности IT-систем, поддерживающих необходимый уровень качества данных, содержащихся в локальных системах.

Принщип самообучения на основе информащии. Принятие решений на основе обработки данных требует, чтобы предприятия относились к информации как к ресурсу, который добавляет ценности, равно, как и того, что данные и информация доступны для всех сотрудников предприятия.

Принции автоматизации анализа данньхx. Принятие решений на основе данных предполагает постоянную агрегацию данных с целью получения информации и последующим извлечением знаний из этой информации. Это требует развития методов автоматического анализа данных, полученных из разных источников, с целью выявления причинно-следственных связей в наблюдаемых явлениях, что создает предпосылки для прогнозирования наступления событий посредством имитационного моделирования. Потоки данных должны постоянно отлеживаться в режиме реального времени с тем, чтобы посредством агрегации данных получать информацию, способствующую повышению эффективности использования активов предприятия. Од- 
ним из возможных приложений этого утверждения является непрерывный анализ параметров разных машин и инструментов, что позволит с высокой достоверностью оценить их текущее и прогнозируемое техническое состояние.

В гибко перестраиваемых предприятиях принятие решений на основе анализа данных осуществляется на всех уровнях управления производством. Например, при оценке того, насколько повлияет на своевременность поставки ранее заказанной продукции переориентация производства на приоритетное выполнение специальных заказов, либо временная остановка техники для ремонта. Иными словами, автоматизация анализа данных необходима не только на уровне машин и инструментов, но на всех уровнях управления производством. Важно обратить внимание на то, что анализ данных не должен сводиться к использованию для решения задач управления уже известных причинно-следственных связей. Организации должны изучать и выявлять новые информационные паттерны во вновь получаемых данных. Когда происходят неожиданные события (поломка машины, разрушение линий связи и т.д.), доступные данные должны анализироваться и интерпретироваться для выявления новых связей, которые впоследствии могут служить основанием для выделения новых информационных паттернов.

Принщип контекстно-ориентированного представления информации. Контекстно-ориентированная информация служит основой поддержки принятия решений. Пользователи информационной системы, вместо того чтобы извлекать информацию из различных IT-систем, либо самостоятельно реализовывать процессы обработки данных, получают её, подготовленную в соответствии с требованиями некоторого контекста их профессиональной деятельности (принцип поддержки push principle). Признаком успешных предприятий является реализация принципа «система зацеплений» (system of engagement). Это означает, что сотрудники получают правильную информацию требуемого объема и качества в нужное время. Примером может служить легко понимаемая сотрудниками предприятия визуализация сложной совокупности операций посредством использования контекстно-ориентированной $3 D$-анимации. Другим примером может служит предоставление в установленном порядке детализированной информации о причинах отказов в отделе контроля продукции сотрудникам, осуществляющим эксплуатацию машин. 
Важно, чтобы, во-первых, сотрудники получали всю информацию из IT-систем. Во-вторых, сотрудники должны получать лишь ту информацию, которая нужна им для выполнения работ в их зоне ответственности.

Принции задачно-ориентированного пользовательского интерфейса. Свойства производимой информации должны постоянно сопоставляться с потребностями пользователей, которые обусловлены особенностями решаемых ими задач. Формат представления должен выбираться с учетом особенностей ситуации, в которой акторы принимают решения. В зависимости от особенностей приложения пользовательский интерфейс может представлять данные в форме таблиц, анимации, добавленной реальности, либо в виде голосового сопровождения. Акторам предоставляются интуитивно понятные опции, позволяющие своевременно реагировать на события, сведения о которых они получили в результате взаимодействия с IT-системами.

Принщип построения гибко перестраиваемой IT-инфраструктуры и создания хранилищ данных, ассоциированных с ситуациями. Основу анализа и представления данных составляет гибко перестраиваемая IT-инфраструктура, позволяющая выполнять сбор данных, характеризующих техническое состояние технических объектов, передачу и хранение данных, а также обеспечивающая требуемые преобразования исходных данных с гарантированным качеством. Реализация этого требования обуславливает необходимость постоянной адаптации $I T$-инфраструктуры к текущим потребностям субъекта управления, что может быть обеспечено либо за счёт избыточности хранимых данных, либо за счёт избыточности в проектных решениях. Избыточность хранимых данных может обеспечиваться либо внутри системы, либо в облаке. Ситуационно-ориентированный сбор и организация хранения данных обеспечивает возможность доступа к данным в режиме реального времени. Хранение данных в оперативной памяти обеспечивает быстрый доступ к часто используемым данным, что также гарантирует своевременную информационную поддержку принятия решений.

\subsection{2. Интеграция информационных систем "умного» предприятия}

Интеграция информационных систем имеет цель обеспечения возможности использования данных, важных с точки зрения разных пользователей, в различных частях цепочки создания продукции. На 
рис. 4.6 представлены основные классы задач, связанных с созданием и использованием информационной системы.

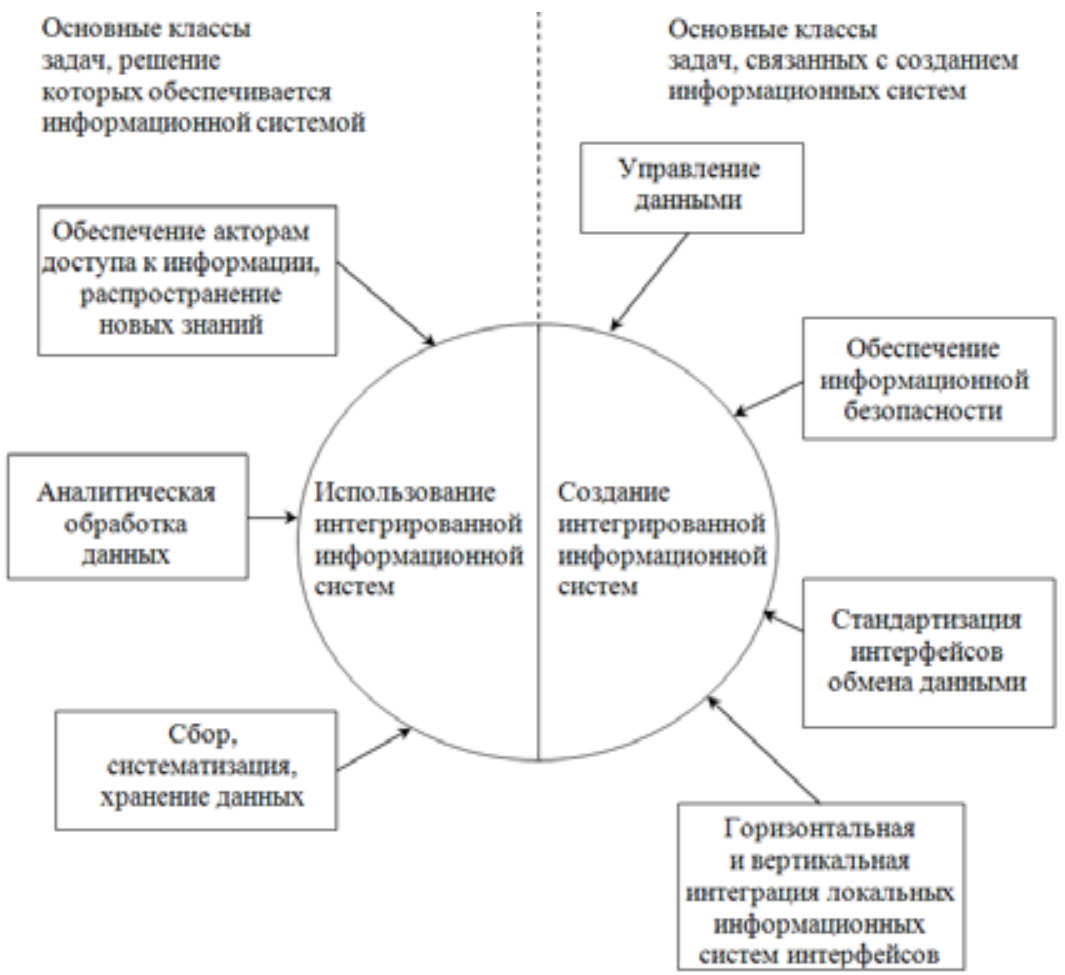

Рис. 4.6. Основные классы задач, связанных с созданием и использованием информационной системы

Вертикальная и горизонтальная интеграция информаџионных систем. Использование данных, представляющих интерес для разных целевых групп пользователей, возможно лишь при наличии вертикальной и горизонтальной интеграции информационных систем. IT-системы, обслуживающие разные звенья цепочки создания востребованных продуктов, постоянно обмениваются информацией, так что структурированная информация всегда «привязана» к жизненному циклу продукта, выполняемым операциям, инструкциям по выполнению опера- 
ций, либо к сведениям о пользователях. Это обеспечивает доступ акторов к одним и тем же наборам данных и одним и тем же информационным массивам. Последнее означает уход от положения, когда бизнес-процессам предприятия соответствуют чрезмерно сложные архитектуры информационных систем и избыточность хранимых в них данных. Первичные IT-системы содержат всю структурированную информацию, соответствующую всем объектам, процессам, протекающим на предприятии - начиная от продуктов и систем планирования и заканчивая описанием производственного оборудования. По мере выполнения задания технические объекты автоматически отправляют отчет вышестоящей системе обработки данных и управления об изменении своего состояния. Это создает источники достоверных данных, причём эти данные ассоциированы с местами их возникновения, то есть, находятся в IT- системах нижнего уровня иерархии, ассоциированных со звеньями цепочки формирования продукта.

В настоящее время информация о продуктах, как и о проектных данных, аккумулируются в PLM-системах, распределительная информация аккумулируется в $E R P$-системах, данные о потребителях в $C R M$-системах. Отсутствие метаданных, необходимых для выполнения интеграции, приводит к тому, что реализация функций развития, производства, маркетинга обеспечиваются своими собственными, локальными информационными системами, и не могут быть эффективно использованы в других структурных подсистемах «умного» предприятия для обеспечения информационной поддержки принятия решений и их последующей реализации. Как результат, изменения, вносимые в отдельные функции и обусловленные этим новые возможности, не становятся своевременно известными всем участникам процесса производства продукции. Таким образом, необходимым условием создания гибко перестраиваемого предприятия является наличие логической и физической платформы для интеграции информационных систем. Наличие такой платформы обеспечивает доступ всем пользователям к информации, необходимой им для принятия на своих рабочих местах решений и их эффективной реализации. Также важно обеспечить транспарентность используемых IT-систем, что означает, что никакие подразделения организации не имеют права создавать свои «теневые» IT-системы, которые не контролируются IT- департаментом «умного» предприятия. 
Стандартизация интерфейсов обмена данными. Более предпочтительным подходом, по сравнению с централизованным хранилищем, является логическое объединение существующих IT-систем на базе стандартных интерфейсов. API, микросервисы, интерфейсы обмена данными обеспечивают возможность обмена данными и информацией между отдельными IT-системами. Примером стандартного интерфейса, часто используемого при реализации положений концепции «Индустрия 4.0», является стандарт взаимодействия машина-машина в рамках архитектуры $O P C-U A$.

Управление данными. Помимо наличия стандартных интерфейсов, интеграция IT-систем предполагает наличие у данных, находящихся в системах, требуемого уровня качества. Недостаточное качество исходных данных является причиной низкого качества агрегированных данных, неточностей в предоставляемых сведениях, несоответствия потенциальных и фактических возможностей IT-систем. Низкое качество данных является препятствием для принятия обоснованных управленческих решений. Предприятиям необходимо обеспечить наличие технических и организационных возможностей и условий, гарантирующих высокое качество данных. Целью политики управления данными в пределах предприятия является построение системы, позволяющей осуществлять управление процессами обработки и хранения данных для предоставления данных требуемого качества по запросам акторов.

К основным техническим вопросам управления качеством данных относятся идентификация пользователей, стандартизация подходов к управлению качеством данных, резервное копирование.

Обеспечение информационной безопасности. Повышение защищенности информационных систем, человеческий и другие факторы, влияющие на качество функционирования IT-систем, сопровождаются рисками, обусловленными криминальными атаками. Защищенность $I T$-систем обеспечивается реализацией различных стратегий. Соблюдение положений стандарта IEC 62443 способствует уменьшению опасности возникновения нештатных ситуаций, а также снижению негативных последствий, обусловленных нештатными ситуациями. Система мер основана на использовании административного ресурса, идентификации и аутентификации пользователей, валидации «здорового» состояния системы, контроля потоков данных. 
В интегрированных информационных системах предприятия, достигшего высокого уровня зрелости, данные обладают высоким качеством и обрабатываются автоматически. Процедуры анализа данных и их обработки обладают свойством самообучаемости, т.е., адаптируются адекватно изменению состояния внешней и внутренней среды предприятия. Предметно- и проблемно-ориентированные знания поставляются акторам средствами интегрированной информационной системы в виде, адаптированном с учетом специфики их деятельности, что позволяет акторам быстро использовать эти новые знания в их практической деятельности. Логическая горизонтальная и вертикальная интеграция данных, стандартные интерфейсы создают базу для формирования гибко настраиваемых информационных систем.

\section{5. Организационная структура «умного» предприятия}

Поскольку преобразование предприятия к виду самообучаемого, гибко перестраиваемого предприятия невозможно вне реализации описанных выше требований, необходима соответствующая организационная структура [151]. Понятие организационной структуры связывается, во-первых, с внутренним устройством предприятия (функциональные структуры и структуры процессов). Во-вторых, с тем, как влияет внутреннее устройство предприятия на его положение во внешнем окружении. Понятие корпоративная (организационная) структура, в отличие от понятия «организационная культура» устанавливает обязательные правила, реализация которых обеспечивает взаимодействие акторов внутри предприятия, а также взаимоотношение предприятия с внешней средой. Понятие «организационная культура» определяет внутренние ценности предприятии, т.е., «мягкую силу», обеспечивающую взаимодействие сотрудников. Тем не менее, обе эти структуры взаимозависимы и взаимосвязаны.

Понятию «организационная структура» ставится в соответствие двумерное пространство: «сбалансированность внутреннего устройства» (organic interior organisation) и «динамика взаимодействия с окружающей средой» (dynamic collaboration). Иными словами, понятие «организационная структура» соотносится как с внутренним устройством, так и с внешним поведением (рис. 4.7). 


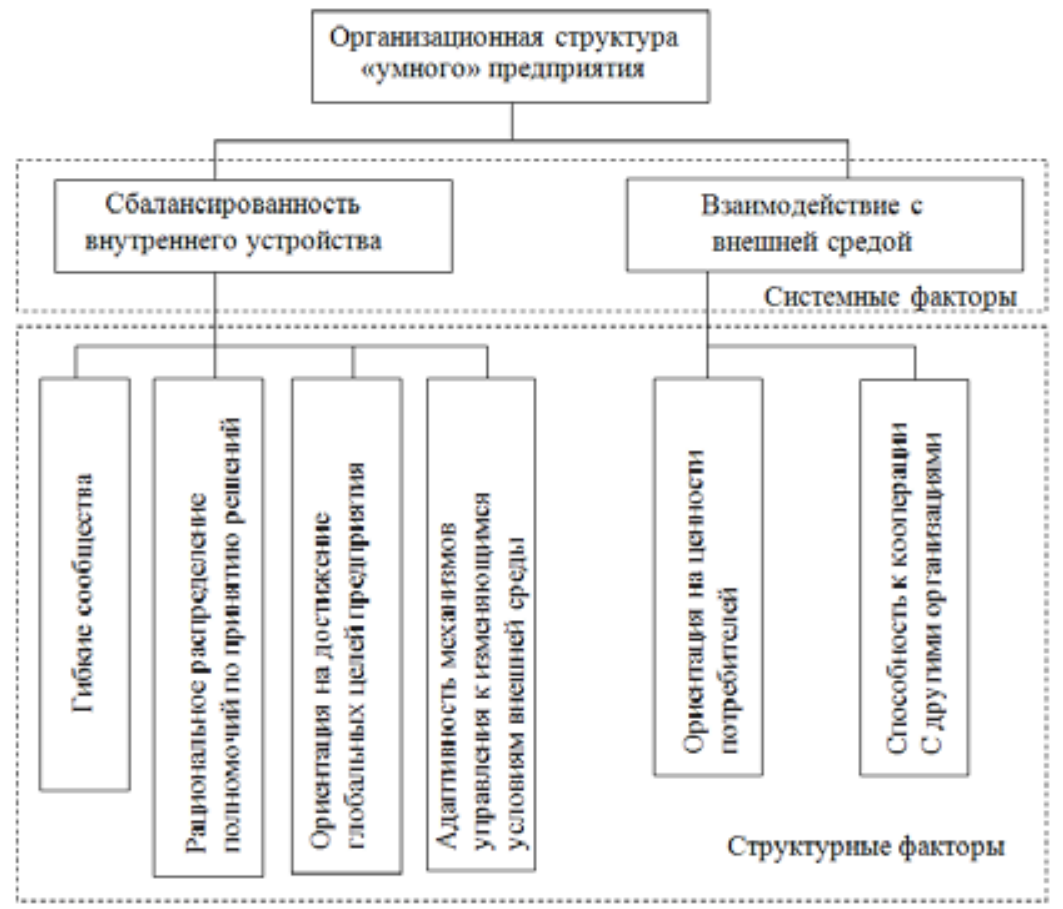

Рис. 4.7. Системные и структурные факторы организации предприятия

\subsection{1. Сбалансированность внутреннего устройства}

Сбалансированное внутреннее устройство является противопоставлением жесткой иерархической организации. Предполагается, что в этом случае сотрудники предприятия имеют меньше ограничений на принятие решений в области своей деятельности, и вместе с тем несут большую персональную ответственность за результаты. Такая форма организации наиболее приемлема в случае, когда сотрудники являются высококвалифицированными, а окружающая предприятие среда динамично изменяется.

Гибкие сообщества. Особенностью предприятия, способного к гибкой реорганизации, является возможность гибкой конфигурации ресурсов. В терминах организационной структуры это означает, что акторы постоянно изменяют свою сферу деятельности, переключают- 
ся на решение разных задач. Даже если сотрудники закреплены за определенными структурными подразделениями предприятия, фактически они являются членами задачно-, либо целе-ориентированных команд. С другой стороны, с тем, чтобы облегчить взаимодействия сотрудников при выработке консолидированного мнения по спорной проблеме, создаются специализированные экспертные группы по разным вопросам, характеризующим проблему. Целью такого подхода является усиление взаимодействия между разными подразделениями, сотрудниками которых являются квалифицированные специалисты. Подобный подход повышает уверенность в том, что действия высококвалифицированных специалистов разных профилей, хорошо понимающих отдельные стороны проблемы, выстраиваются на одной линии с глобальными целями «умного» предприятия. Иными словами, предлагаемый подход способствует организации временных творческих коллективов исходя из потребностей, обуславливаемых динамично изменяющейся обстановкой. Сообщества формируются для проведения исследований в рамках какой-либо темы (например, целесообразность внедрения нового IT-решения), либо решение задачи (например, организация эффективного использования фрезерного станка). Некоторые сообщества на предприятии формируются на постоянной основе для обеспечения качественной реализации постоянно существующих бизнес-процессов. Другие сообщества являются проектно-ориентированными, представляют собой временные образования и расформировываются после реализации проекта. Целью такой организации деятельности является возможность привлечения специалистов требуемой квалификации для выполнения определенной работы независимо от того, какое место в иерархии предприятия они занимают и сотрудниками какого подразделения они являются. Такой подход также обеспечивает быструю реакцию на новые события, либо появление новых знаний. Например, в Google типичной практикой является спонтанное формирование малых команд для того, чтобы в течение нескольких дней, либо недель, сформировать прототип программного продукта для принятия решения о целесообразности продолжения этой разработки.

Вместе с тем, для этого подхода характерен ряд ограничений. Он не применим при выполнении рутинных бизнес-процессов. Кроме того, возможности подхода, основанного на гибком формировании команд и исполнителей, ограничены в случае предъявления к процессам высоких требований по эффективности и стабильности. 
Областью применимости подхода, основанного на формировании временных команд, в первую очередь являются инновационные и проблемные задачи. В этом случае возможность гибкого формирования команд высококвалифицированных специалистов является той силой, которая позволяет достичь желаемого.

Гибко перестраиваемые предприятия способны не только быстро адаптироваться на решение новых задач, но и эффективно реализовывать рутинные бизнес-процессы. Вместе с тем, внедрение такого подхода к формированию команд серьёзно усложняет задачи менеджмента, поскольку каждый из сотрудников свободен в выборе сообществ, в которых он участвует. Более того, переход из сообщества в сообщество является типичным явлением. Наличие $I T$-платформы способствует более эффективному взаимодействию, так как делает прозрачным требуемый квалификационный профиль, облегчает вхождение в сообщество сотрудников организации и определение роли в нём отдельного сотрудника.

Рациональное распределение полномочий по принятию решений. Возможность получения всей относящейся к делу информации является необходимым условием принятия хорошего решения. При ориентации на децентрализованную схему принятия решений, акторы «на местах» обладают лучшей информацией о фактическом положении дел, так как они ближе к местам событий. Обеспечение того же качества данных при ориентации на централизованную схему принятия решений требует дополнительных затрат на доставку актуальных данных к месту принятия решения. С другой стороны, реализация децентрализованной схемы также требует дополнительных затрат, поскольку в места принятия локальных решений должна поставляться дополнительная информация, позволяющая обеспечить соответствие локальных управленческих решений глобальной цели организации. В противном случае локально принимаемые в разных местах решения могут оказаться слабо скоординированными. Из этого следует, что часть решений, связанных с выработкой стратегии организации, должна приниматься централизованно, в то время как другие решения, связанные с решением тактических и оперативных задач, исходя из экономических либо иных соображений, целесообразно принимать децентрализованно.

Базовым положением доктрины «Индустрия 4.0» является реализация требования доступности информации для разных акторов. Это оз- 
начает, что в условиях децентрализованного принятия решений имеется возможность объективно оценить последствия решений, принимаемых на локальном уровне, и их соответствия глобальным целям организации. Следствием этого является сокращение времени и повышение качества решений, принимаемых на локальном уровне. Доступность информации создает условия для коллективного принятия решений, признаваемых всеми участниками. Появляется возможность вовлечения в процесс принятия решений акторов, наиболее компетентных в обсуждаемых вопросах. Например, команда экспертов может быть сформирована из компетентных кандидатов, которые имеют возможность информационно взаимодействовать между собой. Более того, оценка альтернатив потенциальных проектов развития осуществляется с привлечением мнения возможных исполнителей, а не только менеджеров. Из сказанного следует, что в рамках перестраиваемого «умного» предприятия необходимо обеспечить рациональный баланс между централизованным и децентрализованным подходами к принятию решений для максимизации результативности и эффективности процессов.

Ориентация на достижение глобальных иуелей организации. Качественно сформированные локальные цели, во-первых, повышают возможность параллельной скоординированной деятельности сотрудников предприятия. Во-вторых, создают условия для того, чтобы деятельность сотрудников обеспечивала достижение основной цели предприятия предоставления потребителям ценных для них продуктов и услуг.

Локальные цели являются одномерными, достигаются в результате локальной оптимизации. Предприятию же следует ориентироваться на многомерные (глобальные) цели, что обеспечивается, в том числе, мотивацией сотрудников на постоянное усовершенствование и повышение эффективности реализуемых ими бизнес-процессов. Это, свою очередь, делает необходимым формирование у сотрудников новых компетенций, таких, например, как оценка успешности деятельности команды экспертов. Примером локальной цели служит задание со стороны руководства предприятия специалисту по подготовке презентационных материалов, которые будут представлены экспертам из сторонних организаций. Подобная формулировка задания означает, что идеи разработчиков презентаций будут критически оцениваться не только непосредственным руководителем, но и независимыми экспертами, что оказывает влияние на выбор подходов к разработке презентаций и повышает ответственность исполнителя. 
Система целей должна быть тесно увязана с системой вознаграждения. Это не означает, что на предприятии должна быть лишь система мотивации в виде оплаты. Система целей и системы вознаграждения, с одной стороны, должны обеспечивать сотрудникам отсутствие наказаний в случае совершения ими непреднамеренных ошибок. С другой стороны, должны стимулировать их к реализации всех своих возможностей и демонстрации преданности интересам предприятия. Это означает разумный баланс между монетарной и не монетарной составляющих в системе стимулирования. Например, в виде получения возможности дополнительного обучения, перспективы карьерного роста, предоставления права самому планировать график своей деятельности.

Адаптивность механизмов управления к изменяющимся условиям внешней среды. Традиционный негибкий процесс развития не способен справиться с неопределенностью либо изменчивостью требований, обусловленных изменчивостью окружающей среды. Динамичный характер окружающей среды выдвигает на первый план требование быстрой разработки прототипов, обеспечение логической завершенности промежуточных результатов, обеспечение оперативной обратной связи между акторами. Одним из принципиальных условий сокращения сроков реализации проектов, обеспечивающих развитие предприятия, является возможность быстрой валидации предположений о свойствах продуктов, являющихся ценными с точки зрения потребителей, либо иных предлагаемых результатах проектов в темпе изменения характеристик и параметров окружающей среды.

Одним из подходов к реализации условия быстрой валидации предложений предполагает создание продукта, обладающего минимальной необходимой функциональностью. Такой подход именуется «Создание жизнеспособного продукта с минимальными возможностями» (Minimum Viable Product - MVP).

Продукты, относящиеся к классу $M V P$ и обладающие ограниченной функциональностью, тем не менее, пользуется спросом на рынке. Это позволяет быстро получить обратную связь о том, насколько такие продукты интересуют потребителя. Подобные подходы могут применяться не только к продуктам, либо сервисам, но также и при реализации внутренних проектов.

Другим подходом в рамках $M V P$ является составление материальных «виртуальных» объектов. Процессы физического производства могут сравниваться с результатами, полученными посредством цифро- 
вого моделирования, что позволяет определить направления усовершенствования как материальных продуктов, так и цифровых моделей. Еще одним примером реализации упомянутого подхода в области программной инженерии является Scrum. Такой подход способствует интенсивной генерации принципов по усовершенствованию, развитию инноваций на основе подхода «начинай с малого и быстро взвешивай» (англ-«start small and scole fast»). «Умные» продукты, у которых большая доля функций реализуются программными средствами, создают базу для реализации указанного подхода. Возможность широкого распространения в среде разработчиков данных о способах фактического использования продукта потребителями создает условия для целенаправленного улучшения потребительских свойств продуктов, либо изъятия продуктов из продажи и уничтожения. Единое цифровое пространство предприятия выступает катализатором реализации упомянутых подходов. Например, сведения о внесении изменений в конструкцию изделия могут автоматически передаваться всем, чьи интересы это может затрагивать (например, для того, чтобы оперативно внести изменения в расписание работ).

\subsection{2. Динамическое взаимодействие цепочек создания ценностей}

Автоматический и «бесшовный» обмен информацией между разными структурными подразделениями предприятия позволяет им более динамично взаимодействовать, более точно понимать фактическое положение дел на рынке. Это является фактором, способствующем снижению барьеров, препятствующих гибкой адаптации к изменяющейся обстановке. Примерами таких барьеров являются ручные процедуры оформления справок, выдача распоряжений. Замена «ручного» выполнения распоряжений на основе использования современных $I T$-технологии позволит качественно улучшить управление бизнеспроцессами, включая контроль поставок, а также контроль качества на всех стадиях жизненного цикла продуктов. Результатом улучшения управления бизнес-процессами является более эффективный обмен информацией, материальными ценностями и сервисами.

Ориентация на цуенности на потребителя. В соответствии с концепцией «Индустрия 4.0» следует определить коренные компетенции (core competence), создающие «стратегическое преимущество» (strategic success positions) предприятия. Иными словами, следует кон- 
центрироваться на ограниченном числе компетенций с тем, чтобы иметь возможность создавать уникальные предложения на рынке. Следование этой идее всё более значимо по мере увеличения прозрачности рынка, а также в силу того, что создание ценности становится всё более сетицентричным и динамичным.

Преуспевать на прозрачном рынке с хорошо действующими рыночными механизмами могут поставщики, способные быстро предоставлять продукты, наиболее полно соответствующие представлениям о ценностях потребителей. Предприятие должно четко определить, что оно должно делать для удовлетворения покупателей. Даже если предприятие не взаимодействует напрямую с покупателями, продукты либо сервисы предприятия опосредованно влияют на решения потребителей о целесообразности приобретения продуктов. Чем больше свойства продукта влияют на решение потребителя воспользоваться им, тем более успешно предприятие в рыночной конкурентной борьбе. Например, более успешным на рынке будет тот производитель роликовых подшипников, который учитывает не только действующие требования сборщиков автомобиля, т.е. непосредственно своих потребителей, но и интересы покупателей автомобиля, т.е. интересы конечных потребителей. Используя облачные технологии, на основе анализа отзывов покупателей о потребительских свойствах автомобилей и данных об условиях их эксплуатации, производитель может предложить продукты, которые будут способствовать более эффективному использованию автомобиля. Глубинное понимание потребностей конечных пользователей продуктов позволяет сделать продукцию предприятия более привлекательной для покупателей. Предприятие должно иметь возможность регулярно пересматривать свои компетенции и, в случае необходимости, изменять их в соответствии с изменением состояния рынка. Предприятие также должно четко определить, какое место оно хочет занимать в распределенной системе (сети) создания ценностей для покупателей. Целевое вложение предприятием в распределенную систему специализированных компетенций участников сети своих компетенций для достижения общей цели участников, может явиться одним из способов достижения предприятием своих стратегических целей.

Способность к кооперации с другими предприятиями. Предприятие может позиционировать себя в сети как производителя определенных материальных ценностей, либо как представляющее определенные компетенции для создания продукта. Предприятия, которые на ос- 
нове взаимных договоренностей объединяют свои компетенции с целью предоставления на рынок востребованных покупателями продуктов, способны быстрее реагировать на изменение ситуации на рынке. Работая совместно, партнеры получают возможность быстрее создавать и поставлять новые продукты. Помимо этого, кооперация может явиться тем спусковым механизмом, который инициирует долговременный процесс развития компетенций самих предприятий. Одним из ключевых вопросов контроля состояния рынка является получение точного описания того, какие продукты и на какой период времени будет востребованы. Усилия предприятий, прежде не имеющих опыта совместной работы, затрачиваемые на формирование соглашения о кооперации, могут не окупиться в случае краткосрочных, либо одноразовых совместных действий. Использование цифровых технологий позволит предприятиям быстрее договариваться о совместной деятельности.

Ориентация на цифровые технологии имеет и теневую сторону. Бесшовный обмен актуальными данными сопровождает риск использования данных для реализации побочных целей. Должны быть приняты меры, предотвращающие использование данных в целях, отличающихся от заявленных.

Предприятия могут приблизиться к цели, стать гибкими, рыночноориентированными организациями в первую очередь за счет более эффективной кооперации внутри существующих сетей создания ценностей. Наведение порядка в системе горизонтальной интеграции в совокупности с созданием платформы для обмена данными между предприятиями (например, с целью реализации совместных проектов развития) может явиться катализатором кооперации.

\section{6. Корпоративная культура «умного» предприятия}

Возможности динамичного изменения поведения предприятия во многом зависят от ее сотрудников. Ключевым условием преобразования предприятия в обучающуюся организацию является изменение менталитета его сотрудников. Предприятие не способно достичь требуемого динамизма в смене поведения лишь за счет внедрения цифровых технологий, без изменения своей корпоративной культуры. Реализация положений доктрины «Индустрия 4.0» предполагает, что сотрудники должны иметь представление о том, что предприятие пред- 
полагает осуществить в будущем, и какими компетенциями для этого должны обладать его сотрудники. Только в этом случае предприятие сможет в нужном темпе осуществить выбор и внедрение инновационных технологий. Цифровые системы в этом случае играют лишь вспомогательную роль. Для того чтобы цифровые системы стали представлять ценность, необходимо так преобразовать корпоративную культуру предприятия, чтобы сотрудники доверяли информационным системам и были готовы воспользоваться предоставляемыми системами данными, информацией и знаниями. Основу трансформации корпоративной культуры предприятия составляют ответы на два ключевых вопроса.

1) До какой степени сотрудники готовы постоянно пересматривать и изменять свое поведение в соответствии с изменением состояния окружающей среды? Идеальным ответом является: полная готовность всего персонала к изменениям. Более того, готовность не должна ограничиваться лишь теми изменениями, которые фактически происходят. Важно чтобы сотрудники предприятия объективно оценивали, насколько их компетенции соответствуют той среде, которая динамически формируется на предприятии. Важно понимание персоналом того, что изменение среды предоставляет им возможность, но также требует их собственного изменения и готовности выполнять адекватные требуемым изменением действия. Готовность к изменениям является первым принципиальным условием культурных изменений, а также ключевым фактором, обеспечивающим возможность гибкой перестройки предприятия.

2) До какой степени, по мнению сотрудников, влияют на их деятельность получаемые ими объективные данные и новые знания? Идеальным ответом является: вся деятельность полностью основана на объективных данных и новых знаниях. Знания могут получаться в результате целенаправленных исследований, либо в результате практической деятельности (аксиологические знания). Атмосфера доверия и социальное партнерство создают условия для открытого обмена новыми знаниями между сотрудниками. Иными словами, вторым принципиальным условием культурных преобразований предприятия является социальное сотрудничество, что способствует ускорению распространения новых полезных знаний внутри предприятия. Системные и структурные факторы корпоративной культуры представлены на рис. 4.8 . 


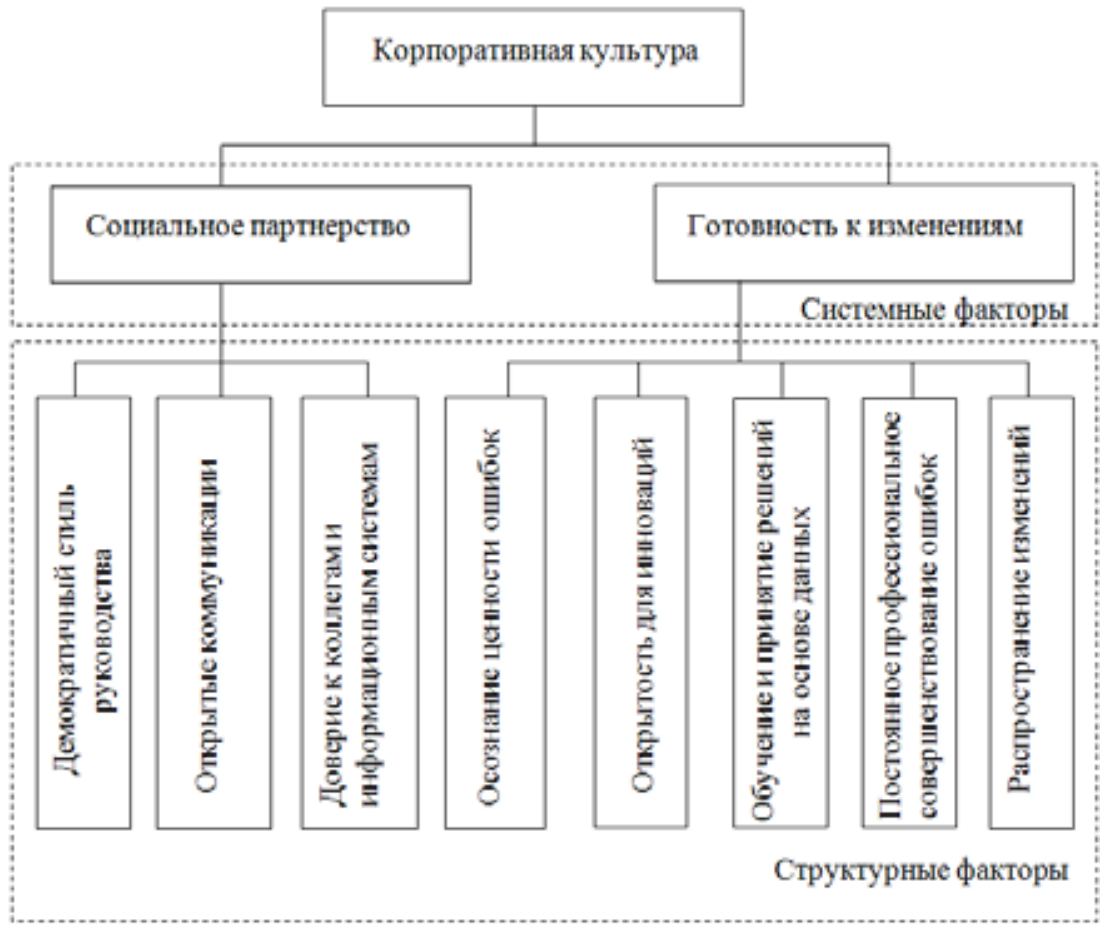

Рис. 4.8. Системные и структурные факторы корпоративной культуры

\subsection{1. Готовность к изменениям}

В рамках первого принципиального условия следует выделить пять признаков, характеризующих возможность рассмотрения сотрудников как представителей обучающейся, гибко перестраиваемой организации. Эти признаки должны рассматриваться как взаимосвязанные, и только совокупность признаков позволяет получить объективную оценку готовности предприятия к изменениям.

Особо следует подчеркнуть важность осознания ценности ошибок (Recognizing the value of mistakes). Обучающиеся, гибко перестраиваемые предприятия осознают большую важность изучения ошибок. Спусковым механизмом, инициирующим процесс обучения и преобразований, являются ошибки. Они же являются предпосылками луч- 
шего понимания процессов, протекающих в организации, а также выявления ранее неизвестных причинно-следственных связей между компонентами «умного» предприятия. Отношение к ошибкам является важным характеристическим признаком корпоративной культуры предприятия. Существует два взаимоисключающих основных подхода к ошибкам. Первый (отрицательный) поход характеризуется стремлением избегать ошибок, строгое наказание допустивших ошибку, стремление как можно быстрее и незаметнее исправить ошибку. Сотрудники предприятия, где господствует такое отношение к ошибкам, стараются скрывать допущенные ими ошибки. Такое отношение к ошибкам не способствует росту готовности к переменам. Если же частью корпоративной культуры предприятия является признание неизбежности непреднамеренных ошибок, то ошибки превращаются в один из источников получения дополнительных ценных знаний. Получение новых знаний достигается за счет открытого обсуждения ошибок в случае их возникновения, систематического документирования ошибок, поиска как причин возникновения ошибок, так и способов их устранения. При исследовании ошибок гораздо важнее установить причину ошибки, нежели найти виноватого.

Открылтость для инноваций. Необходимо полное понимание того, как и насколько новые технологии, либо способы выполнения работ, внедренные на предприятии, будут способствовать получению дополнительных ценностей. Возможно, что преимущества инноваций станут очевидны не сразу. Это обусловлено тем, что изначально сотрудникам предприятия придется осваивать неизвестные технологии. Например, при использовании системы поддержки принятия решений в сельском хозяйстве была оптимизирована траектория движения уборочных машин за счет применения специализированных программных продуктов. Это позволило увеличить сбор урожая по меньшей мере, на 20\%. Однако, многие фермеры неохотно отказывались от привычного образа действий. В этих условиях один из производителей уборочной техники стал бесплатно предоставлять фермерам технику с целью ее испытаний. Это позволило фермерам убедиться в преимуществах, предоставляемых новой техникой, и послужило основанием для пересмотра устоявшихся подходов к ведению работ. Испытания продемонстрировали, что “скрытые” данные и получаемая на их основе информация являются реальной ценностью. Необходимым условием трансформации предприятия в гибкое и обучаемое является открытость для вне- 
дрения инноваций и готовность использовать новые приемы в работе, даже если они достаточно сильно отличаются от привычных.

Обучение и принятие решений на основе данных. Инновационные циклы на промышленных предприятиях становятся все короче. Остается все меньше времени для изучения последствий от внедрения изменений в бизнес-среду предприятия. Это означает, что ошибки в принимаемых решениях и способах их реализации, а также причины возникновения ошибок должны выявляться настолько быстро, насколько возможно. Установление коренных причин возникновения ошибок на основе анализа содержимого баз данных и устранение этих причин является более предпочтительным подходом, нежели интуитивный поиск непосредственных причин отклонения поведения объекта управления от желаемого. Обучаемые, гибко перестраиваемые предприятия способны на это, поскольку они постоянно наблюдают за процессами создания дополнительных ценностей и осуществляют сбор подходящей информации. Помимо этого, постоянно осуществляется сопоставление результатов цифрового моделирования с результатами фактических измерений. Это служит основой постоянного совершенствования рабочих процессов и гарантией сокращения времени принятия решений и повышения их качества за счет того, что решения принимаются на объективной основе, а не на основе мнений отдельных субъектов.

Постоянное профессиональное совершенствование. Цифровизация изменяет требования к профессиональной подготовке сотрудников предприятия. Изменения технологий производства продукции, возрастающая роль информационных технологий, обусловленная трансформацией информационных систем в системообразующую компоненту предприятия, приводит к необходимости быстрых изменений профессиональных навыков. Если раньше требовались специалисты, обладающие глубокими знаниями в предметной области, то теперь оказываются востребованными многосторонне развитые специалисты, способные постоянно обновлять свои знания на основе междисциплинарного подхода. Такие сотрудники осознают, что ранее приобретенные профессиональные знания и навыки будут полезными лишь ограниченное время. Для них характерна готовность к обучению в течение всей жизни. То, что сотрудники постоянно отслеживают изменение состояния окружающей среды, означает, что они способны быстро выявить новые требования к уровню образования. Они способны в структурированном виде представить образовательные программы, в кото- 
рых определены компетенции, соответствующие тем, которые диктуются состоянием окружающей среды.

Расширяюшиеся изменения. Чем быстрее организация успевает реагировать на внешние воздействия, тем большую выгоду получают те, чьи интересы эти воздействия затрагивают. Следовательно, различные изменения должны начаться, осуществиться и завершиться очень быстро. Важно быть уверенным в том, что инициатива провести изменение исходит от тех сотрудников, которые лучше всех способны правильно интерпретировать наблюдаемые события на основе тех знаний, которыми они располагают. Такими сотрудниками могут оказаться те, которые находятся ближе всех к месту события, однако у них отсутствуют полномочия по принятию решений. Важным условием в такой ситуации являются возможности передачи и расширения полномочий сотрудников по принятию решений для осуществления изменений в бизнес-процессах, а также оповещения персонала о результатах технической экспертизы, что фактически является распространением знаний экспертов. Критически важным фактором получения новых ценностей за счет передачи полномочий на нижние уровни иерархии организационной системы является осознание сотрудниками ответственности за осуществляемые ими изменения. Важна готовность сотрудников предприятия инициировать изменения в своей сфере деятельности, быть готовым совершить первый шаг и нести за это ответственность.

4.6.2. Социальное партнерство. В подходе к структуризации области «корпоративная культура» лежат три компонента - демократичный стиль лидерства, открытые коммуникации и доверие коллегам и информационным системам. Объединение указанных компонентов в систему обеспечивается социальным партнерством, которое является катализатором распространения знаний внутри предприятия. Опишем кратко каждую из выделенных компонент.

Демократичньй стиль лидерства (Democratic leadership style). Рост частоты событий, происходящих в окружающей среде, означает, что решения о том, как на них реагировать, должны приниматься быстрее, но без потери качества. Необходимым условием этого является наличие полных, актуальных и достоверных данных. Гибкий подход к принятию решений и предоставление сотрудникам больших полномочий по принятию решений создает организационную основу для распространения знаний и ускорения процесса принятия решений. Большое значение с точки зрения ускорения принятия решений имеет атмосфера взаимно- 
го доверия между сотрудниками предприятия, что является основой не только для быстрого принятия решений, но и для их быстрой и качественной реализации. Управление взаимоотношениями между сотрудниками должно базироваться на восприятии сотрудников как частей сообщества, владеющими ресурсами в сфере своих компетенций, которые необходимы для создания ценностей. Основой такого управления является демократический стиль лидерства.

Открытые коммуникации. Для того чтобы организация могла быстро и адекватно реагировать на неожиданные события, происходящие во внешней среде, ее сотрудники должны иметь немедленный доступ к необходимым явным и неявным знаниям. Доступ к явным знаниям осуществляется через соответствующие коммуникационные технологии. Распространение неявных знаний происходит в результате прямых коммуникаций между субъектами-обладателями и субъектами, нуждающимися в таких знаниях. Например, в случае повреждения, либо отказа машины оператор, обслуживающий ее, должен иметь доступ к техническим параметрам, необходимым для анализа ситуации, которые он может получить, обращаясь к информационным системам (MES/ERPсистемам). Однако оператор в ряде случаев может получить информацию, не фиксируемую сенсорами (например, в виде изменения уровня шума работающего механизма). Эта информация может оперативно распространяться среди сотрудников предприятия. Если сотрудники имеют возможность открытых коммуникаций, появляется возможность коллективного установления истинной причины наблюдаемого явления за счет синергии персональных данных. Если все сотрудники готовы обмениваться знаниями посредством коммуникационной сети, это откроет возможность существенного ускорения процесса обучения в организации за счет ускорения распространения новых знаний.

Доверие к коллегам и информационным системам. Опыт использования информационных систем, накопленный с 1970-х годов, учит, что недостаточно концентрировать внимание лишь на функциональных требованиях. Получение ценностей от использования информационных технологий возможно лишь при условии, что персонал предприятия вовлечен в процесс изменений, обусловленных появлением информационных систем, и может активно влиять на способы реализации изменений. Помимо вовлечения сотрудников предприятия в процесс создания информационных систем с нужными потребительскими свойствами, необходимо чтобы все сотрудники осознали, что 
потенциальные возможности информационных систем реализуются лишь в том случае, если систематическое их использование станет органической потребностью каждого сотрудника. Для того, чтобы руководство обучающейся, гибко настраиваемой организации имело доверие к получаемым из информационных систем сведениям, необходимо, чтобы знания представлялись в той форме, которая обеспечивает возможность сотрудникам эффективной реализации стратегии предприятия. Доверие к сведениям, предоставляемым информационной системой, обеспечивается за счет того, что руководство понимает механизмы информационной поддержки принятия решений, следствием которых является получение конкретной выгоды. В то же время руководители предприятия должны конструктивно и критически оценивать потребительские свойства информационной системы и способствовать усилению ее потенциала за счет размещения в системе своих собственных знаний. 


\section{ЗАКЛЮЧЕНИЕ}

Содержание монографии посвящено основным особенностям и проблемам управления инновационными проектами, а также требованиям к методам и моделям, применяемым для решения задач проектного менеджмента.

Эффективность управления инновационными проектами во многом определяется качеством принимаемых управленческих решений, которые осуществляются в условиях недостаточности данных и ресурсов, неопределенности последствий принимаемых решений, нестабильности внешних условий, недостаточно эффективного информационного взаимодействия управляющих проектом с той или иной стороны при наличии различных критериев выбора альтернатив. Уменьшение влияния факторов неопределенности может быть достигнуто за счет использования формализованного подхода к управлению проектом на основе рекомендаций стандартов проектного менеджмента в совокупности с оказанием интеллектуальной поддержки принятия решений для участников проекта, основанной на технологиях инженерии знаний.

Приобретение и накопление знаний особенно важно при создании инновационных технологий, являющихся результатом выполнения инновационных проектов. Инновационное проектирование наряду с формальными механизмами управления обеспечивает основу для осуществления неформальных механизмов координации, целью которых является интеграция существующх явных и неявных знаний, а также их накопление и использование для обоснования управленческих решений. Одним из основных свойств систем управления знаниями является эмерджентность, благодаря которой взаимодействие специалистов на основе формализации представления и обработки знаний при разработке интеллектуальных компонентов (онтологии, базы знаний) способствует созданию новых знаний.

Предлагаемая в монографии методология интеллектуальной поддержки принятия решений направлена на организацию и систематизацию деятельности в области управления инновационными проектами с применением онтологического инжиниринга и проблемно-ориентированной базы знаний. Методология предназначена прежде всего для решения проблем повышения эффективности управления инновационными проектами в производственно-экономических системах. 
Она включает применение перспективных технологий поддержки принятия решений на базе методов инженерии знаний и имитационного моделирования, обеспечивающих эффективную информационную поддержку в ходе разработки и реализации инновационных проектов, выполняющихся в субъектах Российской Федерации. При разработке методологии использовался системный подход к рассмотрению проблем управления региональными инновационными проектами, а также к разработке интеллектуальных и аналитических моделей применительно к задаче инновационной активности региона.

Новизна предложенной методологии заключается в разработке и применении комплексного инструментария для поддержки принятия решений в процессе управления инновационными проектами. Комплексный инструментарий содержит модели, методы и средства поддержки принятия решений на основе технологий инженерии знаний, обеспечивающих информационно-аналитическую поддержку управляющей системы на базе интегрированного описания ситуаций, требующих принятия решений, системного сочетания знаний и опыта экспертов, результатов математического и имитационного моделирования. Разрабатываемый инструментарий, основанный на унифицированной методологии системного моделирования и обобщении опыта и знаний в управлении проектами без привязки к специфике конкретного инновационного проекта, вместе с тем обеспечивает возможности уникального «наполнения» в зависимости от специфики проекта, данных и знаний о составе этапов и стадий, перечня оцениваемых показателей и методик их оценки, что позволяет автоматизировать процесс подготовки решений, а также создавать алгоритмическое и программное обеспечение для обеспечения процессов принятия управленческих решений, адаптируемое под конкретную отрасль и проекты инновационного развития на региональном уровне.

Существенное внимание в работе уделено анализу рисков инновационной деятельности производственно-экономических систем. Приведены примеры анализа рисков инновационных проектов с использованием многослойных нечетких когнитивных карт. Описана концепция инновационного развития производственно-экономических систем на основе доктрины «Индустрия 4.0» на примере создания «умных» предприятий.

Монография наглядно показывает на практических примерах необходимость применения интеллектуальных моделей и методов и поэтому представляет интерес для широкого круга читателей - представителей научного сообщества. 


\section{ПЕРЕЧЕНЬ СОКРАЩЕНИЙ И УСЛОВНЫХ ОБОЗНАЧЕНИЙ}

API - интерфейс прикладного программирования (Application Programming Interface)

BPM - управление бизнес-процессами (business process management)

BPMN - нотация управления бизнес-процессами (business process management notation)

CPS - кибер-физические системы (cyber-physical systems)

CRM - Управление взаимоотношениями с клиентами (Customer Relationship Management)

$D L \quad$ - описательные (дескрипционные) логики (Description logics)

DSS - система поддержки принятия решений (Decision Support System);

ERP - планирование и управление ресурсами предприятия (Enterprise Resource Planning);

IT - информационная технология (Information Technology)

KPI - ключевой показатель эффективности (Key Performance Indicator)

MES - система управления производственными процессами (Manufactoring Execution System);

MVP - минимально жизнеспособный продукт (Minimum Viable Product);

OWL - язык описания онтологий (Ontology Web Language);

PLM - системы управления жизненным циклом продукции (Product Lifecycle Management);

PMBоK - руководство к своду знаний по управлению проектами (A Guide to the Project Management Body of Knowledge);

RPA - программный робот (Robotic Process Automation);

SPARQL - язык запросов к семантическим базам данных(Semantic Protocol and RDF Query Language);

$S Q L \quad$ - язык структурированных запросов (Structured Query Language);

$S W R L$ - язык описания правил в семантической паутине (Semantic Web Rule Language);

АИС - автоматизированная информационная система; 


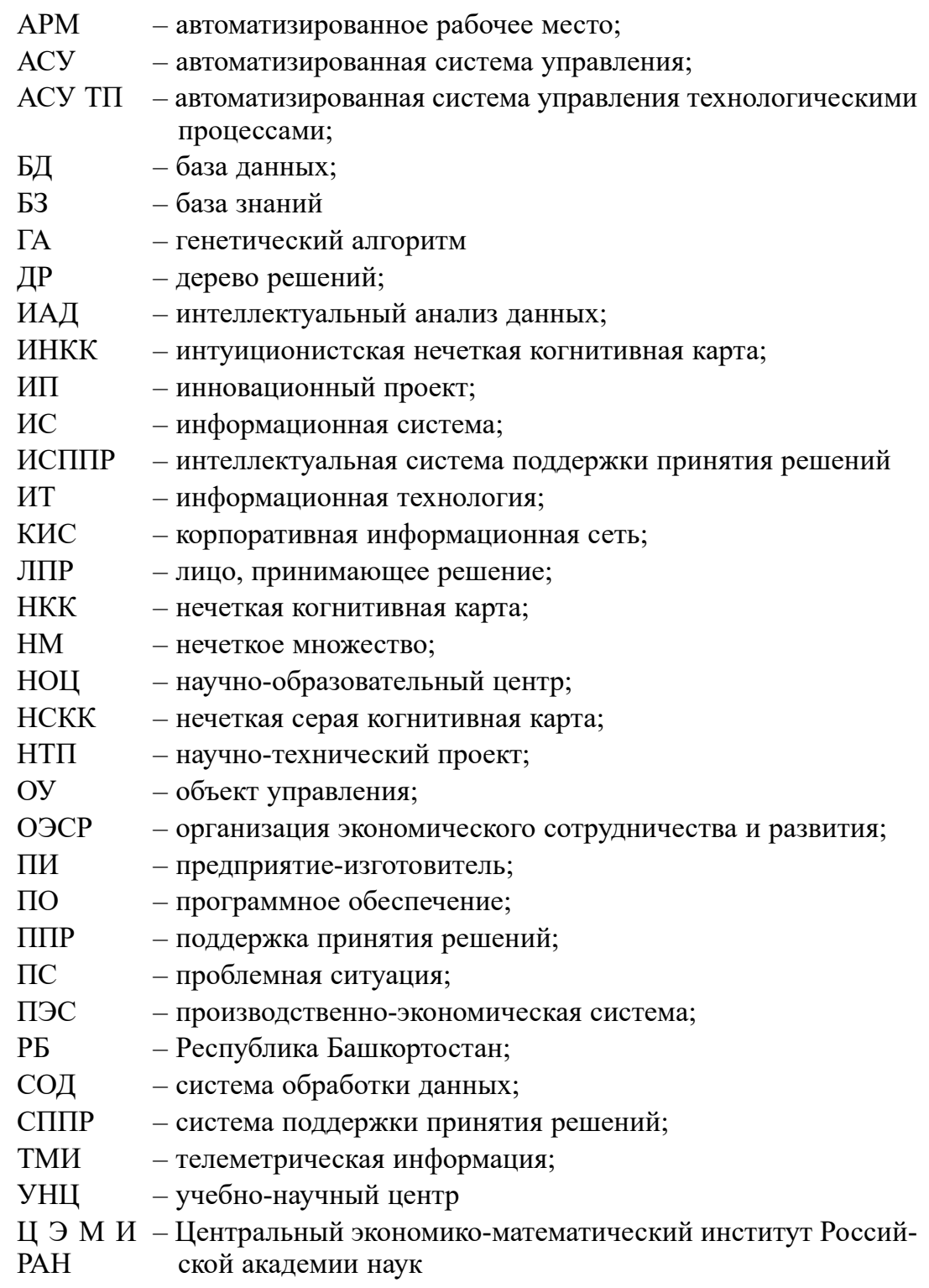




\section{СПИСОК ЛИТЕРАТУРЫ}

1. Рейтинг инновационного развития субъектов Российской Федерации. Национальный исследовательский университет «Высшая школа экономики», Выпуск 6, 2019 г. [Электронный ресурс]. URL: https://issek.hse.ru/rirr2019 (дата обращения: 13.10.2020).

2. Уровень инновационной активности организаций. Официальный сайт Территориального органа Федеральной службы государственной статистики по Республике Башкортостан. [Электронный ресурс]. URL: https://bashstat.gks. ru/folder/26074 (дата обращения: 16.10.2020).

3. ГОСТ Р 54875-2011. Менеджмент знаний. Руководство по устоявшейся практике внедрения системы менеджмента знаний. М.: Стандартинформ, 2020. 15 c.

4. A Guide to the Project Management Body of Knowledge (PMBoK Guide) / Project Management Institute. 2017. Pensylvanya: Sixth Edition, PMI Publications, 2017. $762 \mathrm{p}$.

5. Массель Л.В., Ворожцова Т.Н., Пяткова Н.И. Онтологический инжиниринг для поддержки принятия стратегических решений в энергетике // Онтология проектирования. 2017. Т. 7, №1(23). С. 66-76. DOI: 10.18287/2223-95372017-7-1-66-76.

6. Болотова Л.С. Системы искусственного интеллекта: модели и технологии, основанные на знаниях: учебник / ФГБОУ ВПО РГУИТП; ФГАУ ГНИИ ИТТ «Информика». М.: Финансы и статистика, 2012. 664 с.

7. Гаврилова Т.А., Кудрявцев Д.В., Муромцев Д.И. Инженерия знаний. Модели и методы: учебник. Санкт-Петербург: Лань, 2016. 324 с.

8. Черняховская Л.Р., Низамутдинов М.М. Разработка базы знаний для интеллектуальной поддержки принятия решений в процессе управления инновационным проектом // Проблемы управления и моделирования в сложных системах: труды XXI Международной конференции (Самара, 3-6 сентября 2019 г.). Самара: ООО «Офорт», 2019. Т.1. С. 528-531.

9. Chernyakhovskaya L.R., Nikulina N.O., Malakhova A.I. Principles of the knowledge base formation as a part of intellectual decision support system in innovative projects management // $21^{s t}$ International Scientific Workshop on Computer Science and Information Technologies (CSIT'2019) (Austria, Vienna, 2-4 October 2019). Atlantis Highlights in Computer Sciences. Vol. 3. P. 125-130. DOI: https:// doi.org/10.2991/csit-19.2019.21.

10. Черняховская Л.Р., Малахова А.И., Никулина Н.О. Исследование содержания проблемы управления инновационными проектами в процесcax стратегического планирования и развития производственно-экономических систем // Информационные технологии. 2020. Т. 26, № 4. С. 239-251. DOI: $10.17587 /$ it.26.239-251. 
11. Руководство Осло: Рекомендации по сбору и анализу данных по инновациям / Совместная публикация ОЭСР и Евростата. М.: Государственное учреждение «Центр исследований и статистики науки» (ЦИСН), 2010. 107 с.

12. Федеральный закон от 23.08.1996 № 127-Ф3 «О науке и государственной научно-технической политике». [Электронный ресурc]. URL: https://base. garant.ru/135919/ (дата обращения 19.11.2020).

13. Стратегия инновационного развития Российской Федерации на период до 2020 года (утверждена Распоряжением Правительства Российской Федерации от 8 декабря 2011г. № 2227-p). [Электронный ресурc]. URL: http://www. consultant.ru/document/cons_doc_LAW_123444/(дата обращения: 15.07.2020).

14. Стратегические документы в сфере инновационного развития. Официальный сайт Министерства экономического развития Российской Федерации. [Электронный ресурc]. URL: https://www.economy.gov.ru/ material/departments/d01/strategicheskie_dokumenty_v_sfere_innovacionnogo_razvitiya/ (дата обращения 10.12.2020).

15. Указ Президента РФ № 899 от 07.07.2011г. «Об утверждении приоритетных направлений развития науки, технологий и техники в Российской Федерации и перечня критических технологий Российской Федерации» (с изменениями на 16.12.2015). [Электронный ресурс] // Электронный фонд правовой и нормативно-технической документации. URL: http://docs.cntd.ru / document/902287707 (дата обращения: 27.03.2019).

16. Индикаторы инновационной деятельности: 2020: статистический сборник / Л.М. Гохберг, К.А. Дитковский, И.А. Кузнецова и др.; Нац. исслед. ун-т «Высшая школа экономики». М.: НИУ ВШЭ, 2020. 337 с.

17. Dutta S, Lanvin B and Wunsch-Vincent S. The Global Innovation Index 2020: Who Will Finance Innovation? (Geneva, New Delhi: Cornell University, INSEAD, and the World Intellectual Property Organization). 2020. p. 448.

18. Индикаторы инновационной деятельности: 2018: статистический сборник / Н.В. Городникова, Л.М. Гохберг, К.А. Дитковский и др.; Нац. исслед. ун-т «Высшая школа экономики». М.: НИУ ВШЭ, 2018. 344 с.

19. Индикаторы инновационной деятельности: 2019: статистический сборник / Л.М. Гохберг, К.А. Дитковский, И.А. Кузнецова и др.; Нац. исслед. ун-т «Высшая школа экономики». М.: НИУ ВШЭ, 2019. 376 с.

20. Pulse of the Profession $\mathbb{R}:$ The Future of Work: Leading the Way with PMTQ, February 2019. [Электронный pecypc]. URL: https://www.pmi.org/learning/thoughtleadership/pulse/pulse-of-the-profession-2019 (дата обращения: 27.07.2020).

21. Наука и инновации. [Электронный ресурс] // Федеральная служба государственной статистики. URL: https://www.gks.ru/folder/14477 (дата обращения: 10.12.2020).

22. Pulse of the Profession ${ }^{\circledR}$ : Success in disruptive times. Expanding the value delivery landscape to address the high cost of low performance, February 2018. [Электронный ресурc]. URL: https://www.pmi.org/learning/thought-leadership/ pulse/pulse-of-the-profession-2018 (дата обращения: 17.07.2019).

23. Liliya Chernyakhovskaya, Marsel Nizamutdinov. Development of Knowledge Base for Intellectual Decision Support in the Process of Innovative Project 
Management // IEEE Xplore Digital Library. Date Added to IEEE Xplore: 03 February 2020. P. 384-387. DOI: 10.1109/CSCMP45713.2019.8976758.

24. Палюх Б.В., Какатунова Т.В. Нечеткая когнитивная карта как инструмент моделирования инновационной деятельности на региональном уровне // Программные продукты и системы. 2012. № 4. С. 128-131.

25. Захарова А.А. Некоторые аспекты разработки информационной системы поддержки принятия стратегических решений об инновационном развитии региона // Современные наукоемкие технологии. 2007. № 9. С. 27-29.

26. Антамошкин А.Н., Антамошкина О.И., Ходос Д.В. Моделирование основных этапов формирования программы инновационного развития // Вестник Сибирского государственного аэрокосмического университета имени академика М.Ф. Решетнева. 2010. №4(30). С. 204-206.

27. Бечелова Т.Р. Проблемы формирования производственно-экономических систем в региональной экономике // Современные проблемы науки и образования. 2012. № 2. URL: http://science-education.ru/ru/article/view?id=5826 (дата обращения: 11.07.2019).

28. Арчибальд Р. А. Управление высокотехнологичными программами и проектами / Рассел Д. Арчибальд; пер. с англ. Мамонтова Е.В.; под ред. Баженова А.Д., Арефьева А.О. 3-е изд., перераб. и доп. М.: Компания АйТи; ДМК Пресс, 2010. 464 с.

29. Мазур И.И., Шапиро В.Д., Ольдерогге Н.Г. Управление проектами: учеб. пособие. М.: Омега-Л, 2005. 664 с.

30. Закон Республики Башкортостан от 28 декабря 2006 года № 400-3 «Об инновационной деятельности в Республике Башкортостан» (с изменениями на: 30.03.2015 г.). // Электронный фонд правовой и нормативно-технической документации. [Электронный ресурс]. URL: http://docs.cntd.ru/document/ 935106470. (дата обращения: 07.07.2019).

31. ГОСТ Р 21500-2014 Руководство по проектному менеджменту. М.: Стандартинформ, 2015. $50 \mathrm{c}$.

32. Liliya Chernyakhovskaya, Natalya Nikulina, Anna Malakhova, Irina Ivanova Simulation modelling of innovative project management processes // Proceedings of the 8th Scientific Conference on Information Technologies for Intelligent Decision Making Support (ITIDS 2020). Advances in Intelligent Systems Research. Vol. 174. P. 24-29. DOI: https://doi.org/10.2991/aisr.k.201029.005.

33. Алетдинова А.А., Кравченко М.С., Королева Н.С. Особенности инновационных проектов в сетевой экономике // Интернет-журнал «НАУКОВЕДЕHИЕ», 2016. Т. 8, № 5. [Электронный ресурс]. URL: http://naukovedenie.ru/ PDF/59EVN516.pdf (дата обращения: 20.07.2019).

34. Никулина Н.О., Иванова И.Ф., Малахова А.И. Применение интеллектуальных технологий в решении проблем инновационных проектов // Проблемы управления и моделирования в сложных системах: труды XXI Междунар. конф. (3-6 сентября 2019 г., Самара): в 2-х т. Самара: ООО «Офорт», 2019. T.2. C. $483-488$.

35. Павлов А.Н. Эффективное управление проектами на основе стандарта PMI PMBoK 6th Edition. М.: Лаборатория знаний, 2019. 270 с. 
36. Руководство к своду знаний по управлению проектами (РMBOK + AGILE): практическое руководство, 6-е изд. М.: Олимп-Бизнес, 2019. 974 с.

37. Новиков Д.А. Методология управления. М.: Либроком, 2011. 128 с.

38. Зандкуль К., Смирнов А.В. Управление знаниями в производственных сетях: классификация и технологии для повторного использования знаний // Труды СПИИРАН. 2018. № 1 (56). С. 5-33. DOI:10.15622/sp.56.1.

39. Sandkuhl K., Stirna J., Persson A., Wißotzki M. Enterprise Modeling: Tackling Business Challenges with the 4EM Method // Springer. 2014. 309 p.

40. Jakubowski J., Peterka J. Design for Manufacturing in Virtual Environment using Knowledge Engineering // Management and Production Engineering Review. 2014. Vol. 5. №. 1. P. 3-10.

41. Бармина О.В., Никулина Н.О. Интеллектуальная система управления взаимодействием деловых процессов в проектно-ориентированных организациях // Онтология проектирования. 2017. Т. 7, №1(23). С. 514-524. DOI: $10.18287 / 2223-9537-2017-7-1-514-524$.

42. Белов М. Статистика сертифицированных РМІ специалистов в России на 10.01.2020. [Электронный pecypc]. URL: https://asiafinance.su/info/news/obistorii-sertifikatsii-pmi-v-rossii-v-tsifrakh-2000-2019q1 (дата обращения: 01.10.2020).

43. Никулина Н.О., Иванова И.Ф., Бармина О.В. Проектный менеджмент в управлении бизнес-процессами: учебное пособие / Уфимск. гос. авиац. техн. ун-т. Уфа: РИК УГАТУ, 2017. 260 с.

44. Liliya Chernyakhovskaya, Anna Malakhova. Methods of decision-making support for innovative projects management using integrated ontology. Proceedings of the $6^{\text {th }}$ International Workshop 'Critical Infrastructures: Contingency Management, Intelligent, Agent-Based, Cloud Computing and Cyber Security' (IWCI 2019). Advances in Intelligent Systems Research. Vol. 169. P. 90-94. DOI: https:// www.atlantis-press.com/proceedings/iwci-19/125917308.

45. Макаров В.Л. Экономика знаний: уроки для России. М.: Вестник Российской академии наук. 2003. Т. 73, № 5. С. 450-455.

46. Виттих В. А. Интеграция знаний при исследованиях сложных систем // Известия Академии наук. Теория и системы управления. 1998. № 5. С. 788-795.

47. Васильев С.Н., Жерлов А.Б., Федосов Е.А., Федунов Б.Е. Интеллектное управление динамическими системами. М.: Физико-математическая литература, 2000. $152 \mathrm{c}$.

48. Методические аспекты искусственного интеллекта: монография / М.Б. Гузаиров, Н.И. Юсупова [и др.]. М.: Машиностроение, 2014. 262 с.

49. Amodt A., Plaza E. Case Based Reasoning: Foundational Issues, Methodological Variations, and System Approaches. AI Communications, 7(i). 1994. P. 39-59.

50. Базы знаний интеллектуальных систем / Т.А. Гаврилова, В.Ф. Хорошевский. СПб: Питер, 2000. 384 с.

51. Guizzardi G., Wagner G., Almeida J.P.A., Guizzardi R.S.S. Towards Ontologica Foundations for Conceptual Modeling: The Unified Foundational Ontology (UFO) Story // Applied ontology. 2015. Vol. 10. № 3-4. P. 259-271.

52. Каныгин Г.В., Полтинникова М.С. Контекстно-ориентированные онтологические методы в социологии // Труды СПИИРАН. 2016. № 48 (5). С. 107-124. 
53. Smirnov A., Sandkuhl K., Shilov N. Multilevel Self-Organization and Context-Based Knowledge Fusion for Business Model Adaptability in Cyber-Physical Systems // IFAC Proceedings Volumes. 2013. Vol. 46. № 9. P. 2045-2050.

54. Blomqvist E., Hammar K., Presutti V. Engineering Ontologies with Patterns: The eXtreme Design Methodology // Ontology Engineering with Ontology Design Patterns. IOS Press. 2016. Vol. 25. P. 23-50.

55. Никулина Н.О., Черняховская Л.Р., Низамутдинов М.М., Малахова А.И., Мухаметьянова Р.И. Методическое обеспечение интеллектуального анализа характеристик инновационной деятельности // Современные наукоемкие технологии. 2020. № 11 (часть 2). С. 313-319.

56. Artemy G. Varzhapetyan, Elena G. Semenova, Remir I. Solnitsev, Alena V. Fomina, Viktor M. Balashov. Knowledge base in system of value-oriented management of innovative projects // Proceedings of the International Conference «Economy in the Modern World» (ICEMW 2018). 2018. Vol. 61. P. 246-251. DOI https:// doi.org/10.2991/icemw-18.2018.45.

57. Dmitry Kudryavtsev, Anna Menshikova, Tatiana Gavrilova. Representing strategic organizational knowledge via diagrams, matrices and ontologies // International Journal «Information Theories and Applications». 2016. Vol. 23. № 1. P. 48-66.

58. Disterer G. Management of Project Knowledge and Experiences // Journal of Knowledge Management. 2002. Vol. 6, № 5. P. 512-520.

59. Goh A.L.S. Harnessing Knowledge for Innovation: An Integrated Management Framework // Journal of Knowledge Management. 2005. Vol. 9, №. 4. P. 6-18.

60. Черняховская Л.Р., Никулина Н.О., Ширяев. О.В. Интеллектуальное управление сложными деловыми процессами на основе онтологических баз знаний: учебное пособие. Уфа: РИК УГАТУ, 2018. 185 с.

61. Поддержка принятия решений при стратегическом управлении предприятием на основе инженерии знаний / под ред. Черняховской Л.Р. Уфа: Гилем, 2010. $180 \mathrm{c.}$

62. Черняховская Л.Р., Малахова А.И. Разработка моделей и методов интеллектуальной поддержки принятия решений на основе онтологии организационного управления программными проектами // Онтология проектирования, 2014. № 4 (10). С. 42-50.

63. Официальная документация по Protégé. [Электронный ресурc]. URL: http://protrgrwiki.stanfotd.edu/index.php/ProtegeUserDocs (дата обращения: 20.03.2020).

64. Черняховская Л.Р., Никулина Н.О., Бармина О.В. Оценка эффективности поддержки принятия решений при реализации проекта по разработке программного обеспечения // Информационные технологии интеллектуальной поддержки принятия решений: труды 6 Всеросс. конф. (с междунар. участием) ITIDS'2018, T.2. Уфа-Ставрополь, Россия, 28-31 мая 2018. C. $16-22$.

65. Товб А.С., Ципес Г.Л. Управление проектами: стандарты, методы, опыт. М.: ЗАО «Олимп - Бизнес», 2003. 240 с.

66. ГОСТ Р 56275-2014. Менеджмент рисков. Руководство по надлежащей практике менеджмента рисков проектов. М.: Стандартинформ, 2015. 31 с. 
67. Гаибова Т.В. Формирование проектных альтернатив на основе онтологического подхода / Т.В. Гаибова, Т.В. Павлович // Онтология проектирования. 2019. Т. 9, №3(33). С. 321-332. DOI: 10.18287/2223-9537-2019-9-3-321-332.

68. Никулина Н.О., Малахова А.И., Иванова И.Ф. Интеллектуальная поддержка принятия решений при анализе рисков инновационного проекта // Онтология проектирования. 2019. Т. 9, №3(33). С. 382-397. DOI: 10.18287/22239537-2019-9-3-382-397.

69. Черняховская Л.Р., Никулина Н.О., Малахова А.И., Гарайшин Ш.Г., Нагимов Т.Р. Проектирование системы управления бизнес-процессами на основе онтологического анализа и имитационного моделирования предметной области // Информационные и математические технологии в науке и управлении. 2019. №3 (15). С. 18-30. DOI:10.25729/2413-0133-2019-3-02.

70. Черняховская Л.Р., Никулина Н.О., Бармина О.В. Применение онтологического анализа и обработки знаний для принятия решений в проблемных ситуациях // Управление экономикой: методы, модели, технологии: Труды XV Международной научной конференции (Уфа, 22-24 октября 2015 г). Уфа: Изд-во Уфимского государственного авиационного технического университета, 2015. Т. 2. С. 181-186.

71. Nikulina N.O., Malakhova A.I., Ivanova I.F. Application of Intelligent Technologies in Solving the Innovative Projects Problems // 2019 XXI International Conference Complex Systems: Control and Modeling Problems (CSCMP). IEEE Xplore Digital Library. Date Added to IEEE Xplore: 03 February 2020. DOI: 10.1109/CSCMP45713.2019.8976870.

72. Проблемы управления сложными динамическими объектами в критических ситуациях на основе знаний / Р.А. Бадамшин, Б.Г. Ильясов, Л.Р. Черняховская. М.: Машиностроение, 2003. 240 с.

73. Chungoora N., Gunendran G.A., Young R.I.M., Usman Z., Anjum N.A., Palmer C., Harding J.A., Case K., Cutting-Decelle A.F. Extending Product Lifecycle Management for Manufacturing Knowledge Sharing. Proceedings of the Institution of Mechanical Engineers. Part B, Journal of Engineering Manufacture, 2012. Vol. 226, № A12. P. 2047-2063. DOI: 10.1177/0954405412461741.

74. Palmer C., Usman Z., Canciglieri O., Malucelli A., Young R.I.M. Interoperable manufacturing knowledge systems, International journal of production research, 2017. Vol. 56, № 8. P. 2733-2752.

75. Borgo S., Leitão P. Foundations for a Core Ontology of Manufacturing Integrated Series in Information Systems, 2007. № 14. P. 751-775. DOI: 10.1007/9780-387-37022-4.

76. Профессиональное управление проектом / К. Хелдман; пер. с англ. А.В. Шаврина. М.: Лаборатория знаний, 2016. 760 с.

77. Лубянская Э.Б., Анисимов Ю.П. Особенности системы стратегического управления инновационными проектами в условиях цифровой экономики // Организатор производства, 2019. Т. 27. № 2. С. 81-93.

78. Хорошевский В.Ф. Проектирование систем программного обеспечения под управлением онтологий: модели, методы, реализации // Онтология проектирования. 2019. Т. 9. №4 (34). C. 429-448. DOI: 10.18287/2223-95372019-9-4-429-448. 
79. Загорулько Г.Б. Модель комплексной поддержки разработки интеллектуальных СППР // Онтология проектирования. 2019. Т. 9. №4 (34). С. 462-479. DOI: $10.18287 / 2223-9537-2019-9-4-462-479$.

80. Уровень инновационной активности организаций. Официальный сайт Территориального органа Федеральной службы государственной статистики по Республике Башкортостан. [Электронный ресурс]. URL: https://bashstat.gks. ru/folder/26074 (дата обращения: 16.10.2020).

81. Реестр приоритетных инвестиционных проектов Республики Башкортостан. Официальный сайт Министерства экономического развития и инвестиционной политики Республики Башкортостан. [Электронный ресуpc]. URL: https:// data.gov.ru/opendata/0274116127-reestrinvestpr (дата обращения: 12.09.2020).

82. Барсегян А.А., Куприянов М.С., Степаненко В.В., Холод С.С. Методы и модели анализа данных: OLAP и Data Mining. СПб: БХВ-Петербург, 2004. $336 \mathrm{c}$. $388 \mathrm{c}$.

83. Дюк В., Самойленко A. Data mining: учебный курс. СПб: Питер, 2001.

84. Introduction to Machine Learning. Ethem Alpaydin. The MIT Press Cambridge, Massachusetts, London, England, 2004. 400 p.

85. Quinlan J.R. C4.5: Programs for Machine Learning. San Mateo: Morgan Kaufmann Publishers Inc., 1993. 302 p.

86. Макаров В.Л., Бахтизин А.Р. Современные методы прогнозирования последствий управленческих решений // Управленческое консультирование. 2015. № 7 (79). C. 12-24.

87. Теория систем и системный анализ в управлении организациями: Справочник: учеб. пособие / под ред. В.Н. Волковой и А.А. Емельянова. М.: Финансы и статистика; ИНФРА-М, 2009. 848 с.

88. Скобелев П.О. Онтологии деятельности для ситуационного управления предприятиями в реальном времени // Онтология проектирования. 2012. №1. C. 6-39.

89. Мадера А.Г. Метод определения вероятностей прогнозируемых событий при принятии решений // Искусственный интеллект и принятие решений. 2016. №2. С. 38-45.

90. Рутковский Лешек. Методы и технологии искусственного интеллекта / пер. с польск. И.Д. Рудинского. М.: Горячая линия - Телеком, 2010. 32 с.

91. Ковалев С.М., Колоденкова А.Е. Построение базы знаний интеллектуальной системы контроля и предупреждения рисковых ситуаций для этапа проектирования сложных технических систем // Онтология проектирования. 2017. T. 7. № 4(26). C. 398-409.

92. OWL 2. Web Ontology Language Guide. Document Overview (Second Edition). [Электронный pecypc]. URL: http://www.w3.org/TR/owl2-overview (дата обращения: 20.10.2020).

93. Черняховская Л.Р., Малахова А.И. Разработка моделей и методов интеллектуальной поддержки принятия решений на основе онтологии организационного управления программными проектами // Онтология проектирования. 2013. №4 (10). С. 42-52. 
94. Mulle Yu., Chernyakhovskaya L.R., Osipova I.V., Nikulina N.O. Interaction Modeling of the Different Knowledge Representation Forms in the Decision Support System $/ / 6^{\text {th }}$ International Scientific Workshop on Computer Science and Information Technologies (CSIT'2004) Budapest, Hungary, 2-4 October 2004. Vol. 1. P. 153-156.

95. Zadeh L.A. The concept of a linquistic variable and its application to approximate reasoning. Information Sciences. 1975. Vol. 8. P. 43-80.

96. Борисов В.В., Круглов В.В., Федулов А.С. Нечеткие модели и сети. М.: Горячая линия-Телеком, 2012. 284 с.

97. Леоненков А.В. Нечеткое моделирование в среде MATLAB и FuzzyTech. СПб.: БХВ-Петербург, 2003. 736 с.

98. Калянов Г.Н. О теории бизнес-процессов. Программная инженерия? 2018. № 9 (3). С. 99-109.

99. Официальный сайт компании ELMA. [Электронный ресурс]. URL: https://www.elma-bpm.ru (дата обращения 12.03.2020).

100. Официальный сайт компании AnyLogic. [Электронный ресуpc]. URL: https://www.anylogic.ru (дата обращения 10.10.2020).

101. Воейкова О. Б., Лячин В. И. Категориальное определение инновационного пространства // Сибир. журн. науки и технологий. 2015. Т. 16. №. 4. С. 1014-1021.

102. О федеральной целевой программе «Научные и научно-педагогические кадры инновационной России» на 2009-2013 годы: Постановление Правительства РФ от 28 июля 2008 г. № 568. [Электронный ресурс]. URL: http:// base.garant.ru/6390825/\#ixzz5lzvQLTIO (дата обращения: 21.03.2020).

103. Методические рекомендации по формированию программ деятельности научно-образовательных центров мирового уровня. [Электронный реcypc]. URL: https://www.minobrnauki.gov.ru/ru/documents/card/?id_4=607\&cat=/ ru/activity/act/dgnintp/nauka/notc/ (дата обращения: 21.03.2020).

104. О мерах государственной поддержки научно-образовательных центров мирового уровня на основе интеграции образовательных организаций высшего образования и научных организаций и их кооперации с организациями, действующими в реальном секторе экономики: Постановление Правительства РФ от 30 апреля 2019 г. № 537. [Электронный ресурc]. URL: https:// www.garant.ru/products/ipo/prime/doc/72140532/ (дата обращения: 21.03.2020).

105. Kosko B. Fuzzy Cognitive Maps // International Journal of Man-Machine Studies. 1986. Vol. 1. P. 65-75.

106. Самсонов Р.О., Кузнецов А.В., Воронина М.А., Кочарова Э.А. Применение нейронной сети для оптимизации проектирования структурной деятельности научно-образовательного центра мирового уровня // Изв. Самар. науч. центра РАН. 2019. Т. 21. №. 4. С. 5-15.

107. Шкарупета Е.В. Научно-образовательные центры мирового уровня: этапы реализации // Цифровая экономика: проблемы и перспективы развития: сб. науч. статей Межрегион. науч.-практ. конф. (Курск, 14-15 ноября 2019 г.). Курск: Изд-во Юго-Запад. гос. ун-та. 2019. С. 497-501.

108. Татьяна Голикова и Андрей Фурсенко провели заседание Совета научно-образовательных центров мирового уровня от 20 февраля 2020 г. [Электронный pecypc]. URL: http://government.ru/news/39005/ (дата обращения: 21.03.2020). 
109. Al-Shebab A.J., Hughes R.T., Winstanley G. Modelling Risks in IS/IT Projects through Causal and Cognitive Mapping // Electronic Journal of Systems Evaluation. 2005. Vol. 8. Is. 1. P. 1-10.

110. Rodriguez-Repiso L., Setchi R., Salmeron J.L. Modelling IT Projects Success with Fuzzy Cognitive Maps // Expert Systems with Applications. 2007. Vol. 32. №2. P. 543-559.

111. Миннибаев Д.М., Зайцева Ж.В. Когнитивные модели для управления инвестиционными рисками предприятий строительного комплекса // Вестник ОГУ. 2008. № 10(92). С. 91-95.

112. Горелова Г.В. Когнитивный подход к имитационному моделированию сложных систем // Известия ЮФУ. Технические науки. 2013. № 3(140). C. $239-250$.

113. Градусов Д.А., Шутов А.В., Анцупова Д.П. Моделирование взаимовлияний целей и рисков проектов внедрения интегрированной системы управления предприятием на основе нечетких когнитивных карт // Экономический анализ: Теория и практика. 2013. № 37(340). С. 50-59.

114. Case D.M., Stylios Ch. D. Fuzzy Cognitive Map to model project management problems // 2016 Annual Conference of the North American Fuzzy Information Processing Society (NAFIPS). IEEE. 2016. P. 1-6.

115. Проценко Е.В., Александрова А.В. Когнитивный подход в оценке рисков инновационных проектов // Экономические аспекты развития промышленности в условиях глобализации: материалы Международной научно-практической конференции. М.: УН-т машиностроения, Изд-во «Научный консультант», 2015. С. 213-216.

116. Ковалев С.М., Колоденкова А.Е. Построение базы знаний интеллектуальной системы контроля и предупреждения рисковых ситуаций для этапа проектирования сложных технических систем // Онтология проектирования. 2017. T. 7. № 4(26). C. 398-409.

117. Боженюк А.В., Гинис Л.А. Об использовании нечетких баз и антибаз при анализе нечетких когнитивных карт // Искусственный интеллект. 2004. №4. C. 276-285.

118. Aguilar J. Multilayer Cognitive Maps in the Resolution of Problems using the FCM Designer Tool // Applied Artificial Intelligence. 2016. Vol. 30. №7. P. 720-743.

119. Mohr S. Modelling Approaches for Multilayer Fuzzy Cognitive Maps. [Электронный peсурc]. URL: https://www.researchgate.net/publication/332158518_Modelling_Approaches_for_Multilayer_Fuzzy_Cognitive_Maps (дата обращения 27.08.2019).

120. Stylios C.D., Groumpos P.P. Fuzzy Cognitive Maps Multi-Model for Complex Manufacturing Systems // IFAC Large Scale Systems: Theory and Applications. Bucharest, Romania, 2001. P. 61-66.

121. Stula M., Stipanicev D., Bodrozic L. Intelligent Modeling with Agentbased Fuzzy Cognitive Map // Intern. Journal on Intell. Systems. 2010. Vol. 25, №10. P. 981-1004.

122. Mohagheghi S. Fuzzy Cognitive Maps for Identifying Fault Activation Patterns in Automation Systems. [Электронный pecypc]. URL: https://www. intechopen.com/books/ (дата обращения 17.08.2019). 
123. Motlagh O., Papageorgiou E.I., Tang S.H., Jamaludin Z. Multivariate Relationship Modeling Using Nested Fuzzy Cognitive Map // Sains Malaysiana. 2014. №43(11). P. 1781-1790.

124. Кулинич А.А. Компьютерные системы моделирования когнитивных карт: подходы и методы // Проблемы управления. М.: Изд-во ИПУ РАН им. В.А. Трапезникова, 2010. Вып. 3. С. 2-16.

125. Zhang J.Y., Liu Z.Q., Zhou S. Quotient FCMs - A Decomposition Theory for Fuzzy Cognitive Maps // IEEE Transactions on Fuzzy Systems. Oct. 2003. Vol. 11. №5. P. 593-604.

126. Salmeron J.L. Modelling grey uncertainty with Fuzzy Grey Cognitive Maps // Expert Systems with Applications. 2010. Vol. 37. №12. P. 7581-7588.

127. Ландшафт угроз для систем промышленной автоматизации. Первое полугодие 2019. [Электронный ресурc]. URL: https://ics-cert.kaspersky.ru/ reports/2019/09/30/threat-landscape-for-industrial-automation-systems-h1-2019/ (дата обращения: 13.03.2020).

128. Ярушевский Д. Кибербезопасность АСУ ТП - что это и зачем? Пресс-центр «ДиалогНаука». [Электронный ресурc]. URL: https://www. dialognauka.ru/press-center/article/13226/ (дата обращения 17.08.2019).

129. Андреев Ю.С., Дергачев А.М., Жаров Ф.А., Садырин Д.С. Информационная безопасность автоматизированных систем управления технологическими процессами // Известия вузов. Приборостроение. 2019. Т. 62. №4. С. 331-339.

130. Васильев В.И., Кириллова А.Д., Кухарев С.Н. Кибербезопасность автоматизированных систем управления промышленных объектов (современное состояние, тенденции) // Вестник УрФО. Безопасность в информационной сфере. 2018. № 4(30). С. 66-74.

131. Ярушевский Д. Обеспечение безопасности АСУ ТП - краткий обзор семейства стандартов IEC 62443 // Information Security/ Информационная безопасность. 2014. №3. C. 34-36. URL: http://lib.itsec.ru/articles2/ (дата обращения 17.08.2019).

132. Salmeron J.L., Palos-Sanchez P.R. Uncertainty propagation in fuzzy grey cognitive maps with Hebbian-like learning algorithms // IEEE transactions on cybernetics. 2017. Vol. 49. №1. P. 211-220.

133. Hajeck P., Prochazka O. Interval-valued fuzzy cognitive maps for supporting business decisions. In Proceedings of IEEE International Conference on Fuzzy Systems, Vancouver, BC, Canada, July 2016. P. 531-536.

134. Espinosa M.L., Depaire B., Vanhoof K. Fuzzy Cognitive Maps with Rough Concepts. In Proceeding of the 9th IFIP WG 12.5 International Conference, AIAI 2013: Artificial Intelligence Applications and Innovations, Paphos, Cyprus, Sept. 30 - Oct. 2, 2013. P. 527-536.

135. Hajek P., Froelich W., Prochazka O. Intuitionistic Fuzzy Grey Cognitive Maps for Forecasting Interval-Valued Time Series // Neurocomputing. 2020. Vol. 1. P. 436-443.

136. Salmeron J.L. A Fuzzy Grey Cognitive Map-based Intelligent Security System. In Proceeding of 2015 IEEE International Conference on Grey Systems and Intelligent Services, Leicester, UK, August 2015. Vol. 2. P. 213-217. 
137. Васильев В.И., Вульфин А.М., Гузаиров М.Б., Кириллова А.Д. Интервальное оценивание информационных рисков с помощью нечетких серых когнитивных карт // Информационные технологии. 2018. Т. 24. №10. С. 657-664.

138. Lei Y., Liu J., Yin H. Intrusion detection techniques based on improved intuitionistic fuzzy neural networks // 2016 International Conference on Intelligent Networking and Collaborative Systems (INCoS). IEEE, 2016. P. 518-521.

139. Reji M. et al. A genetic-Fuzzy Approach for Detection of Worm Attack in Ad-Hoc Wireless Networks // Indian Journal of Public Health Research \& Development. 2017. Vol. 8. №4. P. 1312-1321.

140. Хачатуров В.Р. и др. Системы планирования и проектирования для нефтегазобывающих регионов и месторождений: математические модели, методы, применение // Исследовано в России. 2012. №15. С. 158-166.

141. Шадькова Д.К., Коркишко А.Н. Стоимостной инжиниринг как основа управления проектом обустройства месторождения на примере компании ПАО «ГАЗПРОМ НЕФТЬ» // Фундаментальные исследования. 2017. Т. 4. №12. С. 930-934.

142. Грачков И.А. Информационная безопасность АСУ ТП: возможные вектора атаки и методы защиты // Безопасность информационных технологий. 2018. Т. 25. №1. С. 90-98. DOI:10.26583/bit.2018.1.09.

143. Сабиров Р.А., Увайсов С.У. Применение средств обеспечения информационной безопасности в промышленных системах управления // Север России: стратегии и перспективы развития: Материалы III Всероссийской научно-практической конференции, г. Сургут. 2017. С. 140-143.

144. Уязвимости в ACУ ТП: итоги 2018 года. [Электронный ресурc]. URL: https://www.ptsecurity.com/ru-ru/research/analytics/ics-vulnerabilities-2019/ (дата обращения: 13.03.2020).

145. Обеспечение кибербезопасности промышленного IT- контура. [Электронный ресурс]. URL: https://www.pta-expo.ru/spb/ethernet/2014/ prosoft_ ProSoft 2.pdf (дата обращения: 13.03.2020).

14б. Шваб К. Четвертая промышленная революция: монография. М.: Издательство «Э», 2017. 208 с.

147. Зырянов М. Умное предприятие - это реально. Computerworld Pocсия. 2017. № 17.

148. Gvozdev V. The Model of the Innovative Project as the Multivariable Control Object / V. Gvozdev, O. Bezhaeva, D. Blinova, D. Achmetova // Proceedings of the 8th Scientific Conference on Information Technologies for Intelligent Decision Making Support (ITIDS 2020). P.278-282.

149. Schuh G. Industrie 4.0 Maturity Index Managing the Digital Transformation of Companies / G. Schuh, R. Anderl, J. Gausemeier, M. Hompel, W. Wahlster // Acatech STUDY, 2018. $60 \mathrm{p}$.

150. Schuh G. Industrie 4.0 Maturity Index. Managing the Digital Transformation of Companies - UPDATE 2020 / G. Schuh, R. Anderl, R. Dumitrescu, A. Krüger, M. Hompel // Acatech STUDY, 2020. 64 p.

151. H. Ahuett-Garzaa, T. Kurfessb. A brief discussion on the trends of habilitating technologies for Industry 4.0 and Smart manufacturing. Manufacturing Letters. January 2018. Vol. 15. Part B. P. 60-63. 
Черняховская Л.Р., Васильев В.И., Гвоздев В.Е., Никулина Н.О., Малахова А.И., Вульфин А.М., Бежаева О.Я.

\section{МЕТОДЫ И МОДЕЛИ ПОДДЕРЖКИ ПРИНЯТИЯ РЕШЕНИЙ ПРИ УПРАВЛЕНИИ ИННОВАЦИОННЫМИ ПРОЕКТАМИ В ПРОИЗВОДСТВЕННО-ЭКОНОМИЧЕСКИХ СИСТЕМАХ}

Сетевое научное издание

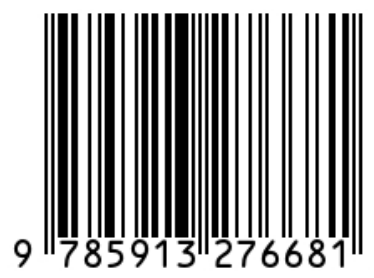

(C) Л.Р. Черняховская, В.И. Васильев,

В.Е. Гвоздев, Н.О. Никулина,

А.И. Малахова, А.М. Вульфин,

О.Я. Бежаева, 2021

(С) ИД «Академия Естествознания»

(c) $\mathrm{AHO} \mathrm{«Академия} \mathrm{Естествознания»}$ 